\title{
Addressing adolescent girls' vulnerability to HIV/AIDS: Lessons from the Meri Life Meri Choice project
}

\author{
Sunil Mehra \\ Rajesh R. Singh \\ Vandana Nair \\ K.G. Santhya \\ Population Council \\ A.J. Francis Zavier \\ Population Council
}

Follow this and additional works at: https://knowledgecommons.popcouncil.org/departments_sbsr-pgy

Part of the Demography, Population, and Ecology Commons, Family, Life Course, and Society Commons, International Public Health Commons, and the Women's Health Commons How does access to this work benefit you? Let us know!

\section{Recommended Citation}

Mehra, Sunil, Rajesh R. Singh, Vandana Nair, K.G. Santhya, and A.J. Francis Zavier. 2016. "Addressing adolescent girls' vulnerability to HIV/AIDS: Lessons from the Meri Life Meri Choice project." New Delhi: Population Council. 


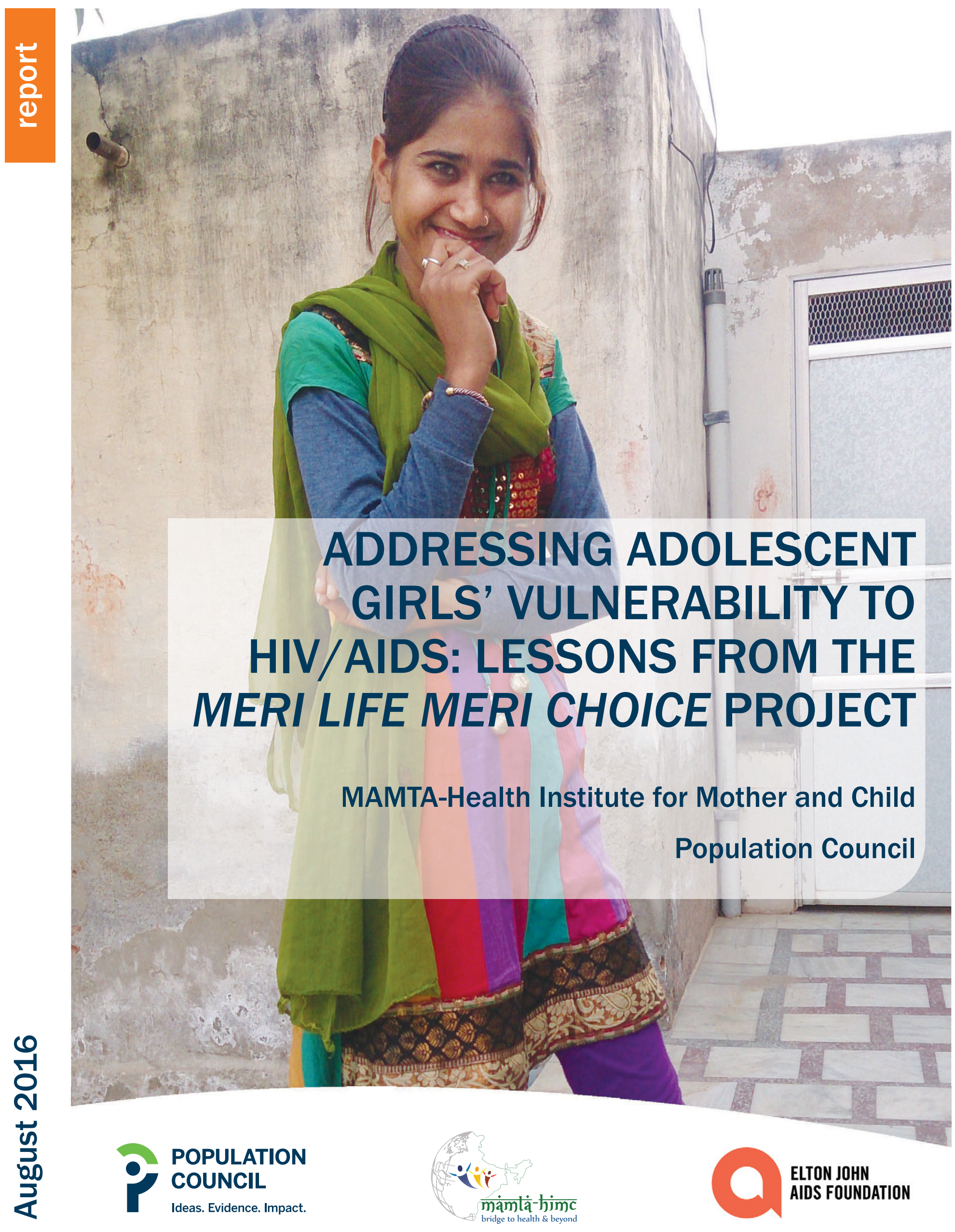




\section{P. popunarow}

Ideas. Evidence. Impact.

The Population Council confronts critical health and development issues-from stopping the spread of HIV to improving reproductive health and ensuring that young people lead full and productive lives. Through biomedical, social science, and public health research in 50 countries, we work with our partners to deliver solutions that lead to more effective policies, programs, and technologies that improve lives around the world. Established in 1952 and headquartered in New York, the Council is a nongovernmental, nonprofit organization governed by an international board of trustees.

\section{Population Council}

Zone 5A, Ground Floor

India Habitat Centre, Lodi Road

New Delhi, India 110003

Phone: +91-11-2464 2901

Email: info.india@popcouncil.org

Website: www.popcouncil.org

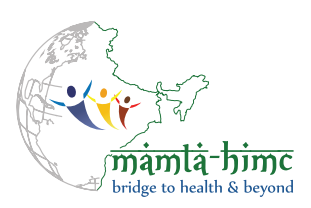

MAMTA-Health Institute for Mother and Child is a not for profit institution, registered under Societies Registration Act1860 of Government of India in the year 1990. In a span of two and half decades, MAMTA has been able to establish itself in program implementation and management at scale, training and capacity building, research and advocacy at national and international Level. As an institution, MAMTA works in close association with the public systems, civil society, academic institutions, corporate sector and with communities. MAMTA has evolved from a community based service provider to an institution of excellence in HIV/AIDS, Tuberculosis, RMNCH+A, Sexual and Non Communicable Diseases at regional/global space. Adolescent health and development is a part of its core strategy and it is working toward making a difference in the lives of young people through empowering them with knowledge, skills and ensuring their rights using innovative strategies. Through the Centre for Adolescent Health and Development (CoAHD) set up under its ageis, MAMTA is extending its footprints globally. MAMTA continues to be a learning organization in the rapidly changing development paradigm.

\section{MAMTA}

MAMTA-Health Institute for Mother and Child

B-5, Greater Kailash Enclave-II

New Delhi, India 110048

Phone: +91-11-2922 0210/20/30

Fax: +91-11-2922 0575

Website:www.mamta-himc.org

Suggested Citation: Mehra, S., R. R. Singh, V. Nair, K. G. Santhya and A. J. Francis Zavier. 2016. Addressing adolescent girls' vulnerability to HIV/OAIDS: Lessons from the Meri Life Meri Choice project. New Delhi: Population Council.

(c) 2016 The Population Council, Inc. 


\section{ADDRESSING ADOLESCENT GIRLS' VULNERABILITY TO HIV/AIDS: LESSONS FROM THE MERI LIFE MERI CHOICE PROJECT}

Sunil Mehra Rajesh R. Singh Vandana Nair MAMTA-Health Institute for Mother and Child

K G Santhya A J Francis Zavier Population Council 


\section{Table of Contents}

List of Tables $\quad v$

List of Figures $\quad$ vii

Acknowledgements $\quad$ xi

Executive summary $\quad$ xiii

$\begin{array}{llr}\text { Chapter } 1 & \text { Introduction } & 1\end{array}$

$\begin{array}{llr}\text { Chapter } 2 & \text { Profile of adolescent girls and their families } & 10\end{array}$

Chapter 3 Meri Life Meri Choice project 23

Chapter 4 Effect of the intervention on protective assets of adolescent girls and their unmarried

$\begin{array}{ll}\text { brothers and husbands } & 38\end{array}$

Chapter 5 Effect of the intervention on sexual risk-taking and health-seeking behaviours and practices of adolescent girls and their unmarried brothers and husbands $\quad 58$

Chapter 6 Effect of the intervention on adolescent girls' access to a supportive and safe environment 69

Chapter 7 Effect of the intervention on awareness and practices of mothers and fathers of adolescent girls 77

Chapter 8 Changes in attitudes and practices among adolescent girls and their family members:

self-assessments

Chapter 9 Summary and recommendations

Annex 1: Detailed description of the selection of intervention and comparison arms and sample size calculation

Annex 2: Calculation of household wealth index

Annex 3: $\quad$ Selected background characteristics of unmarried and married adolescent girls and their unmarried brothers and husbands, by treatment arms, baseline survey

Annex 4: $\quad$ Selected background characteristics of unmarried and married adolescent girls and their unmarried brothers and husbands, baseline and endline surveys

Annex 5: Items included in the summary measures related to agency and gender role attitudes and their baseline values

Annex 6: Items included in the summary measure related to awareness of sexual and reproductive matters and their baseline values 
Annex 8: Items included in the summary measure related to parental awareness of sexual and reproductive matters and their baseline values

Annex 9: Items included in the summary measure related to gender role attitudes of parents and their baseline values

Annex 10: Selected background characteristics of unmarried and married adolescent girls and their unmarried brothers and husbands by their participation in the MLMC activities, endline survey

References:

Authors 


\section{List of Tables}

Table 1.1: Profile of the study districts and states 4

Table 1.2: Response rates by category of respondents at baseline and endline surveys 8

Table 1.3: Reasons for non-responses by category of respondents at baseline and endline surveys 9

Table 2.1: $\quad$ Selected background characteristics of unmarried and married adolescent girls and their unmarried brothers and husbands, baseline survey 10

Table 2.2: Selected background characteristics of mothers and fathers of adolescent girls, baseline survey 11

Table 2.3: Size of peer networks, regularity of peer interactions and access to non family trusted mentors among unmarried and married adolescent girls and their unmarried brothers and husbands, baseline survey

Table 2.4: $\quad$ Agency and gender role attitudes of unmarried and married adolescent girls and their unmarried brothers and husbands, baseline survey

Table 2.5: Awareness of sexual and reproductive matters among unmarried and married adolescent girls and their unmarried brothers and husbands, baseline survey

Table 2.6: Financial literacy and related practices, and participation in a vocational training programme among unmarried and married adolescent girls and their unmarried brothers and husbands, baseline survey

Table 2.7: $\quad$ Places where unmarried and married adolescent girls and their unmarried brothers and husbands typically met their friends, baseline survey

Table 2.8: Nature of sexual experiences and intentions to use condoms among unmarried and married adolescent girls and their unmarried brothers and husbands, baseline survey

Table 2.9: Health-seeking practices among unmarried and married adolescent girls and their unmarried brothers and husbands, baseline survey

Table 2.10: Communication with mothers and fathers reported by unmarried and married adolescent girls, baseline survey

Table 2.11: Percentage of unmarried and married adolescent girls who received support from their brothers (unmarried girls) and husbands (married girls), baseline survey

Table 2.12: Unmarried and married adolescent girls' perceptions of safety in their village and experiences of sexual harassment, baseline survey

Table 2.13: Awareness of sexual and reproductive matters among mothers and fathers of unmarried and married adolescent girls, baseline survey

Table 2.14: Gender role attitudes and socialisation practices reported by mothers and fathers of unmarried and married adolescent girls, baseline survey

Table 3.1: Modifications in the MLMC project following the proof-of-concept phase

Table 3.2: $\quad$ Reasons for not participating in MLMC project activities cited by unmarried and married adolescent girls and their unmarried brothers and husbands, intervention arm, endline survey

Table 3.3: $\quad$ Reasons for participating in MLMC project activities reported by unmarried and married adolescent girls and their unmarried brothers and husbands, intervention arm, endline survey

Table 3.4: Regularity of participating in MLMC project activities reported by unmarried and married adolescent girls and their unmarried brothers and husbands, intervention arm, endline survey

Table 3.5: Reasons for non regular participation in MLMC project activities reported by unmarried and married adolescent girls and their unmarried brothers and husbands, intervention arm, endline survey 
Table 3.6A: Unmarried and married adolescent girls' recall of and perceptions about topics included in the life skills education curriculum, intervention arm, endline survey

Table 3.6B: Unmarried brothers' and husbands' recall of and perceptions about topics included in the life skills education curriculum, intervention arm, endline survey

Table 3.7: $\quad$ Perceptions of unmarried and married adolescent girls and their unmarried brothers and husbands about peer mentors, intervention arm, endline survey

Table 3.8: Support received in seeking health services by unmarried and married adolescent girls and their unmarried brothers and husbands, intervention arm, endline survey

Table 3.9: Support received in seeking health services by unmarried and married adolescent girls and their unmarried brothers and husbands, intervention arm, endline survey

Table 3.10: Awareness of and participation in MLMC project activities among mothers and fathers of unmarried and married adolescent girls, intervention arm, endline survey

Table 4.1: Effect of exposure to the MLMC project on peer networks and interactions among unmarried and married adolescent girls and their unmarried brothers and husbands: Summary of regression results

Table 4.2: Effect of exposure to the MLMC project on agency and gender role attitudes among unmarried and married adolescent girls and their unmarried brothers and husbands: Summary of regression results

Table 4.3: Effect of exposure to the MLMC project on awareness of sexual and reproductive matters, including HIV/AIDS among unmarried and married adolescent girls and their unmarried brothers and husbands: Summary of regression results

Table 4.4: Effect of exposure to the MLMC project on financial literacy and related practices, and participation in vocational skills training programmes among unmarried and married adolescent girls and their unmarried brothers and husbands by treatment arms: Summary of regression results

Table 4.5: Effect of exposure to the MLMC project in facilitating access to social space for unmarried and married adolescent girls and their unmarried brothers and husbands to network with their peers: Summary of regression results

Table 5.1: Effect of exposure to the MLMC project on sexual risk-taking practices among unmarried and married adolescent girls and their unmarried brothers and husbands: Summary of regression results

Table 5.2: Effect of exposure to the MLMC project on health-seeking practices: Summary of regression results 66

Table 6.1: Effect of exposure to the MLMC project on communication between unmarried and married adolescent girls and their mothers and fathers: Summary of regression results

Table 6.2: Effect of exposure to the MLMC project on support received from brothers (for unmarried girls) and husbands (for married girls): Summary of regression results

Table 6.3: Effect of exposure to the MLMC project on unmarried and married adolescent girls' perceptions of safety and experience of sexual harassment: Summary of regression results

Table 7.1: Effect of exposure to the MLMC project on awareness of sexual and reproductive matters among mothers and fathers of unmarried and married adolescent girls: Summary of regression results

Table 7.2: Effect of exposure to the MLMC project on gender role attitudes and socialisation practices among mothers and fathers of unmarried and married adolescent girls: Summary of regression results

Table 8.1: Unmarried and married adolescent girls' and their unmarried brothers' and husbands' perceptions of changes experienced in the six months preceding the interview by treatment arms, endline survey 85

Table 8.2: Perceptions of mothers and fathers about changes that they had experienced in the six months preceding the interview by treatment arms, endline survey 


\section{List of Figures}

Figure 3.1: Percentage of unmarried and married adolescent girls and their unmarried brothers and husbands who were aware of the MLMC project, intervention arm, endline survey

Figure 3.2: Percentage of unmarried and married adolescent girls and their unmarried brothers and husbands who had participated in MLMC project activities, intervention arm, endline survey

Figure 4.1: Percentage of unmarried and married adolescent girls and their unmarried brothers and husbands who made new friends in the six months prior to the interview by treatment arms, baseline and endline surveys

Figure 4.2: Percentage of unmarried and married adolescent girls and their unmarried brothers and husbands who reported at least one friend by treatment arms, baseline and endline surveys

Figure 4.3: Percentage of unmarried and married adolescent girls and their unmarried brothers and husbands who reported at least once-a-week interaction with friends by treatment arms, baseline and endline surveys

Figure 4.4: Percentage of unmarried and married adolescent girls and their unmarried brothers and husbands who would confide a personal problem in a non family member by treatment arms, baseline and endline surveys

Figure 4.5: Percentage of unmarried and married adolescent girls and their unmarried brothers and husbands who displayed self-efficacy by treatment arms, baseline and endline surveys

Figure 4.6: Percentage of unmarried and married adolescent girls and their unmarried brothers and husbands who reported decision making autonomy by treatment arms, baseline and endline surveys

Figure 4.7: Mean score on the index of mobility obtained by unmarried and married adolescent girls and their unmarried brothers and husbands by treatment arms, baseline and endline surveys

Figure 4.8: Mean score on the index of gender egalitarian attitudes obtained by unmarried and married adolescent girls and their unmarried brothers and husbands by treatment arms, baseline and endline surveys

Figure 4.9: Mean scores on the index of awareness of sexual and reproductive matters obtained by unmarried and married adolescent girls and their unmarried brothers and husbands by treatment arms, baseline and endline surveys

Figure 4.10: Percentage of unmarried and married adolescent girls and their unmarried brothers and husbands who were aware of HIV/AIDS by treatment arms, baseline and endline surveys

Figure 4.11: Percentage of unmarried and married adolescent girls and their unmarried brothers and husbands who knew about two ways of preventing HIV transmission by treatment arms, baseline and endline surveys

Figure 4.12: Percentage of unmarried and married adolescent girls and their unmarried brothers and husbands who rejected at least two misconceptions about HIV transmission by treatment arms, baseline and endline surveys

Figure 4.13: Percentage of unmarried and married adolescent girls and their unmarried brothers and husbands who displayed comprehensive awareness of HIV/AIDS by treatment arms, baseline and endline surveys

Figure 4.14: Percentage of unmarried and married adolescent girls and their unmarried brothers and husbands who knew a facility to go for an HIV test by treatment arms, baseline and endline surveys 
Figure 4.15: Percentage of unmarried and married adolescent girls and their unmarried brothers and husbands who displayed financial literacy by treatment arms, baseline and endline surveys

Figure 4.16: Percentage of unmarried and married adolescent girls and their unmarried brothers and husbands who reported some savings by treatment arms, baseline and endline surveys

Figure 4.17: Percentage of unmarried and married adolescent girls and their unmarried brothers and husbands who owned a savings account and operated it on their own by treatment arms, baseline and endline surveys

Figure 4.18: Percentage of unmarried and married adolescent girls and their unmarried brothers and husbands who had visited a bank in the six months prior to the interview by treatment arms, baseline and endline surveys

Figure 4.19: Percentage of unmarried and married adolescent girls and their unmarried brothers and husbands who expressed a savings goal by treatment arms, baseline and endline surveys

Figure 4.20: Percentage of unmarried and married adolescent girls and their unmarried brothers and husbands who had participated in vocational skills training programmes by treatment arms, baseline and endline surveys

Figure 4.21: Percentage of unmarried and married adolescent girls and their unmarried brothers and husbands who reported access to social spaces to network with peers by treatment arms, baseline and endline surveys

Figure 5.1: Percentage of unmarried and married adolescent girls and their unmarried brothers and husbands who reported sexual experiences ${ }^{0}$ in the six months prior to the interview by treatment arms, baseline and endline surveys

Figure 5.2: Percentage of sexually experienced unmarried adolescent girls and their unmarried brothers who reported multiple sexual partnerships in the six months prior to the interview by treatment arms, baseline and endline surveys

Figure 5.3: Percentage of sexually experienced unmarried adolescent girls, and their unmarried brothers and husbands who reported condom use at last sex in the six months prior to the interview by treatment arms, baseline and endline surveys

Figure 5.4: Percentage of sexually experienced unmarried adolescent girls, and unmarried brothers and husbands who reported consistent condom use at last sex in the six months prior to the interview by treatment arms, baseline and endline surveys

Figure 5.5a: Percentage of married adolescent girls and their husbands who reported condom use at last sex within marriage in the six months prior to the interview by treatment arms, baseline and endline surveys

Figure 5.5b: Percentage of married adolescent girls and their husbands who reported consistent condom use within marriage in the six months prior to the interview by treatment arms, baseline and endline surveys

Figure 5.6: Percentage of unmarried and married adolescent girls and their unmarried brothers and husbands who reported intentions to use condom in the future by treatment arms, baseline and endline surveys

Figure 5.7: Percentage of unmarried and married adolescent girls and their unmarried brothers and husbands who had had an HIV test by treatment arms, baseline and endline surveys

Figure 5.8: Percentage of unmarried and married adolescent girls and their unmarried brothers and husbands who had experienced symptoms suggestive of reproductive tract infections in the three months prior to the interview by treatment arms, baseline and endline surveys

Figure 5.9: Percentage of unmarried and married adolescent girls and their unmarried brothers and husbands who sought treatment for symptoms suggestive of reproductive tract infections experienced by treatment arms, baseline and endline surveys 
Figure 5.10: Percentage of unmarried and married adolescent girls who reported using disposable sanitary napkins during menstruation and changing them regularly by treatment arms, baseline and endline surveys

Figure 6.1: Percentage of unmarried and married adolescent girls who discussed general topics with their mother and father in the month prior to the interview by treatment arms, baseline and endline surveys

Figure 6.2: Percentage of unmarried and married adolescent girls who reported having discussed sexual and reproductive topics with their mother in the month prior to the interview by treatment arms, baseline and endline surveys

Figure 6.3: Percentage of unmarried and married adolescent girls who received support from their brothers (for unmarried girls) or husbands (for married girls) in the month prior to the interview by treatment arms, baseline and endline surveys

Figure 6.4: Percentage of married adolescent girls who had discussed financial and sexual and reproductive matters with their husband in the month prior to the interview, baseline and endline surveys

Figure 6.5: Percentage of married adolescent girls who experienced marital violence in the month prior to the interview by treatment arms, baseline and endline surveys

Figure 6.6: Percentage of unmarried and married adolescent girls who felt safe in their village and confident about community support if experienced sexual harassment by treatment arms, baseline and endline surveys

Figure 6.7: Percentage of unmarried and married adolescent girls who were aware of the location of the nearest police station by treatment arms, baseline and endline surveys

Figure 6.8: Percentage of unmarried and married adolescent girls who had experienced non contact forms of sexual harassment in the six months prior to the interview by treatment arms, baseline and endline surveys

Figure 6.9: Percentage of unmarried and married adolescent girls who had experienced contact forms of sexual harassment in the six months prior to the interview by treatment arms, baseline and endline surveys

Figure 7.1: Mean score on the index of awareness of sexual and reproductive matters obtained by mothers and fathers of unmarried and married adolescent girls by treatment arms, baseline and endline surveys

Figure 7.2: Percentage of mothers and fathers of unmarried and married adolescent girls who were aware of HIV/AIDS by treatment arms, baseline and endline surveys

Figure 7.3: Percentage of mothers and fathers of unmarried and married adolescent girls who knew about two ways of preventing HIV transmission by treatment arms, baseline and endline surveys

Figure 7.4: Percentage of mothers and fathers of unmarried and married adolescent girls who rejected at least two misconceptions about HIV transmission by treatment arms, baseline and endline surveys

Figure 7.5: Percentage of mothers and fathers of unmarried and married adolescent girls who displayed comprehensive awareness of HIV/AIDS by treatment arms, baseline and endline surveys

Figure 7.6: Percentage of mothers and fathers of unmarried and married adolescent girls who knew a facility to go to for an HIV test by treatment arms, baseline and endline surveys

Figure 7.7: Mean score on the index of gender egalitarian attitudes obtained by mothers and fathers of unmarried and married adolescent girls by treatment arms, baseline and endline surveys

Figure 7.8: Percentage of mothers and fathers of unmarried and married adolescent girls who reported that they treated their daughters/daughters-in-law and sons equally by treatment arms, baseline and endline surveys

Figure 7.9: Percentage of mothers and fathers of unmarried and married adolescent girls who communicated with their daughters/daughters-in-law, baseline and endline surveys 


\section{Acknowledgements}

This study has benefitted immeasurably from the inputs of many. We are extremely grateful to the Elton John AIDS Foundation for envisioning the need for the Meri Life Meri Choice project, and for supporting MAMTA-Health Institute for Mother and Child and partners, Anupama Education Society and Lok Smriti Sewa Sansthan, to implement it and the Population Council to evaluate it. In particular, we are grateful to Mohamed Osman, Anne Aslett and Prasanna Kannan for their suggestions and comments at various stages of this project. We are also thankful to Amy McDonagh and Samit Tandon from BlueLotus Advisory for their inputs in the early stages of this project.

We could not have successfully completed this study without the support of the Health and Family Welfare Department, Government of Madhya Pradesh and Government of Uttar Pradesh. We would like to acknowledge with gratitude the support that we received from Mr. Amit Kumar, Mission Director (National Health Mission) and Project Director, Uttar Pradesh State AIDS Control Society (UPSACS); Mr. V. Kiran Gopal, Mission Director (National Health Mission) and Project Director, Madhya Pradesh State AIDS Control Society (MPSACS); Mr. Prashant Malaiya, Deputy Director, MPSACS and Ms. Smita Shendye, Consultant Adolescent Health, National Health Mission, Madhya Pradesh.

We are grateful to our implementing partners Shaila Tiwari, Anupama Education Society, Satna; Alok Kumar, Lok Smriti Sewa Sansthan, Allahabad; Gulam Hasan Khan, Qazi Najmddin, Samta Paik and Sujeet Kumar from MAMTA, Banda and Rewa districts for their support in implementing the project.

At the Population Council, several colleagues have supported us in both the technical and administrative aspects of this study. A special thanks goes to Shireen Jejeebhoy for her collegial support, mentoring and guidance at every stage of this study. We are grateful to Rajib Acharya for his contribution in designing the evaluation, and to Shireen Jejeebhoy and Nicole Haberland for reviewing an earlier draft of this report and giving valuable comments and suggestions. We would also like to thank M.A. Jose for ably managing the administrative aspects of the project, Shilpi Rampal for her support with data management and Komal Saxena for efficiently coordinating the printing of the report. We would like to thank Komal Saxena and Christina Tse for their editorial contributions. We also appreciate the efforts of our investigators who painstakingly collected the data.

Finally, and most importantly, we would like to thank the adolescent girls and boys, and their parents who generously gave us their time and shared their views and experiences with us.

Sunil Mehra

Rajesh R Singh

Vandana Nair

MAMTA-Health Institute for Mother and Child

K G Santhya

A J Francis Zavier

Population Council 


\section{Executive summary}

Adolescent programming in India has been given a much needed fillip with the launch of the Rashtriya Kishor Swasthya Karyakram (RKSK, the National Adolescent Health Programme). While programmes like RKSK are commendable efforts, rigorous evidence on what works and what does not in terms of meeting the multiple needs of adolescents remains patchy. Indeed, although numerous programmes to support adolescent girls are implemented by government and nongovernmental organisations (NGOs) in India, most have focused on two areas: sexuality and life skills education for the unmarried and services for the married. Fewer programmes have focused on meeting the service needs of the unmarried, bringing boys and young men into the picture or addressing obstacles at the gatekeeper level. Not a single intervention has focused on the HIV vulnerability of adolescent girls, and few have addressed the multiple facets of girls' lives. Moreover, most have not been rigorously evaluated.

MAMTA-Health Institute for Mother and Child, with the support of the Elton John AIDS Foundation, implemented an intervention project entitled Meri Life Meri Choice (MLMC) project. The MLMC project sought to reduce the vulnerability of rural adolescent girls to HIV by enhancing their knowledge about sexual and reproductive matters and equipping them with skills that enable them to address vulnerability to HIV; increasing their utilisation of sexual and reproductive health services from the public sector; and developing a supportive environment that enables adolescent girls to adopt protective actions to reduce vulnerability to HIV. The project was implemented among unmarried girls aged 15-19 who had never been to school or who had discontinued school and who belonged to socially disadvantaged castes/tribes/religions; and married girls aged 15-21 who belonged to socially disadvantaged castes/tribes/religions. It also targeted unmarried brothers aged 15-19, husbands aged 15-24, and mothers and fathers of these girls as well as other gatekeepers in the intervention villages, including frontline health workers.

Activities implemented over a six-month period included the formation of adolescent girls' and groups in each of the intervention villages; establishment of Gender Resource Centres in each intervention village that offered a safe space for girls to network with peers as well as opportunities to receive life skills education; the provision of support for girls to open bank accounts and avail themselves of existing vocational skills training programmes; and the establishment of referral linkages with existing public-sector health services, especially with the Integrated Counselling and Testing Centers to encourage the utilisation of these services, particularly HIV counselling and testing services by adolescent girls. Similar activities were organised for unmarried adolescent brothers and husbands of adolescent girls. Finally, family events during which family members got an opportunity to observe girls' participation in the Gender Resource Centre, meetings of parents' groups and community support groups formed in each intervention village, training workshops for healthcare providers, especially, frontline health workers, and villagewide behaviour change communication campaigns were also organised.

The Population Council evaluated the acceptability, feasibility, and effectiveness of this model, using a quasiexperimental design, with cross-sectional surveys undertaken in the comparison and intervention arms prior to the implementation of intervention activities (baseline) and at its conclusion (endline), and post-survey in-depth interviews with selected survey respondents in the intervention arm at endline. The evaluation focused on unmarried and married adolescent girls, their brothers and husbands, and their mothers and fathers. Respondents for the baseline survey included: (1) unmarried girls aged 15-19 who had never been to school or had discontinued school, and who belonged to socially disadvantaged groups; (2) married girls aged 15-21 who belonged to socially disadvantaged groups; (3) unmarried brothers aged 15-19 of eligible unmarried girls; (4) husbands aged 15-24 of eligible married girls; and (5) mothers and fathers of eligible unmarried and married girls, respectively. At baseline, a total of 1,375 unmarried girls, 1,460 married girls, 311 unmarried brothers, 917 husbands and 614 mothers and fathers were successfully interviewed. The categories of respondents for the endline survey were the same as those at the baseline survey, except that we decided to interview somewhat older adolescents (i.e., 15-20 year-olds among unmarried girls, 15-22 year-olds among married girls, 15-20 year-olds among unmarried brothers of unmarried girls and 15-25 year-olds among husbands of married girls) to ensure that those interviewed at the time of the endline 
survey had been eligible for the intervention at baseline. At endline, a total of 1,754 unmarried girls, 1,780 married girls, 496 unmarried brothers, 1,056 husbands and 599 mothers and fathers were successfully interviewed. We used the difference-in-difference (DiD) method to ascertain the degree of change in indicators attributable to the MLMC project.

\section{Relevance of the MLMC project}

The Meri Life Meri Choice project was implemented to reduce rural adolescent girls' vulnerability to HIV. The baseline assessment prior to launching the intervention underscored that adolescent girls, their unmarried brothers, and husbands in the study settings were vulnerable to HIV in many, but different, ways. Adolescent girls and their brothers and husbands were not typically endowed with assets that can prevent conditions that are precursors of HIV. For example, social isolation characterised the lives of many adolescent girls in the study settings. Moreover, they lacked social spaces to network with their peers. Few adolescent girls exercised agency in their lives. Adolescent girls and their brothers and husbands all adhered to unequal gender norms. They remained largely uninformed about sexual and reproductive matters, including HIV/AIDS. Moreover, what they knew about these matters was far from comprehensive. They lacked financial literacy and opportunities to acquire livelihood skills. Sizeable proportions had engaged in unprotected sex. Treatment-seeking for sexual health problems was limited among girls as well as their brothers and husbands. Moreover, a supportive and safe environment was by and large lacking for many adolescent girls. Findings also show that mothers and fathers were not equipped with knowledge and skills to play a protective role in the lives of their adolescent children. In short, the baseline assessment highlights the vulnerability of adolescents to HIV, the limited role of parents in addressing these vulnerabilities, and the relevance of a project like the MLMC in the study settings as well as in other settings in which adolescent girls and their brothers and husbands face similar disadvantages.

Moreover, the lessons learned from implementing the MLMC project, beginning with a proof-of-concept phase and upscaling it to a larger number of villages, are of huge policy and programme relevance in the Indian context, particularly in the wake of launching the Rashtriya Kishor Swasthya Karyakram that seeks to enable adolescents to realise their full potential by making informed and responsible decisions concerning their health and well-being and by accessing the services and support they need to implement their decisions.

\section{Acceptability and feasibility of the MLMC project}

Findings indicate that the majority of study participants in the intervention arm were aware of MLMC project. Between two-thirds and four-fifths of adolescent girls and their unmarried brothers and husbands had heard about the project.

Participation in MLMC project activities ranged from nine percent among husbands to 48 percent among unmarried girls. The most prominent reason motivating adolescent girls and their unmarried brothers and husbands for participating in the project activities was the opportunity to get information on different issues. Other frequently cited reasons included the desire to acquire a vocational skill and the opportunity that the project offered to be with their friends, to make new friends and to interact in a group. Findings also show that the vast majority did not attend activities for the full length of the project. In fact, just 25 percent of unmarried girls, 15 percent of married girls and 7-10 percent of their unmarried brothers and husbands who had participated in MLMC project activities reported that they had attended the activities for the full 5-6 months. The major reasons cited for not attending the project activities regularly included inconvenient schedule of MLMC project activities and household workload.

The major activity carried out as part of the MLMC project was imparting a life skills education curriculum that comprised 21 sessions for unmarried girls, 14 sessions for married girls, and 21 sessions for unmarried brothers and husbands of eligible girls. Half or more of unmarried girls and one-third or more of married girls recalled each of the topics included in the curriculum. Three-quarters or more of unmarried and married girls who had attended the sessions reported that they had learned something new about the topic discussed in the sessions that they had attended. Likewise, 60 percent or more of unmarried girls and 50 percent or more of married girls reported that this was the first time anyone had discussed the topics included in the life skills education curriculum. About one-third 
or more of unmarried brothers and one-quarter or more of husbands recalled each of the topics included in the curriculum. Some 80 percent or more of unmarried brothers and husbands who had attended the sessions reported that they had learned something new about the topic discussed in the sessions that they attended, and 50 percent or more of unmarried brothers and 70 percent or more of husbands reported that this was the first time anyone had discussed the topics included in the life skills education curriculum.

Findings also show that a substantial proportion of MLMC participants were supported in undergoing HIV testing and seeking treatment for symptoms of reproductive tract infections, as well as in attending vocational skills training programmes and opening a bank account. For example, 49 percent of unmarried girls and 39 percent of married girls who had participated in MLMC project activities had an opportunity to undergo an HIV test. So did 44 percent of unmarried brothers and 24 percent of husbands. Some 17-21 percent of unmarried and married girls and 9-21 percent of unmarried brothers and husbands who had participated in MLMC project activities reported that they were given a referral slip to seek services for symptoms of reproductive tract infections or for HIV testing. About three-fifths of unmarried girls and over two-fifths of married girls received information about vocational skills training programmes from the project staff, and 25 percent of unmarried girls and 14 percent of married girls received support from project staff in attending a vocational skills training programme. Compared to adolescent girls, far fewer unmarried brothers and husbands received information about vocational skills training programmes or support in attending such a programme. The project staff also assisted 21 percent of unmarried girls and 14 percent of married girls in opening a bank account. The corresponding percentages among unmarried brothers and husbands were four and 13, respectively.

Findings suggest that a larger proportion of adolescent girls and their unmarried brothers and husbands in the intervention arm perceived positive changes in their life in the six months prior to the interview, compared to their counterparts in the comparison arm. Specifically, adolescent girls and their unmarried brothers and husbands in the intervention arm were more likely than their counterparts in the comparison arm to report positive changes in their agency and gender role attitudes in the six months prior to the interview. They were also more likely to report that they were better informed about selected matters now than earlier, compared to their counterparts in the comparison arm.

Findings also show that adolescent girls and their unmarried brothers and husbands in the intervention arm were more likely than their counterparts in the comparison arm to report positive changes in terms of economic empowerment. Furthermore, unmarried girls and unmarried brothers in the intervention arm were more likely than their counterparts in the comparison arm to report that they made new friends in the six months prior to the interview. All categories of study participants in the intervention arm were more likely than their counterparts in the comparison arm to report that they had developed closer relationships with their mothers and fathers, and with their siblings (unmarried)/spouse (married).

Finally, findings show that 80 percent or more of mothers and fathers had heard about the MLMC project. However, fewer had participated in any project activities-29 percent of mothers and 23 percent of fathers. Even so, findings indicate that mothers in the intervention arm were more likely than their counterparts in the comparison arm to report positive changes in terms of their interactions with their adolescent children in the six months prior to the interview. However, no such differences were observed in the perceptions of fathers in the intervention and comparison arms.

\section{Effectiveness of the MLMC project}

The MLMC project sought to reduce adolescent girls' vulnerability to HIV by enhancing their protective assets, including knowledge and skills that can reduce vulnerability to HIV, enabling them to adopt safe practices to reduce their vulnerability to HIV, enhancing their access to a supportive and safe environment at the family and community level, and encouraging mothers and fathers to play a supportive role in reducing adolescent girls' HIV vulnerability. As summarised below, the MLMC project was effective in meeting these objectives to a large extent, particularly in the case of unmarried girls. 


\section{Effectiveness in enhancing protective assets of adolescent girls and their unmarried brothers and husbands}

The evaluation shows that the MLMC project was effective, for the most part, in enhancing protective assets of adolescent girls that can reduce their vulnerability to HIV. First, the project contributed to enabling unmarried and married adolescent girls to network with their peers and make new friends. Second, the project contributed to improving unmarried and married girls' agency as measured by their self-efficacy, decision making autonomy, and freedom of movement. Third, gender role attitudes became more egalitarian among unmarried girls following the implementation of the project, although no such effect was observed among married girl. Fourth, awareness of sexual and reproductive matters among unmarried and married girls improved substantially with the implementation of the MLMC project. Of particular note was the improvement in awareness of HIV/AIDS. Fifth, financial literacy improved among unmarried and married girls. Additionally, the project contributed to enabling unmarried and married girls to own a savings account and operate it on their own. The project provided unmarried girls an opportunity to visit a bank in the recent past, although no such effect was observed among married girls. Sixth, the project succeeded in enabling unmarried and married girls to participate in vocational skills training programmes.

At the same time, the project was not effective in increasing adolescent girls' access to non familial trusted mentors to discuss their personal problems or in promoting savings habits among adolescent girls. Findings also highlight that the MLMC project was more effective in enhancing protective assets of unmarried girls than married girls. This is not surprising because the reach of the intervention was highest among unmarried girls. Findings also show that the effectiveness of a group-based model like MLMC differed between adolescent girls and their brothers and husbands. In fact, the project was less effective in enhancing the protective assets of unmarried brothers and husbands of adolescent girls than of adolescent girls. They also underscore that the project was more effective among MLMC participants than all adolescent girls and their unmarried brothers and husbands.

\section{Effectiveness in reducing sexual risk-taking and promoting health-seeking behaviours and practices among adolescent girls and their unmarried brothers and husbands}

The evaluation shows that the MLMC project had a different effect in reducing sexual risk-taking practices among adolescent girls and their unmarried brothers and husbands. First, it contributed to moderately promoting sexual abstinence among unmarried girls, but no such effect was observed with respect to engaging in extra marital relationships among married girls. Contrary to what was hypothesised, unmarried brothers and husbands in the intervention arm were more likely than others to report sexual experiences (extra marital sexual experiences for husbands). Second, the project resulted in reducing multiple partnerships among sexually experienced unmarried brothers; however, no such effect was observed among sexually experienced unmarried girls. Third, the project had a positive net effect in promoting condom use at last sex and consistent condom use within sexual relationships outside marriage among unmarried brothers and husbands who had participated in the MLMC activities; we note that the number of MLMC participants who were engaged in sexual relationships outside marriage was small, and therefore, these findings are indicative rather than conclusive. No such effect was observed among sexually experienced unmarried girls. Fourth, the project had a positive effect in promoting condom use within marriage as reported by married girls. We note that husbands' reports showed a similar positive effect with respect to condom use at last sex in the restricted analysis of MLMC participants, concurring with the girls' reports. Finally, the project was successful in increasing intentions to use condoms among unmarried girls; however, no such effect was observed among married girls and unmarried brothers and husbands.

Findings show mixed results with regard to effectiveness of the project in promoting health-seeking practices. For example, the project had a positive net effect in improving health-seeking practices among unmarried girls. Specifically, unmarried girls in the intervention arm were more likely than those in the comparison arm to have sought treatment for reproductive tract infections and to have used and regularly changed disposable sanitary napkins during menstruation. However, no such effect was evident among married girls. Moreover, a contrasting pattern was observed among unmarried brothers and husbands, with the project having a weak negative effect on treatment-seeking practices for reproductive tract infections. 


\section{Effectiveness in enhancing adolescent girls' access to a supportive and safe environment}

The evaluation indicates mixed results with regard to improving adolescent girls' access to a supportive environment. The positive changes following the implementation of the MLMC project included a decline in marital violence, improvement in unmarried and married girls' perceptions of safety in their community, and an increase in unmarried girls' awareness of the nearest police station. However, the project had no effect on such indicators as communication between adolescent girls and their parents, support provided to unmarried girls by their brothers or to married girls by their husbands, and experience of non contact forms of sexual harassment.

\section{Effectiveness in improving awareness and practices of mothers and fathers of adolescent girls}

Findings show that the MLMC project had mixed effect on the mothers and fathers of adolescent girls. On a positive note, the project contributed to improving awareness and practices of mothers and fathers of sexual and reproductive matters, including awareness of HIV/AIDS and ways of preventing HIV transmission, among mothers of adolescent girls, and enabling them to uphold gender egalitarian attitudes. At the same time, the project had no effect in enabling mothers to adopt gender egalitarian socialisation practices. Findings also show that the project had, for the most part, no effect on fathers' knowledge and practices, except that they were more likely than their counterparts in the comparison arm to uphold gender egalitarian attitudes.

\section{Sustainability of the MLMC project}

The evaluation of the MLMC project demonstrates that a safe space model and a peer educator model can be effective and acceptable. There exists a great potential for up-scaling and sustaining projects like MLMC by drawing links with available programmes, such as the Sabla programme for adolescent girls, the NYKS Youth Clubs largely attended by boys, and the Rashtriya Kishor Swasthya Karyakram that rely on such strategies as a peer education approach and group formation.

\section{Recommendations}

We highlight below a few recommendations emerging from the evaluation that have relevance for adolescent programming in the country, including for scaling up interventions for adolescents.

The evaluation highlights the fact that the MLMC project had a differential impact on different categories of study participants: the project had maximum impact on the lives of unmarried adolescent girls, the group that was reached most by the intervention activities, and least impact in the lives of unmarried brothers and husbands, the group that was reached the least. These findings underscore the importance of reaching out to a critical mass of target groups to generate the desired impact at the community level as well as revisiting strategies used to mobilise the hard-toreach, particularly the married. Enrolling the married, particularly girls, additionally calls for expanded efforts to make husbands and in-laws the allies of the project.

Although the project was successful in reducing sexual risk-taking practices, it had limited success in promoting health-seeking practices, for example, for seeking treatment for symptoms of genital infections among married girls and unmarried brothers and husbands of adolescent girls. These findings emphasise that healthcare providers need to be oriented, to a greater extent than projects like MLMC have done, to the special needs of different categories of adolescents and young people and make special efforts to provide sexual and reproductive health services directly to them through community outreach and clinic-based services.

Ensuring regular attendance of girls and their brothers and husbands was a major challenge faced by the MLMC project. Flexibility in timing, locations, and forums suitable for different categories of adolescents needs to be explored. Moreover, programme designs must take into consideration adolescents' own preferences with regard to components other than life skills education to be included in the programme.

Strategies for reaching boys and husbands in models like MLMC need to be reconsidered. Delivering life skills education through forums more acceptable to boys than Gender Resource Centres may be considered. Moreover, reaching boys in order to improve girls' situation needs to be replaced by more boy-focussed objectives as well. 
Findings suggest that mothers and father may not have been fully engaged in the MLMC programme and the intervention had limited success in equipping parents and parents-in-law with knowledge and skills to play a supportive role in reducing adolescent girls' vulnerability. In order to engage mothers and fathers more comprehensively, projects like the MLMC may need to consider a more structured programme for parents that responds to the priorities expressed by mothers and father, and at the same time break down traditional gendered socialisation practices, build greater communication between parents and children, and encourage parental participation in addressing the sexual and reproductive health concerns of their children.

Finally, the MLMC experience highlights several lessons of up-scaling programmes for adolescents. First, having a proof-of-concept phase that allows programme implementers to understand what worked, what was acceptable, and what was relevant, and to tailor the project design based on lessons learned during the proof-of-concept phase is important. Second, even when scaling up, phasing is important for managing the implementation with quality. Third, strong capacity-building efforts to identify and train peer mentors and a strong supportive supervision mechanism are required. Fourth, it is important to have government buy-in from the very beginning of the project. 


\section{Chapter 1 Introduction}

Adolescent programming in India has been given a much needed fillip with the launch of the Rashtriya Kishor Swasthya Karyakram (RKSK, the National Adolescent Health Programme). The programme seeks to enable all adolescents to realise their full potential by making informed and responsible decisions concerning their health and well-being, and by accessing the services and support they need to implement their decisions (Ministry of Health and Family Welfare, 2014). While programmes like RKSK are commendable efforts, rigorous evidence on what works and what does not in terms of meeting the multiple needs of adolescents remains patchy. Indeed, although numerous programmes to support adolescent girls are implemented by government and nongovernmental organisations (NGOs) in India, most have focused on two areas: sexuality and life skills education for the unmarried and services for the married. Fewer programmes have focused on meeting the service needs of the unmarried, bringing boys and young men into the picture or addressing obstacles at the gatekeeper level. Not a singleintervention has focused on the HIV vulnerability of adolescent girls, and few have addressed the multiple facets of girls' lives. Moreover, most have not been rigorously evaluated.

In this context, MAMTA-Health Institute for Mother and Child, with the support of the Elton John AIDS Foundation, implemented an intervention project entitled Meri Life Meri Choice (MLMC) that sought to reduce the vulnerability of rural adolescent girls to HIV. The Population Council undertook an evaluation of the project, using a quasi-experimental design. This report describes the MLMC project and examines the extent to which it reduced vulnerability of adolescent girls to HIV and strengthened key factors known to reduce such vulnerability.

\section{Background and rationale}

The 2011 Indian census shows that, with a sub-population of 120 million, every tenth person is an adolescent girl aged 10-19 (Office of the Registrar General and Census Commissioner, 2014). Over the decades, the situation of adolescent girls has improved considerably in the country. They are better educated and more likely to be enrolled in school at least during early adolescence (i.e., at ages 10-14) than earlier generations; for example, 88 percent of adolescent girls were literate in 2011, compared to 75 percent a decade ago (Office of the Registrar General and Census Commissioner, 2014). Likewise, few girls are entering the labour force prematurely; just five percent of adolescent girls aged 10-14 were working in 2011 (Office of the Registrar General and Census Commissioner, 2014). Early marriage is on the decline, although at a slow pace: the proportion of girls aged 15-17 who were ever married declined from 13 percent in 2001 to 10 percent in 2011 (Office of the Registrar General and Census Commissioner, 2015a).

Several vulnerabilities, however, persist and many adolescent girls are not able to make a healthy transition to young adulthood and beyond. For example, in 2011, 30 percent of ever-married girls aged 15-19 were already mothers (Office of the Registrar General and Census Commissioner, 2015b). Moreover, adolescent girls aged 15-19 accounted for six percent of maternal deaths in the country during 2011-13 (Office of the Registrar General, n.d). Data on HIV prevalence among adolescents for the year 2005-06 show a prevalence 0.07 percent among girls aged 15-19, compared to 0.01 among similarly aged boys (Parasuraman et al., 2009). ${ }^{1}$ Additionally, 11 percent of girls aged 15-19 who had ever had sex reported having experienced a sexually transmitted infection or its symptoms in the year preceding the 2005-06 survey (Parasuraman et al., 2009). More than two-fifths (45\%) of girls aged 15-18 were abnormally thin, while five percent were overweight or obese in 2013-14 (Ministry of Women and Child Development, 2015). Some eight percent of young women aged 15-24 were using tobacco products in 2009-10 (IIPS, 2010).

The lives of many adolescent girls are also characterised by limited awareness of health matters, including sexual and reproductive matters, restricted mobility, constrained access to resources and very little ability to exercise choice in matters relating to their own lives, including protecting themselves from unsafe sex (IIPS and Population Council, 2010). For example, only 21 percent of girls aged 15-19 knew that one condom can be used for one sexual act

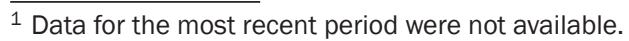


only; a quarter of girls aged 15-19 had comprehensive knowledge of HIV/AIDS; and 11 percent of girls aged 15-19 had heard about sexually transmitted infections other than HIV. Similarly, 23 percent of girls aged 15-19 made independent decisions on such day-to-day matters as choice of friends, spending money and buying clothes for themselves; 11 percent were allowed to visit a health facility unescorted; and although some 34 percent of girls aged 15-19 had some savings, only 9 percent owned a savings account in a bank or post office. Moreover, many adhered to unequal gender role attitudes.

Although adolescent girls require safe and supportive families and schools, and positive and supportive peers, the environment, including relationships between adolescent girls and their parents, teachers, or other potential adult mentors, falls short of meeting adolescent girls' needs and protecting their rights. Available evidence suggests that parents rarely provide adolescents information or guidance on sexual and reproductive matters (Jejeebhoy and Santhya, 2015; IIPS and Population Council, 2010). For example, in India, hardly any girls aged 15-19 (4\% or fewer) reported that a parent had discussed reproductive processes with them (IIPS and Population Council, 2010). The reach of healthcare providers is similarly limited: just 3 percent of girls aged 15-24 had obtained information on sexual matters from a healthcare provider (IIPS and Population Council, 2010). Moreover, healthcare providers do not often make efforts to tailor service delivery strategies to accommodate constraints faced by adolescent girls. For example, evidence from the National Family Health Survey-3 shows that adolescent girls were only half as likely as young women ( $7 \%$ vs. $15 \%$ ), and unmarried young women were only one quarter as likely as married young women ( $4 \%$ vs. $17 \%$ ), to have received a visit at home from a health worker in the three months preceding the survey (IIPS and Macro International, 2007).

These findings underscore the multiple vulnerabilities adolescent girls face in India and call for programmes that provide safe social spaces for girls, build their ability to exercise informed life choices, deliver comprehensive sexuality education, sensitise the health system to make health services approachable and non judgemental, and engage families and communities.

There are a number of programmes implemented by both government and non governmental organisations that seek to support adolescent girls in India. Most programmes have focused on two areas: sexuality and life skills education for the unmarried and services for the married. A review of these programmes highlights that they have focused more on adolescent girls in schools and colleges than those outside the educational system, and therefore have a limited reach among the most vulnerable girls, for example, girls who had never been to school or discontinued school at the primary level (Jejeebhoy and Santhya, 2011). Even programmes implemented in community settings tend to attract the richer and the more educated segments of girls in the communities (Acharya et al., 2009), suggesting the need for adopting measures to reach the most vulnerable girls. Similarly, although programmes that facilitate adolescents' access to sexual and reproductive health counselling and services-overwhelmingly conducted by the health department-are expected to meet the needs of different categories of adolescents, they tend to focus largely on females, exclude unmarried adolescent girls and reach out to married adolescent girls only after they have proven their fertility(Jejeebhoy et al., 2014; Santhya et al., 2014; Jejeebhoy and Santhya, 2011; Santhya et al., 2007). Clearly, there is a need to sensitise and build the skills of healthcare providers to respond to the needs of all categories of adolescents, including the unmarried.

Further, evaluations of programmes to improve girls' lives in India have often observed that interventions for girls cannot afford to neglect those who control or influence their lives-parents, husbands, brothers, boys and men outside the family, as well as community members-and that any attempt at enhancing girls' agency must simultaneously work from within (at the level of the individual girl) and beyond the girl herself (at the level of those who control or influence girls' lives) (Acharya et al., 2009; Santhya et al., 2008; SEWA et al., 2006). However, programmes that attempt to work within and beyond the girl herself are almost non-existent in India.

Finally, while many existing interventions claim success, their experiences and lessons are poorly documented and most have not been rigorously evaluated. Hence, while they are promising, it is difficult to establish the effectiveness of these models and the extent to which they can be effectively replicated and scaled up. Clearly, there is a need for programmes that focus on adolescent girls as well as the people who influence their lives, that address the multiple facets of girls' lives, and that are rigorously documented and evaluated. Lessons from such programmes can be useful at a time when the government is rolling out ambitious and potentially far-reaching, yet pioneering, initiatives such as RKSK. 


\section{Objectives of the evaluation}

The objective of the evaluation was to assess the feasibility and acceptability of the Meri Life Meri Choice project and its impact on key factors known to reduce adolescent girls' vulnerability to HIV. Specifically, it assessed:

- the feasibility and acceptability of the project as perceived by unmarried and married adolescent girls, their unmarried adolescent brothers and husbands, and their mothers/mothers-in-law and fathers/fathers-in-law, hereafter referred to as mothers and fathers;

- the effect of the intervention in improving the protective assets of unmarried and married adolescent girls and their unmarried adolescent brothers and husbands, enabling them to adopt safe practices to reduce their vulnerability to HIV; and in enhancing adolescent girls' access to a supportive and safe environment at the family and community levels; and

- the effect of the intervention in encouraging mothers and fathers to play a supportive role in reducing adolescent girls' HIV vulnerability.

\section{Study setting}

The states of Madhya Pradesh and Uttar Pradesh were selected by MAMTA for the implementation of the MLMC project as they represented two of the most backward states in India.

Madhya Pradesh, the sixth largest state of India, has a population of 72.6 million of which 22 percent are adolescents aged 10-19 years (Office of the Registrar General and Census Commissioner, India, 2013; 2014). Its population continues to be characterised by population and child sex ratios unfavourable to females and lower than the national averages (overall sex ratio of 931 and child sex ratio of 918, compared to 943 and 919, respectively, nationally in 2011; Office of the Registrar General and Census Commissioner, India, 2013). A substantial proportion of households in the state belong to socially disadvantaged groups, namely, scheduled castes and tribes (37\%; Office of the Registrar General and Census Commissioner, India, 2013). Madhya Pradesh is one of the most backward states economically; it ranked 11th among the states of India in terms of gross state domestic product and in 2012-13, it accounted for four percent of the national gross domestic product (Planning Commission, 2014). One-third (32\%) of its population was estimated to live below the poverty line in 2011-12 (Planning Commission, 2013). Moreover, a significant proportion of the population in the state remain illiterate: in 2011, the overall literacy rate was 69 percent in Madhya Pradesh, compared to 73 percent nationally (Office of the Registrar General and Census Commissioner, India, 2013); gender differences were, moreover, considerable: 79 percent of males, compared to 59 percent of females, were literate.

Uttar Pradesh, the largest state in the country, contains a population of 199.8 million (Office of the Registrar General and Census Commissioner, India, 2013; 2014). Adolescents aged 10-19 years comprise 24 percent of the state's population. The overall sex ratio and child sex ratio in the state are considerably lower than the national averages (912 and 902, respectively, per 1,000 males). One-fifth (21\%) of the population belong to scheduled castes and tribes (Office of the Registrar General and Census Commissioner, India, 2013). Unlike Madhya Pradesh, Uttar Pradesh is one of the most progressive states economically. It ranked third among the states of India in terms of gross state domestic product and in 2012-13, accounting for eight percent of the national gross domestic product (Planning Commission, 2014). Yet, 29 percent of its population was estimated to live below the poverty line in 2011-12 (Planning Commission, 2013). As in Madhya Pradesh, the overall literacy rate (68\%) was lower than the national average and gender differences were considerable ( $77 \%$ of males vs. $57 \%$ of females; Office of the Registrar General and Census Commissioner, India, 2013).

The situation of adolescent girls in both states suggests that several vulnerabilities persist and transitions to adulthood are too frequently marked by premature exit from school, early marriage, and strongly held gender norms. For example, even in 2011, just 88 and 84 percent of adolescent girls aged 10-19 were literate in Madhya Pradesh and Uttar Pradesh, respectively (Office of the Registrar General and Census Commissioner, 2014). A substantial proportion of adolescents, considerably more girls than boys, do not progress to secondary school: 55 percent of girls compared to 81 percent of boys in Madhya Pradesh and 61 percent of girls compared to 73 percent of boys in Uttar Pradesh were enrolled in a secondary school (Classes 9-10) in 2011-12 (Ministry of Human Resource Development, 2014). One in ten girls aged 15-17 was already married in both states (Office 
of the Registrar General and Census Commissioner, 2015a). Moreover, 27-29 percent of currently married girls aged 15-19 years in these states were already mothers in 2011 (Office of the Registrar General and Census Commissioner, 2015b).

Available data also show that few girls display agency in day-to-day matters. For example, the NFHS-3 data show that just 29-38 percent of married girls aged 15-19 participated in decisions regarding their own health care; 5-13 percent of married girls had the freedom to visit a health facility on their own; and 4-5 percent owned an account in a bank or post office (IIPS and Macro International, 2007). Almost one in four girls experienced physical or sexual violence within marriage. Furthermore, awareness of sexual and reproductive matters is limited among both girls and boys; for example, 48 and 32 percent of boys and 26 and 18 percent of girls in Madhya Pradesh and Uttar Pradesh, respectively, displayed comprehensive knowledge of HIV/AIDS. Access to sexual and reproductive health services is also limited; just 9 and 15 percent of married girls in Madhya Pradesh and Uttar Pradesh, respectively, practised contraception within marriage; and 4-5 percent reported condom use within marriage.

The districts of Rewa and Satna in Madhya Pradesh and Allahabad and Banda in Uttar Pradesh were purposively selected by MAMTA for locating the MLMC project. A few key indicators of the study districts and states are presented in Table 1.1.

Table 1.1: Profile of the study districts and states

\begin{tabular}{|c|c|c|c|c|c|c|}
\hline \multirow[t]{2}{*}{ Characteristics } & \multicolumn{3}{|c|}{ Madhya Pradesh } & \multicolumn{3}{|c|}{ Uttar Pradesh } \\
\hline & Rewa & Satna & State & Allahabad & Banda & State \\
\hline Population & $2,365,106$ & $2,228,935$ & $72,626,809$ & $5,954,391$ & $1,799,410$ & $199,812,341$ \\
\hline Overall sex ratio $(\mathrm{F} / \mathrm{M})$ & 931 & 926 & 931 & 901 & 863 & 912 \\
\hline $\begin{array}{l}\text { Child sex ratio }(0-6 \text { years }) \\
(F / M)\end{array}$ & 885 & 910 & 918 & 893 & 902 & 902 \\
\hline Male literacy (\%) & 81.4 & 81.4 & 78.7 & 82.6 & 77.8 & 77.3 \\
\hline Female literacy (\%) & 61.2 & 62.5 & 59.2 & 61.0 & 53.7 & 57.2 \\
\hline $\begin{array}{l}\text { 15-17-year-old girls who were } \\
\text { ever married }(\%)\end{array}$ & 8.1 & 7.8 & 9.8 & 8.9 & 6.7 & 8.6 \\
\hline $\begin{array}{l}\text { 15-19-year-old married girls } \\
\text { who were already mothers (\%) }\end{array}$ & 26.3 & 28.0 & 28.7 & 32.4 & 26.9 & 26.9 \\
\hline
\end{tabular}

Sources: Office of the Registrar General and Census Commissioner, 2013; 2015a, 2015b

Within each study district, four blocks-three intervention blocks and one comparison block-were selected ${ }^{2}$ in such a way that the combined averages of such indicators as the female literacy rate, the proportion of the population belonging to scheduled castes or tribes (SC/ST), and the percentage of males engaged in non-agricultural work were similar between the intervention and comparison arms at the individual state level as well as at the combined level (i.e., two states taken together). Thus, a total of 12 blocks were selected to serve as the intervention arm and four blocks to serve as the comparison arm (see Annex 1 for a detailed description of the sele ction of the intervention and comparison arms and the sample size calculation).

From the 12 intervention blocks, a total of 770 villages were selected for implementing the intervention activities. The project was implemented in two phases. The first phase of the project, implemented over a 10-month period in 2012, was designed to serve as a proof-of-concept phase, and covered 184 villages. The second phase was a scaled-up phase, incorporating the lessons of Phase 1, and implemented in 586 villages in three consecutive batches over an 18-month period, with intervention activities completed in each batch of villages over a six-month period. The project was implemented by MAMTA directly in Banda and Rewa districts and through partners, Anupama Education Society in Satna and Lok Smriti Sewa Sansthan in Allahabad.

The Population Council conducted the evaluation in a sample of villages out of the 200 villages covered in the third and the final batch of the scaled-up phase. The evaluation was conducted in a total of 80 villages-40 intervention

\footnotetext{
${ }^{2}$ In Rewa and Satna, four out of seven blocks were thus selected, respectively; in Allahabad, four out of eight blocks were selected; and in Banda,
} all four blocks were selected. 
and 40 comparison villages across the four districts. More specifically, we obtained the list of the final batch of villages covered in the scaled-up phase and selected 40 villages randomly from this list, using the probability proportional to size sampling technique. In the comparison arm, similarly, we randomly selected 40 villages, using the same technique.

\section{Intervention}

The Meri Life Meri Choice project, implemented by MAMTA and its partners, sought to reduce the vulnerability of rural adolescent girls to HIV by enhancing their knowledge about sexual and reproductive matters and equipping them with skills that enable them to address vulnerability to HIV; increasing their utilisation of sexual and reproductive health services from the public sector; and developing a supportive environment that enables adolescent girls to adopt protective actions to reduce vulnerability to HIV. The project was implemented among unmarried girls aged 15-19 who had never been to school or who had discontinued school and who belonged to socially disadvantaged castes/tribes/religions; and married girls aged 15-21 who belonged to socially disadvantaged castes/tribes/religions. It also targeted unmarried brothers aged 15-19, husbands aged 15-24, and mothers and fathers of these girls as well as other gatekeepers in the intervention villages, including frontline health workers.

Activities implemented over a six-month period included the formation of adolescent girls' groups in each of the intervention villages; establishment of Gender Resource Centres (GRCs) in each intervention village that offered a safe space for girls to network with peers as well as opportunities to receive life skills education; the provision of support for girls to open bank accounts and avail themselves of existing vocational skills training programmes; and the establishment of referral linkages with existing public-sector health services, especially with the Integrated Counselling and Testing Centers (ICTCs) to encourage the utilisation of these services, particularly HIV counselling and testing services by adolescent girls. Similar activities were organised for unmarried adolescent brothers and husbands of adolescent girls. Finally, family events during which family members got an opportunity to observe girls' participation in the Gender Resource Centre, meetings of parents' groups and community support groups formed in each intervention village, training workshops for healthcare providers, especially, frontline health workers, and village wide behaviour change communication campaigns were also organised.

The Population Council evaluated the acceptability, feasibility, and effectiveness of this model. In assessing the effectiveness of the model, the Council used indicators that measured the success of the project not only in terms of averting a bad outcome (multiple partnerships, inconsistent condom use, for example) but building the protective assets of girls and thereby preventing conditions that are social precursors of HIV. These protective assets include: (1) human assets comprising skills, knowledge, agency, health, and so on; (2) social assets including friends, mentors, other trusted relationships, and access to other institutions in society; (3) financial assets comprising access to cash, savings, and financial literacy; and (4) physical assets including personal items, access to safe social spaces, and various tools that often produce monetary value (Sebstad and Bruce, 2004; Bruce et al., 2012). They can prepare adolescents for meeting day-to-day needs, dealing with life-cycle events, coping with emergencies, crisis, and unexpected events, and taking advantage of opportunities when they present themselves. In other words, they help reduce adolescents' vulnerabilities and expand their opportunities.

\section{Study design}

We used a quasi-experimental design, with cross-sectional surveys undertaken in the comparison and intervention arms prior to the implementation of intervention activities (baseline) and at its conclusion (endline). We also conducted post-survey in-depth interviews with selected survey respondents in the intervention arm at endline. We used repeated cross-sectional surveys in the same villages at baseline and endline to assess the effects of the project because such a design provided us a panel dataset at the village-level, thereby reducing the cluster effect in models based on baseline-endline differences.

The evaluation focused on unmarried and married adolescent girls, their brothers and husbands, and parents. Specifically, respondents for the baseline survey included: (1) unmarried girls aged 15-19 who had never been to school or had discontinued school, and who belonged to socially disadvantaged groups (that is, scheduled castes, scheduled tribes, or Muslims); (2) married girls aged 15-21 who belonged to socially disadvantaged groups; (3) 
unmarried brothers aged 15-19 of eligible unmarried girls; (4) husbands aged 15-24 of eligible married girls; and (5) mothers and fathers of eligible unmarried and married girls, respectively (see Annex 1 for more details).

Following the selection of the intervention and comparison villages, we conducted a baseline assessment, comprising a household listing and a survey of eligible respondents. We completed the baseline data collection in April-June 2014.

During the household listing, the field team enumerated all households in the study villages with 400 or fewer households. In villages with more than 400 households, we segmented the village on the basis of the caste and religious concentration of the households, and listed all households in segments that were known to be largely inhabited by those belonging to scheduled castes, scheduled tribes, or Muslims. The field investigators who enumerated the households enquired whether the household belonged to a scheduled caste, scheduled tribe, or was Muslim and whether the household contained any girl aged 10-24 years. At baseline, a total of 9,261 households were identified that contained a potential eligible girl.

The field team entrusted with the task of interviewing the eligible girls, their brothers and husbands, and parents first re-confirmed the eligibility of the girls and successfully administered a household schedule in 96 percent of the households identified by the listing team. The team invited all girls who met the eligibility criteria to take part in the survey. In households containing more than one eligible girl, one was selected randomly using the Kish table. The team identified a total of 1,493 unmarried girls and 1,654 married girls at baseline. Unmarried brothers aged 15-19, including co-residing cousin brothers, of eligible unmarried girls, and husbands aged 15-24 of eligible married girls, were also invited to take part in the survey. As in the case of girls, in households containing more than one eligible unmarried brother, one was selected randomly using the Kish table. The team identified 1,487 unmarried brothers and husbands of eligible girls-382 unmarried brothers and 1,105 husbands at baseline. For the interview of mothers and fathers of eligible girls, we fixed a quota of eight parents-two each of mothers, mothers-inlaw, fathers and fathers-in-law-per village and these mothers and fathers were conveniently recruited into the study on the basis of their availability during the field visits by the research team.

The categories of respondents for the endline survey were the same as those at the baseline survey, with some revision in the eligibility criteria. We decided to interview somewhat older adolescents (i.e., 15-20 year-olds among unmarried girls, 15-22 year-olds among married girls, 15-20 year-olds among unmarried brothers of unmarried girls and 15-25 year-olds among husbands of married girls) to ensure that those interviewed at the time of the endline survey had been eligible for the intervention at baseline. Thus, at endline, 10,382 households were identified as containing a potentially eligible girl. The field team re-confirmed the eligibility of the girls and successfully administered a household schedule in 90 percent of these households. The team identified a total of 2,007 unmarried girls, 2,045 married girls, 636 unmarried brothers, and 1,332 husbands. As at basline, mothers and fathers were conveniently recruited into the study on the basis of their availability during the field visits by the research team. The endline data collection was completed in December 2014-May 2015.

At the endline, we also conducted in-depth interviews with selected surveyed girls from the intervention arm. The respondents for the in-depth interviews were selected based on their responses to the endline survey questions related to changes they reported as having experienced during the six months prior to the interview. Specifically, all the surveyed girls in the intervention arm were categorised into two groups-those who reported positive changes in their lives and those who did not. We selected 18 girls who reported positive changes and 8 girls who reported no change. A total of 26 in-depth interviews were completed.

Quantitative data were entered in CSPro and analysed using SPSS. The textual data from the in-depth interviews were transcribed by the research assistants who conducted the in-depth interviews and translated into English by consultants recruited by the Council. These transcripts were thematically coded in Atlas. ti.

\section{Study instruments}

Six survey instruments were developed-a household listing form, a household schedule to collect socio-economic characteristics of households in which eligible girls were interviewed, a girls' questionnaire to elicit information from eligible unmarried and married girls, a boys' questionnaire to gather information from unmarried brothers and husbands of eligible girls, a questionnaire to elicit information from mothers and mothers-in-law of eligible girls, and a questionnaire to collect information from fathers and fathers-in-law of eligible girls. 
Responses to the household listing form were gathered from a responsible adult member of all the households enumerated in the study villages. Responses to the household questionnaire were also obtained from a responsible adult member of the household to which the eligible girl belonged. The household questionnaire contained a roster in which age, sex, marital status, and schooling status of all household members who usually resided in the household were recorded; it also collected information about the household's access to various amenities.

At baseline, the girls' questionnaire sought information on educational experiences, including participation and interest in vocational skills training programmes; peer networks; agency and gender role attitudes; financial literacy; relationship with parents (for unmarried girls) and parents-in-law (for married girls), and brothers (for unmarried girls) and husbands (for married girls); awareness of sexual and reproductive matters, including HIV/AIDS; engagement in pre-and extra marital relationships and safe sex practices; and contact with the health system. The contents of the male questionnaire were similar to that of the female questionnaire. Recognizing the reluctance of adolescents to disclose sexual experiences in face-to-face interviews, at the conclusion of the interview, we asked respondents to report their premarital (for unmarried)/extra marital (for married) sexual experiences in the six months prior to the interview on four cards, which they placed in an envelope that they then sealed. Specifically, study participants were asked to mark four blank cards indicating: (1) whether they had engaged in premarital/ extra marital sex in the six months prior to the interview; (2) the number of partners with whom they had engaged in premarital/extra marital sex; (3) whether they used a condom at last sex; and (4) whether they used condoms consistently. Respondents were informed that only the principal investigators would be able to link the information provided in the envelope with that provided in the main body of the questionnaire. Questionnaires for mothers and mothers-in-law of eligible girls collected information about their background characteristics, their gender role attitudes, their aspirations for their children and socialisation practices, their awareness of sexual and reproductive matters, and their relationship with their children. The contents of the questionnaires for fathers and fathers-in-law were similar. The questionnaires were translated into Hindi, pre-tested, and revised in light of the insights obtained during pre-testing.

At endline, we used identical questionnaires, except for an additional module to capture respondents' exposure to the project activities. The module on project exposure sought to capture respondents' experiences and perceptions about the acceptability and quality of the project and their perceptions about changes experienced in their lives in the six months prior to the interview. Additionally, at endline, we developed a guide to interview in-depth selected surveyed girls. The in-depth interview guide sought to probe girls in detail about their participation in the project, as well as their family members' participation in project activities; the support they received in accessing sexual and reproductive health services, opening bank accounts, and accessing vocational skills training programmes; the nature of their relationship with their brothers (for unmarried girls) and husbands (for married girls) as well as parents (for unmarried girls) and parents-in-law (for married girls); and so on.

\section{Recruitment, training and fieldwork}

The training of research assistants who were recruited for the household listing and the survey was conducted by Population Council staff in partnership with MAMTA staff both at baseline and endline. The training duration for the household listing and the survey was two days and one week, respectively, at both baseline and endline. These research assistants were graduates in science or social science streams, were proficient in Hindi, and had 3-4 years of experience in conducting field-based studies. The training team monitored each trainee's progress on a regular basis and selected as interviewers only those trainees who demonstrated a full understanding of the questionnaire as well as the ability to ask questions appropriately and record responses accurately. A total of eight young men underwent training for undertaking the household listing at baseline, and all were selected for the household listing. Likewise, 13 young men and 16 young women underwent training for administering the survey instruments at baseline; of these, all except one young women were recruited for the baseline survey. Finally, 12 young men and 13 young women underwent training for listing households and administering the survey instruments at endline; of these, all except one young women were recruited for the endline survey. Moreover, to ensure data quality and adherence to ethical principles, Council staff provided ongoing supervision and support to the interviewers. 
Table 1.2: Response rates by category of respondents at baseline and endline surveys

\begin{tabular}{lrr}
\hline Respondents & Combined \\
\cline { 2 - 3 } & $\begin{array}{r}\text { Identified } \\
\text { Interviewed }\end{array}$ & $\begin{array}{c}\text { Response } \\
\text { Rate (\%) }\end{array}$ \\
\hline Baseline & & 9,855 \\
Responsible adult household member & 9,261 & 95.6 \\
Unmarried girls & 1,493 & 1,375 \\
Married girls & 1,654 & 1,460 \\
Unmarried brothers & 382 & 311 \\
Husbands & 1,105 & 88.3 \\
Mothers and fathers & $640^{\mathrm{a}}$ & 917 \\
Endline & 81.4 \\
Responsible adult household member & 83.0 \\
Unmarried girls & 10,382 & 95.9 \\
Married girls & 2,007 & 9,303 \\
Unmarried brothers & 2,045 & 1,754 \\
Husbands & 636 & 1,780 \\
Mothers and fathers & 1,332 & 89.6 \\
\hline
\end{tabular}

Note: ${ }^{a}$ The number of mothers and fathers to be interviewed as per the quota fixed.

\section{Response rates}

Table 1.2 summarises the number of respondents identified and successfully interviewed at baseline and endline. At baseline, of the 9,261 households identified as containing potentially eligible girls, we successfully interviewed a responsible adult member in 96 percent of households. We identified a total of 1,493 unmarried girls and successfully interviewed 92 percent of these girls; we note that the actual number of girls interviewed was more than the required number of girls to be interviewed. Similarly, we identified 1,654 married girls and successfully interviewed 88 percent of them. As with unmarried girls, the actual sample size for married girls exceeded the required sample size. In comparison, the actual sample size we obtained for boys, particularly unmarried brothers of eligible girls fell short of the required sample size. We identified just 382 unmarried brothers of eligible girls and successfully interviewed 81 percent of them. Similarly, we identified 1,105 husbands of eligible girls and interviewed 83 percent of them. We note that the response rates were similar in both states for all four categories of study participants. Finally, we interviewed 614 mothers and fathers of eligible girls which amounted to 96 percent of the quota fixed.

At endline, the response rates were slightly lower than those at the baseline; however, the response rate was 78 percent or above for all categories of respondents. Of the 10,382 households identified as containing potentially eligible girls, we successfully interviewed a responsible adult member in 90 percent of households. We identified a total of 2,007 unmarried girls and 2,045 married girls, and successfully interviewed 87 percent of these girls. Similarly, we identified 636 unmarried brothers of eligible unmarried girls and 1,332 husbands of eligible married girls, and successfully interviewed 78-79 percent of them. Finally, we interviewed 599 mothers and fathers of eligible girls which amounted to 94 percent of the quota fixed.

The non-responses were largely because the entire household had temporarily migrated for work-related reasons or the respondent was not at home even after the field team made at least three visits (Table 1.3). Refusal among adolescent girls and their brothers and husbands was one percent or less at the baseline and three percent or less at the endline.

\section{Structure of the report}

The report is divided into nine chapters, including this introductory chapter. In Chapter 2, we present a profile of the lives of unmarried and married adolescent girls, their unmarried brothers and husbands in the project settings at the time of the baseline assessment, including the extent to which adolescent girls and their brothers and husbands were 
Table 1.3: Reasons for non-responses by category of respondents at baseline and endline surveys

\begin{tabular}{lrrrrrr}
\hline Reasons & \multicolumn{7}{c}{ Category of respondents } \\
\cline { 2 - 7 } & HHM & UF & MF & UM & MM & P \\
\hline Baseline & & & & & & \\
Interview completed & 95.6 & 92.1 & 88.3 & 81.4 & 83.0 & 95.9 \\
Respondent not at home & 1.9 & 5.6 & 11.1 & 17.0 & 15.3 & - \\
Postponed & - & - & 0.1 & - & 0.2 & 1.1 \\
Refused & 0.1 & 0.1 & 0.1 & 0.5 & 0.8 & 2.5 \\
Parents refused & - & 0.5 & 0.1 & 0.5 & 0.1 & - \\
Partly completed & - & 0.2 & 0.2 & - & 0.3 & 0.5 \\
Incapacitated & - & 1.4 & 0.1 & 0.5 & 0.4 & - \\
Household temporarily migrated & 2.1 & - & - & - & - & - \\
Endline & & & & & & \\
Interview completed & 8.6 & 87.4 & 87.0 & 78.0 & 79.3 & 93.6 \\
Respondent not at home & 3.6 & 10.0 & 11.5 & 17.9 & 17.4 & - \\
Postponed & - & - & - & - & - & 2.0 \\
Refused & 0.1 & 0.6 & 0.6 & 1.4 & 2.6 & 3.7 \\
Parents refused & - & 1.1 & 0.4 & 0.6 & 0.2 & - \\
Partly completed & - & 0.1 & - & 0.2 & - & 0.7 \\
Incapacitated & - & 0.8 & 0.3 & 1.9 & 0.5 & - \\
Household temporarily migrated & 6.7 & - & - & - & - & - \\
\hline
\end{tabular}

Note: HHM: Responsible adult member who responded to the household schedule; UF: unmarried eligible girl; MF: married eligible girl; UM: unmarried brother of eligible unmarried girls; MM: husband of married eligible girls; P: mothers and fathers of eligible girls.

endowed with protective assets that can prevent conditions leading to HIV infection, their engagement in behaviours and practices that may compromise or reduce their vulnerability to HIV, and adolescent girls' access to a supportive and safe environment at the family and the broader community level. We also briefly describe the background characteristics of mothers and fathers of adolescent girls, their awareness of sexual and reproductive matters, their gender role attitudes, and socialisation practices, including communication with their adolescent daughters. In Chapter 3 , we describe the objectives, the design, and the key components of the MLMC project. Drawing on data collected from adolescent girls, their unmarried brothers and husbands, and their mothers and fathers who participated in the endline survey, we also describe study participants' awareness and experiences of the MLMC project.

In Chapter 4, we present findings with regard to the effect of the MLMC project in strengthening protective assets of adolescent girls and their unmarried brothers and husbands that could mitigate their vulnerability to HIV. We describe the effect of the MLMC project in changing sexual risk-taking behaviours and health-seeking practices of adolescent girls and their unmarried brothers and husbands in Chapter 5. In Chapter 6, we examine the changes in adolescent girls' access to a supportive and safe environment at the family and the broader community level following the implementation of the MLMC project. Chapter 7 describes the changes in mothers' and fathers' awareness of sexual and reproductive matters, their gender role attitudes and socialisation practices following the implementation of the MLMC project. We present data on study participants' perceptions of changes that they experienced in the six months preceding the survey, which roughly corresponded with the intervention period, in both the intervention and comparison arms in Chapter 8. Finally, Chapter 9 summarises the main findings of the evaluation.

All means, medians and percentages indicated in the tables describing findings from the surveys of adolescent girls and their brothers and husbands have been weighted using normalized weights for the total population. However, in order to show the total number of adolescent girls and their brothers and husbands interviewed, unweighted numbers of respondents (Ns) are provided in each table. Because numbers are unweighted and percentages are weighted, we caution readers against deriving numbers based on the percentages provided in the tables. We further note that numbers and percentages given in the tables describing findings from the surveys of mothers and fathers are unweighted. 


\section{Chapter 2}

\section{Profile of adolescent girls and their families}

Drawing on data from the baseline assessment, this chapter presents a brief profile of the lives of unmarried and married adolescent girls and their unmarried brothers and husbands in the study settings. We first present the background characteristics of the adolescent girls, their unmarried brothers and husbands, and mothers and fathers who participated in the survey. We follow this with a description of the extent to which adolescent girls and their unmarried brothers and husbands were endowed with protective assets that can prevent conditions leading to HIV infection, their engagement in behaviours and practices that may compromise or reduce their vulnerability to HIV, and adolescent girls' access to a supportive and safe environment at the family and the broader community level. We also present findings related to awareness of sexual and reproductive matters, gender role attitudes, and socialisation practices among adolescent girls' mothers and fathers.

\section{Background characteristics of adolescent girls, their unmarried brothers, husbands, mothers and fathers}

Drawing on data from the household questionnaire and survey questionnaires, Table 2.1 presents a profile of the adolescent girls and their unmarried brothers and husbands who participated in the survey at baseline. Unmarried girls were aged, on average, 17 years, and married girls were, on average, two years older than unmarried girls. Unmarried brothers were similarly aged as unmarried girls (mean age of 17 years), and husbands were, on average (mean age of 19 years) three years older than married girls (mean age of 22 years).

On average, unmarried girls had completed six years of schooling and married girls had completed seven years of schooling. Unmarried brothers and husbands of eligible girls had completed on average eight years of schooling.

Participation in paid economic activities was common among study participants. A larger proportion of unmarried than married girls reported engagement in such activities: almost three-fifths of unmarried girls had engaged in paid work in the year preceding the interview compared to one-third of married girls. Four-fifths of unmarried brothers and almost all husbands were engaged in paid work in the year preceding the interview. Findings also show that the vast majority of study participants came from economically poor households (mean score of 14-16 on a household wealth index, the value of which ranged from 0 to 54; see Annex 2 for details about the construction of the household wealth index).

Exposure to mass media was fairly common among study participants. Half of girls, regardless of marital status, were regularly exposed to mass media, as were 65-71 percent of unmarried brothers and husbands.

Table 2.1: Selected background characteristics of unmarried and married adolescent girls and their unmarried brothers and husbands, baseline survey

\begin{tabular}{lcrrr}
\hline Characteristics & $\begin{array}{c}\text { Unmarried } \\
\text { adolescent } \\
\text { girls }\end{array}$ & $\begin{array}{c}\text { Married } \\
\text { adolescent } \\
\text { girls }\end{array}$ & $\begin{array}{c}\text { Unmarried } \\
\text { brothers }\end{array}$ & Husbands \\
\hline Mean age (years) & 16.8 & 19.2 & 17.0 & 21.8 \\
Median years of schooling successfully completed & 6.0 & 7.0 & 8.0 & 8.0 \\
Currently attending school (\%) & 0.0 & 7.9 & 31.2 & 7.0 \\
Engaged in paid work in the year prior to the interview (\%) & 58.4 & 32.8 & 79.3 & 94.2 \\
Mean score, household wealth index (range 0-54) & 14.2 & 15.9 & 15.5 & 15.8 \\
Exposed to mass media regularly (\%) & 51.4 & 52.4 & 71.1 & 64.5 \\
Number of respondents & $\mathbf{1 , 3 7 5}$ & $\mathbf{1 , 4 6 0}$ & $\mathbf{3 1 1}$ & $\mathbf{9 1 7}$ \\
\hline
\end{tabular}

Note: All means and percentages are weighted. 
We note that the background characteristics of the study participants in the intervention and comparison arms were, for the most part, similar; however, differences were observed in terms of household wealth index and exposure to mass media (see Annex 3). Specifically, unmarried girls and their brothers in the intervention arm were somewhat more likely to belong to economically better off households and considerably more likely to be exposed to mass media than those in the comparison arm. Among the married, those in the intervention arm were somewhat less likely to belong to an economically better off households than their counterparts in the comparison arm. We also note that the background characteristics of the endline cohort of girls and their unmarried brothers and husbands were similar to those of the baseline cohort for the most part (see Annex 4). However, a somewhat smaller proportion of the endline cohort of girls reported exposure to mass media than the baseline cohort, and a reverse pattern was evident among their unmarried brothers and husbands.

Mothers of surveyed girls were on average aged 45 years and fathers were five years older than mothers (mean age of 50 years). Educational attainment was extremely low. While fathers were more educated than mothers-54 percent of fathers had ever attended school compared to just eight percent of mothers-on average men still had only completed one year of school. A slightly larger proportion of fathers were engaged in paid work in the year prior to the interview compared to mothers (87\% vs. $79 \%$ ). Similar proportions of fathers and mothers were exposed to mass media regularly (29\% vs. $27 \%$ ) (Table 2.2$)$.

Table 2.2: Selected background characteristics of mothers and fathers of adolescent girls, baseline survey

\begin{tabular}{lrr}
\hline Characteristics & Mothers & Fathers \\
\hline Mean age (years) & 45.2 & 49.8 \\
Ever attended school (\%) & 8.1 & 54.0 \\
Median years of schooling successfully completed & NC & 1.0 \\
Engaged in paid work in the year prior to the interview (\%) & 78.7 & 86.5 \\
Exposed to mass media regularly (\%) & 26.5 & 29.0 \\
Number of respondents & $\mathbf{3 1 0}$ & $\mathbf{3 0 4}$ \\
\hline
\end{tabular}

Note: All means and percentages are unweighted; NC-not calculated as more than half of the respondents had never attended school.

\section{Assets acquired by adolescent girls and their unmarried brothers and husbands}

This section presents evidence at baseline on the extent to which adolescent girls and their unmarried brothers and husbands were endowed with a selected set of assets that can prevent conditions leading to HIV infection, namely, their peer networks and interactions; agency and gender role attitudes; awareness of sexual and reproductive matters, including HIV/AIDS; financial literacy and related practices; participation in vocational skills training programmes; and access to social spaces to network with peers. The baseline assessment highlights that adolescent girls and their unmarried brothers and husbands in the study settings typically were not endowed with assets that can prevent conditions that are precursors of HIV, as summarised below.

\section{Peer networks and interactions}

We measured study participants' peer networks and interactions in terms of the number of friends they had, the frequency of their interactions with their friends, and the person in whom they would confide personal problems, such as a sexual and reproductive health $(\mathrm{SRH})$ problem.

Findings presented in Table 2.3 suggest that limited peer networks and interactions characterised the lives of many adolescent girls in the study settings. Opportunities to make new friends were limited: 4-5 percent of girls, regardless of marital status, reported having made new friends in the six months preceding the interview; so did 6-12 percent of unmarried brothers and husbands. Only two-thirds of unmarried and married girls reported at least one friend. In comparison, 91 percent of unmarried brothers and 80 percent of husbands reported at least one friend. Findings also show that adolescent girls' interactions with their friends were infrequent, particularly among married girls: 55 percent of all unmarried girls (i.e., $78 \%$ of girls with at least one friend) and 21 percent of 
all married girls (i.e., 30\% of girls with at least one friend) reported that they met their friends once a week or more often. In comparison, unmarried brothers and husbands reported frequent interactions with their friends: 86 percent of brothers (i.e., $95 \%$ of those with at least one friend) and 73 percent of husbands (i.e., $91 \%$ of those with at least one friend) reported that they met their friends once a week or more often.

Adolescent girls' access to non family trusted mentors with whom they could discuss personal problems was considerably limited, particularly among the married: 22 percent of unmarried girls compared to seven percent of married girls reported a non family member as a confidant for discussing a sexual and reproductive health problem. In comparison, 71 percent of unmarried brothers and 44 percent of husbands cited a non family member as a confidante for discussing a sexual and reproductive health problem.

Table 2.3: Size of peer networks, regularity of peer interactions and access to non family trusted mentors among unmarried and married adolescent girls and their unmarried brothers and husbands, baseline survey

\begin{tabular}{|c|c|c|c|c|}
\hline Indicators (\%) & $\begin{array}{c}\text { Unmarried } \\
\text { adolescent } \\
\text { girls }\end{array}$ & $\begin{array}{c}\text { Married } \\
\text { adolescent } \\
\text { girls }\end{array}$ & $\begin{array}{c}\text { Unmarried } \\
\text { brothers }\end{array}$ & Husbands \\
\hline Made new friends in the six months prior to the interview & 4.5 & 3.8 & 12.3 & 5.5 \\
\hline Reported at least one friend & 69.9 & 68.2 & 90.6 & 79.9 \\
\hline Met friends once a week or more often & 54.8 & 20.5 & 86.3 & 73.1 \\
\hline Would confide a SRH problem in a non family member & 21.6 & 7.1 & 71.3 & 44.0 \\
\hline Number of respondents & 1,375 & 1,460 & 311 & 917 \\
\hline
\end{tabular}

Note: All percentages are weighted.

\section{Agency and gender role attitudes}

We captured adolescent girls' and their unmarried brothers' and husbands' agency in terms of their self-efficacy, decision making autonomy and mobility, and findings summarised below suggest that few adolescents, particularly girls, exercised agency in their lives (see Annex 5 for the individual components included in the summary measures related to agency and gender role attitudes and their baseline values).

In order to capture their self-efficacy, we asked study participants whether they would express their opinion to their mother and father, respectively, about something that concerns them and whether they would confront a person who had done or said something wrong to them. All those who responded affirmatively to at least two out of these three questions were considered to have self-efficacy. Findings, presented in Table 2.4, indicate limited self-efficacy of adolescent girls and their unmarried brothers and husbands. Just one-third of girls, irrespective of marital status, displayed self-efficacy in two out of three situations posed to them. A larger proportion of unmarried brothers and husbands than girls displayed self-efficacy ( $50 \%$ and $46 \%$, respectively).

Table 2.4: Agency and gender role attitudes of unmarried and married adolescent girls and their unmarried brothers and husbands, baseline survey

\begin{tabular}{lcccc}
\hline Indicators & $\begin{array}{c}\text { Unmarried } \\
\text { adolescent } \\
\text { girls }\end{array}$ & $\begin{array}{c}\text { Married } \\
\text { adolescent } \\
\text { girls }\end{array}$ & $\begin{array}{c}\text { Unmarried } \\
\text { brothers }\end{array}$ & Husbands \\
\hline Displayed self-efficacy (\%) & 31.1 & 29.9 & 49.7 & 46.0 \\
Made/will make independent decisions in personal & 47.6 & 36.3 & 67.0 & 79.1 \\
matters (\%) & 2.2 & 1.8 & 6.9 & 7.8 \\
$\begin{array}{l}\text { Index of mobility (mean score, range 0-8; } \alpha=0.7-0.8) \\
\text { Index of gender egalitarian attitudes (mean score, }\end{array}$ & 6.1 & 6.1 & 5.1 & 5.4 \\
range 0-12; $\alpha=0.5-0.7$ ) & $\mathbf{1 , 3 7 5}$ & $\mathbf{1 , 4 6 0}$ & $\mathbf{3 1 1}$ & $\mathbf{9 1 7}$ \\
Number of respondents & & & & \\
\hline
\end{tabular}

Note: All means and percentages are weighted. 
We measured adolescents' involvement in decision making by asking them about who made/will make decisions related to three specific matters: going to a friend's house, whom to marry, and spending her/his own money. All those who reported that they made/will make independent decisions in at least two of these personal matters were considered to have decision making autonomy. Findings, summarised in Table 2.4, highlight the limited decision making autonomy of adolescent girls. Specifically, 48 and 36 percent of unmarried and married girls, respectively, reported that they made/will make independent decisions. A larger proportion of unmarried brothers and husbands than girls exercised decision making autonomy (67\% and $79 \%$, respectively).

In order to assess adolescents' freedom of movement, we asked whether the respondent was permitted to visit selected locations-a shop or market, a health facility, a programme, and the house of a friend or a relative-inside and outside their village unescorted, only if accompanied by someone else, or not permitted to visit the place at all. We created an index of mobility that summed their responses, assigning a score of 1 if the respondent could go unescorted to each destination and 0 otherwise. The value of the index ranged from 0 , indicating no mobility to 8 , indicating a high degree of mobility (Cronbach's alpha ranged from 0.7 to 0.8 for different categories of study participants). Findings clearly indicate that adolescent girls' mobility was extremely limited: unmarried and married girls scored 2.2 and 1.8 on the scale. In contrast, their unmarried brothers and husbands displayed a high degree of mobility, scoring 6.9 and 7.8 , respectively (Table 2.4).

A major theme in the survey was related to gender role attitudes of adolescent girls and their unmarried brothers and husbands. We posed 12 statements pertaining to such topics as the importance of educating girls compared to boys, and of girls completing higher secondary education compared to getting married early for girls, girls having male friends, girls' interest in being teased by boys, girls' right to decide the timing of their marriage, the need for paying dowry, husbands' authority over household matters, sharing responsibilities between husbands and wives, and marital violence. We created an index of gender egalitarian attitudes that summed their responses, assigning a score of 1 for each gender egalitarian statement with which s/he agreed and non egalitarian statement with which $\mathrm{s} /$ he disagreed and 0 otherwise. The value of the index ranged from 0 , indicating adherence to gender stereotypical attitudes, to 12, indicating adherence to gender egalitarian attitudes (Cronbach's alpha ranged from 0.5 to 0.7 for different categories of study participants). Findings show that gender role attitudes remained unequal for the most part, with girls displaying more gender egalitarian attitudes than their brothers and husbands; adolescent girls scored 6.1 each and their unmarried brothers and husbands scored 5.1-5.4 on the index of gender egalitarian attitudes (Table 2.4).

\section{Awareness of sexual and reproductive matters}

We included several questions to assess adolescent girls' and their unmarried brothers' and husbands' awareness of sexual and reproductive matters. Specifically, respondents were asked, in detail, about their awareness of sexand pregnancy-related matters, legal minimum age at marriage, contraception, sexually transmitted infections, and HIV/AIDS. We created an index of awareness of sexual and reproductive matters. The respondent was given a score of 1 for each question that was correctly answered and 0 otherwise, and the scores were summed to create the index, the value of which ranged from 0 , indicating no awareness, to 16, indicating high levels of awareness (Cronbach's alpha was 0.8; see Annex 6 for the individual components included in the summary measure related to awareness of sexual and reproductive matters and their baseline values). Additionally, given the focus of the MLMC project on reducing adolescent girls' vulnerability to HIV, we present evidence separately on study participants' awareness of HIV/AIDS. Findings underline the limited awareness of sexual and reproductive matters among adolescent girls and their unmarried brothers and husbands, particularly among girls at baseline (Table 2.5). Specifically, unmarried and married girls scored 6.6 and 8.6, respectively, on a scale that ranged from 0 to 16. Unmarried brothers and husbands scored better than girls, with a mean score of 9.1 and 10.9, respectively.

Data on awareness of HIV/AIDS show that just 33 percent of unmarried girls had ever heard of HIV/AIDS; a much larger proportion of married girls (46\%), unmarried brothers (68\%) and husbands (83\%) had heard about it (Table 2.5). Findings also indicate that very few adolescents knew about ways of preventing HIV transmission, rejected misconceptions about HIV/AIDS and knew a facility to go for an HIV test. For example, 15 and 31 percent of unmarried and married girls, respectively, knew about two ways of preventing HIV transmission (i.e., condom use and single-partner relations). A much larger proportion of unmarried brothers and husbands than girls reported awareness of two ways of preventing HIV transmission ( $54 \%$ and $72 \%$, respectively). Likewise, only a small 
Table 2.5: Awareness of sexual and reproductive matters among unmarried and married adolescent girls and their unmarried brothers and husbands, baseline survey

\begin{tabular}{lcccc}
\hline Indicators & $\begin{array}{c}\text { Unmarried } \\
\text { adolescent } \\
\text { girls }\end{array}$ & $\begin{array}{c}\text { Married } \\
\text { adolescent } \\
\text { girls }\end{array}$ & $\begin{array}{c}\text { Unmarried } \\
\text { brothers }\end{array}$ & Husbands \\
\hline $\begin{array}{l}\text { Index of awareness of sexual and reproductive matters } \\
\text { (mean score, range 0 to 16, } \alpha=0.8 \text { ) }\end{array}$ & 6.6 & 8.6 & 9.1 & 10.9 \\
Heard about HIV/AIDS (\%) & 32.8 & 46.1 & 68.3 & 82.5 \\
Knew about two ways of preventing HIV transmission (\%) & 14.8 & 30.8 & 54.1 & 71.9 \\
Rejected two misconceptions about HIV/AIDS (\%) & 9.8 & 12.7 & 30.3 & 38.0 \\
Displayed comprehensive awareness about HIV/AIDS (\%) & 5.2 & 9.1 & 23.9 & 32.3 \\
Knew a facility to go for an HIV test (\%) & 16.5 & 24.0 & 40.1 & 47.8 \\
Number of respondents & $\mathbf{1 , 3 7 5}$ & $\mathbf{1 , 4 6 0}$ & $\mathbf{3 1 1}$ & $\mathbf{9 1 7}$ \\
\hline
\end{tabular}

Note: All means and percentages are weighted.

proportion of study participants did not hold any misconceptions about HIV/AIDS: just 10-13 percent of girls and 30-38 percent of unmarried brothers and husbands rejected two or more misconceptions about HIV/AIDS. We also calculated the percentage of study participants who displayed comprehensive awareness, as defined by knowledge of two ways of preventing HIV infection (specifically, condom use and single-partner relations), rejection of common misconceptions about HIV transmission in the study settings (namely, that HIV can be transmitted through hugging and sharing food) and awareness that one cannot tell by looking at a person whether he or she has HIV. Just 5-9 percent of girls and 24-32 percent of unmarried brothers and husbands displayed comprehensive awareness of HIV/AIDS. Finally, 17-24 percent of girls and 40-48 percent of unmarried brothers and husbands reported that they knew about health facilities where they could get an HIV test.

\section{Financial literacy and related practices and participation in vocational skills training programmes}

We posed several questions to study participants to better understand their financial literacy and related practices. We assessed financial literacy in terms of their awareness of at least two formal places for saving money, at least two services offered by banks, and the term 'budget'. We also assessed whether they were able to correctly sum different denominations of currency and whether they understood the basics of budgeting by asking them to assess the financial situation of a person who spends more than what s/he earns. Based on responses to these five questions, we classified respondents into those who displayed financial literacy (i.e., answered four of the five questions correctly) or not (see Annex 7 for the individual components included in the summary measure related to financial literacy and their baseline values). We also posed questions related to their savings habits, including having some savings, holding an account in a bank or post office, and operating their account, if any. Finally, we included questions related to their savings goals, such as whether they plan to save money for meeting future needs. Findings presented in Table 2.6 show that financial literacy was low among adolescent girls and their unmarried brothers and husbands. Just 8-13 percent of girls, regardless of marital status, and 17-21 percent of their unmarried brothers and husbands displayed financial literacy.

The majority of study participants reported that they had some savings. For example, three-fifths of unmarried girls and two-thirds of married girls reported some savings. A larger proportion of husbands than unmarried brothers reported some savings ( $87 \%$ vs. $76 \%$ ). Fewer study participants owned and operated a savings account. Specifically, just five percent of unmarried girls and 19 percent of married girls owned and operated a savings account; another four percent of unmarried girls and nine percent of married girls owned a savings account, but did not operate it on their own. Similarly, 25 percent of unmarried brothers and 38 percent of husbands owned and operated a savings account, and an additional 1-2 percent owned an account but did not operate it. Findings also show that only a minority of girls-11 percent of unmarried girls and 19 percent of married girls had visited a 
Table 2.6: Financial literacy and related practices, and participation in a vocational training programme among unmarried and married adolescent girls and their unmarried brothers and husbands, baseline survey

\begin{tabular}{|c|c|c|c|c|}
\hline Indicators (\%) & $\begin{array}{c}\text { Unmarried } \\
\text { adolescent } \\
\text { girls }\end{array}$ & $\begin{array}{l}\text { Married } \\
\text { adolescent } \\
\text { girls }\end{array}$ & $\begin{array}{l}\text { Unmarried } \\
\text { brothers }\end{array}$ & Husbands \\
\hline Displayed financial literacy & 8.2 & 13.2 & 16.7 & 21.4 \\
\hline Reported some savings & 60.2 & 66.6 & 75.5 & 87.0 \\
\hline \multicolumn{5}{|l|}{ Ownership of a savings account and its operation } \\
\hline Owned a savings account and operated it on her/his own & 4.7 & 18.9 & 25.0 & 37.8 \\
\hline Owned a savings account but didn't operate it on her/his own & 3.6 & 9.3 & 2.3 & 1.4 \\
\hline No account & 91.8 & 71.8 & 72.7 & 60.7 \\
\hline Visited a bank in the six months prior to the interview & 10.5 & 19.1 & 56.0 & 64.9 \\
\hline Expressed a savings goal & 15.3 & 25.2 & 21.1 & 37.7 \\
\hline \multicolumn{5}{|l|}{ Participation in vocational training programmes } \\
\hline $\begin{array}{l}\text { Attended vocational skills training programmes in the six months } \\
\text { prior to the interview }\end{array}$ & 13.5 & 9.6 & 10.8 & 9.2 \\
\hline Number of respondents & 1,375 & 1,460 & 311 & 917 \\
\hline
\end{tabular}

Note: All percentages are weighted.

bank in the six months preceding the interview; in comparison, as many as 56 percent of unmarried brothers and 65 percent of husbands had visited a bank in the six months preceding the interview. Many adolescents did not have any savings goal to meet future needs. For example, just 15 percent of unmarried girls and 25 percent of married girls had a savings goal. Similarly, 21 percent of unmarried brothers and 38 percent of husbands reported a savings goal.

Finally, findings highlight the limited opportunities for acquiring vocational skills training in the study settings. Just 9-14 percent of adolescent girls, regardless of marital status, and their unmarried brothers and husbands had ever attended a vocational skills training programme (Table 2.6).

\section{Access to social spaces to network with peers}

We also assessed adolescent girls' and their unmarried brothers' and husbands' access to social spaces to network with their peers. We asked study participants about the locations in which they typically interacted with their friends, and we defined social spaces as places outside home and school in which adolescents congregate for the purpose of socialising with their friends and which offer them privacy. Findings presented in Table 2.7 show that adolescent girls' access to social spaces outside their home and school where they can regularly interact with their friends was quite limited. Adolescent girls typically met their friends at each other's home or at school, with 96-99 percent reporting so. However, venues outside the home and school were infrequently mentioned; moreover, the venues thus cited were mostly locations that girls visited during the course of their daily chores such as near the water tap, hand pump or pond where they would go to fetch water and wash their clothes; fields where they would go to collect fodder or cut crops; the shop or market where they would go to buy groceries; places of worship; and places where they work for pay (38\% and $12 \%$ of unmarried and married girls, respectively, cited these locations). Only a small minority of girls mentioned such social spaces as a playground, a garden or an adolescent club $10 \%$ and $6 \%$ of unmarried and married girls, respectively). In contrast, while unmarried brothers and husbands also reported meeting their peers in similar locations, they were more likely than girls to mention social spaces (19-26\%).

\section{Engagement in risk-taking and health-seeking behaviours and practices}

We describe below behaviours and practices of adolescent girls and their unmarried brothers and husbands that directly aggravate or reduce their vulnerability to HIV at baseline. Specifically, we present evidence on sexual risk- 
Table 2.7: Places where unmarried and married adolescent girls and their unmarried brothers and husbands typically met their friends, baseline survey

\begin{tabular}{lcccc}
\hline Locations (\%) & $\begin{array}{c}\text { Unmarried } \\
\text { adolescent } \\
\text { girls }\end{array}$ & $\begin{array}{c}\text { Married } \\
\text { adolescent } \\
\text { girls }\end{array}$ & $\begin{array}{c}\text { Unmarried } \\
\text { brothers }\end{array}$ & Husbands \\
\hline Home or school & 96.2 & 99.3 & 85.3 & 83.2 \\
Venues outside home and school, related to daily chores, & & & & \\
including work & 37.7 & 11.5 & 77.2 & 81.2 \\
Venues outside home and school, not related to daily chores & 9.7 & 5.9 & 25.5 & 18.6 \\
Number of respondents with at least one friend & $\mathbf{9 6 3}$ & $\mathbf{9 3 4}$ & $\mathbf{2 7 9}$ & $\mathbf{7 3 3}$ \\
\hline
\end{tabular}

Note: All percentages are weighted; two percent or fewer respondents with at least one friend reported that they interacted with their friends over the phone and are not shown in this table.

taking behaviours, HIV testing, experience of symptoms suggestive of reproductive tract infections, and related treatment-seeking practices. Additionally for girls, we present evidence on their menstrual hygiene practices. Findings highlight that adolescent girls and their unmarried brothers and husbands were at risk of HIV in different ways, as described below.

\section{Nature of sexual experiences}

We probed unmarried adolescent girls and their unmarried brothers about engagement in sexual relationships in the six months prior to the interview, the number of sexual partners that they had had, and condom use. Likewise, we probed married girls and their husbands about their experiences of extra marital sex in the six months preceding the interview, the number of sexual partners that they had had, and condom use within marriage and extra marital sexual relationships. As mentioned in Chapter 1, the questions related to sexual experiences were posed in the course of the face-to-face interview as well as using the anonymous sealed envelope. All those who reported sexual experiences in the face-to-face interview or in the anonymous approach were shown in Table 2.8.

In the six months preceding the interview, a sizeable number of unmarried girls and their unmarried brothers had engaged in sex-12 percent and 19 percent, respectively (Table 2.8). Of these, six percent of girls and 33 percent of boys reported two or more sexual partners. Fewer married girls and husbands reported having engaged in extra marital sex in the six months preceding the interview-four percent and nine percent, respectively (Table 2.8).

Use of condoms in sexual relationships including within marriage was limited. Of unmarried adolescent girls who had engaged in sex in the six months preceding the interview, only 29 percent reported use of condom at last sex. Somewhat fewer reported consistent condom use (22\%). Of unmarried brothers who had engaged in sex in the six months preceding the interview, 26 percent reported condom use at last sex and 17 percent reported consistent condom use. Of married girls who reported extra marital sexual experiences in the six months preceding the interview, 43 percent reported condom use at last sex and 20 percent reported consistent condom use. Given the small number of married girls who reported an extra marital sexual relationship, we note that these percentages need to be interpreted with caution. Surprisingly, fewer husbands who reported extra marital sexual experiences in the six months prior to the interview reported condom use at last sex and consistent condom use (16\% and $10 \%$, respectively). Findings show that condom use within marriage was also limited. Just seven percent of married girls and their husbands reported condom use at last sex and 1-2 percent reported consistent condom use within marriage.

Sizeable proportions of study participants, except unmarried adolescent girls, reported that they intended to use condoms in the future. Specifically, a quarter of unmarried girls, half of married girls, and two-thirds of unmarried brothers and husbands reported that they would use condoms in the future. 
Table 2.8: Nature of sexual experiences and intentions to use condoms among unmarried and married adolescent girls and their unmarried brothers and husbands, baseline survey

\begin{tabular}{|c|c|c|c|c|}
\hline Indicators (\%) & $\begin{array}{c}\text { Unmarried } \\
\text { adolescent } \\
\text { girls }\end{array}$ & $\begin{array}{c}\text { Married } \\
\text { adolescent } \\
\text { girls }\end{array}$ & $\begin{array}{l}\text { Unmarried } \\
\text { brothers }\end{array}$ & Husbands \\
\hline $\begin{array}{l}\text { Engaged in sexual relationships }{ }^{1} \text { in the six months prior to } \\
\text { the interview }\end{array}$ & 11.5 & 4.1 & 19.1 & 9.1 \\
\hline Number of respondents & 1,375 & 1,460 & 311 & 917 \\
\hline $\begin{array}{l}\text { Reported two or more sexual partners in the six months } \\
\text { preceding the interview }{ }^{2}\end{array}$ & 6.0 & 4.1 & 33.0 & 9.1 \\
\hline $\begin{array}{l}\text { Used a condom at last sex in the six months preceding the } \\
\text { interview }{ }^{1}\end{array}$ & 29.0 & 43.4 & 25.7 & 16.1 \\
\hline $\begin{array}{l}\text { Used condoms consistently in the six months preceding the } \\
\text { interview }^{1}\end{array}$ & 22.2 & 19.7 & 17.4 & 10.3 \\
\hline $\begin{array}{l}\text { Number of respondents who were engaged in sexual } \\
\text { relationships }{ }^{1} \text { in the six months preceding the interview }\end{array}$ & 192 & 56 & 62 & 74 \\
\hline $\begin{array}{l}\text { Used a condom at last sex within marriage in the six } \\
\text { months preceding the interview }\end{array}$ & & 7.1 & & 6.8 \\
\hline $\begin{array}{l}\text { Used condoms consistently within marriage in the six } \\
\text { months preceding the interview }\end{array}$ & & 1.8 & & 1.1 \\
\hline Number of married respondents who had cohabited & & 1,417 & & 917 \\
\hline Intends to use condom in future & 26.2 & 51.1 & 68.5 & 65.7 \\
\hline Number of respondents & 1,375 & 1,460 & 311 & 917 \\
\hline
\end{tabular}

Note: All percentages are weighted; ${ }^{1}$ Refers to extra marital relationship for the married; ${ }^{2}$ The percentage who reported two or more sexual partners was not shown for married girls and their husbands because all those who reported extra marital sexual experiences in the six months preceding the interview also reported sex with their spouse and therefore, all had two or more partners.

\section{Health seeking practices}

To assess study participants' health seeking practices, we included a number of indicators-HIV testing, treatment seeking for symptoms suggestive of reproductive tract infections, and, additionally for girls, menstrual hygiene practices.

Given the focus of the MLMC project on reducing adolescent girls' vulnerability to HIV, the proportion of adolescents who knew whether they were HIV infected or not was identified as an important indicator to be tracked over the course of the project. Therefore, we asked all the study participants whether they had undergone an HIV test and whether they had received the test result. Findings, presented in Table 2.9, show that undergoing HIV testing is rare among adolescents in the study settings. Just 0.1-0.6 percent of unmarried girls and their unmarried brothers and 2 percent each of married girls and their husbands reported that they had had an HIV test. Of those who had had an HIV test, all of unmarried girls and three-fifths of married girls reported that they had received their HIV test results; among boys, none of unmarried brothers and all of husbands had received their HIV test results (not shown in table).

We posed questions about the experience of symptoms suggestive of reproductive tract infections in the three months prior to the interview and treatment-seeking for any symptoms experienced. Findings, summarised in Table 2.9, show that a sizeable number of adolescent girls and their unmarried brothers and husbands had experienced symptoms suggestive of reproductive tract infections in the three months preceding the interview. One-fifth of unmarried girls and one-third of married girls reported having experienced symptoms of reproductive tract infections as did onequarter of unmarried brothers and husbands. Findings also show that many study participants who had experienced such symptoms had not sought any treatment, particularly unmarried girls. Of those who experienced such symptoms, one-fifth of unmarried girls and about half of married girls reported that they sought treatment from a healthcare provider as did over half of unmarried brothers and husbands. 
Table 2.9: Health-seeking practices among unmarried and married adolescent girls and their unmarried brothers and husbands, baseline survey

\begin{tabular}{|c|c|c|c|c|}
\hline Indicators (\%) & $\begin{array}{l}\text { Unmarried } \\
\text { adolescent } \\
\text { girls }\end{array}$ & $\begin{array}{c}\text { Married } \\
\text { adolescent } \\
\text { girls }\end{array}$ & $\begin{array}{l}\text { Unmarried } \\
\text { brothers }\end{array}$ & Husbands \\
\hline \multicolumn{5}{|l|}{ HIV testing } \\
\hline Ever had an HIV test & 0.1 & 2.2 & 0.6 & 2.4 \\
\hline \multicolumn{5}{|l|}{ Treatment-seeking for symptoms of reproductive tract infections } \\
\hline $\begin{array}{l}\text { Experienced symptoms of reproductive tract infections in the } \\
\text { three months preceding the interview }\end{array}$ & 21.2 & 35.2 & 28.1 & 24.4 \\
\hline $\begin{array}{l}\text { Of those who experienced symptoms of reproductive tract } \\
\text { infections, sought treatment from a healthcare provider }\end{array}$ & 21.6 & 45.5 & 55.8 & 53.9 \\
\hline Number of respondents & 1,375 & 1,460 & 311 & 917 \\
\hline \multicolumn{5}{|l|}{ Menstrual hygiene practices } \\
\hline $\begin{array}{l}\text { Used sanitary napkins to absorb menstrual blood and changed } \\
\text { napkins regularly }\end{array}$ & 5.6 & 11.0 & & \\
\hline Number of female respondents who had begun menstruating & 1,353 & 1,459 & & \\
\hline
\end{tabular}

Note: All percentages are weighted.

Finally, although not linked to HIV vulnerability, but rather with the intention of understanding adolescent girls' sexual and reproductive health-seeking behaviours generally, we included two questions to assess their menstrual hygiene practices, specifically, whether they used sanitary napkins and how frequently they changed the napkins. Findings, presented in Table 2.9, highlight poor menstrual hygiene; only a minority of girls-six percent of unmarried girls and 11 percent of married girls-reported using sanitary napkins and changing them regularly.

\section{Adolescent girls' access to a supportive and safe environment}

While a focus on strengthening individual-level assets is critical, approaches to reduce the vulnerability of adolescent girls must also address the environment in which they live, and more specifically, the extent to which they derive support from key stakeholders in their lives (husbands and brothers, parents and parents-in-law, healthcare providers, community leaders, and so on) and the physical safety of their community. In this context, the baseline survey explored the support received by adolescent girls from their mothers and fathers as well as brothers (for unmarried girls) and husbands (for married girls). It also assessed girls' sense of safety in their village and their experience of sexual harassment. Findings, summarised in the sub sections below, indicate that a supportive and safe environment was by and large lacking for many adolescent girls.

\section{Support received from mothers and fathers}

We measured support derived by adolescent girls from their mothers and fathers by enquiring about whether they had discussed such topics as friendship, any problem in the family, sexual and reproductive matters, and HIV/AIDS with their mother and father, respectively, in the month prior to the interview. We note that we did not ask married girls whether they had discussed these topics with their fathers-in-law for ethical reasons. Two summary measures were created: (1) discussed such general topics as friends or any problem in the family; and (2) discussed any sexual and reproductive matters, including HIV/AIDS. Findings are summarised in Table 2.10.

Communication with mothers on general topics was quite common. For example, 95 and 85 percent of unmarried and married girls, respectively, reported having talked to their mother about their friends or a problem in the family in the month prior to the interview. However, considerably fewer girls (35-39\%) reported having discussed any sexual and reproductive matters, including HIV/AIDS with their mother.

Communication with fathers was, for the most part, more limited than with mothers. About two-thirds of unmarried girls reported having discussed general topics with their father in the month prior to the interview. Less than one percent of unmarried girls reported having discussed sexual and reproductive matters with their father. 
Table 2.10: Communication with mothers and fathers reported by unmarried and married adolescent girls, baseline survey

\begin{tabular}{|c|c|c|}
\hline Indicators (\%) & $\begin{array}{c}\text { Unmarried } \\
\text { adolescent } \\
\text { girls }\end{array}$ & $\begin{array}{c}\text { Married } \\
\text { adolescent } \\
\text { girls }\end{array}$ \\
\hline \multicolumn{3}{|l|}{ Discussed the following topics with their mother in the month prior to the interview } \\
\hline General topics & 94.8 & 84.8 \\
\hline Sexual and reproductive topics & 34.9 & 38.7 \\
\hline Number of respondents whose mother was alive at the time of the interview & 1,297 & 1,341 \\
\hline \multicolumn{3}{|l|}{ Discussed the following topics with their father in the month prior to the interview } \\
\hline General topics & 64.2 & \\
\hline Sexual and reproductive topics & 0.3 & \\
\hline Number of respondents whose father was alive at the time of the interview & 1,270 & \\
\hline
\end{tabular}

Note: All percentages are weighted; ${ }^{1}$ Questions related to communication with father-in-law were not posed to married girls.

\section{Support received from brothers (for unmarried girls) and husbands (for married girls)}

We asked unmarried adolescent girls with a co-residing brother whether, in the month prior to the interview, their brothers had helped them in doing household chores or solving a problem; convinced parents or elders in the family to allow them to do things that they wanted to do; encouraged them to acquire vocational skills, seek health services, and so on; or tried to convince parents or elders in the family to delay their marriage. Findings related to unmarried girls who received any form of support mentioned above from their brothers are summarised in Table 2.11. Findings suggest that most unmarried girls (69\%) received some form of support from their brothers in the month preceding the interview.

We probed married girls about the nature of their marital relationship. Specifically, we asked married girls whether their husband, in the month prior to the interview, had helped them in doing household chores or solving a problem; convinced parents or elders in the family to allow them to do things that they wanted to do; or encouraged them to acquire vocational skills, seek health services, and so on. We also posed questions related to whether they had discussed financial and sexual and reproductive matters with their husband in the month prior to the interview. Finally, we included questions related to their experience of emotional, physical, and sexual violence perpetrated by their husband in the month prior to the interview.

Findings show that most married girls (74\%) received some support from their husband in the month preceding the interview (Table 2.11). Some 78 and 68 percent of married girls reported that they had discussed financial matters

Table 2.11: Percentage of unmarried and married adolescent girls who received support from their brothers (unmarried girls) and husbands (married girls), baseline survey

\begin{tabular}{|c|c|c|}
\hline Indicator (\%) & $\begin{array}{c}\text { Unmarried } \\
\text { adolescent } \\
\text { girls }\end{array}$ & $\begin{array}{l}\text { Married } \\
\text { adolescent } \\
\text { girls }\end{array}$ \\
\hline Received support from brothers (for unmarried girls)/husbands (married girls) & 69.3 & 73.7 \\
\hline Discussed financial matters with husband in the month prior to the interview & & 77.6 \\
\hline $\begin{array}{l}\text { Discussed sexual and reproductive matters with husband in the month prior to the } \\
\text { interview }\end{array}$ & & 68.3 \\
\hline Experienced violence perpetrated by husband in the month prior to the interview & & 17.5 \\
\hline $\begin{array}{l}\text { Number of respondents with a co-residing brother (unmarried girls)/who had begun } \\
\text { cohabiting (married girls) }\end{array}$ & 352 & 1,417 \\
\hline
\end{tabular}

Note: All percentages are weighted. 
and sexual and reproductive matters, respectively, with their husband in the month preceding the interview. About one-fifth of married girls reported having experienced emotional, physical, or sexual violence at the hands of their husband in the month preceding the interview.

\section{Girls' experience of safety within their village}

To assess adolescent girls' experience of safety, we included questions related to their perception of safety within their village, their awareness of the location of the nearest police station, and their experience of sexual harassment in the six months preceding the interview. Specifically, we asked adolescent girls whether they felt safe walking alone in their village and if they were alone at a bus stop, and whether they believed that adults in the community would help if they experienced any sexual harassment. Girls' experience of sexual harassment in the six months prior to the interview was measured in two ways. First, they were asked whether any boys or older men passed 'dirty' comments, made 'dirty' gestures at them or looked at them in a 'dirty' way, and all those who responded affirmatively to any of these questions were considered to have experienced non contact forms of sexual harassment. Second, they were asked whether any boys or older men touched them in a 'dirty' way, attempted to have sex with them using physical force and/or threat, or had sex with them using physical force and/or threat, and all those who responded affirmatively to any of these questions were considered to have experienced contact forms of sexual harassment. Findings are summarised in Table 2.12.

Findings show that only 41-46 percent of girls felt safe in their village and confident about support from the community in case they experienced sexual harassment. Four-fifths of unmarried girls and two-thirds of married girls reported that they knew the location of the nearest police station. With regard to their experience of sexual harassment, findings show that 42 percent of unmarried girls and 24 percent of married girls had experienced non contact forms of sexual harassment in the six months preceding the interview. Some 12 percent of unmarried girls and five percent of married girls reported having experienced contact forms (non consensual sexual touch, attempted rape, or forced sex) of sexual harassment in the six months prior to the interview. We note that 0.9 and 0.11 percent of unmarried and married girls reported having experienced forced sex in the six months prior to the interview.

Table 2.12: Unmarried and married adolescent girls' perceptions of safety in their village and experiences of sexual harassment, baseline survey

\begin{tabular}{|c|c|c|}
\hline Indicators (\%) & $\begin{array}{c}\text { Unmarried } \\
\text { adolescent } \\
\text { girls }\end{array}$ & $\begin{array}{c}\text { Married } \\
\text { adolescent } \\
\text { girls }\end{array}$ \\
\hline $\begin{array}{l}\text { Felt safe in the village and confident about support from the community in } \\
\text { the event of sexual harassment }\end{array}$ & 40.6 & 46.1 \\
\hline Knew about the location of the nearest police station & 83.5 & 69.3 \\
\hline $\begin{array}{l}\text { Experienced non contact forms of sexual harassment in the six months } \\
\text { prior to the interview }\end{array}$ & 41.8 & 23.9 \\
\hline $\begin{array}{l}\text { Experienced contact forms of sexual harassment in the six months prior to } \\
\text { the interview }{ }^{1}\end{array}$ & 11.8 & 5.2 \\
\hline Number of respondents & 1,375 & 1,460 \\
\hline
\end{tabular}

Note: All percentages are weighted; ${ }^{1}$ Excludes forced sex in romantic relationship or marriage.

\section{A brief profile of mothers and fathers of adolescent girls}

Parents are in a unique position to protect their adolescent children's sexual and reproductive health and enable them to make a safe transition to sexual life (WHO, 2007). Drawing on survey data from mothers and fathers of adolescent girls, we briefly profile the extent to which mothers and fathers in the study settings were equipped to play such a protective role in the lives of adolescent girls. Specifically, we explore their awareness of sexual and reproductive matters, their gender role attitudes, and socialisation practices, including communication with their adolescent daughters. 


\section{Parental awareness of sexual and reproductive matters}

Previous studies in India have shown that parents themselves are not fully informed about sexual and reproductive matters (Jejeebhoy and Santhya, 2011; Jejeebhoy et al., 2014). In our survey with mothers and fathers, we included several questions to assess their awareness of sexual and reproductive matters, including physical and behavioural changes associated with adolescence, sex- and pregnancy-related matters, legal minimum age at marriage, contraception, sexually transmitted infections, and HIV/AIDS. We created an index of awareness of sexual and reproductive matters. The respondent was given a score of 1 for each question that was correctly answered and 0 otherwise. Scores were summed to create the index, the value of which ranged from 0 , indicating no awareness to 19, indicating high levels of awareness (Cronbach's alpha was 0.8; see Annex 8 for the individual components included in the summary measure related to parental awareness of sexual and reproductive matters and their baseline values). Additionally, given the focus of the MLMC project on reducing adolescent girls' vulnerability to HIV, we present evidence separately on study participants' awareness of HIV/AIDS in detail. Findings are summarised in Table 2.13.

Findings suggest that mothers and fathers were less informed about sexual and reproductive matters than their adolescent children. For example, they scored on average 7.5-9.4 on a scale that ranged from 0 to 19 (See Table 2.13), while adolescent girls scored 6.6-8.6 and their unmarried brothers and husbands scored 9.1-10.9 on a score that ranged from 0 to 16 (See Table 2.5). Only 13 percent of mothers and 51 percent of fathers had heard about HIV/AIDS. In comparison, 33-46 percent of adolescent girls and 68-83 percent of their unmarried brothers and husbands were aware of HIV/AIDS. Far fewer mothers and fathers, particularly mothers knew about two ways of preventing HIV transmission (9\% and 39\% of mothers and fathers, respectively), rejected two misconceptions about HIV/AIDS (3\% and 18\%, respectively), displayed comprehensive awareness of HIV/AIDS (2\% and 13\%, respectively) and knew a facility where one could obtain an HIV test ( $8 \%$ and $26 \%$, respectively).

Table 2.13: Awareness of sexual and reproductive matters among mothers and fathers of unmarried and married adolescent girls, baseline survey

\begin{tabular}{lrr}
\hline Indicators & Mothers & Fathers \\
\hline Index of awareness of sexual and reproductive matters (mean score, & 7.5 & 9.4 \\
range O to 19, $\alpha=0.8$ ) & 13.2 & 51.0 \\
Heard about HIV/AIDS (\%) & 8.7 & 38.8 \\
Knew about two ways of preventing HIV transmission (\%) & 2.9 & 18.1 \\
Rejected two misconceptions about HIV/AIDS (\%) & 1.9 & 12.5 \\
Displayed comprehensive awareness about HIV/AIDS (\%) & 7.7 & 25.7 \\
Knew a facility to go for an HIV test (\%) & $\mathbf{3 1 0}$ & $\mathbf{3 0 4}$ \\
Number of respondents & \\
\hline
\end{tabular}

Note: All means and percentages are unweighted

\section{Parental gender role attitudes and socialisation practices}

In order to capture parental gender role attitudes, we posed the same 12 statements that we posed to adolescent girls and their unmarried brothers and husbands. As with the adolescents, we created an index of gender egalitarian attitudes, the value of which ranged from 0 , indicating adherence to gender stereotypical attitudes to 12 , indicating adherence to gender egalitarian attitudes (Cronbach's alpha ranged from 0.4 to 0.6 ; see Annex 9 for the individual components included in the summary measure related to parental gender role attitudes and their baseline values). We measured socialisation practices based on responses to such questions as whether in the month prior to the interview they allowed their daughter/daughter-in-law and son to go out with her/his friends, and to make decisions about when to meet her/his friends. Mothers and fathers who reported that they treated their daughter/daughter-inlaw and son equally on both matters were considered to have followed egalitarian socialisation practices.

Findings presented in Table 2.14 show that most mothers and fathers, like their adolescent daughters/daughtersin-law and sons adhered to gender in egalitarian attitudes, scoring 4.9 to 5.5 on the index of gender egalitarian attitudes. Furthermore, just a quarter of mothers and fathers treated their daughter/daughter-in-law and son equally in terms of both mobility and agency. 
Table 2.14: Gender role attitudes and socialisation practices reported by mothers and fathers of unmarried and married adolescent girls, baseline survey

\begin{tabular}{|c|c|c|}
\hline Indicators & Mothers & Fathers \\
\hline \multicolumn{3}{|l|}{ Gender role attitudes } \\
\hline Index of gender egalitarian attitudes (mean score, range $0-12 ; \alpha=0.4-0.6$ ) & 4.9 & 5.5 \\
\hline Number of respondents & 310 & 304 \\
\hline \multicolumn{3}{|l|}{ Socialisation practices (\%) } \\
\hline $\begin{array}{l}\text { Treated daughter/ daughter-in-law and son equally both in terms of mobility and } \\
\text { agency }\end{array}$ & 23.5 & 23.4 \\
\hline Number of respondents with both daughters/daughters-in-law and sons & 290 & 133 \\
\hline \multicolumn{3}{|l|}{ Communication $^{1}(\%)$} \\
\hline $\begin{array}{l}\text { Discussed general topics with daughter/daughter-in-law in the month prior to the } \\
\text { interview }\end{array}$ & 64.2 & 39.6 \\
\hline $\begin{array}{l}\text { Discussed sexual and reproductive topics with daughter/daughter-in-law in the } \\
\text { month prior to the interview }\end{array}$ & 25.8 & 0.0 \\
\hline Number of respondents with daughters/daughters-in-law & 310 & 154 \\
\hline
\end{tabular}

Note: ${ }^{1}$ Questions related to communication with daughter-in-law were not posed to fathers-in-law.

We also asked mothers and fathers whether they had discussed such topics as friendship, any problem in the family, sexual and reproductive matters, and HIV/AIDS with their daughter/daughter-in-law in the month prior to the interview. We note, however, that, for ethical reasons, we did not probe about communication with daughter-in-law in interviews of fathers-in-law.

Findings, summarised in Table 2.14, suggest that almost two-thirds of mothers (far less than what was reported by unmarried and married girls) had discussed such general topics as friendship and problems in the family with their daughter/daughter-in-law in the month prior to the interview. However, just one-quarter had discussed sexual and reproductive matters, including HIV/AIDS. Responses of fathers indicate that fewer fathers reported discussing these topics with their daughter (40\% with respect to general topics, much less than what unmarried girls reported).

\section{Summary}

Findings presented in this chapter underscore that adolescent girls, their unmarried brothers and husbands in the study settings were vulnerable to HIV in many, but different, ways. Both adolescent girls and their brothers and husbands were not typically endowed with assets that can prevent conditions that are precursors of HIV. For example, social isolation characterised the lives of many adolescent girls in the study settings. Moreover, they lacked social spaces to network with their peers. Few adolescent girls exercised agency in their lives. Adolescent girls and their brothers and husbands all adhered to unequal gender norms. They remained largely uninformed about sexual and reproductive matters, including HIV/AIDS. Moreover, what they knew about these matters was far from comprehensive. They lacked financial literacy and opportunities to acquire livelihood skills. Sizeable proportions had engaged in unprotected sex. Treatment-seeking for sexual health problems was limited among girls as well as their brothers and husbands. Moreover, a supportive and safe environment was by and large lacking for many adolescent girls. Findings also show that mothers and fathers were not equipped with knowledge and skills to play a protective role in the lives of their adolescent children. In short, the baseline assessment highlights the vulnerability of adolescents to HIV, the limited role of parents in addressing these vulnerabilities, and the relevance of a project like the MLMC. 


\section{Chapter 3 \\ Meri Life Meri Choice project}

In recognition of the need for effective models to reduce adolescent girls' vulnerability to HIV, MAMTA, with the support of the Elton John AIDS Foundation, implemented the Meri Life Meri Choice (MLMC) project in the states of Madhya Pradesh and Uttar Pradesh. In this chapter, we briefly describe the MLMC project, including its goal and objectives, target audience, key components, steps taken for rolling out and for upscaling the project, and modifications made in the intervention design during the scaled-up phase. Drawing on data collected from adolescent girls, their unmarried brothers and husbands, and their mothers and fathers who participated in the endline survey, we also describe study participants' awareness and experiences of the MLMC project.

\section{Goal and objectives of the MLMC project}

The goal of the MLMC project was to reduce the vulnerability of adolescent girls in rural areas to HIV. Specifically, the objectives of the project were to:

- Enhance adolescent girls' knowledge about sexual and reproductive matters and equip them with skills that enable them to reduce vulnerability to HIV;

- Increase adolescent girls' and boys' utilisation of public sector sexual and reproductive health services;

- Develop a supportive environment for adolescent girls that enables them to adopt protective actions to reduce vulnerability to HIV.

\section{Target audience}

Although a large number of programmes have been implemented to enhance adolescent girls' knowledge and skills, they have focused more on those in schools and colleges, and as such, those who discontinue school prematurely, particularly those belonging to economically and socially disadvantaged households, are not reached by schoolbased programmes. Even programmes implemented at the community level tend to attract the better educated and those belonging to economically better-off households (Acharya et al., 2009; Santhya and Jejeebhoy, 2014). As such, the MLMC project team made a conscious decision to focus on vulnerable adolescent girls, defined as those belonging to economically poor households or socially disadvantaged religious or caste groups. It also targeted unmarried adolescent brothers, adolescent and young husbands, and mothers and fathers of these girls as well as critical adults in their community, particularly frontline health workers. We note that the target groups were slightly modified in the scaled-up phase, as seen in Table 3.1.

\section{Intervention components}

Given the focus of the project on vulnerable girls, the project staff first undertook a household vulnerability mapping exercise to identify households containing vulnerable girls in all the intervention villages.

The intervention recognised the multiple needs of adolescent girls-for information, for skills, for safe spaces, for services, and for support. Activities focusing on adolescent girls were group-based: community workers employed by the project facilitated the formation of adolescent girls' groups in each of the intervention villages. Gender Resource Centres (GRCs), established in each intervention village, offered a safe space for girls to network with peers as well as opportunities to receive information on sexual and reproductive matters and acquire financial literacy skills.

The key activity organised for adolescent girls and their unmarried brothers and husbands through the GRCs was the provision of life skills education, delivered over a six-month period. In preparing the life skills education curriculum, the project team reviewed and adapted existing curricula to meet the project objectives. The sessions were conducted by trained peer mentors with the support of community workers; the sessions were held weekly for unmarried girls and their brothers and husbands, and fortnightly for married girls and their husbands. Apart from the 
life skills sessions, project participants were supported in getting tested to know their HIV status. The participants were also provided referral services for diagnosis and treatment for sexually transmitted infections/reproductive tract infections and counselling on adolescent sexual and reproductive matters, as appropriate. Finally, participant girls were helped in opening a bank account in their name. A similar set of activities were organised for unmarried adolescent brothers and husbands of adolescent girls.

The project recognised the need for reaching out to parents and other key influential adults in adolescent girls' lives, and a number of activities were conducted with the intention of creating a supportive family and community environment for adolescent girls. Specifically, parents' groups were formed and meetings with parents were held at regular intervals. Additionally, family events were organised at the GRCs. Training workshops were organised for paramedical staff in which they were oriented about ways to better serve adolescent girls and boys. Community support groups were also formed and meetings were held at regular intervals. Finally, community-wide campaigns by way of street plays and wall paintings were organised to strengthen community support for addressing the sexual and reproductive health concerns of adolescents.

\section{Project implementation phases}

Intervention areas included two districts each in Madhya Pradesh (Rewa and Satna) and Uttar Pradesh (Allahabad and Banda). The project was implemented in two phases. Phase 1 was a proof-of-concept phase implemented in 184 villages and was completed in 2012. In Phase 2, the project was up-scaled to an additional 586 villages after incorporating lessons learned in Phase 1.

\section{Steps taken for rolling out the project and for upscaling the project}

MAMTA and its partners undertook several activities to build the capacity of project staff as well as peer mentors, to develop the life skills education curriculum and to ensure government buy-in.

\section{Capacity building of project staff and peer mentors}

MAMTA organised training workshops to orient the project staff about the goal and various components of the MLMC project, their roles and responsibilities and the monitoring formats, as well as on building their skills with a focus on communication and negotiation skills and skills for mobilising parents and communities. In addition to these workshops, the Population Council was invited to organise specialised training workshops - a three-day training workshop and a two-day refresher workshop - in implementing girl-centred programmes. These training workshops sought to enable MAMTA and partner NGOs to better understand why and how to design a girl-centred programme; enhance their capacity to implement strategies for reaching the most vulnerable girls, building their assets, involving their gatekeepers, and mobilising resources that can support girl-centred programmes; and build their skills in monitoring and tracking the progress made by girls who were enrolled in the project. The refresher training workshop was organised after reviewing project experiences and challenges faced during the proof-of-concept phase.

Peer mentors played a significant role in implementing the MLMC project. They were entrusted with the task of mobilising adolescents to join the project as well as conducting the life skills education sessions for the project participants, using the MLMC curriculum, and sensitising parents and communities more generally about the unique needs of adolescent girls and boys. In each girls' and boys' group, one peer mentor was identified and trained to impart the curriculum and lead group activities. Peer mentors were selected on the basis of their educational attainment levels, their communication skills, commitment to the goal of the project, and willingness to spend the stipulated time on project activities. Peer mentors underwent an initial three-day training workshop prior to the initiation of the intervention, followed by monthly training workshops over the course of the intervention. Peer mentors were supported by the MLMC community workers in imparting the life skills education curriculum.

\section{Developing a life skills education curriculum for adolescent girls and boys}

MAMTA developed a life skills education curriculum for adolescent girls and boys. The curriculum drew upon and adapted various tested curricula that have focused on transforming gender norms, enhancing communication and negotiation skills, providing information about health- and nutrition-related topics, with a focus on HIV/AIDS, developing financial literacy, and orienting about healthcare providers and facilities locally available. 


\section{Beginning with a proof-of-concept phase}

As mentioned earlier, with the intention of scaling up if proven successful, MAMTA and its partners decided to initiate the project with a 10-month proof-of-concept phase to assess the feasibility and acceptability of the project as perceived by adolescent girls, their brothers and husbands, mothers and fathers, and influential adults in the community, and to identify areas for modifications in the intervention design for the scaled-up phase. During this phase, the project was implemented in 184 villages in Madhya Pradesh and Uttar Pradesh. The project team documented experiences during this phase using monitoring systems developed for the project and process documentation. The Population Council evaluated this phase using qualitative methodologies among adolescent girls, their brothers and husbands, mothers and fathers, and critical adults in the community, prior to the launch of this phase and at its conclusion, as well as a survey of peer mentors at the conclusion of this phase.

\section{Modifications in the intervention design following the proof-of-concept phase}

Table 3.1 presents briefly modifications made in the project design during the scaled-up phase following the proofof-concept phase. The major modifications included redefining the target groups, reducing the duration of the intervention, expanding the targeted coverage within intervention villages and reducing the number of life skills education sessions. Specifically, the target groups included 10-19 year-old girls belonging to economically or socially disadvantaged households, and their unmarried brothers aged 10-19 and husbands (no age limit was imposed) in the proof-of-concept phase; however in the scaled-up phase, MAMTA and its partners decided to focus on (1) unmarried girls aged 15-19 who had never been to school or had discontinued school and who belonged to socially disadvantaged castes/tribes/religions, that is, scheduled castes, scheduled tribes, or Muslim; (2) married girls aged 15-21 who belonged to socially disadvantaged castes/tribes/religions; and (3) unmarried brothers aged 15-19 and husbands aged 15-24. The intervention duration was reduced from 10 months in the proof-of-concept phase to 6 months in the scaled-up phase; the number of life skills sessions was reduced from 24 sessions to 21 sessions for unmarried girls, 14 sessions for married girls, and 21 sessions for unmarried brothers and husbands of eligible girls. Finally, MAMTA and its partners decided to increase the targeted reach within each village from one-third of eligible girls in the proof-of-concept phase to as many as possible and to establish more than one Gender Resource Centre in bigger villages to saturate the coverage.

With a view to monitoring programme implementation on an ongoing basis, MAMTA and partner organisations regularly collected MIS data.

Table 3.1: Modifications in the MLMC project following the proof-of-concept phase

\begin{tabular}{|c|c|c|}
\hline Features & Proof-of-concept phase & Scaled-up phase \\
\hline Geographical coverage & 184 villages & $\begin{array}{l}586 \text { villages, covered in three consecutive } \\
\text { batches }\end{array}$ \\
\hline \multirow[t]{5}{*}{ Target groups } & $\begin{array}{l}\text { 10-19 year-old girls, disaggregated by age } \\
\text { and marital status, belonging to households } \\
\text { that were economically poor or from } \\
\text { socially disadvantaged castes/religion }\end{array}$ & $\begin{array}{l}\text { 15-19 year-old unmarried girls who had } \\
\text { never been to school or had discontinued } \\
\text { school, belonging to socially disadvantaged } \\
\text { castes/religion }\end{array}$ \\
\hline & & $\begin{array}{l}\text { 15-21 year-old married girls, belonging to } \\
\text { socially disadvantaged castes/religion }\end{array}$ \\
\hline & Unmarried brothers aged $10-19 /$ husbands & $\begin{array}{l}\text { Unmarried brothers aged } 15-19 / \text { husbands } \\
\text { aged } 15-24\end{array}$ \\
\hline & Parents & Parents \\
\hline & Critical adults in the community & Critical adults in the community \\
\hline Duration & 10 months & 6 months \\
\hline Targeted reach within village & One-third & $\begin{array}{l}\text { As many as possible; more than one GRC } \\
\text { in bigger villages to saturate }\end{array}$ \\
\hline $\begin{array}{l}\text { Number of life skills } \\
\text { education sessions }\end{array}$ & 24 weekly sessions & $\begin{array}{l}21 \text { weekly sessions for unmarried girls; } 14 \\
\text { fortnightly for married girls; } 21 \text { weekly for } \\
\text { brothers and husbands }\end{array}$ \\
\hline
\end{tabular}




\section{Awareness and experiences of the MLMC project among unmarried and married adolescent girls and their family members}

Drawing on data collected from adolescent girls and their family members who participated in the endline survey and girls who participated in the post-survey in-depth interviews in the intervention arm, we describe below study participants' awareness and experiences of the MLMC project.

\section{Awareness of the MLMC project among unmarried and married adolescent girls and their unmarried brothers and husbands}

We probed all girls and their unmarried brothers and husbands who participated in the endline survey in both the intervention and comparison arms as to whether they were aware of the MLMC project. Findings presented in Figure 3.1 show that awareness of the MLMC project varied across groups. About four-fifths of unmarried girls who were interviewed in the intervention arm at endline reported awareness of the project; somewhat fewer (65\%) of married girls were aware of the project. Among unmarried brothers and husbands, awareness of the MLMC project was similar to that observed among unmarried girls-78-82 percent reported that they had heard about the MLMC project. We also note that two percent or fewer survey participants in the comparison arm also reported that they had heard about the MLMC project.

Figure 3.1: Percentage of unmarried and married adolescent girls and their unmarried brothers and husbands who were aware of the MLMC project, intervention arm, endline survey

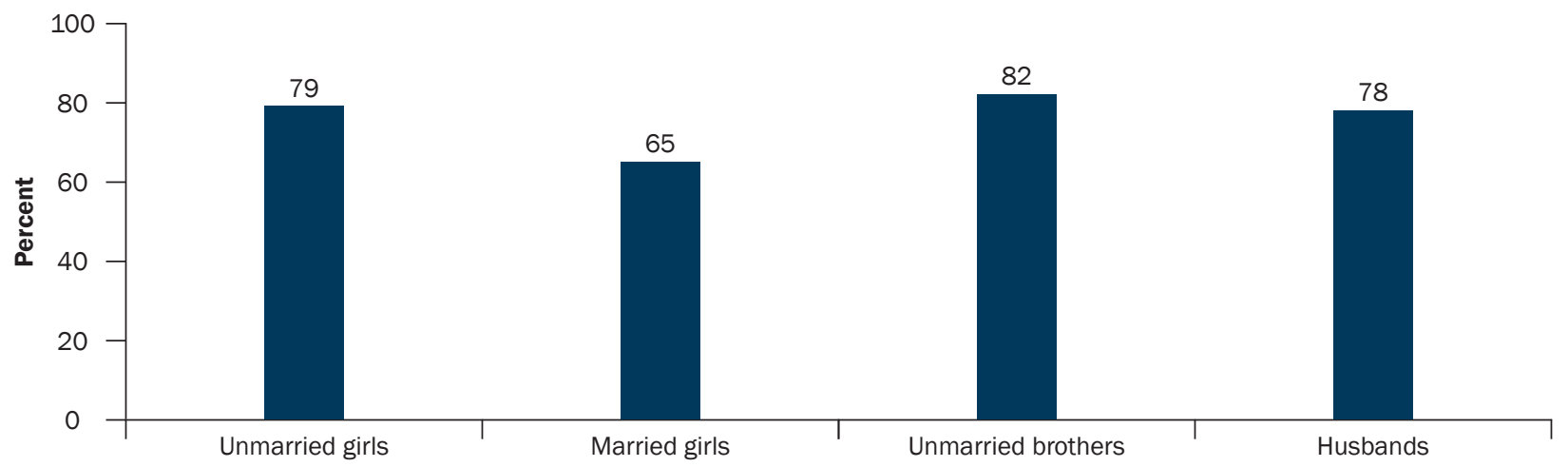

Note: All percentages shown in the figure are weighted.

\section{Participation in the MLMC project by unmarried and married adolescent girls and their unmarried brothers and husbands}

As with awareness of the MLMC project, participation in MLMC project activities varied across groups (Figure 3.2). Among girls, the unmarried were more likely than the married to report that they had participated in MLMC project activities almost half of unmarried girls who participated in the survey compared to a quarter of married girls so reported. Differences by marital status in participation in MLMC project activities were evident among boys too: unmarried brothers were more likely than husbands to have participated in some MLMC activities (24\% vs. 9\%).

\section{Reasons for non participation in the MLMC project activities}

Adolescent girls and their unmarried brothers and husbands who had heard about the MLMC project and did not take part in the project activities were asked about the reasons for doing so. Findings are summarised in Table 3.2. The most frequently cited reasons for non participation in the project activities were lack of adequate information about the MLMC project and lack of time. For example, 59 and 70 percent of unmarried and married girls, respectively, and 54 and 49 percent of unmarried brothers and husbands, respectively, who had heard about the MLMC project but had not participated in the project activities attributed their non participation to lack of adequate information. Similarly, two-fifths of unmarried girls, one-third of married girls, two-thirds of unmarried brothers, and 
Figure 3.2: Percentage of unmarried and married adolescent girls and their unmarried brothers and husbands who had participated in MLMC project activities, intervention arm, endline survey

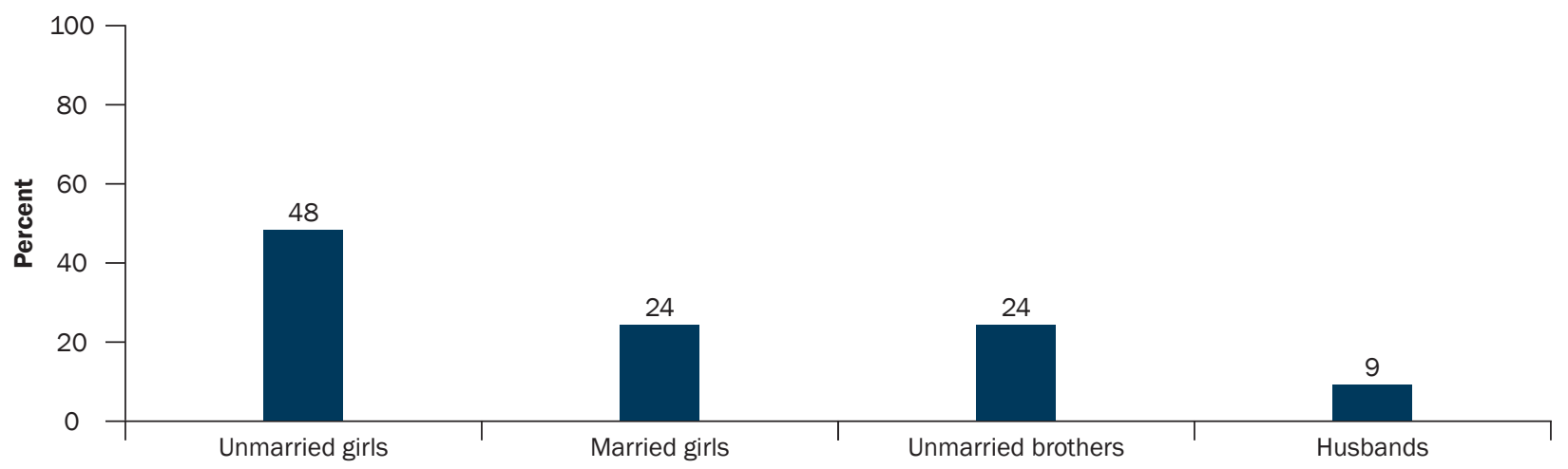

Note: All percentages shown in the figure are weighted.

Table 3.2: Reasons for not participating in MLMC project activities cited by unmarried and married adolescent girls and their unmarried brothers and husbands, intervention arm, endline survey

\begin{tabular}{|c|c|c|c|c|}
\hline Reasons (\%) & $\begin{array}{c}\text { Unmarried } \\
\text { adolescent } \\
\text { girls }\end{array}$ & $\begin{array}{c}\text { Married } \\
\text { adolescent } \\
\text { girls }\end{array}$ & $\begin{array}{c}\text { Unmarried } \\
\text { brothers }\end{array}$ & Husbands \\
\hline Lack of adequate information about the project ${ }^{1}$ & 58.5 & 70.2 & 53.6 & 49.1 \\
\hline Lack of time ${ }^{2}$ & 40.7 & 33.9 & 68.0 & 86.8 \\
\hline Refusal by family members & 17.3 & 18.2 & 0.4 & 0.0 \\
\hline Lack of interest ${ }^{3}$ & 13.0 & 14.0 & 21.2 & 10.2 \\
\hline Inconvenient location of the GRC & 3.5 & 0.4 & 2.5 & 0.0 \\
\hline Health problems, pregnancy, etc. & 1.9 & 2.5 & 1.2 & 0.0 \\
\hline $\begin{array}{l}\text { Number of respondents who had heard about the MLMC } \\
\text { project but had not participated in it }\end{array}$ & 251 & 389 & 144 & 371 \\
\hline
\end{tabular}

Note: All percentages are weighted; ${ }^{1}$ Includes such responses as nobody invited them to join the project and perceptions that the project targeted females only; ${ }^{2}$ Includes such responses as timing of the session did not suit, stayed outside the village most of the time; ${ }^{3}$ ncludes such responses as the perception that no benefit may accrue by joining the project.

over four-fifths of husbands reported that they did not participate because of lack of time. Other reasons reported by more than 10 percent of non participants included family members' refusal (cited by $17-18 \%$ of unmarried and married girls) and lack of interest (mentioned by $13-14 \%$ of unmarried and married girls and $10-21 \%$ of unmarried brothers and husbands).

\section{Expectations about the project}

We probed adolescent girls and their unmarried brothers and husbands who reported that they had participated in MLMC project activities about their reasons for participating in the project. As seen in Table 3.3, the opportunity to get information on different issues was the most prominent reason motivating adolescent girls and their unmarried brothers and husbands to participate in the project-95-96 percent of adolescent girls and their unmarried brothers and 89 percent of husbands who had participated in MLMC project activities so reported. Likewise, in in-depth interviews with selected surveyed girls, almost every girl reported that they expected to 'learn something new.' Some 13-17 percent of girls and 15-21 percent of unmarried brothers and husbands reported that they had participated in the project activities to become literate and acquire reading skills. 
Table 3.3: Reasons for participating in MLMC project activities reported by unmarried and married adolescent girls and their unmarried brothers and husbands, intervention arm, endline survey

\begin{tabular}{|c|c|c|c|c|}
\hline Reasons (\%) & $\begin{array}{l}\text { Unmarried } \\
\text { adolescent } \\
\text { girls }\end{array}$ & $\begin{array}{c}\text { Married } \\
\text { adolescent } \\
\text { girls }\end{array}$ & $\begin{array}{l}\text { Unmarried } \\
\text { brothers }\end{array}$ & Husbands \\
\hline Wanted to get information on different issues & 96.4 & 95.8 & 95.2 & 88.8 \\
\hline Wanted to learn a vocational skill & 50.5 & 45.4 & 33.0 & 44.6 \\
\hline Wanted to acquire literacy and/or reading skills & 17.1 & 12.9 & 21.2 & 15.0 \\
\hline $\begin{array}{l}\text { Wanted to be with friends/to make new friends/to interact in a } \\
\text { group }\end{array}$ & 67.9 & 53.3 & 42.3 & 37.6 \\
\hline Encouraged by friends & 34.8 & 32.7 & 34.8 & 32.3 \\
\hline Encouraged by a family member & 3.5 & 1.8 & 7.6 & 2.9 \\
\hline $\begin{array}{l}\text { Number of respondents who had participated in MLMC project } \\
\text { activities }\end{array}$ & 454 & 238 & 65 & 55 \\
\hline
\end{tabular}

Note: All percentages are weighted.

Notable proportions of girls and their unmarried brothers and husbands had participated in the project activities to acquire a vocational skill-45-51 percent of girls and 33-45 percent of unmarried brothers and husbands. Girls who participated in the in-depth interviews also articulated that they had expected to learn some vocational skills such as stitching and knitting.

She told my father about the GRC; she also told my father that stitching would be taught. So my father told me: 'You can go since it is once a week and also nearby' [Unmarried girl, perceived changes, SatnaRaghurajnagar-18-29-3]

The opportunity that the MLMC project offered to be with their friends, to make new friends, and to interact in a group was also an important reason for participating in the project activities for many, particularly for girls: two-thirds of unmarried girls, half of married girls, two-fifths of their unmarried brothers, and more than one-third of husbands cited that they had joined the project because they wished to spend time with their peers. Moreover, one-third of girls and their unmarried brothers and husbands reported that they had joined the project because they were motivated by their friends.

Additionally, some girls who participated in the in-depth interviews mentioned that they had joined the project with the hope of becoming independent, although the narratives were not always clear about whether they were referring to financial independence or independence more broadly.

I used to think about becoming a doctor or police officer, but then circumstances were such that I never got a chance. I had thought I would get the benefit of learning something so that I could do something in the future. I wanted to become something in the future. Like some people become peer mentors, some complete their education and take up a job, and others go and learn stitching, etc. I think that I should study more, at least till class 10 so I can make my home secure by taking up a proper job. [Married girl, perceived changes, Rewa-Mauganj-4-90-2]

\section{Extent of regular participation in the intervention}

Survey respondents who reported that they had participated in MLMC project activities were probed about the extent to which they regularly participated in the intervention. Findings presented in Table 3.4 suggest that although the MLMC project was of six months duration, the vast majority did not attend the full length of the project. In fact, as many as 55 percent of unmarried girls, 68 percent of married girls, 77 percent of unmarried brothers, and 69 percent of husbands reported that they had attended the MLMC activities for only 1-2 months. Just 25 percent of unmarried girls, 15 percent of married girls, and 7-10 percent of their unmarried brothers and husbands reported that they had attended the activities for 5-6 months. The mean number of months of participation was 2.3-2.8 months among girls and 2.0-2.1 months among their unmarried brothers and husbands. When probed about whether they had participated in the MLMC activities always, sometimes, or rarely, only a minority-13-16 percent among girls and 6-8 percent among unmarried brothers and husbands-reported that they had always attended the MLMC activities. 
Table 3.4: Regularity of participating in MLMC project activities reported by unmarried and married adolescent girls and their unmarried brothers and husbands, intervention arm, endline survey

\begin{tabular}{lrrrr}
\hline Indicators (\%) & $\begin{array}{c}\text { Unmarried } \\
\text { adolescent } \\
\text { girls }\end{array}$ & $\begin{array}{c}\text { Married } \\
\text { adolescent } \\
\text { girls }\end{array}$ & $\begin{array}{c}\text { Unmarried } \\
\text { brothers }\end{array}$ & Husbands \\
\hline Months respondent had participated in MLMC project activities & & & & \\
1-2 months & 55.1 & 68.2 & 76.7 & 68.8 \\
3-4 months & 20.4 & 16.4 & 16.0 & 20.9 \\
5-6 months & 24.5 & 15.4 & 7.3 & 10.3 \\
Mean number of months & 2.8 & 2.3 & 2.0 & 2.1 \\
Regularity of attending MLMC project activities & & & & \\
Always & 16.4 & 12.5 & 6.0 & 8.4 \\
Sometimes & 54.2 & 48.7 & 58.6 & 64.8 \\
Rarely & 26.6 & 35.6 & 28.5 & 18.3 \\
Number of respondents who had participated in MLMC project & & & & $\mathbf{5 5}$ \\
activities & $\mathbf{4 5 4}$ & $\mathbf{2 3 8}$ & $\mathbf{6 5}$ & $\mathbf{5 5}$ \\
\hline
\end{tabular}

Note: All percentages are weighted.

The major reasons cited for not regularly attending MLMC project activities included inconvenient timings of MLMC project activities and household workload (Table 3.5). For example, 65-72 percent and 56-64 percent of adolescent girls reported that they had not attended MLMC project activities regularly because of the household workload and inconvenient timing of MLMC project activities, respectively. Likewise, 27-43 percent and 75-87 percent of unmarried brothers and husbands attributed their irregular participation to these two reasons. Additionally, 10-15 percent of girls and 18 percent of unmarried brothers reported that they had not attended MLMC project activities because they did not like the activities.

Table 3.5: Reasons for non regular participation in MLMC project activities reported by unmarried and married adolescent girls and their unmarried brothers and husbands, intervention arm, endline survey

\begin{tabular}{lcccc}
\hline Reasons (\%) & $\begin{array}{c}\text { Unmarried } \\
\text { adolescent } \\
\text { girls }\end{array}$ & $\begin{array}{c}\text { Married } \\
\text { adolescent } \\
\text { girls }\end{array}$ & $\begin{array}{c}\text { Unmarried } \\
\text { brothers }\end{array}$ & Husbands \\
\hline Household workload & 64.6 & 72.3 & 26.7 & $(43.4)$ \\
Time did not suit & 55.9 & 63.5 & 75.3 & $(86.5)$ \\
Did not like the activities & 15.2 & 9.7 & 18.2 & $(3.9)$ \\
Parents refused & 9.0 & 6.8 & 0.9 & $(0.0)$ \\
IIIness of respondent or a family member & 3.6 & 3.3 & 0.0 & $(0.0)$ \\
Location did not suit & 1.3 & 2.3 & 4.3 & $(1.9)$ \\
No friends in the group & 0.1 & 0.7 & 0.0 & $(0.0)$ \\
Got married/pregnant & 0.0 & 3.6 & 0.0 & $(0.0)$ \\
Respondents who had attended MLMC activities sometimes or & & & & \\
rarely & $\mathbf{3 6 3}$ & $\mathbf{2 0 3}$ & $\mathbf{5 6}$ & $\mathbf{4 7}$ \\
\hline
\end{tabular}

Note: All percentages are weighted; () Based on fewer than 50 unweighted cases.

\section{Perceptions about the life skills education sessions}

We probed adolescent girls and their unmarried brothers and husbands who reported that they had participated in MLMC project activities about their perspectives on the life skills education sessions. Specifically, in the course of the survey, adolescent girls and their unmarried brothers and husbands were asked about the topics included in the life skills education sessions-whether they had attended sessions relating to each topic, whether they had 
learned something new, and whether it was the first time this topic had been discussed with them. Additionally, we probed girls who participated in the in-depth interviews about the topics that were discussed. Findings presented in Table 3.6A show that half or more of unmarried girls and one-third or more of married girls had recalled each of the topics included in the curriculum. The topics that were frequently recalled (i.e., by three-quarters or more) included communicating effectively, physical and emotional changes in adolescence, and prevention and treatment of STIs/ HIV/AIDS among unmarried girls, and communicating effectively and prevention and treatment of STIS/HIV/AIDS among married girls. Three-quarters or more of unmarried and married girls who had attended the sessions reported that they had learned something new about the topic discussed in the sessions that they had attended. Likewise, 60 percent or more of unmarried girls and 50 percent or more of married girls reported that this was the first time anyone had discussed the topics included in the life skills education curriculum.

Table 3.6A: Unmarried and married adolescent girls' recall of and perceptions about topics included in the life skills education curriculum, intervention arm, endline survey

\begin{tabular}{|c|c|c|c|c|c|c|}
\hline \multirow[t]{2}{*}{ Topics (\%) } & \multicolumn{2}{|c|}{ Attended the session } & \multicolumn{2}{|c|}{$\begin{array}{l}\text { Learned something } \\
\qquad \text { new }^{1}\end{array}$} & \multicolumn{2}{|c|}{$\begin{array}{l}\text { The topic had been } \\
\text { discussed with them for } \\
\text { the first time }{ }^{1}\end{array}$} \\
\hline & $\begin{array}{l}\text { Unmarried } \\
\text { adolescent } \\
\text { girls }\end{array}$ & $\begin{array}{c}\text { Married } \\
\text { adolescent } \\
\text { girls }\end{array}$ & $\begin{array}{l}\text { Unmarried } \\
\text { adolescent } \\
\text { girls }\end{array}$ & $\begin{array}{l}\text { Married } \\
\text { adolescent } \\
\text { girls }\end{array}$ & $\begin{array}{c}\text { Unmarried } \\
\text { adolescent } \\
\text { girls }\end{array}$ & $\begin{array}{c}\text { Married } \\
\text { adolescent } \\
\text { girls }\end{array}$ \\
\hline Communicating effectively & 78.9 & 76.2 & 87.0 & 91.7 & 79.4 & 78.7 \\
\hline Applying life skills in one's own life & 72.7 & 66.0 & 86.9 & 89.8 & 88.5 & 83.0 \\
\hline $\begin{array}{l}\text { Gender issues and ways in which gender } \\
\text { affects the lives of girls and boys }\end{array}$ & 54.1 & 52.0 & 84.4 & 91.6 & 83.6 & 74.9 \\
\hline Violence against women and girls & 64.2 & 51.9 & 87.1 & 93.3 & 77.6 & 71.4 \\
\hline $\begin{array}{l}\text { Physical and emotional changes in } \\
\text { adolescence }\end{array}$ & 74.8 & 65.9 & 84.9 & 84.6 & 81.4 & 63.7 \\
\hline Nutritional needs in adolescence & 50.6 & 34.6 & 90.1 & 94.9 & 86.4 & 82.8 \\
\hline Prevention and treatment of STIs/HIV/AIDS & 75.9 & 75.2 & 93.6 & 94.9 & 97.0 & 92.6 \\
\hline HIV testing and counselling & 64.0 & 60.4 & 93.4 & 93.5 & 97.7 & 96.2 \\
\hline Family planning methods & 57.2 & 56.1 & 89.3 & 83.7 & 79.2 & 58.7 \\
\hline Importance of savings & 61.6 & 55.6 & 78.1 & 78.2 & 61.5 & 49.9 \\
\hline $\begin{array}{l}\text { Healthcare providers/facilities available in } \\
\text { respondent's village }\end{array}$ & 49.9 & 43.5 & 88.4 & 81.2 & 87.2 & 66.3 \\
\hline $\begin{array}{l}\text { Number of respondents who had } \\
\text { participated in MLMC project activities }\end{array}$ & 454 & 238 & NS & NS & NS & NS \\
\hline
\end{tabular}

Note: All percentages are weighted; ${ }^{1}$ Of those who had attended the session in which the topic was discussed; NS-the denominator for each row varied and therefore is not shown.

The responses of unmarried brothers and husbands suggest that about one-third or more of unmarried brothers and one-quarter or more of husbands had recalled each of the topics included in the curriculum (Table 3.6B). The session that was frequently recalled by unmarried brothers and husbands focused on prevention and treatment of STIS/HIV/AIDS. Unlike adolescent girls, several topics were recalled by less than half of unmarried brothers and husbands. For example, fewer than half of unmarried brothers recalled that they had attended a session on such topics as violence against women and girls, nutritional needs in adolescence, and healthcare providers/ facilities available in their village. Among husbands, less frequently recalled topics included gender issues and the ways in which gender affects the lives of adolescent girls and boys, violence against women and girls, nutritional needs during adolescence, importance of savings, and healthcare providers/facilities available in their village. Like adolescent girls, 80 percent or more of unmarried brothers and husbands who had attended the sessions reported that they had learned something new about the topic discussed in the sessions that they had attended. Like girls again, 50 percent or more of unmarried brothers and 70 percent or more of husbands reported that this was the first time anyone had discussed the topics included in the life skills education curriculum. 
Table 3.6B: Unmarried brothers' and husbands' recall of and perceptions about topics included in the life skills education curriculum, intervention arm, endline survey

\begin{tabular}{|c|c|c|c|c|c|c|}
\hline \multirow[t]{2}{*}{ Topics (\%) } & \multicolumn{2}{|c|}{ Attended the session } & \multicolumn{2}{|c|}{$\begin{array}{l}\text { Learned something } \\
\qquad \text { new }^{1}\end{array}$} & \multicolumn{2}{|c|}{$\begin{array}{l}\text { The topic had been } \\
\text { discussed with them } \\
\text { for the first time }{ }^{1}\end{array}$} \\
\hline & $\begin{array}{l}\text { Unmarried } \\
\text { brothers }\end{array}$ & Husbands & $\begin{array}{l}\text { Unmarried } \\
\text { brothers }\end{array}$ & Husbands & $\begin{array}{l}\text { Unmarried } \\
\text { brothers }\end{array}$ & Husbands \\
\hline Communicating effectively & 67.6 & 58.4 & $(93.0)$ & $(89.0)$ & $(78.2)$ & $(85.8)$ \\
\hline Applying life skills in one's own life & 61.1 & 53.0 & $(93.9)$ & * & $(84.2)$ & * \\
\hline $\begin{array}{l}\text { Gender issues and ways in which gender } \\
\text { affects the lives of girls and boys }\end{array}$ & 49.3 & 31.4 & $(84.4)$ & * & $(70.8)$ & * \\
\hline Violence against women and girls & 38.9 & 40.3 & * & * & * & * \\
\hline $\begin{array}{l}\text { Physical and emotional changes in } \\
\text { adolescence }\end{array}$ & 60.0 & 47.5 & $(98.8)$ & * & $(88.9)$ & * \\
\hline Nutritional needs in adolescence & 35.6 & 24.9 & * & * & * & * \\
\hline Prevention and treatment of STIS/HIV/AIDS & 80.7 & 77.3 & 98.7 & $(95.2)$ & $(89.2)$ & $(89.6)$ \\
\hline HIV testing and counselling & 57.7 & 60.2 & $(100.0)$ & $(100.0)$ & $(94.9)$ & $(74.7)$ \\
\hline Family planning methods & 54.3 & 51.1 & $(89.9)$ & $(84.6)$ & $(63.7)$ & $(70.2)$ \\
\hline Importance of savings & 56.1 & 43.6 & $(82.8)$ & * & $(52.9)$ & * \\
\hline $\begin{array}{l}\text { Healthcare providers/facilities available in } \\
\text { respondent's village }\end{array}$ & 30.3 & 32.7 & * & * & * & * \\
\hline $\begin{array}{l}\text { Number of respondents who had participated } \\
\text { in MLMC project activities }\end{array}$ & 65 & 55 & NS & NS & NS & NS \\
\hline
\end{tabular}

Note: All percentages are weighted; ${ }^{1}$ Of those who had attended the session in which the topic was discussed; NS-The denominator for each row varied and therefore is not shown; () Based on fewer than 50 unweighted cases; *Not shown because based on fewer than 25 unweighted cases.

In in-depth interviews with selected surveyed girls, most girls reported that they were told about HIV. Specifically, their narratives show that peer mentors and community workers discussed the importance of undergoing HIV testing to know their HIV status, including before getting married and during pregnancy. They also discussed with the MLMC participants how HIV is transmitted, including transmission through unprotected sexual intercourse with infected sexual partners, infected needles used in the course of injection drug use or medical treatment, infected blood during blood transfusions, and transmission to the child from infected mothers. They informed study participants about various ways of preventing HIV, including using condoms, insisting on using unused needles and uninfected blood. They also sought to dispel common misconceptions about HIV, including that HIV can be transmitted by shaking hands, hugging, and sharing food with an infected person, and encouraged participants not to discriminate against people who are living with HIV.

We got full knowledge about HIV. They told us that when we go to the hospital, and if the doctor injects us, we have to ensure that he is using a new needle. They also told us that if anybody is injured in an accident or if someone's child is not well and blood is to be transfused because of loss of blood, we should get all the details about the blood which is being transfused, whether it is clean or not. Ma'am also told us that during sexual intercourse, condoms are to be used. All these things were new to us. [Unmarried girl, perceived changes, Allahabad-Karchana-34-251-03]

HIV doesn't happen by touching an infected person, eating food with her/him, or talking to her/him. It is a virus. It doesn't happen by just physical relations, but because of unsafe sexual relationships. We were told about HIV test and advised that we should go for the test in the hospital. If a person is infected and if the needle used on that person is used on another person, the latter can get infected. It happens if blood from an infected person is transfused to another. That's why we should have our test done. We were told to go to the Government hospital. [Married girl, perceived changes, Banda-Banda-24-37-4] 
It spreads through sexual intercourse, i.e., through the wrong kind of relationship. It also spreads from mother's milk to the baby and not by normally eating food with an infected person. It can also spread through infected injections, i.e., when a needle used for an infected person is used for a healthy person. If infected blood is transfused into the body, then also it spreads. They told us to go to a government hospital for an HIV test... We should behave well with an HIV patient. Some people don't talk to people with HIV, don't eat food with them, and don't even walk with them, and we should not behave in this manner [Unmarried girl, perceived changes, Banda-Naraini-29-94-4]

They were also informed about other diseases, including sexually transmitted infections other than HIV, and ways of preventing such infections, and the importance of maintaining personal hygiene, including during menstruation.

We learned about different kinds of diseases and the ways to prevent them. We learned about ways to keep our body healthy and clean. [Married girl, perceived changes, Allahabad-Bara-39-98-02]

She told us that we should keep our children clean. After getting up in the morning, we should make them take a bath. We should keep our premises clean, etc. [Married girl, perceived changes, AllahabadKarchana-31-134-2]

They told us about venereal disease, i.e., diseases that are spread through physical relations. They told us that one may experience itching, wounds, etc., and if we experience any such things, we should go to the hospital. [Married girl, perceived changes, Banda-Banda-24-37-4]

They told us to go to the government hospital in case of such diseases. If we notice symptoms like white discharge, allergic reactions, and problems in passing urine, we should go to hospital. These symptoms usually occur because of sexual contact, but can also happen without it. [Unmarried girl, perceived changes, Banda-Naraini-29-94-4]

They told us about symptoms of genital diseases. Like the problem of white discharge in women, irritation while passing urine, pain in stomach, itching. [Married girl, perceived changes, Rewa-Mauganj-4-65-2]

They gave us information about white discharge, genital itching, etc. They told us what to do and where to go for treatment in case of such infections and that we should inform others about it. [Married girl, perceived changes, Satna-Birsinghpur-19-248-4]

Some also mentioned that peer mentors and community workers informed them about family planning methods generally and making informed contraceptive choices. For example, they were informed that they should maintain a three-year gap between births. They were also informed about different contraceptive methods that they may use, including condoms, injectables, and oral pills.

You should delay giving birth to babies, you should maintain a gap of three years between two children. She told us that we can use condom, injections, or pills. [Married girl, perceived changes, BandaBanda-24-37-4]

They told us about using condoms, injections, and pills to prevent having children. [Married girl, perceived changes, Satna-Birsinghpur-19-248-4]

Yet another important topic that was discussed related to saving money, particularly in a bank. The narratives indicate that the MLMC participants were informed about the importance of saving money, for example, for meeting emergencies; meeting future needs, including for education, marriage, and so on; as well as about the benefits of saving money in a bank.

We should spend only as much as is needed and we should save the remaining. If we save money, we can use it for emergency, for example, to buy medicines for children, get treatment done. She told us about saving money in a bank. If we open an account in a bank, we can deposit our money in the bank, we can withdraw whenever there is a need; otherwise, it remains saved in the bank and can be useful in the future. [Married girl, perceived changes, Allahabad-Karchana-31-134-2]

When they discussed about the budget they told us that we should not spend money without any control and for trivial things, we should save it for the future. It might come handy when someone falls ill or we ourselves fall ill. At that time, we can use our savings. I felt that I got to learn something new. [Unmarried girl, perceived no change, Allahabad-Karchana-37-158-03] 
Another commonly cited topic related to gender and power imbalances. The narratives suggest that the participants were oriented about the biological and sociological constructs of sex and gender, respectively, and about viewing opposite-sex relationship from a healthy perspective.

Gender means what society has made and sex is what nature has made. [Married girl, perceived changes, Rewa-Mauganj-4-65-2]

The narratives from in-depth interviews with many girls suggest that the topic of recognising and responding to experiences of gender-based violence, particularly sexual harassment was discussed at length during the life skills education sessions. They were also oriented about how they might seek redressal through collective actions or by approaching adults at home or in the community who could help them.

We learned about violence against women and ways to overcome and react against such violence. They built our confidence to act against such violence. If a woman is undergoing violence or anything wrong is being done towards her, all of us can unite together and raise our voice against it. If a male is beating and shouting at his wife, we can talk to him and make him understand that violence is not a solution for the problem, the only solution is to talk and find out a solution together. If the male understands, it is good; otherwise, we can get help from the police. We can call the Panchayat and make the villagers sit together and tell everyone that beating or harassing a woman is not good. If a girl is being beaten or abused for dowry, that person should be taken to the police. [Married girl, perceived changes, Allahabad-Bara-39-98-02]

They told us about how to handle if someone molests us or tortures us, about how to answer them. If we are not able to answer them, we should talk to others who can help us. MLMC taught the importance of answering back and not keeping quiet. [Unmarried girl, perceived changes, Allahabad-Karchana-34-251-03]

Boys throw acid at girls, threaten girls that they will and destroy their faces, threaten to rape, show their private parts to girls, they show porn photos. One should not eat anything that was given by a stranger, one should call 1090. I dialed it but it wasn't working. [Unmarried girl, perceived no change, BandaBanda-24-87-2]

A few also mentioned that discussions during the life skills education sessions also delved into the importance of healthy interactions and communication among family members.

Husband and wife together should take decisions, for example, about when to have a child and what methods to adopt to delay childbearing. They told us that if there is disagreement in the family, one should understand and make the other person understand and try to resolve it by talking to each other [Married girl, perceived changes, Rewa-Mauganj-4-65-2]

The MLMC participants also assessed the performance of the peer mentors in the course of the endline interview. We asked girls and their unmarried brothers and husbands who participated in the MLMC activities whether sessions had been regularly held, whether the peer mentor had been able to explain different topics and whether they felt comfortable about approaching the peer mentors, if necessary. Results, presented in Table 3.7, suggest that MLMC participants who were satisfied with the performance of their peer mentors varied across groups. Between 71 and 86 percent of unmarried girls reported that their peer mentor had held sessions regularly, explained things clearly, answered questions raised by the MLMC participants and was approachable to discuss personal problems. Among married girls, 65-71 percent gave such positive feedback on their peer mentor, as did between 60 and 80 percent of unmarried brothers and between 56 and 74 percent of husbands.

In in-depth interviews too, most MLMC participants gave positive assessments of the peer mentors. They observed that if the peer mentor was not able to conduct any sessions properly, the community worker stepped in. Moreover, they were given the opportunity to raise any doubts and concerns that they had had in an anonymous way.

The peer mentor taught us all these things. The sessions were taken over a period of six months. She held one meeting in a week and four meetings in a month; she took classes in two meetings and made us play games or held competitions in the other two meetings. She taught us from a book, sometimes they asked one of us to read from the book and sometimes she herself read from the book and explained things. We didn't feel shy in asking any question because she was from our village. We used to feel shy sometimes with Geetika ma'am as she was older than us; we used to talk less with her. [Unmarried girl, perceived changes, Satna-Raghurajnagar-18-29-3] 
Table 3.7: Perceptions of unmarried and married adolescent girls and their unmarried brothers and husbands about peer mentors, intervention arm, endline survey

\begin{tabular}{|c|c|c|c|c|}
\hline \multirow[t]{2}{*}{ Indicators (\%) } & $\begin{array}{l}\text { Unmarried } \\
\text { adolescent } \\
\text { girls }\end{array}$ & $\begin{array}{l}\text { Married } \\
\text { adolescent } \\
\text { girls }\end{array}$ & $\begin{array}{l}\text { Unmarried } \\
\text { brothers }\end{array}$ & Husbands \\
\hline & Total & Total & Total & Total \\
\hline Peer mentor held sessions regularly & 70.8 & 65.4 & 59.9 & 56.4 \\
\hline Peer mentor explained things clearly & 74.9 & 67.2 & 62.0 & 56.1 \\
\hline $\begin{array}{l}\text { Felt always or sometimes comfortable in approaching } \\
\text { peer mentor to discuss personal problems }\end{array}$ & 81.5 & 67.8 & 74.9 & 68.4 \\
\hline $\begin{array}{l}\text { Peer mentor was always or sometimes able } \\
\text { to answer questions raised by MLMC project } \\
\text { participants }\end{array}$ & 85.8 & 71.4 & 79.9 & 73.5 \\
\hline $\begin{array}{l}\text { Number of respondents who had participated in } \\
\text { MLMC project activities }\end{array}$ & 454 & 238 & 65 & 55 \\
\hline
\end{tabular}

Note: All percentages are weighted.

\section{Perceptions about support received in seeking health services}

We probed MLMC project participants in the course of the endline survey and post-survey in-depth interviews about the support they received in undergoing HIV testing and seeking treatment for symptoms of reproductive tract infections, if experienced. Findings presented in Table 3.8 indicate that 49 percent of unmarried girls and 39 percent of married girls who had participated in MLMC project activities reported having been offered an opportunity to undergo an HIV test. So did 44 percent of unmarried brothers and 24 percent of husbands. Some $17-21$ percent of unmarried and married girls and 9-21 percent of unmarried brothers and husbands who had participated in MLMC project activities reported that they had received a referral slip to seek services for symptoms of reproductive tract infections or HIV testing. Finally, 15-16 percent of girls (that is, 75-90\% of those who had received the referral slip) and 9-20 percent of unmarried brothers and husbands (almost all those who had received the referral slip) reported that they used the referral slip to seek services.

Table 3.8: Support received in seeking health services by unmarried and married adolescent girls and their unmarried brothers and husbands, intervention arm, endline survey

\begin{tabular}{|c|c|c|c|c|}
\hline Indicators (\%) & $\begin{array}{c}\text { Unmarried } \\
\text { adolescent } \\
\text { girls }\end{array}$ & $\begin{array}{c}\text { Married } \\
\text { adolescent } \\
\text { girls }\end{array}$ & $\begin{array}{l}\text { Unmarried } \\
\text { brothers }\end{array}$ & Husbands \\
\hline Offered an opportunity for getting tested to know HIV status & 49.3 & 39.2 & 44.3 & 23.6 \\
\hline $\begin{array}{l}\text { Received referral slip for seeking services for symptoms of } \\
\text { reproductive tract infections or HIV testing }\end{array}$ & 20.6 & 17.4 & 21.4 & 8.5 \\
\hline Used referral slip to seek services & 15.4 & 15.6 & 19.9 & 8.5 \\
\hline $\begin{array}{l}\text { Number of respondents who had participated in MLMC project } \\
\text { activities }\end{array}$ & 454 & 238 & 65 & 55 \\
\hline
\end{tabular}

Note: All percentages are weighted.

Participants in the in-depth interviews described in detail what happened when they went to get an HIV test. The narratives of girls suggest a mixed experience. Some girls reported that the staff at the facility took a short history before taking their blood sample, enquired the reasons for undergoing the HIV test, and asked whether they were undergoing the test voluntarily.

He asked my age and if I had come on my own and on my own free will for the test, and I said yes. Then, he asked me if I had ever had sexual relationship with anyone and I told him I never had any such relationships. He then asked me if I wanted to get myself tested for HIV and why and I said that it should be done since sexual intercourse is not the only means through which it spreads. It can also spread if one does not 
maintain cleanliness and hygiene. He asked me if I knew why the blood was being taken and I said I did not know. He said it is only through blood test that HIV can be confirmed. After some time, they informed me that the test report was negative, which meant that I did not have HIV. The report came after about 5-10 minutes [Unmarried girl, perceived changes, Banda-Naraini-29-94-4]

We note that not all girls who participated in the in-depth interview gave a positive assessment of the support they received in getting tested, as the excerpts below suggest. Some narrated that they were not informed about the HIV test at all. Others noted that they were taken for the test, but were not given any information about which hospital they were being taken to, how the test would be done and so on. Not all received the results of their test.

They came and told my mother that they were taking everyone for the test. She said okay. They took us to a government hospital in Mauganj. Seven to eight girls were there. They only told us that it is a blood test. When we went there, our appointment was already taken, we were asked to give our signature and then they took our blood for the test. Yes, we saw the doctor. The doctor did not ask anything. He asked Aarti, she told all our names. There was a material made of glass, they took blood in that. They took blood from the middle finger. Nothing was told to us about how they will do the test and what they will do with our blood. They did not tell us anything about after how many days we will get reports. Aarti also did not tell us. I haven't got the result yet. [Unmarried girl, perceived no change, Rewa-Mauganj-06-55-0]

\section{Perceptions about support received in opening bank accounts and attending vocational skills training programmes}

We asked study participants from the intervention arm about support they received from MLMC project staff in attending vocational skills training programmes and opening a bank account. Findings are summarised in Table 3.9. Three-fifths of unmarried girls and over two-fifths of married girls reported that they received information about vocational skills training programmes from the project staff. Fewer girls- 25 percent of unmarried girls and 14 percent of married girls-reported that they received support from project staff in attending vocational skills training programmes. Compared to adolescent girls, far fewer unmarried brothers and husbands received information about vocational skills training programmes (31\% of unmarried brothers and $12 \%$ of husbands) and support in attending vocational skills training programmes (19\% of unmarried brothers and $3 \%$ of husbands).

With regard to support received in opening a bank account, findings show that the project staff assisted 21 percent of unmarried girls and 14 percent of married girls in opening a bank account. The corresponding percentages among unmarried brothers and husbands were four and 13 percent, respectively.

In in-depth interviews, some participants noted that they had opened a bank account before joining the MLMC project, while others reported that they opened the bank account with the help of the MLMC project.

We had our account opened already. The account which is in my name was opened last year. The programme was started in June-July. My account was opened in May, a month before the programme was initiated. [Married girl, perceived changes, Rewa-Mauganj-4-65-2]

I did not have an account previously; my account was opened under the GRC. It was the first time I went to a bank. [Unmarried girl, perceived changes, Banda-Naraini-29-03-04]

Table 3.9: Support received in seeking health services by unmarried and married adolescent girls and their unmarried brothers and husbands, intervention arm, endline survey

\begin{tabular}{|c|c|c|c|c|}
\hline Indicators (\%) & $\begin{array}{c}\text { Unmarried } \\
\text { adolescent } \\
\text { girls }\end{array}$ & $\begin{array}{c}\text { Married } \\
\text { adolescent } \\
\text { girls }\end{array}$ & $\begin{array}{c}\text { Unmarried } \\
\text { brothers }\end{array}$ & Husbands \\
\hline Received information about vocational skills training programmes & 60.2 & 45.4 & 30.9 & 11.5 \\
\hline Received support in attending vocational skills training programmes & 25.0 & 13.9 & 18.6 & 2.9 \\
\hline Received support in opening a bank account & 21.2 & 13.9 & 4.0 & 13.4 \\
\hline $\begin{array}{l}\text { Number of respondents who had participated in MLMC project } \\
\text { activities }\end{array}$ & 454 & 238 & 65 & 55 \\
\hline
\end{tabular}

Note: All percentages are weighted. 


\section{Awareness and experiences of the MLMC project among mothers and fathers of adolescent girls}

Mothers and fathers of adolescent girls were asked about their awareness of and participation in MLMC project. Findings summarised in Table 3.10 show that 80 percent or more of mothers and fathers had heard about the MLMC project. However, fewer had participated in any project activities-29 percent of mothers and 23 percent of fathers. Even fewer attended family events-16 percent of mothers and six percent of fathers-and village-level activities-19 percent of mothers and seven percent of fathers-organised as part of the project.

Table 3.10: Awareness of and participation in MLMC project activities among mothers and fathers of unmarried and married adolescent girls, intervention arm, endline survey

\begin{tabular}{lcc}
\hline Indicators (\%) & Mothers & Fathers \\
\hline Heard about MLMC project & 83.3 & 79.6 \\
Participated in project activities & 29.0 & 23.2 \\
Attended family events organised as part of MLMC project & 16.1 & 5.6 \\
Attended village-level activities organised as part of MLMC project & 19.1 & 7.0 \\
Number of respondents & $\mathbf{1 6 2}$ & $\mathbf{1 4 2}$ \\
\hline
\end{tabular}

\section{Summary}

Findings presented in this chapter indicate that the majority of study participants in the intervention arm were aware of MLMC project. Between two-thirds and four-fifths of adolescent girls and their unmarried brothers and husbands had heard about the project.

Participation in MLMC project activities ranged from nine percent among husbands to 48 percent among unmarried girls. The most prominent reason motivating adolescent girls and their unmarried brothers and husbands for participating in the project activities was the opportunity to get information on different issues. Other frequently cited reasons included the desire to acquire a vocational skill and the opportunity that the project offered to be with their friends, to make new friends and to interact in a group. Findings also show that the vast majority did not attend activities for the full length of the project. In fact, just 25 percent of unmarried girls, 15 percent of married girls and 7-10 percent of their unmarried brothers and husbands who had participated in MLMC project activities reported that they had attended the activities for the full 5-6 months. The major reasons cited for not attending the project activities regularly included inconvenient schedule of MLMC project activities and household workload.

The major activity carried out as part of the MLMC project was imparting a life skills education curriculum that comprised 21 sessions for unmarried girls, 14 sessions for married girls, and 21 sessions for unmarried brothers and husbands of eligible girls. Half or more of unmarried girls and one-third or more of married girls recalled each of the topics included in the curriculum. Three-quarters or more of unmarried and married girls who had attended the sessions reported that they had learned something new about the topic discussed in the sessions that they had attended. Likewise, 60 percent or more of unmarried girls and 50 percent or more of married girls reported that this was the first time anyone had discussed the topics included in the life skills education curriculum. About one-third or more of unmarried brothers and one-quarter or more of husbands recalled each of the topics included in the curriculum. Some 80 percent or more of unmarried brothers and husbands who had attended the sessions reported that they had learned something new about the topic discussed in the sessions that they attended, and 50 percent or more of unmarried brothers and 70 percent or more of husbands reported that this was the first time anyone had discussed the topics included in the life skills education curriculum.

Findings also show that a substantial proportion of MLMC participants were supported in undergoing HIV testing and seeking treatment for symptoms of reproductive tract infections, as well as in attending vocational skills training programmes and opening a bank account. For example, 49 percent of unmarried girls and 39 percent of married girls who had participated in MLMC project activities had an opportunity to undergo an HIV test. So did 44 percent of unmarried brothers and 24 percent of husbands. Some 17-21 percent of unmarried and married girls and 
9-21 percent of unmarried brothers and husbands who had participated in MLMC project activities reported that they were given a referral slip to seek services for symptoms of reproductive tract infections or for HIV testing. About three-fifths of unmarried girls and over two-fifths of married girls received information about vocational skills training programmes from the project staff, and 25 percent of unmarried girls and 14 percent of married girls received support from project staff in attending a vocational skills training programme. Compared to adolescent girls, far fewer unmarried brothers and husbands received information about vocational skills training programmes or support in attending such a programme. The project staff also assisted 21 percent of unmarried girls and 14 percent of married girls in opening a bank account. The corresponding percentages among unmarried brothers and husbands were four and 13 , respectively.

Finally, findings show that 80 percent or more of mothers and fathers had heard about the MLMC project. However, fewer had participated in any project activities-29 percent of mothers and 23 percent of fathers. 


\section{Chapter 4 \\ Effect of the intervention on protective assets of adolescent girls and their unmarried brothers and husbands}

In this chapter, we describe the effect of the intervention on building protective assets of adolescent girls and their unmarried brothers and husbands. Specifically, we present evidence on changes in their peer networks and interactions, and access to trusted mentors; agency and gender role attitudes; awareness of sexual and reproductive matters, including HIV/AIDS; financial literacy and related practices; participation in vocational skills training programmes; and access to social spaces to network with peers.

\section{Methodology}

We used the difference-in-difference (DiD) method to ascertain the degree of change in indicators attributable to the MLMC project. In view of the fact that a sizeable number of respondents in the intervention arm did not participate in MLMC project activities, findings are presented separately for the full sample of respondents, regardless of their participation in MLMC project activities and a sub-sample of respondents who had participated in MLMC project activities in the intervention arm. As seen Annex 10, the MLMC participants and non-participants did not differ significantly with respect to most background characteristics. We also note that because the sample size achieved for unmarried brothers and husbands of eligible girls fell short of the required, findings are presented for the combined sample of unmarried brothers and husbands.

We used the difference-in-difference estimation approach to assess the net effect of the MLMC project (Ashenfelter, 1978; Ashenfelter and Card, 1985). The DiD method contrasts the difference in average outcome in the intervention arm before and after the exposure to the intervention, with the difference in average outcome in the comparison arm at baseline and endline. In this way, the model isolates the effect of exposure to the intervention by cancelling out the effect of other factors external to the intervention that both arms may have experienced in the period between the baseline and endline surveys. A key assumption of the DiD model is that other factors external to the intervention (such as the introduction of a new programme) that have the potential to affect outcome measures affect both the intervention and comparison arms in a similar way. The model also isolates the effect of any pre-existing difference between the intervention and comparison arms. Independent t-tests were first used to assess the significance of change over time, if any, in both the groups. Additionally, regression models were estimated for each of the indicators to assess the net effect of exposure to the intervention on the outcome indicators after controlling for potentially confounding factors such as years of schooling completed, household economic status, and exposure to mass media.

\section{Effect on peer networks and interactions among adolescent girls and their unmarried brothers and husbands}

The MLMC project activities, particularly the establishment of Gender Resource Centres and the formation of girls' and boys' groups, sought to expand the peer networks of adolescent girls and their unmarried brothers and husbands. Drawing on data from the baseline and endline, Figures 4.1-4.4 present findings on peer networks and interactions among adolescent girls and their unmarried brothers and husbands. Specifically, we compare the extent to which the study participants made new friends in the six months preceding the interview, the size of their peer networks, frequency of their interactions with their friends, and the extent to which they would confide a personal problem in a non family member at baseline and endline.

Findings on the percentage of study participants who made new friends in the six months preceding the interview are presented in Figure 4.1. While similar proportions of unmarried girls made new friends in the six months preceding the interview both at baseline and endline in the comparison arm ( $2 \%$ and $4 \%$, respectively), a larger proportion of 
Figure 4.1: Percentage of unmarried and married adolescent girls and their unmarried brothers and husbands who made new friends in the six months prior to the interview by treatment arms, baseline and endline surveys

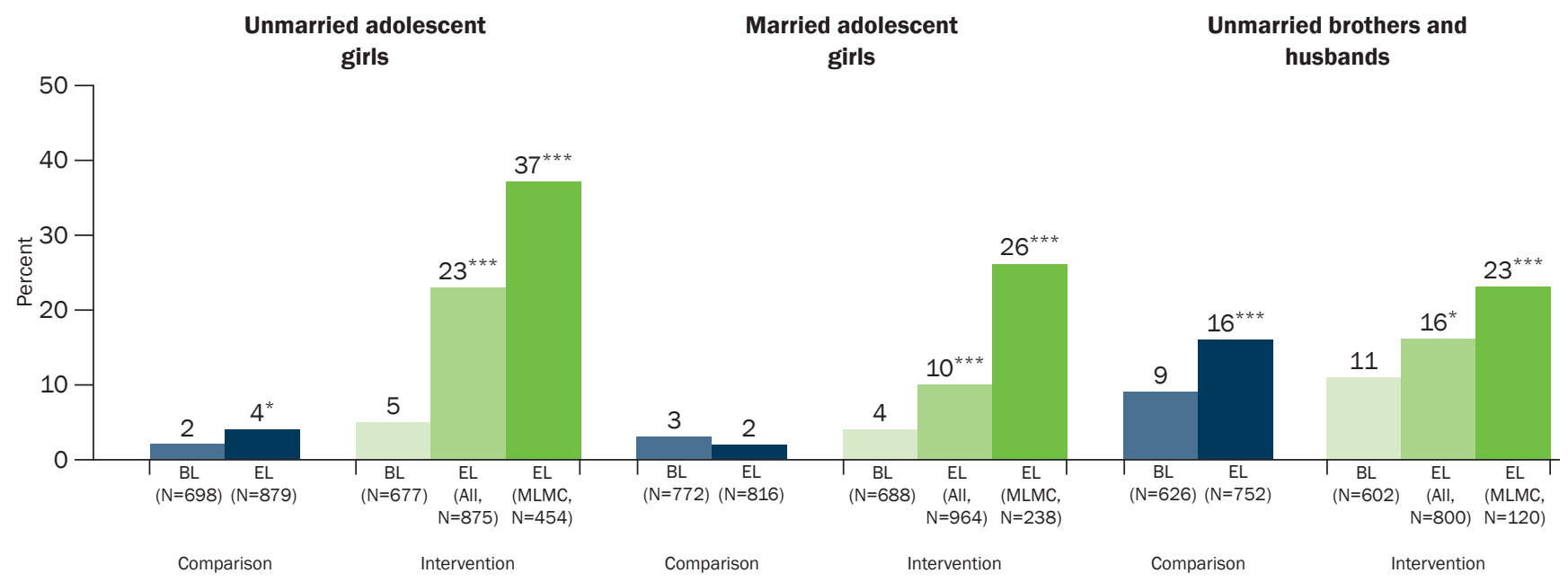

Note: All percentages shown in the figure are weighted; ${ }^{*}$ and ${ }^{* *}{ }^{*}$ indicate that the difference between baseline and endline is significant at $p \leq 0.05, p \leq 0.001$, respectively; $B L=$ Baseline; $E L=E n d l i n e ; E L A l l=A l l$ respondents irrespective of their participation in $M L M C$ project; $E L$ $M L M C=$ Respondents who had participated in MLMC project.

the endline cohort than the baseline cohort so reported in the intervention arm (23-37\% vs. 5\%). A similar trend was observed among married girls, although the percentage change was smaller than that observed among unmarried girls. The proportion of married girls who made new friends in the six months preceding the interview was larger by $6-22$ percentage points among the endline cohort compared to the baseline cohort in the intervention arm (10-26\% vs. $4 \%)$, while no change was observed in the comparison arm. Among unmarried brothers and husbands, a larger proportion reported that they made new friends in the last six months at endline than at baseline both in the intervention (16-23\% vs. 11\%) and comparison (16\% vs. $9 \%$ ) arms. However, the percentage point difference between baseline and endline was larger in the intervention arm than in comparison arm when we restricted the analyses to the MLMC participant sample.

The results of the logistic regression analyses using the DiD estimator are presented in Table 4.1. Findings show that after controlling for potentially confounding socio-demographic factors and time, the MLMC project had a positive net effect on enabling unmarried and married girls to make new friends. In the full sample analyses, unmarried girls in the intervention arm were three times as likely as girls in the comparison arm to have made new friends in the six months prior to the interview. The effect was even greater among unmarried girls who had participated in MLMC project activities; they were six times more likely than those in the comparison arm to have had made new friends in the same period. In the full sample analyses, married girls, similarly, were almost four times more likely than their counterparts in the comparison arm to report new friends in the same period. Again, the effect was substantially higher among MLMC participants. However, no such effect was observed among unmarried brothers and husbands, even when we restricted the analyses to the MLMC participant sample.

Findings related to study participants who reported at least one friend, summarised in Figure 4.2, show that the endline cohort of unmarried girls was more likely than the baseline cohort to report at least one friend in the intervention arm, regardless of whether we considered the full sample or the MLMC sample (80-89\% vs. $73 \%$ ), but no such change was observed in the comparison arm. Among married girls and unmarried brothers and husbands, no difference was observed between the baseline and endline cohorts in both the intervention and comparison arms when we considered the full sample. However, the MLMC participants were more likely than others to report at least one friend ( $86 \%$ vs. $60-71 \%$ among married girls; $95 \%$ vs. $88-91 \%$ among unmarried brothers and husbands). 
Table 4.1: Effect of exposure to the MLMC project on peer networks and interactions among unmarried and married adolescent girls and their unmarried brothers and husbands: Summary of regression results

\begin{tabular}{|c|c|c|c|c|c|c|}
\hline \multirow[t]{2}{*}{ Indicators } & \multicolumn{2}{|c|}{$\begin{array}{l}\text { Unmarried adolescent } \\
\text { girls }\end{array}$} & \multicolumn{2}{|c|}{$\begin{array}{l}\text { Married adolescent } \\
\text { girls }\end{array}$} & \multicolumn{2}{|c|}{$\begin{array}{l}\text { Unmarried brothers \& } \\
\text { husbands }\end{array}$} \\
\hline & All & MLMC & All & MLMC & All & MLMC \\
\hline $\begin{array}{l}\text { Made new friends in the six months prior } \\
\text { to the interview\# }\end{array}$ & $3.00^{* *}$ & $6.19^{* * *}$ & $3.61^{* *}$ & $12.84^{* * *}$ & 1.17 & 1.70 \\
\hline Reported at least one friend ${ }^{\#}$ & $1.52^{*}$ & $3.37^{* * *}$ & 1.04 & $2.65^{* * *}$ & 1.25 & $2.77^{\sim}$ \\
\hline Met friends once a week or more often\# & 1.17 & $1.75^{* * *}$ & 1.27 & $2.01^{* * *}$ & 1.15 & 1.73 \\
\hline $\begin{array}{l}\text { Would confide a sexual and reproductive } \\
\text { health problem in a non family member }\end{array}$ & 0.82 & 0.98 & $0.46^{*}$ & $0.37^{*}$ & $1.34^{\sim}$ & 1.17 \\
\hline Number of respondents & 3,129 & 2,708 & 3,240 & 2,514 & 2,780 & 2,100 \\
\hline
\end{tabular}

Note: $\sim{ }^{*},{ }^{* *}$ and ${ }^{* *}$ indicate that net effect of exposure to the intervention is significant at $P \leq .10, p \leq 0.05, p \leq 0.01, p \leq 0.001$, respectively; "Refers to odds ratio from logistic regression.

Figure 4.2: Percentage of unmarried and married adolescent girls and their unmarried brothers and husbands who reported at least one friend by treatment arms, baseline and endline surveys
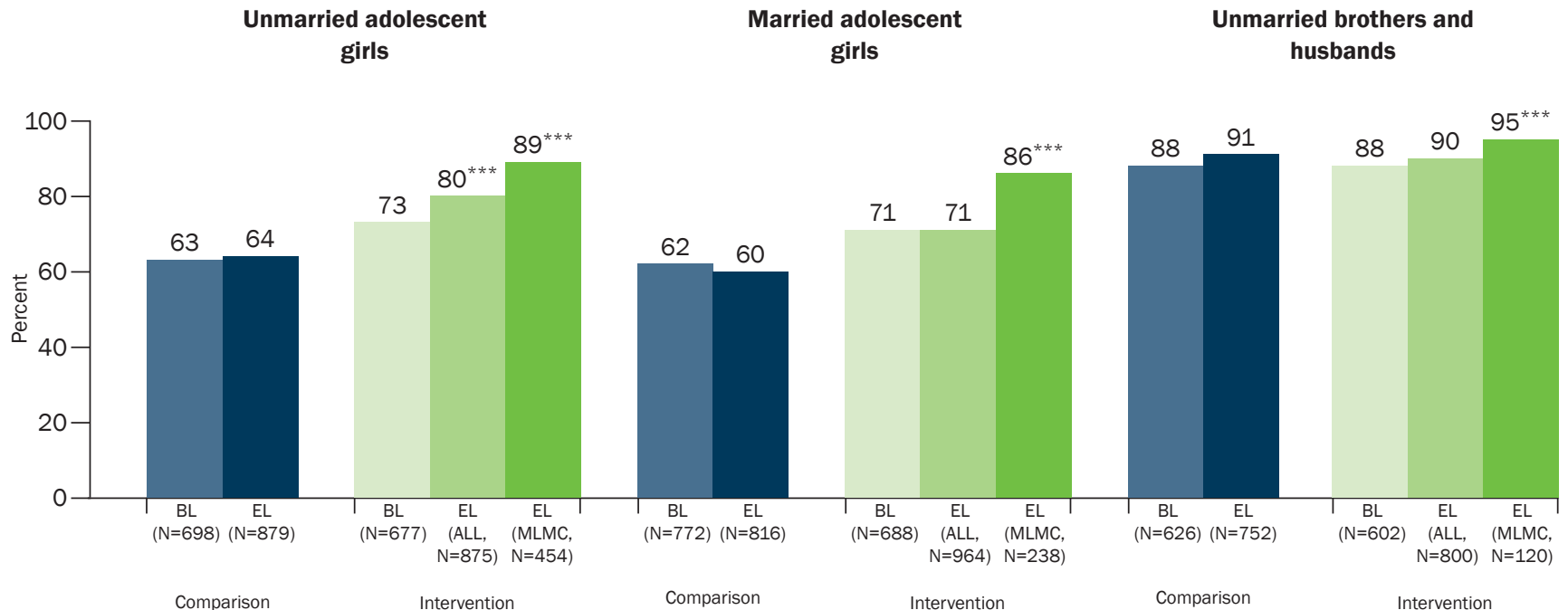

Note: All percentages shown in the figure are weighted; ${ }^{* * *}$ indicates that the difference between baseline and endline is significant at $p \leq 0.001$; $B L=$ Baseline; $E L=E n d l i n e ; E L A l l=A l l$ respondents irrespective of their participation in MLMC project; EL MLMC=Respondents who had participated in MLMC project.

The results of the logistic regression analyses using the DiD estimator show that after controlling for potentially confounding socio-demographic factors and time, the MLMC project had a positive net effect on expanding the peer network of unmarried adolescent girls (Table 4.1). Unmarried girls in the intervention arm were more likely than girls in the comparison arm to report at least one friend (OR 1.52 for the full sample and 3.4 for the MLMC sample). No net effect of the MLMC project was observed among married girls, nor among unmarried brothers and husbands in the full sample analyses. However, restricted analyses show that the MLMC participants were more likely than those in the comparison arm to report at least one friend, although the effect was only mildly significant in the case of unmarried brothers and husbands (OR 2.65 and 2.77 , respectively).

Figure 4.3 describes findings pertaining to study participants' frequency of interaction with friends. We found only a modest difference in the frequency of interaction with friends between baseline and endline cohorts across all three groups of study participants in the intervention and comparison arms in the full sample analyses, except that married girls in the intervention arm reported more frequent interaction with their friends at endline than at baseline 
Figure 4.3: Percentage of unmarried and married adolescent girls and their unmarried brothers and husbands who reported at least once-a-week interaction with friends by treatment arms, baseline and endline surveys

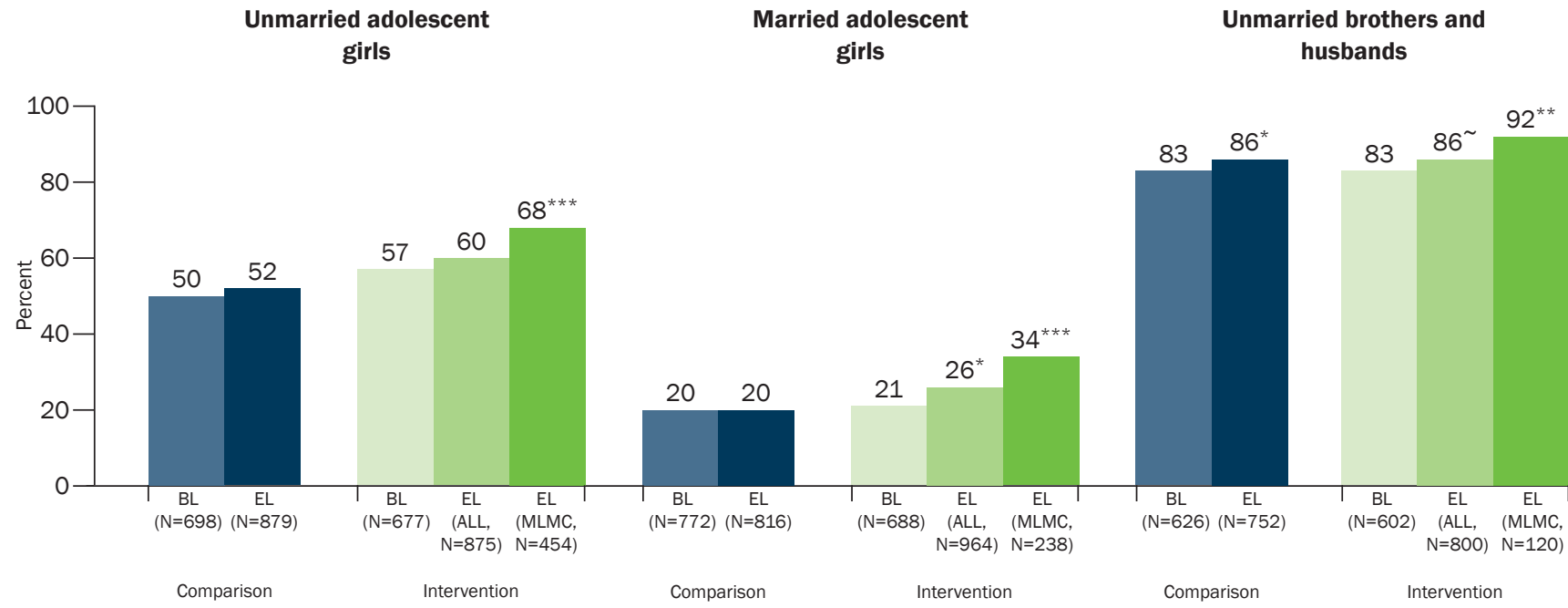

Note: All percentages shown in the figure are weighted; ${ }^{*},{ }^{* *}$ and ${ }^{* * *}$ indicate that the difference between baseline and endline is significant at $p \leq 0.10, p \leq 0.05, p \leq 0.01, p \leq 0.001$, respectively; $B L=$ Baseline; $E L=E n d l i n e ; E L A l l=A l l$ respondents irrespective of their participation in $M L M C$ project; $E L M L M C=$ Respondents who had participated in MLMC project.

(26\% vs. $21 \%$ ). However, the MLMC participants were more likely than others to report that they met their friends once a week or more often across all three groups (68\% vs. $50-60 \%$ among unmarried girls; $34 \%$ vs. $20-26 \%$ among married girls; and $92 \%$ vs. $83-86 \%$ among unmarried brothers and husbands).

The logistic regression analyses using the DiD estimator indicate no net effect of the MLMC project on study participants' frequency of interaction in the full sample analyses. However, in the restricted analyses, MLMC participant girls were more likely than those in the comparison arm to have met their friends once a week or more often (OR 1.75 for unmarried girls; OR 2.01 for married girls). This finding indicates the positive effect of the MLMC project in enabling unmarried and married girls who had participated in the project activities to interact with their friends. No such positive effect was observed among unmarried brothers and husbands in the full sample or the restricted sample analyses.

Figure 4.4: Percentage of unmarried and married adolescent girls and their unmarried brothers and husbands who would confide a personal problem in a non family member by treatment arms, baseline and endline surveys

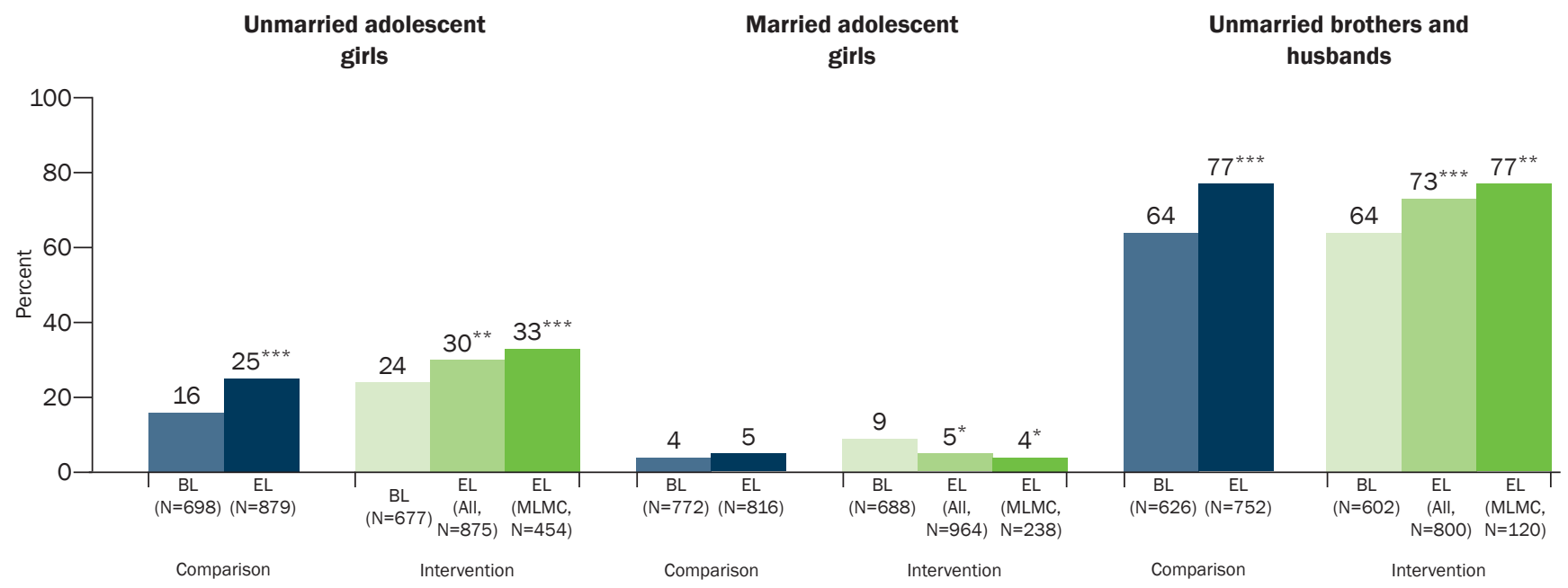

Note: All percentages shown in the figure are weighted; * ** and ***indicate that the difference between baseline and endline is significant at $p \leq 0.05, p \leq 0.01, p \leq 0.001$, respectively; $B L=B$ aseline; $E L=E n d l i n e ; E L A l l=A l l$ respondents irrespective of their participation in $M L M C$ project; $E L$ $M L M C=$ Respondents who participated in MLMC project. 
The MLMC project activities were expected to improve access to non familial trusted mentors among adolescent girls and their unmarried brothers and husbands. Findings pertaining to study participants' access to a non familial confidante to discuss personal problems-for example, a sexual and reproductive health problem-at baseline and endline are summarised in Figure 4.4. Findings show that unmarried girls in the intervention and comparison arms were more likely at endline than baseline to report a non family member as a confidante to discuss personal problems (30-33\% vs. $24 \%$ in the intervention arm; $25 \%$ vs. $16 \%$ in the comparison arm). However, the percentage point difference between baseline and endline assessments was similar in the intervention and comparison arms. Among married girls, the proportions reporting a non family confidante to discuss personal problems were similar both at baseline and endline in the intervention and comparison arms, respectively. Among unmarried brothers and husbands, the endline cohorts were more likely than the baseline cohorts to report a non family confidante in the intervention and comparison arms. However, the percentage point difference between baseline and endline assessments was similar in the intervention and comparison arms (73-77\% vs. $64 \%$ in the intervention arm and $77 \%$ vs. $64 \%$ in the comparison arm).

The results of the logistic regression analyses using the DiD estimator indicate, by and large, no effect of the MLMC project among unmarried girls and unmarried brothers and husbands (Table 4.1). Surprisingly, married girls in the intervention arm were less likely than their counterparts in the comparison arm to report a non family confidante in the full sample and restricted sample analyses (OR 0.46 and 0.37 , respectively).

We note that the findings presented in this section on the effect of the MLMC project on study participants' peer networks and interactions concur, for the most part, with study participants' perceptions of changes experienced in the six months prior to the interview (see Table 8.1).

\section{Effect on agency and gender role attitudes among adolescent girls and their unmarried brothers and husbands}

Several sessions at the GRC sought to orient adolescent girls and their unmarried brothers and husbands about life skills and how to apply these skills in their life, how gender and power imbalances affect the lives of adolescent girls and boys differently, how to communicate effectively, and so on. As such, we used three indicators-self-efficacy, decision making autonomy, and mobility-to capture changes in adolescents' agency.

Findings pertaining to study participants' self-efficacy at baseline and endline presented in Figure 4.5 show that the endline cohorts of unmarried and married girls were more likely than their corresponding baseline cohorts to display self-efficacy in the intervention and comparison arms ( $52-53 \%$ vs. $27 \%$ among unmarried girls and $41-44 \%$ vs. $26 \%$ among married girls in the intervention arm; $52 \%$ vs. $42 \%$ among unmarried girls and $48 \%$ vs. $40 \%$ among married girls in the comparison arm). The percentage point difference between the baseline and endline cohorts was larger in the intervention than the comparison arm (25-26 percentage point increase vs. 10 percentage point increase among unmarried girls; 15-18 percentage point increase vs. 8 percentage point increase among married girls). Among unmarried brothers and husbands, the difference between baseline and endline cohorts was modest in the intervention and comparison arms (46-52\% vs. $52 \%$ in the intervention arm; $46 \%$ vs. $40 \%$ in the comparison arm).

The results of the logistic regression analyses using the DiD estimator, presented in Table 4.2, show a positive net effect of the MLMC project in improving the self-efficacy of unmarried and married girls in the full sample and restricted sample analyses. Unmarried and married girls in the intervention arm were more likely than their counterparts in the comparison arm to display self-efficacy (OR 2.07-2.26 for unmarried girls; OR 1.53-1.64 for married girls). Among unmarried brothers and husbands, surprisingly, the net effect was negative for the full sample. We note, however, that the net effect became insignificant when we restricted the analyses to the MLMC participant sample.

With respect to decision making autonomy as well, the endline cohort of unmarried girls in the intervention arm were more likely to report that they made independent decisions on personal matters than their baseline counterparts in the intervention arm (61-62\% vs. $47 \%)$ and their baseline and endline counterparts in the comparison arm (49-53\%; Figure 4.6). Among married girls, a different pattern was observed: a larger proportion of girls displayed decision making autonomy at endline than at baseline in the intervention arm (41-45\% vs. 31\%), while the proportion of girls who made independent decisions remained largely unchanged in the comparison arm (44-48\%). A similar pattern was observed among unmarried brothers and husbands too ( $86-89 \%$ vs. $67 \%$ in the intervention arm; $80-82 \%$ in the comparison arm). 
Figure 4.5: Percentage of unmarried and married adolescent girls and their unmarried brothers and husbands who displayed self-efficacy by treatment arms, baseline and endline surveys

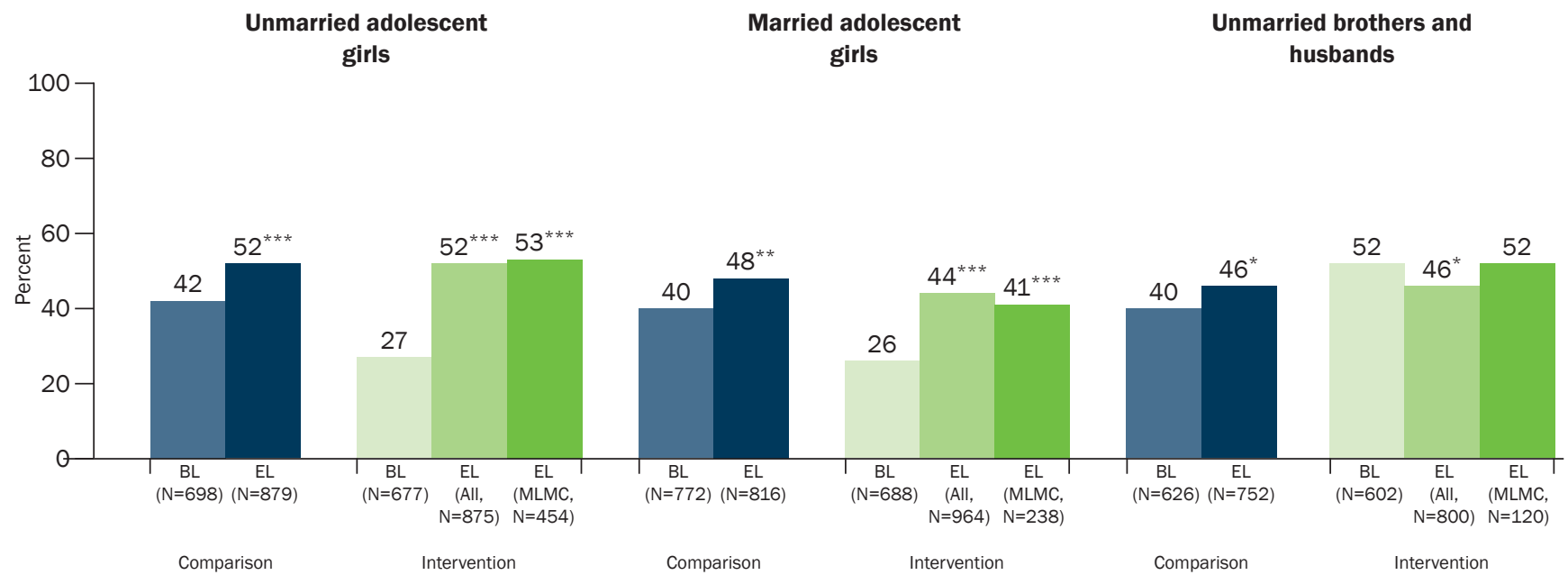

Note: All percentages shown in the figure are weighted; ${ }^{* *}{ }^{*}$ and ${ }^{* *}{ }^{*}$ indicate that the difference between baseline and endline is significant at $p \leq 0.05, p \leq 0.01, p \leq 0.001$, respectively; $B L=$ Baseline; $E L=E n d l i n e ; E L A l l=A l l$ respondents irrespective of their participation in $M L M C$ project; $E L$ $M L M C=$ Respondents who had participated in MLMC project.

Table 4.2: Effect of exposure to the MLMC project on agency and gender role attitudes among unmarried and married adolescent girls and their unmarried brothers and husbands: Summary of regression results

\begin{tabular}{|c|c|c|c|c|c|c|}
\hline \multirow[t]{2}{*}{ Indicators } & \multicolumn{2}{|c|}{$\begin{array}{l}\text { Unmarried adolescent } \\
\text { girls }\end{array}$} & \multicolumn{2}{|c|}{$\begin{array}{l}\text { Married adolescent } \\
\text { girls }\end{array}$} & \multicolumn{2}{|c|}{$\begin{array}{l}\text { Unmarried brothers \& } \\
\text { husbands }\end{array}$} \\
\hline & All & MLMC & All & MLMC & All & MLMC \\
\hline $\begin{array}{l}\text { Displayed self-efficacy in two out of } \\
\text { three situations }{ }^{\#}\end{array}$ & $2.07^{* * *}$ & $2.26^{* * *}$ & $1.64^{* * *}$ & $1.53^{*}$ & $0.58^{* *}$ & 0.80 \\
\hline $\begin{array}{l}\text { Made/will make independent decision } \\
\text { in two out of three personal matters }{ }^{\#}\end{array}$ & $1.53^{* *}$ & $1.68^{* * *}$ & $1.81^{* * *}$ & $2.18^{* * *}$ & $2.50^{* * *}$ & $4.59^{* * *}$ \\
\hline Index of mobility@ & $0.21^{* * *}$ & $0.24^{* * *}$ & $0.08^{*}$ & $0.12^{* * *}$ & -0.01 & -0.013 \\
\hline Index of gender egalitarian attitudes ${ }^{@}$ & $0.09^{* *}$ & $0.10^{* * *}$ & 0.04 & 0.008 & 0.04 & 0.03 \\
\hline Number of respondents & 3,129 & 2,708 & 3,240 & 2,514 & 2,780 & 2,100 \\
\hline
\end{tabular}

Note: ${ }^{*}{ }^{* *}$ and ${ }^{* * *}$ indicate that the net effect of exposure to the intervention is significant at $p \leq 0.05, p \leq 0.01, p \leq 0.001$, respectively; ${ }^{\#}$ Refers to odds ratio from logistic regression; ${ }^{\circledR}$ Refers to regression coefficient from linear regression.

The results of the logistic regression analyses using the DiD estimator, presented in Table 4.2, show a positive net effect of the MLMC project in improving decision making capacity across all three groups of study participants in both the full sample and restricted sample analyses. After controlling for potentially confounding factors and time, unmarried girls in the intervention arm were 1.5-1.7 times more likely than their counterparts in the comparison arm to display decision making capacity. Likewise, married girls in the intervention arm were 1.8-2.2 times more likely than others to have displayed decision making capacity. The findings were similar for unmarried brothers and husbands (OR 2.5 for the full sample and 4.6 for the MLMC sample).

Figure 4.7 presents mean score on the mobility index at baseline and endline in intervention and comparison arms. Findings show that the endline cohort of unmarried girls in the intervention arm was allowed to visit more locations unescorted (3.3-3.5 locations) compared to their baseline counterparts in the intervention arm (2.2 locations) and their baseline and endline counterparts in the comparison arm (2.1-2.4 locations). A similar trend was observed among married girls (2.8-3.4 locations at endline vs. 1.8 locations at baseline in the intervention arm and 1.6-2.3 locations at baseline and endline in the comparison arm). Only a modest difference was observed among unmarried brothers and husbands between baseline and endline assessments which is not surprising given the high levels of mobility already enjoyed by them at baseline. 
Figure 4.6: Percentage of unmarried and married adolescent girls and their unmarried brothers and husbands who reported decision making autonomy by treatment arms, baseline and endline surveys

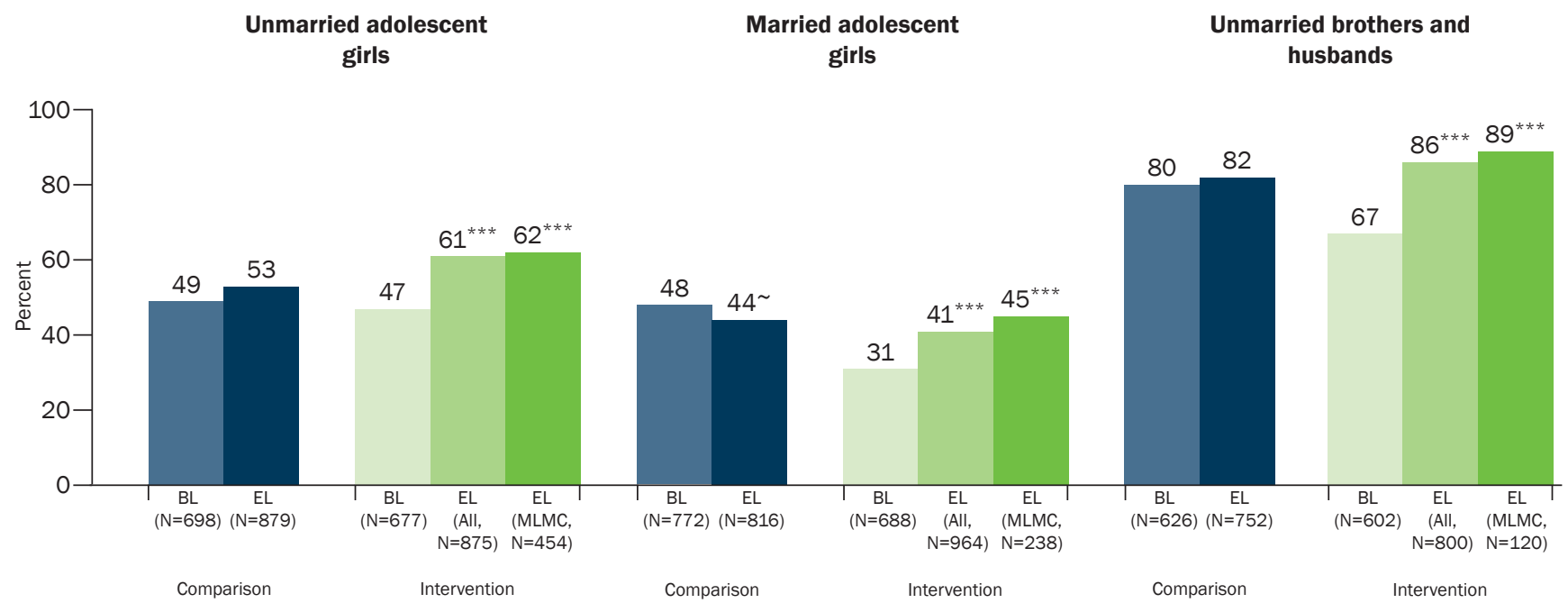

Note: All percentages shown in the figure are weighted; and ${ }^{* *}{ }^{*}$ indicate that the difference between baseline and endline is significant at $p \leq 0.10, p \leq 0.001$, respectively; $B L=$ Baseline; $E L=$ Endline; $E L$ All=All respondents irrespective of their participation in $M L M C$ project; $E L$ $M L M C=$ Respondents who had participated in MLMC project.

Figure 4.7: Mean score on the index of mobility obtained by unmarried and married adolescent girls and their unmarried brothers and husbands by treatment arms, baseline and endline surveys

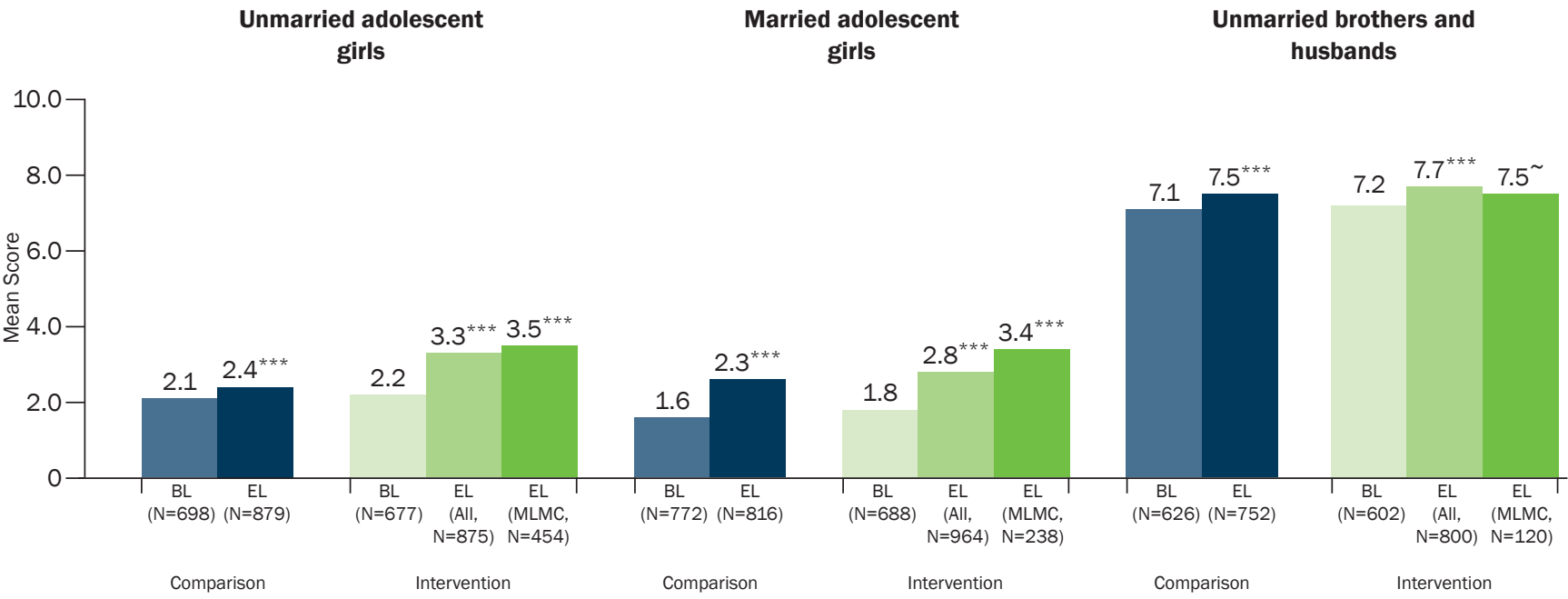

Note: All means shown in the figure are weighted; and ${ }^{* * *}$ indicate that the difference between baseline and endline is significant at $p \leq 0.10, p \leq 0.001$, respectively; $B L=$ Baseline; $E L=E n d l i n e ; E L A l l=A l l$ respondents irrespective of their participation in $M L M C$ project; $E L M L M C=$ Respondents who had participated in MLMC project.

The linear regression results confirm the positive net effect of the MLMC project in improving the freedom of movement of both unmarried and married girls in the full sample and restricted sample analyses (Table 4.2). Unmarried and married girls in the intervention arm enjoyed greater freedom of movement than their counterparts in the comparison arm (regression coefficient of 0.21-0.24 for unmarried girls; 0.08-0.12 for married girls). However, no such effect was observed among unmarried brothers and husbands.

Findings on gender role attitudes among study participants, presented in Figure 4.8, show that gender role attitudes were moderately more egalitarian among the endline than baseline cohorts across all groups in the intervention and comparison arms. However, the changes between baseline and endline assessments were similar in the intervention 
Figure 4.8: Mean score on the index of gender egalitarian attitudes obtained by unmarried and married adolescent girls and their unmarried brothers and husbands by treatment arms, baseline and endline surveys

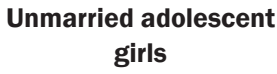

girls
Married adolescent

girls
Unmarried brothers and husbands

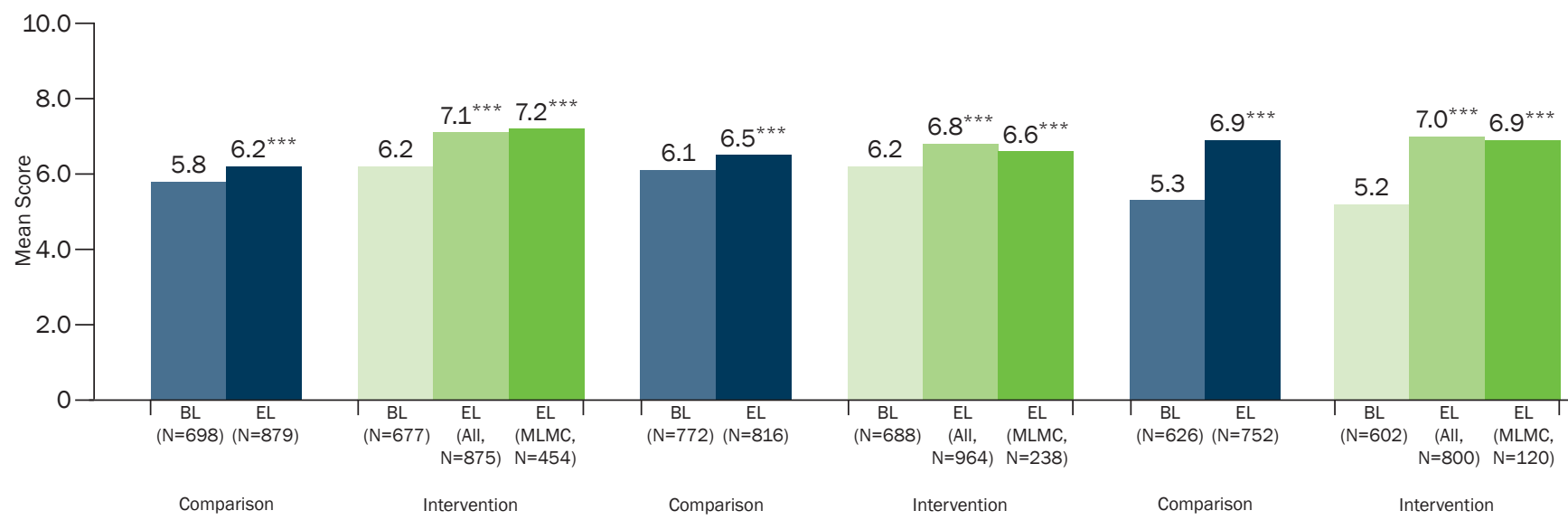

Note: All means shown in the figure are weighted; ${ }^{* *}$ indicates that the difference between baseline and endline is significant at $p \leq 0.001$; $B L=$ Baseline; $E L=E n d l i n e ; E L A l l=A l l$ respondents irrespective of their participation in $M L M C$ project; $E L M L M C=R e s p o n d e n t s$ who had participated in MLMC project.

and comparison arms across all groups, except unmarried girls. Among unmarried girls, the endline cohort in the intervention arm scored higher (7.1-7.2) than their baseline counterparts in the intervention arm (6.2) and their baseline and endline counterparts in the comparison arm (5.8-6.2).

The linear regression results confirm the positive net effect of the MLMC project in enabling unmarried girls to adopt gender egalitarian attitudes (Table 4.2). Unmarried girls in the intervention arm were more likely to adhere to gender egalitarian attitudes than their counterparts in the comparison arm in both the full sample and restricted sample analyses (regression coefficient of 0.09-0.10). However, no such effect was observed among married girls and unmarried brothers and husbands.

We note that the findings presented in this section on the effect of the MLMC project on study participants' agency and gender role attitudes concur with study participants' perceptions of changes experienced in the six months prior to the interview (see Table 8.1).

\section{Effect on awareness of sexual and reproductive matters among adolescent girls and their unmarried brothers and husbands}

One of the objectives of the MLMC project was to enhance adolescent girls' and their unmarried brothers' and husbands' awareness of sexual and reproductive matters. Findings pertaining to study participants' awareness of sexual and reproductive matters at baseline and endline are summarised in Figures 4.9 to 4.14.

A comparison of scores obtained by unmarried girls on the index of awareness of sexual and reproductive matters in the intervention and comparison arms at baseline and endline shows a positive difference of 2.0-3.6 points in the intervention arm (6.8 to 8.8-10.4) compared to almost no difference in the comparison arm (6.0 to 6.2) between baseline and endline assessments (Figure 4.9). Among married girls too, a similar trend-a positive difference of 1.0-2.5-was observed, although the effect size was somewhat smaller (8.5 to 9.5-11.0 in the intervention arm vs. 8.9 to 9.1 in the comparison arm). Finally, among unmarried brothers and husbands, a similar trend was observed-a positive difference of 1.6-2.8 in the intervention arm compared to a 0.7 difference in the comparison arm.

The results of linear regression analyses using the DiD estimator, presented in Table 4.3, reiterate the positive net effect of the MLMC project in increasing the awareness of sexual and reproductive matters across all three groups of study participants in the full sample and restricted sample analyses. Unmarried and married girls as well as 
Figure 4.9: Mean scores on the index of awareness of sexual and reproductive matters obtained by unmarried and married adolescent girls and their unmarried brothers and husbands by treatment arms, baseline and endline surveys

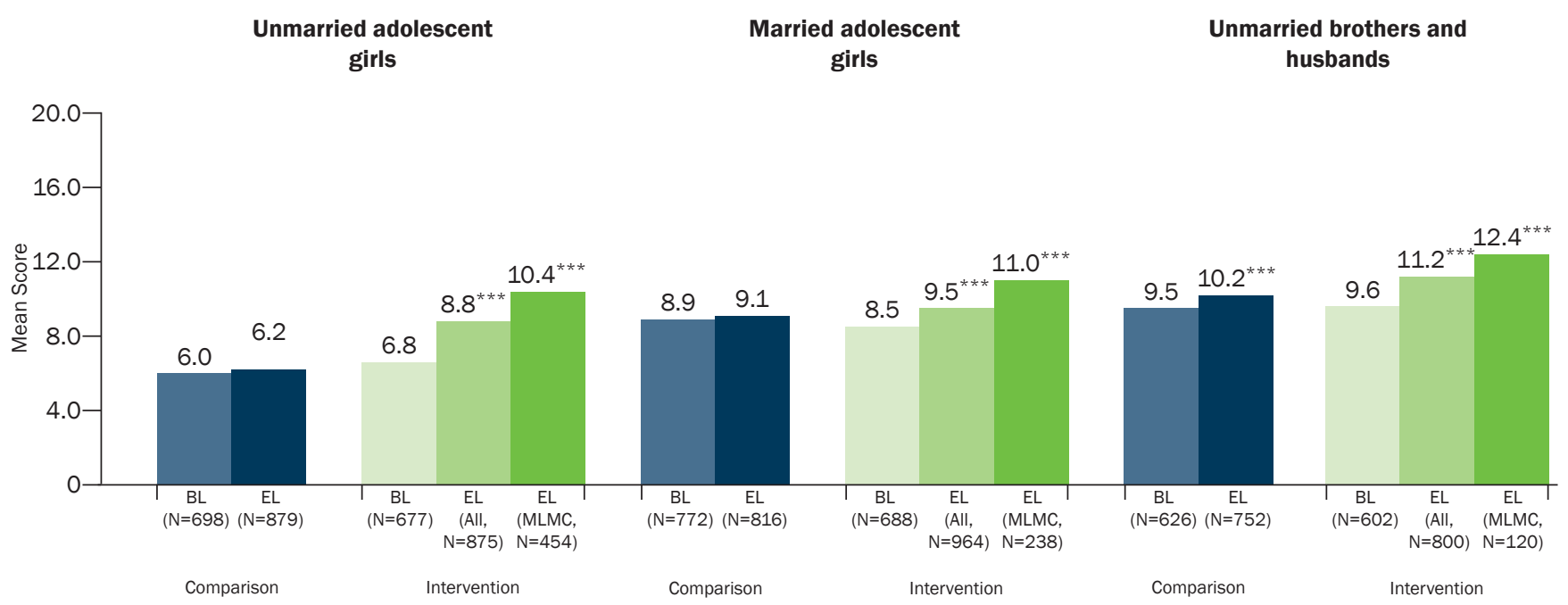

Note: All means shown in the figure are weighted; ${ }^{* *}$ indicates that the difference between baseline and endline is significant at $p \leq 0.001$; $B L=$ Baseline; $E L=E n d l i n e ; E L A l l=A l l$ respondents irrespective of their participation in $M L M C$ project; $E L M L M C=$ Respondents who had participated in $M L M C$ project.

Table 4.3: Effect of exposure to the MLMC project on awareness of sexual and reproductive matters, including HIV/ AIDS among unmarried and married adolescent girls and their unmarried brothers and husbands: Summary of regression results

\begin{tabular}{|c|c|c|c|c|c|c|}
\hline \multirow[t]{2}{*}{ Indicators } & \multicolumn{2}{|c|}{$\begin{array}{l}\text { Unmarried adolescent } \\
\text { girls }\end{array}$} & \multicolumn{2}{|c|}{$\begin{array}{l}\text { Married adolescent } \\
\text { girls }\end{array}$} & \multicolumn{2}{|c|}{$\begin{array}{c}\text { Unmarried brothers\& } \\
\text { husbands }\end{array}$} \\
\hline & All & MLMC & All & MLMC & All & MLMC \\
\hline $\begin{array}{l}\text { Index of awareness of sexual and } \\
\text { reproductive matters }{ }^{@}\end{array}$ & $0.22^{* * *}$ & $0.35^{* * *}$ & $0.08^{*}$ & $0.19^{* * *}$ & $0.09^{* *}$ & $0.13^{* * *}$ \\
\hline Heard about HIV/AIDS\# & $2.33^{* * *}$ & $8.88^{* * *}$ & 1.08 & $4.32^{* * *}$ & $1.46^{*}$ & $4.63^{* * *}$ \\
\hline $\begin{array}{l}\text { Knew about two ways of preventing } \\
\text { HIV transmission"\# }\end{array}$ & $1.94^{* *}$ & $4.16^{* * *}$ & 1.15 & $2.72^{* * *}$ & 1.26 & $3.03^{* * *}$ \\
\hline $\begin{array}{l}\text { Rejected two misconceptions about } \\
\text { HIV/AIDS\# }\end{array}$ & $1.62^{\sim}$ & $2.95^{\star * *}$ & 1.03 & $2.77^{* * *}$ & $1.68^{* *}$ & $2.13^{* * *}$ \\
\hline $\begin{array}{l}\text { Displayed comprehensive awareness } \\
\text { about HIV/AIDS\# }\end{array}$ & 1.39 & $2.87^{*}$ & 1.09 & $2.74^{* * *}$ & $1.78^{* * *}$ & $2.55^{* * *}$ \\
\hline $\begin{array}{l}\text { Knew a facility to go to for an HIV } \\
\text { test" }\end{array}$ & $2.86^{* * *}$ & $9.76^{* * *}$ & 1.04 & $4.31^{* * *}$ & 0.91 & $2.91^{* * *}$ \\
\hline Number of respondents & 3,129 & 2,708 & 3,240 & 2,514 & 2,780 & 2,100 \\
\hline
\end{tabular}

Note: ${ }^{*}{ }^{* *}$ and ${ }^{* * *}$ indicate that the net effect of exposure to the intervention is significant at $p \leq 0.05, p \leq 0.01, p \leq 0.001$, respectively; ${ }^{\#}$ Refers to odds ratio from logistic regression; ${ }^{\circledR}$ Refers to regression coefficient from linear regression.

their unmarried brothers and husbands in the intervention arm displayed higher levels of awareness of sexual and reproductive matters than their corresponding counterparts in the comparison arm (regression coefficient of 0.22-0.35 for unmarried girls; 0.08-0.19 for married girls; and 0.09-0.13 for unmarried brothers and husbands).

Findings presented in Figure 4.10 show the percentage of study participants who were aware of HIV/AIDS. The percentage of unmarried girls who were aware of HIV/AIDS was significantly larger at endline, particularly among the MLMC participants in the intervention arm (59-81\%), compared to their counterparts in the intervention 
Figure 4.10: Percentage of unmarried and married adolescent girls and their unmarried brothers and husbands who were aware of HIV/AIDS by treatment arms, baseline and endline surveys

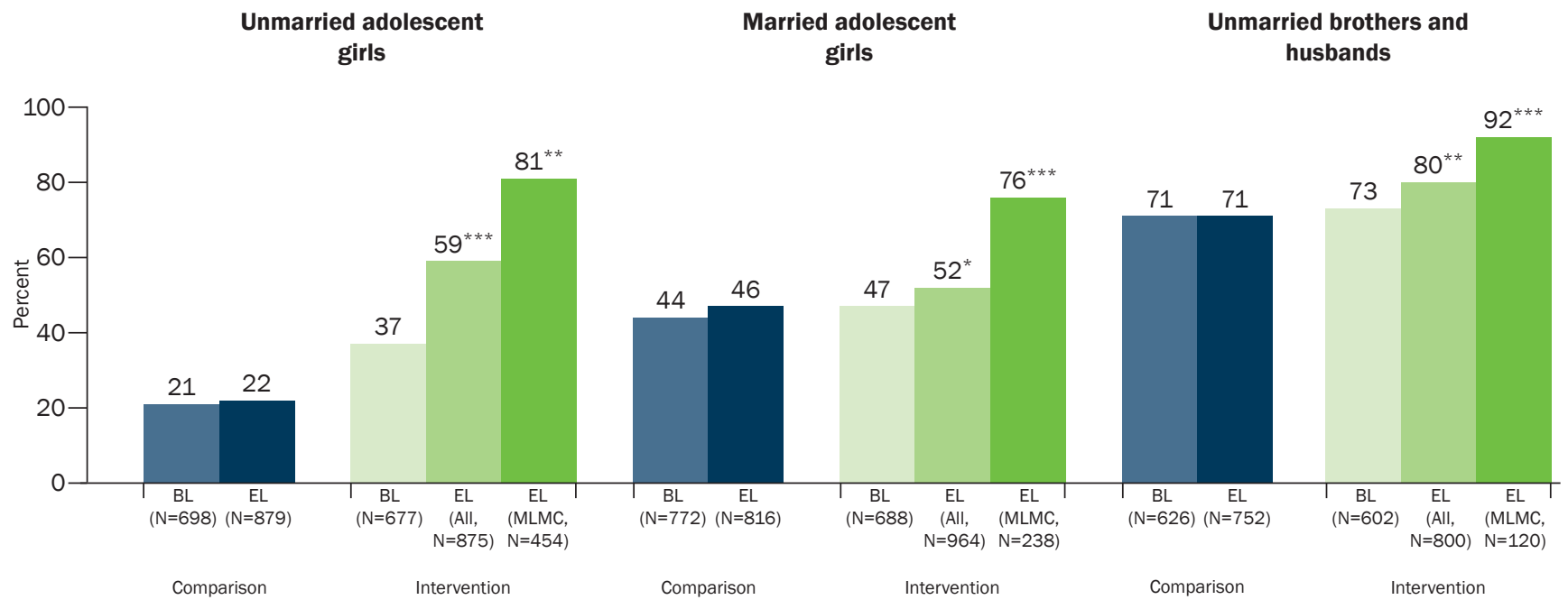

Note: All percentages shown in the figure are weighted; ${ }^{*},{ }^{* *}$ and ${ }^{* *}$ indicate that the difference between baseline and endline is significant at $p \leq 0.05, p \leq 0.01, p \leq 0.001$, respectively; $B L=$ Baseline; $E L=E n d l i n e ; E L A l l=A l l$ respondents irrespective of their participation in $M L M C$ project; $E L$ $M L M C=$ Respondents who had participated in MLMC project.

arm at baseline (37\%) and in comparison arm at baseline and endline (21-22\%). These data suggest a positive difference of 22-44 percentage points in the intervention arm compared to almost no difference in the comparison arm between baseline and endline assessments. Similarly, married girls in the endline cohort of the intervention arm (52-76\%) were more likely than their baseline cohort in the intervention arm (47\%) and the baseline and endline cohorts in the comparison arm (44-46\%) to be aware of HIV/AIDS. In other words, a positive difference of 5-29 percentage points was observed in the intervention arm compared to a 2 percentage point difference in the comparison arm between baseline and endline assessments. Among unmarried brothers and husbands too, the endline cohort in the intervention arm was more likely to be aware of HIV/AIDS (80-92 percent) compared to their baseline counterparts in the intervention arm (73\%) and baseline and endline counterparts in the comparison arm (71\%). These data suggest a positive difference of 7-19 percentage points in the intervention arm compared to no difference in the comparison arm.

The logistic regression results confirm that exposure to the MLMC project had a positive net effect on adolescents' awareness of HIV/AIDS (Table 4.3). Specifically, unmarried girls in the intervention arm were 2.3 times more likely than those in the comparison arm to have heard about HIV/AIDS in the full sample analyses (the corresponding odds ratio in the restricted analyses was 8.9). While no effect of exposure to the intervention was observed among married girls in the full sample analyses, the restricted analyses shows that married girls who had participated in the MLMC were four times more likely than those in the comparison arm to be aware of HIV/AIDS after controlling for potentially confounding factors. Finally, unmarried brothers and husbands in the intervention arm were 1.5 times more likely than those in the comparison arm to have heard about HIV/AIDS in the full sample analyses (the corresponding odds ratio in the restricted analyses was 4.6).

Awareness about two ways of preventing HIV transmission had improved across all three groups of study participants (Figure 4.11). The endline cohort of unmarried girls in the intervention arm (32-47\%) were more likely to be aware of two ways of preventing HIV transmission, namely, consistent condom use and single partner relationship, than their counterparts at baseline in the intervention arm (18\%) and those at baseline and endline in the comparison arm (7-8\%). In other words, a 14-29 percentage point difference was observed between the two assessments in the intervention arm compared to almost no change in the comparison arm. Likewise, a somewhat larger proportion of the endline cohort of married girls in the intervention arm (39-54\%) knew about two ways of preventing HIV transmission than their counterparts at baseline in the intervention arm (31\%) and those at baseline and endline in the comparison arm (29-32\%). This translates into an 8-23 percentage point difference in the intervention arm between the two assessments compared to a difference of three percentage points in the comparison arm. Among 
Figure 4.11: Percentage of unmarried and married adolescent girls and their unmarried brothers and husbands who knew about two ways of preventing HIV transmission by treatment arms, baseline and endline surveys

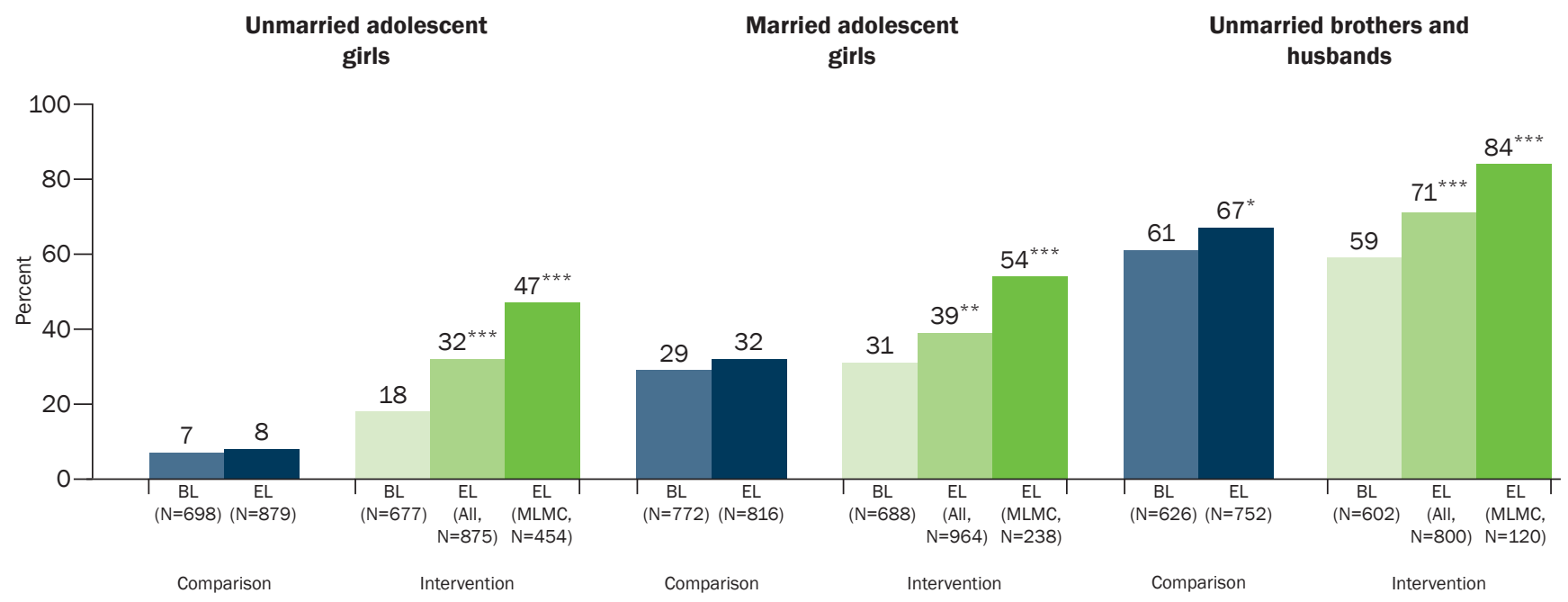

Note: All percentages shown in the figure are weighted; ${ }^{* * *}$ and ${ }^{* * *}$ indicate that the difference between baseline and endline is significant at $p \leq 0.05, p \leq 0.01, p \leq 0.001$, respectively; $B L=$ Baseline; $E L=E n d l i n e ; E L A l l=A l l$ respondents irrespective of their participation in $M L M C$ project; $E L$ $M L M C=$ Respondents who had participated in MLMC project.

unmarried brothers and husbands too, the endline cohort in the intervention arm was more likely to know about two ways of preventing HIV transmission (71-84\%) compared to those in the intervention arm at baseline (59\%) and in the comparison arm at baseline and endline (61-67\%).

The regression results confirm the positive net effect of exposure to the MLMC project on unmarried adolescent girls' awareness of two ways of preventing HIV transmission (OR 1.94 for the full sample and 4.16 for the MLMC participant sample) (Table 4.3). Although a similar positive net effect was not observed among married girls and unmarried brothers and husbands in the full sample analyses, a positive net effect was observed when we restricted the analyses to the MLMC participant sample (OR 2.72 and 3.03, respectively).

Figure 4.12 compares the percentage of study participants who dispelled misconceptions about HIV transmission at baseline and endline. The endline cohort of unmarried girls in the intervention arm were more likely to reject misconceptions about HIV transmission (22-31\%) than their counterparts in the intervention arm at baseline (11\%) and in the comparison arm at baseline and endline (6-7\%). In other words, an 11-20 percentage point difference was observed between the two assessments in the intervention arm compared to almost no difference in the comparison arm. Likewise, a larger proportion of married girls, particularly the MLMC participants in the intervention arm, rejected at least two misconceptions about HIV transmission at endline (17-28\%) compared to their baseline counterparts in the intervention arm (12\%) and their baseline and endline counterparts in the comparison arm (14-17\%). A similar pattern was observed among unmarried brothers and husbands: while 45-50 percent of the endline cohort of unmarried brothers and husbands in the intervention arm rejected at least two misconceptions about HIV transmission, a smaller proportion in the intervention arm so rejected at baseline (32\%) and in the comparison arm at baseline and endline (36-39\%). This translates into a 13-18 percentage point difference in the intervention arm between the two assessments compared to a difference of three percentage points in the comparison arm.

The regression results confirm the positive net effect of exposure to the MLMC project on enabling unmarried adolescent girls to reject misconceptions about HIV transmission (OR 1.62 for the full sample and 2.95 for the MLMC participant sample) (Table 4.3). Although a similar positive net effect was not observed among married girls in the full sample analyses, a positive net effect was observed when we restricted the analyses to the MLMC participant sample (OR 2.77). As with unmarried girls, unmarried brothers and husbands in the intervention arm were more likely than those in the comparison arm to reject misconceptions about HIV transmission (OR 1.68 for the full sample and 2.13 for the MLMC participant sample). 
Figure 4.12: Percentage of unmarried and married adolescent girls and their unmarried brothers and husbands who rejected at least two misconceptions about HIV transmission by treatment arms, baseline and endline surveys

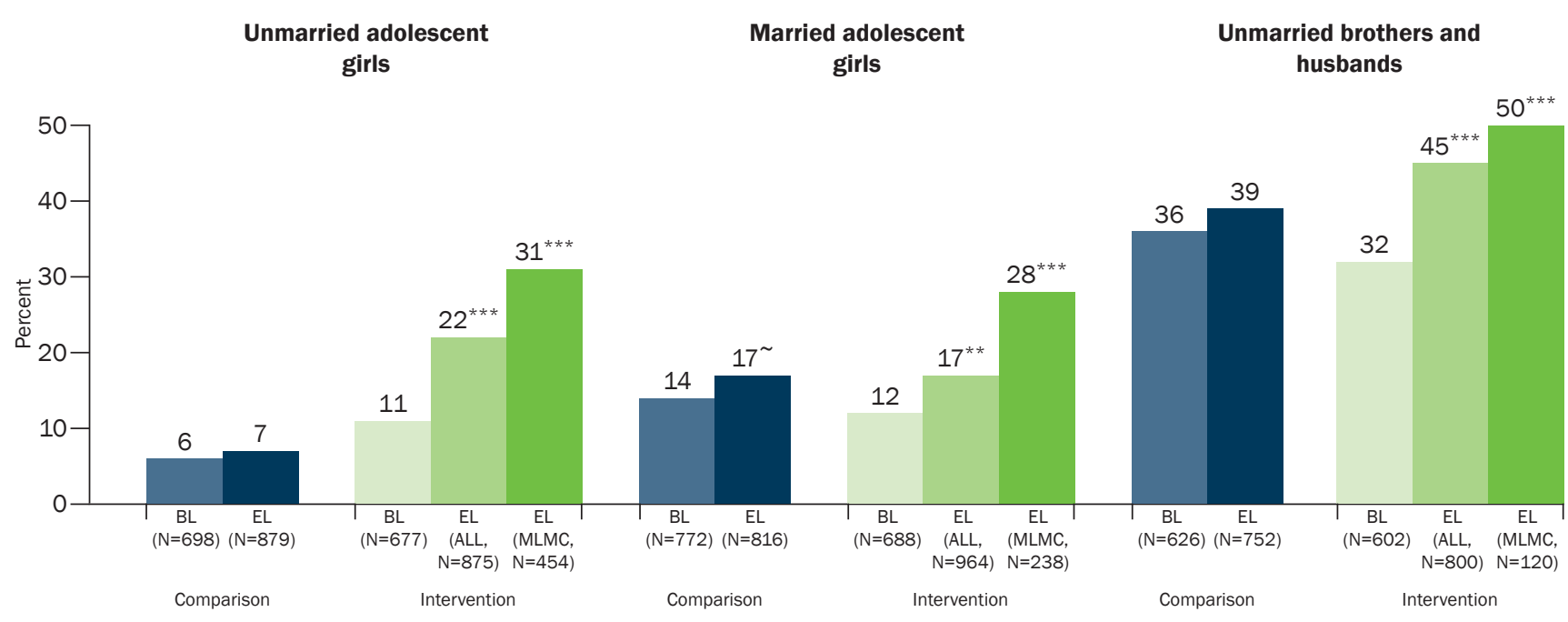

Note: All percentages shown in the figure are weighted; $\sim$, ${ }^{*}$ and ${ }^{* \star *}$ indicate that the difference between baseline and endline is significant at $p \leq 0.10, p \leq 0.01, p \leq 0.001$, respectively; $B L=$ Baseline; $E L=E n d l i n e ; E L A l l=A l l$ respondents irrespective of their participation in $M L M C$ project; $E L$ $M L M C=$ Respondents who had participated in MLMC project.

Findings presented in Figure 4.13 show that endline cohorts of study participants across all three groups were more likely than their baseline cohorts to display comprehensive awareness of HIV/AIDS in the intervention and comparison arms. A larger proportion of unmarried girls in the intervention arm displayed comprehensive awareness of HIV/AIDs at endline (14-22\%) compared to the intervention arm cohort at baseline (6\%) and the comparison arm cohort at baseline and endline (2-4\%). In other words, 8-16 percentage point improvement in comprehensive awareness of HIV/AIDS was observed in the intervention arm between the two assessments, compared to a two percentage point improvement in the comparison arm. Married girls in the intervention arm at endline were, similarly, more likely than others to display comprehensive awareness of HIV/AIDS (14-22\% vs. 9\% in the intervention arm at baseline and $11-14 \%$ in the comparison arm at baseline and endline). This implies a percentage point difference of 5-13 in the intervention arm between baseline and endline assessments compared to a three-point difference in

Figure 4.13: Percentage of unmarried and married adolescent girls and their unmarried brothers and husbands who displayed comprehensive awareness of HIV/AIDS by treatment arms, baseline and endline surveys

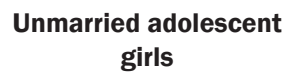
girls

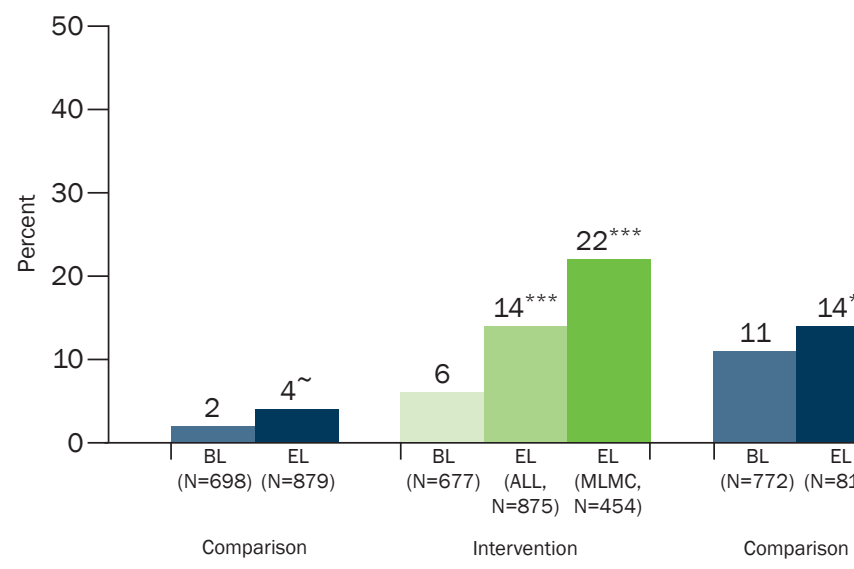

Married adolescent girls
Unmarried brothers and husbands

Note: All percentages shown in the figure are weighted;,${ }^{*}$ and ${ }^{* *}$ indicate that the difference between baseline and endline is significant at $p \leq 0.10, p \leq 0.05, p \leq 0.001$, respectively; $B L=$ Baseline; $E L=E n d l i n e ; E L A l l=A l l$ respondents irrespective of their participation in $M L M C$ project; EL $M L M C=$ Respondents who had participated in MLMC project. 
the comparison arm. Unmarried brothers and husbands in the intervention arm at endline were also more likely to display comprehensive awareness of HIV/AIDS than their counterparts in the intervention arm at baseline (25\%) and the comparison arm at baseline and endline (31-37\%). This implies a percentage point difference of 16-24 in the intervention arm between the two assessments, compared to six points in the comparison arm.

The regression results indicate that although the MLMC project had no effect on adolescent girls' comprehensive awareness of HIV/AIDS in the full sample analyses, a positive net effect was observed when we restricted the analyses to the MLMC participant sample. Unmarried and married girls who had participated in the MLMC project activities were almost three times more likely than those in the comparison arm to display comprehensive awareness (Table 4.3). Findings also show that unmarried brothers and husbands were more likely than those in the comparison arm to display comprehensive awareness (OR 1.8 for the full sample and 2.6 for the MLMC participant sample).

Finally, findings related to study participants' awareness of a facility where one can obtain an HIV test are presented in Figure 4.14. A larger proportion of unmarried girls in the intervention arm reported at endline that they knew a facility to go to for an HIV test (45-69\%) compared to the intervention arm cohort at baseline (18\%) and the comparison arm cohort at baseline and endline (12-16\%). In other words, a 27-51 percentage point improvement in awareness of a facility offering HIV tests was observed in the intervention arm between the two assessments, compared to a four percentage point improvement in the comparison arm. Likewise, married girls in the intervention arm at endline were more likely than their counterparts in the intervention arm at baseline and in the comparison arm at baseline and endline to report awareness of a testing facility $(40-68 \%$ vs. $25 \%$ in the intervention arm at baseline and $22-33 \%$ in the comparison arm at baseline and endline This implies a percentage point difference of 15-43 points in the intervention arm between the two assessments compared to 11 points in the comparison arm. A similar pattern was observed among unmarried brothers and husbands: 57-80 percent of those in the intervention arm at endline compared to 43 percent in the intervention arm at baseline and 41-57 percent in the comparison arm at baseline and endline reported awareness of an HIV testing facility. Moreover, the percentage point difference between the baseline and endline assessments was larger in the intervention arm, especially in the sample of MLMC participants (14-37 percentage points) than in the comparison arm (16 percentage points).

Figure 4.14: Percentage of unmarried and married adolescent girls and their unmarried brothers and husbands who knew a facility to go for an HIV test by treatment arms, baseline and endline surveys

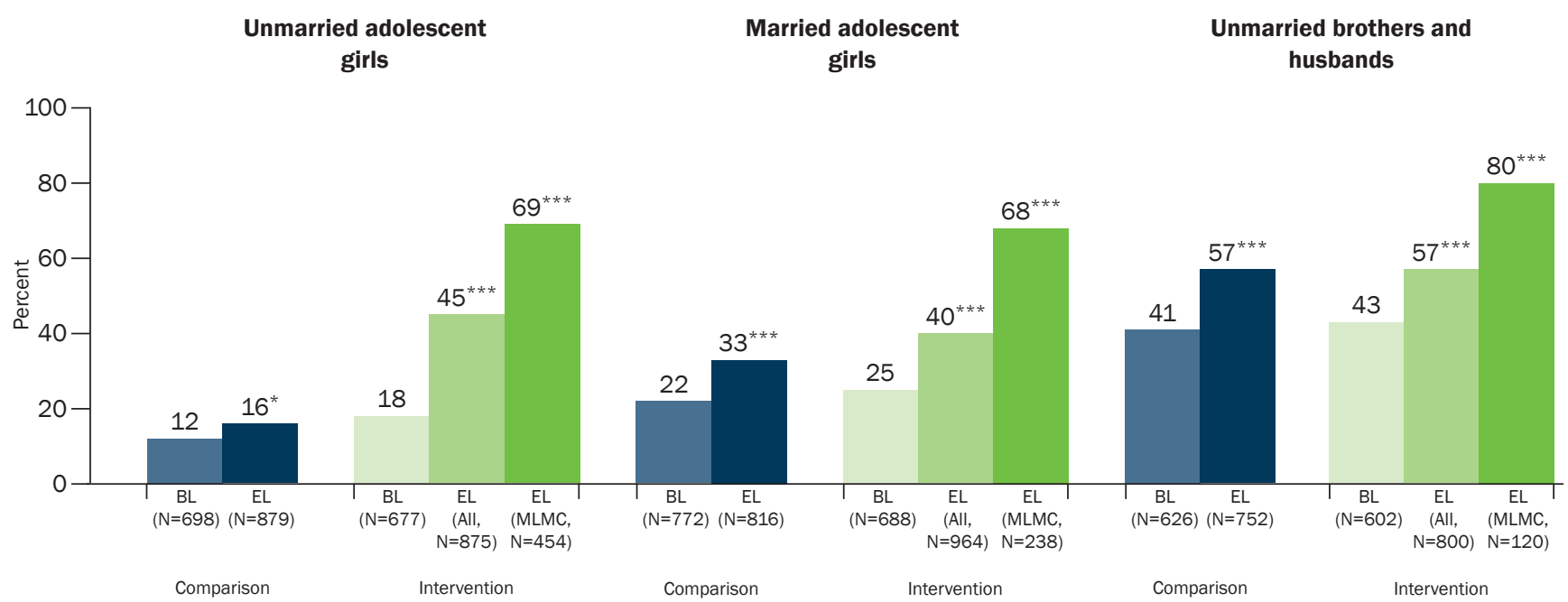

Note: All percentages shown in the figure are weighted; ${ }^{*}$ and ${ }^{* * *}$ indicate that the difference between baseline and endline is significant at $p \leq 0.05, p \leq 0.001$, respectively; $B L=$ Baseline; $E L=$ Endline; $E L$ All=All respondents irrespective of their participation in $M L M C$ project; $E L$ $M L M C=$ Respondents who had participated in MLMC project.

The regression results indicate differential effect of the MLMC project on study participants' awareness of a health facility that provides HIV tests (Table 4.3). Unmarried girls in the intervention arm were more likely than those in the comparison arm to report awareness of a health facility that does HIV testing (OR 2.86 and 9.76 in the full sample analyses and the MLMC participant sample analyses, respectively). Although no effect of the project was observed among married girls and unmarried brothers and husbands in the full sample analyses, a positive net effect was 
observed when we restricted the analyses to the MLMC participant samples. Married girls who had participated in MLMC project activities were four times more likely than those in the comparison arm to be aware of a testing facility. Likewise, unmarried brothers and husbands who had participated in MLMC project activities were three times more likely than those in the comparison arm to be aware of a testing facility.

We note that the findings presented in this section on the effect of the MLMC project on study participants' awareness of sexual and reproductive matters, including HIV/AIDS, concur with study participants' perceptions of changes experienced in the six months prior to the interview (see Table 8.1).

\section{Effect on financial literacy and related practices among adolescent girls and their unmarried brothers and husbands}

The MLMC project activities sought to improve financial literacy among participants, foster a savings orientation among participants, and help them open a bank account in their name. Findings presented in Figure 4.15 suggest that the percentage of unmarried girls who displayed financial literacy was larger in the intervention arm at endline (15-17\%) compared to those in the intervention arm at baseline $(9 \%)$ and in the comparison arms at baseline and endline (7-8\%). In other words, a 6-8 percentage point improvement in financial literacy was observed in the intervention arm between the two assessments, compared to almost no change in the comparison arm. Similarly, although the percentage of married girls who displayed financial literacy was similar between the intervention and comparison arms at endline, the percentage point difference between the two assessments was larger in the intervention arm (11-13 percentage points, from 10\% to 21-23\%) than in the comparison arm (3 percentage point decline, from $22 \%$ to $19 \%$ ). Finally, 23-31 percentage point improvements in financial literacy were observed among unmarried brothers and husbands in the intervention arm between the two assessments (from 16\% to 39-47\%), compared to 18 percentage point improvements in the comparison arm (from $24 \%$ to $42 \%$ ).

Figure 4.15: Percentage of unmarried and married adolescent girls and their unmarried brothers and husbands who displayed financial literacy by treatment arms, baseline and endline surveys

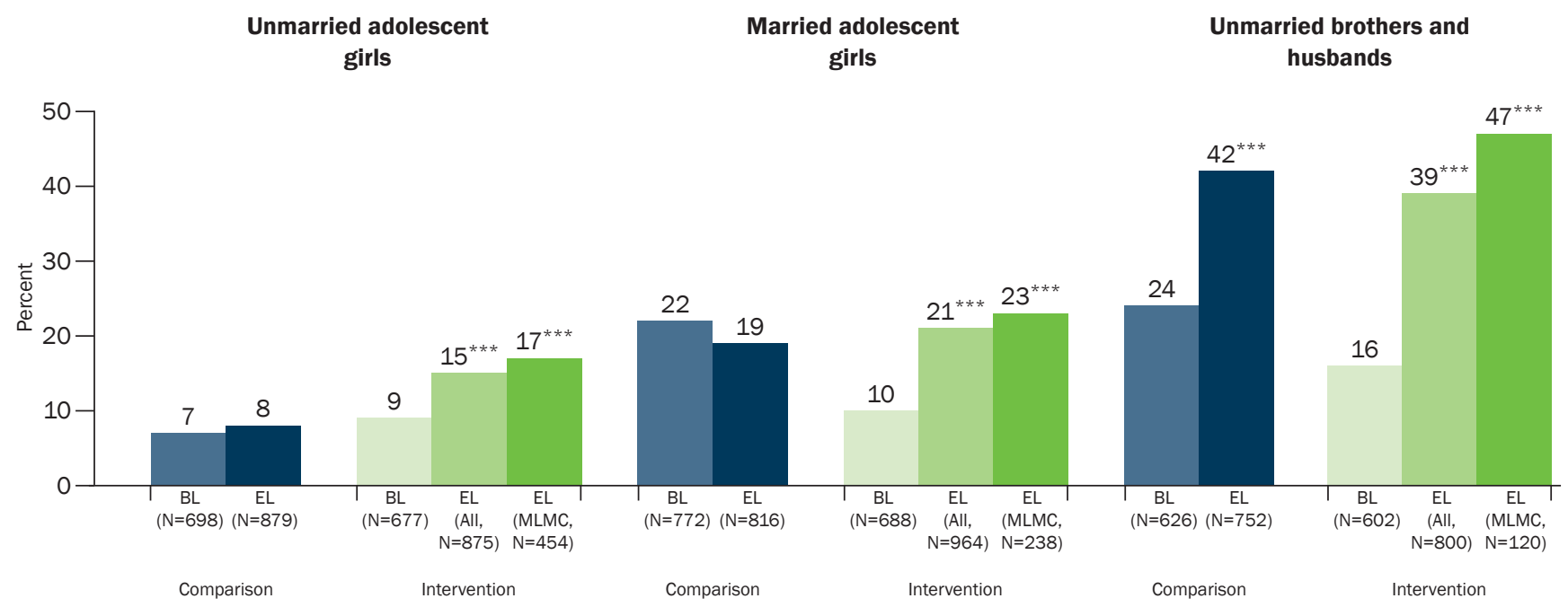

Note: All percentages shown in the figure are weighted; ${ }^{* *}$ indicates that the difference between baseline and endline is significant at $p \leq 0.001$; $B L=$ Baseline; $E L=E n d l i n e ; E L A l l=A l l$ respondents irrespective of their participation in $M L M C$ project; $E L M L M C=R e s p o n d e n t s$ who had participated in MLMC project.

The regression results highlight a positive net effect of the MLMC project on improving the financial literacy of adolescent girls and their unmarried brothers and husbands after controlling for potential confounding factors and time (Table 4.4). Unmarried girls in the intervention arm were almost twice as likely as girls in the comparison arm to display financial literacy (OR 1.72 for the full sample and 2.23 for the MLMC participant sample), while married girls were three to four times more likely to do so (OR 3.29 and 3.77 for the full sample and the MLMC participant sample, respectively). Likewise, unmarried brothers and husbands in the intervention arm were 1.7 (for the full sample) to 2.1 (for the MLMC participant sample) times more likely to display financial literacy than those in the comparison arm. 
We used a number of indicators-having some savings, owning and operating a savings account, visiting a bank, and having a savings goal-to assess the effect of the MLMC project on adolescent girls' and their unmarried brothers' and husbands' savings related practices. Findings are summarised in Figures 4.16 to 4.19 and suggest mixed effect of the MLMC project.

Figure 4.16 shows that the endline cohorts of study participants were more likely than their corresponding baseline cohorts to report some savings in the intervention and comparison arms. The percentage difference between baseline and endline assessments among unmarried girls was smaller in the intervention arm (24-25 points, from $62 \%$ to $86-87 \%$ ) than in the comparison arm (32 percentage points, from $56 \%$ to $88 \%$ ). Among married girls,

Table 4.4: Effect of exposure to the MLMC project on financial literacy and related practices, and participation in vocational skills training programmes among unmarried and married adolescent girls and their unmarried brothers and husbands by treatment arms: Summary of regression results

\begin{tabular}{|c|c|c|c|c|c|c|}
\hline \multirow[t]{2}{*}{ Indicators } & \multicolumn{2}{|c|}{$\begin{array}{l}\text { Unmarried adolescent } \\
\text { girls }\end{array}$} & \multicolumn{2}{|c|}{$\begin{array}{l}\text { Married adolescent } \\
\text { girls }\end{array}$} & \multicolumn{2}{|c|}{$\begin{array}{l}\text { Unmarried brothers \& } \\
\text { husbands }\end{array}$} \\
\hline & All & MLMC & All & MLMC & All & MLMC \\
\hline Displayed financial literacy\# & $1.72^{*}$ & $2.23^{* *}$ & $3.29^{* * *}$ & $3.77^{* * *}$ & $1.71^{* *}$ & $2.13^{* *}$ \\
\hline Reported some savings ${ }^{\#}$ & $0.73^{\sim}$ & 0.75 & 0.72 & 1.04 & 1.37 & 1.17 \\
\hline $\begin{array}{l}\text { Owned a savings account and } \\
\text { operated it on her/his own\# }\end{array}$ & $1.87^{\star}$ & $2.27^{*}$ & $1.45^{*}$ & $2.27^{* * *}$ & 1.12 & 1.31 \\
\hline $\begin{array}{l}\text { Visited a bank in the six months } \\
\text { preceding the interview }\end{array}$ & $1.68^{*}$ & $2.61^{* * *}$ & $0.65^{*}$ & 1.22 & $1.71^{* *}$ & $2.82^{* * *}$ \\
\hline Expressed a savings goal ${ }^{\#}$ & $1.42^{\sim}$ & 1.37 & 1.31 & $1.46^{\sim}$ & 0.77 & 0.74 \\
\hline $\begin{array}{l}\text { Attended vocational skills } \\
\text { training programmes in the six } \\
\text { months prior to the interview }\end{array}$ & 1.29 & $2.49^{* * *}$ & $2.76^{* * *}$ & $8.54^{* * *}$ & $2.76^{* * *}$ & $7.74^{* * *}$ \\
\hline Number of respondents & 3,129 & 2,708 & 3,240 & 2,514 & 2,780 & 2,100 \\
\hline
\end{tabular}

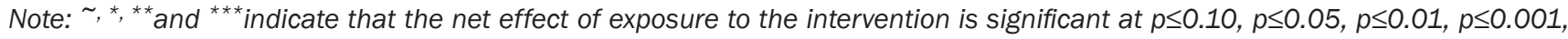
respectively; "Refers to odds ratio from logistic regression.

Figure 4.16: Percentage of unmarried and married adolescent girls and their unmarried brothers and husbands who reported some savings by treatment arms, baseline and endline surveys

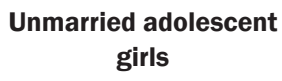

girls
Married adolescent girls
Unmarried brothers and husbands

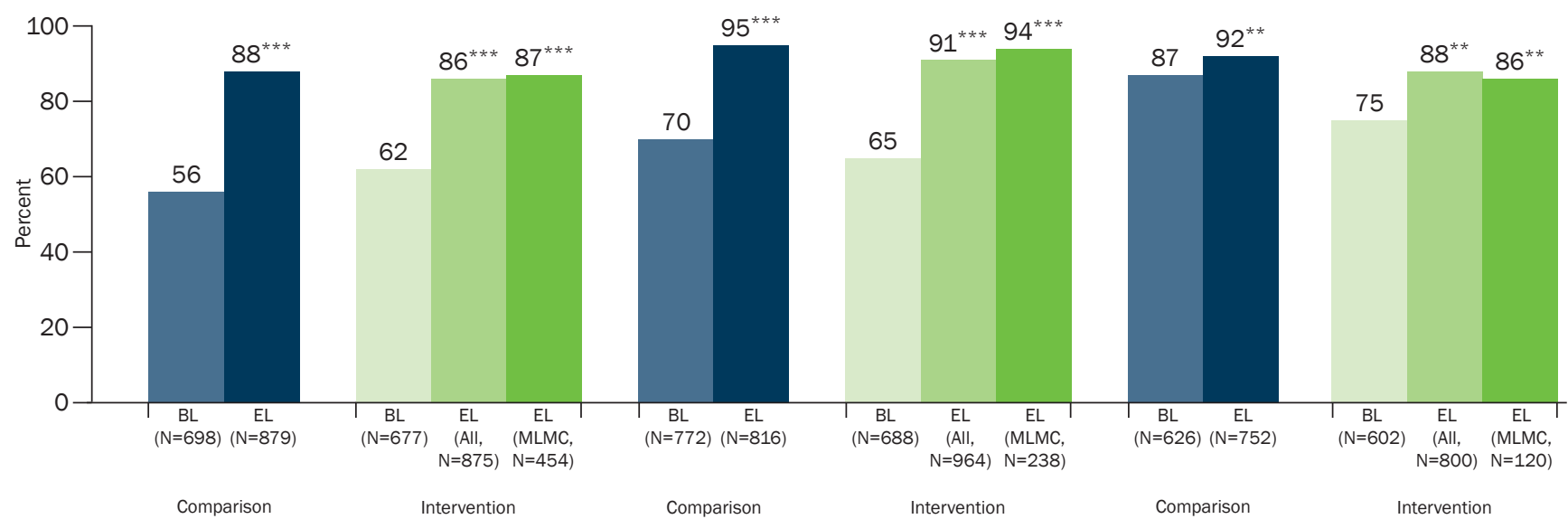

Note: All percentages shown in the figure are weighted; ${ }^{* *}$ and ${ }^{* *}$ indicate that the difference between baseline and endline is significant at $p \leq 0.01, p \leq 0.001$, respectively; $B L=$ Baseline; $E L=E n d l i n e ; E L A l l=A l l$ respondents irrespective of their participation in $M L M C$ project; $E L$ $M L M C=$ Respondents who had participated in MLMC project. 
the percentage point differences between baseline and endline assessments were similar in the intervention and comparison arms (25-29 percentage points). Finally, among unmarried brothers and husbands, the percentage point differences were somewhat larger in the intervention arm (11-13 percentage points, from $75 \%$ to $86-88 \%$ ) than the comparison arm (5 percentage points, from $87 \%$ to $92 \%$ ). The regression results highlight that,across all three groups, the MLMC project had no effect in enabling adolescents to have some savings (Table 4.4).

Findings related to the proportion of study participants who owned a savings account and operated it on their own are depicted in Figure 4.17. They suggest that the endline cohorts of study participants were more likely than the baseline cohorts to report that they owned a savings account and operated it on their own. For example, the percentage of unmarried girls who owned and operated a savings account on their own increased by 10-12 percentage points in the intervention arm (from 5\% to 15-17\%) compared to five percentage points in the comparison arm (from 4\% to 9\%) between baseline and endline assessments. Similarly, it increased by 13-20 percentage points among married girls in the intervention arm (from $17 \%$ to $30-37 \%$ ) compared to seven percentage points in the comparison arm (from $24 \%$ to $31 \%$ ) during the same period. Finally, it increased among unmarried brothers and husbands by 19-25 percentage points in the intervention arm (from 29\% to 48-54\%) compared to 16 percentage points in the comparison arm (27\% to $43 \%)$ during the same period.

Figure 4.17: Percentage of unmarried and married adolescent girls and their unmarried brothers and husbands who owned a savings account and operated it on their own by treatment arms, baseline and endline surveys

Unmarried adolescent girls
Married adolescent girls
Unmarried brothers and husbands

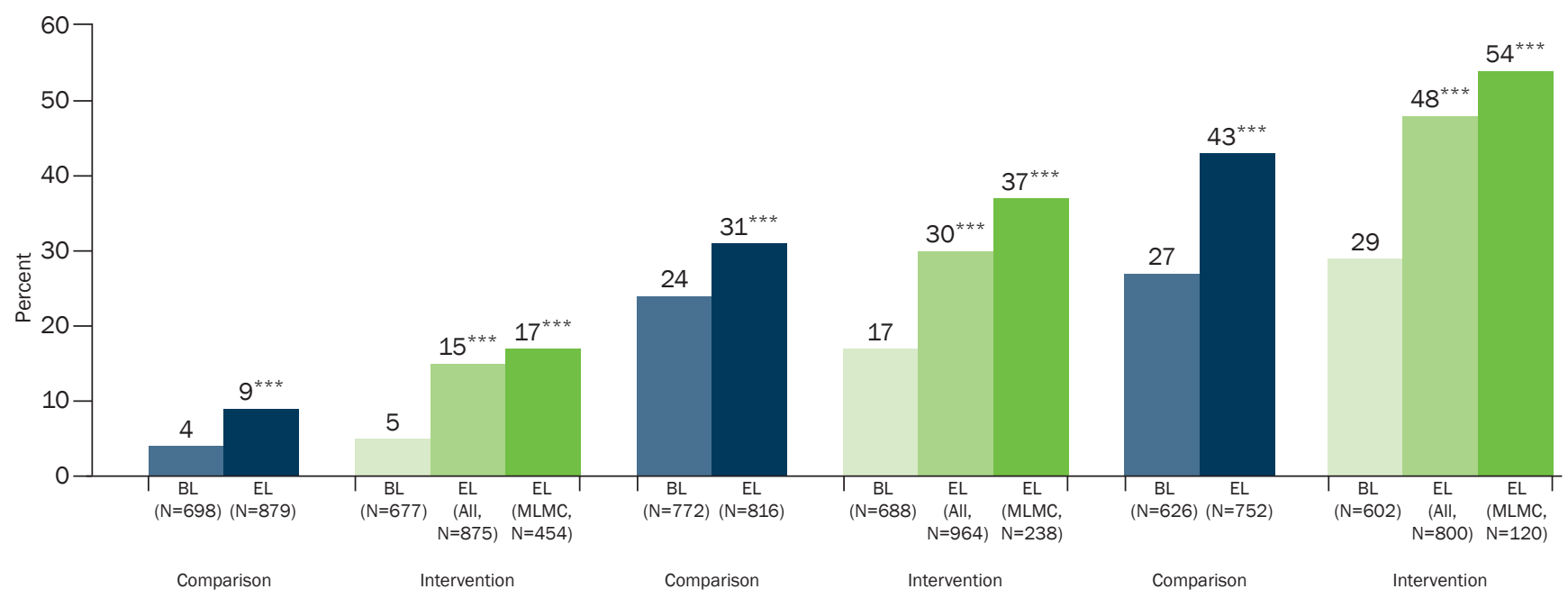

Note: All percentages shown in the figure are weighted; ${ }^{* *}$ indicates that the difference between baseline and endline is significant at $p \leq 0.001$; $B L=$ Baseline; $E L=E n d l i n e ; E L A l l=A l l$ respondents irrespective of their participation in $M L M C$ project; $E L M L M C=$ Respondents who had participated in MLMC project.

The regression results show a positive effect of exposure to the MLMC project on enabling adolescent girls to have a savings account and operate it on their own in the full sample analyses as well as in the restricted anlyses. Unmarried and married girls were more likely than girls in the comparison arm to have a savings account and operated it on their own (OR 1.9-2.3 for unmarried girls and 1.5-2.3 for married girls; Table 4.4). However, no such effect was observed among unmarried brothers and husbands.

Figure 4.18 shows the percentage of study participants who had visited a bank in the six months prior to the interview at baseline and endline. Findings show that a larger proportion of the endline cohort of unmarried girls in the intervention arm had visited a bank in the six months preceding the interview (24-33\%) than those in the intervention arm at baseline (11\%) and in the comparison arm at baseline and endline (10-15\%). Among married girls too, those in the intervention arm, particularly the MLMC participants, were more likely than others to have visited a bank (31-45\% vs. $20 \%$ in the intervention arm at baseline and in the comparison arm at baseline and endline (18-36\%). Findings also show that while the proportion of unmarried brothers and husbands who had 
Figure 4.18: Percentage of unmarried and married adolescent girls and their unmarried brothers and husbands who had visited a bank in the six months prior to the interview by treatment arms, baseline and endline surveys

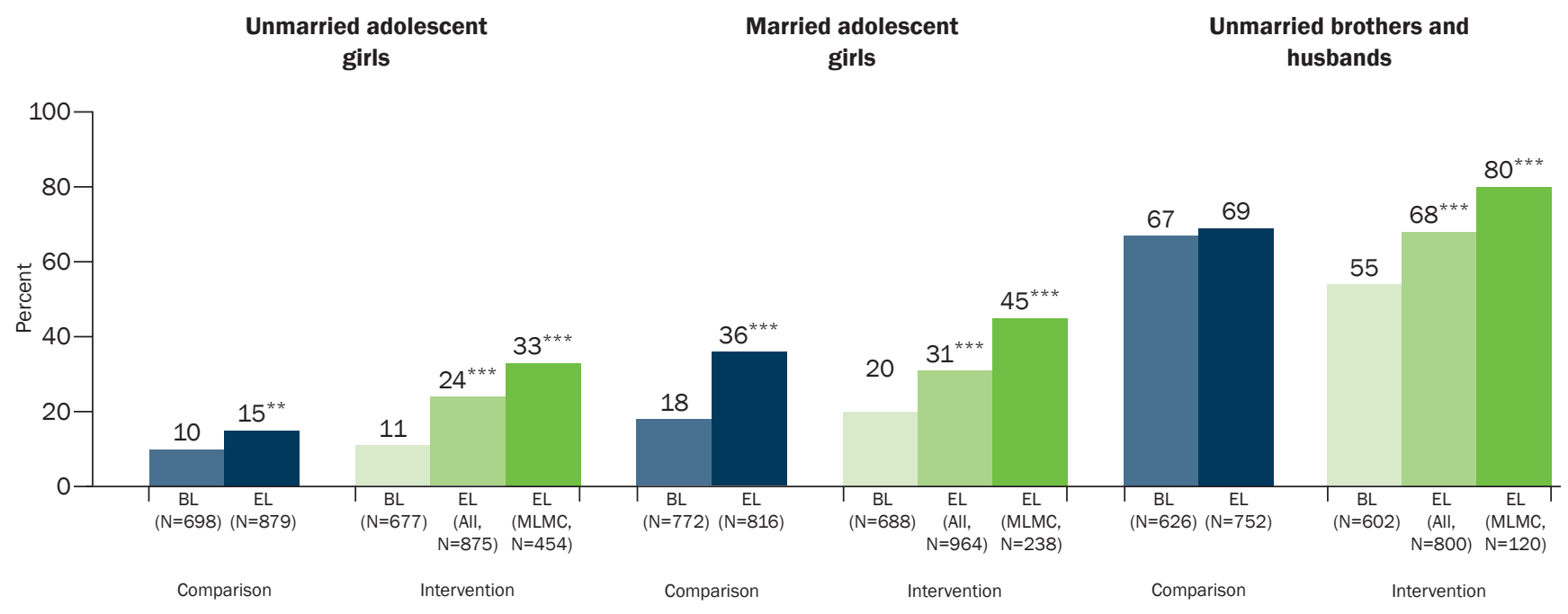

Note: All percentages shown in the figure are weighted; ${ }^{* *}$ and ${ }^{* *}$ indicate that the difference between baseline and endline is significant at $p \leq 0.01, p \leq 0.001$, respectively; $B L=$ Baseline; $E L=$ Endline; $E L A l l=A l l$ respondents irrespective of their participation in $M L M C$ project; $E L$ $M L M C=$ Respondents who had participated in MLMC project.

visited a bank in the six months preceding the interview increased by 13-25 percentage points between the two assessments in the intervention arm (55\% to 68-80\%), it remained unchanged during the same period in the comparison arm (67-69\%).

The regression results suggest that the MLMC project provided a greater opportunity for unmarried adolescent girls and unmarried brothers and husbands to visit a bank in the six months prior to the interview (Table 4.4). Unmarried girls in the intervention arm were 1.7 (for the full sample) to 2.6 (for the MLMC participant sample) times more likely than girls in the comparison arm to have visited a bank in the six months preceding the interview after controlling for potentially confounding factors and time. Among married girls, a negative net effect was observed in the full sample analyses; however, this effect became insignificant when we restricted the analyses to the MLMC participant sample. As with unmarried girls, unmarried brothers and husbands were 1.7 (for the full sample) to 2.8 (for the MLMC participant sample) times more likely than those in the comparison arm to have visited a bank in the six months prior to the interview.

Finally, the proportion of study participants who expressed a savings goal are depicted in Figure 4.19. They suggest that the endline cohorts of study participants were more likely to have a savings goal than their corresponding baseline cohorts in the intervention and comparison arms. The proportion of unmarried girls who expressed a goal to save money for future needs increased by 13-14 percentage points in the intervention arm (from 16\% to 29-30\%), compared to a seven percentage point increase in the comparison arm (from $15 \%$ to $22 \%$ ) between the baseline and endline assessments. Similarly, it increased by 14-16 percentage points among married girls in the intervention arm (from $24 \%$ to $38-40 \%$ ) compared to seven percentage points in the comparison arm (from $27 \%$ to $34 \%$ ) during the same period. Among unmarried brothers and husbands, it increased by 5-10 percentage points in the intervention arm (from $28 \%$ to $33-38 \%$ ) and by nine percentage points in the comparison arm (from $18 \%$ to $27 \%$ ) during the same period.

The regression results indicate, at best, a modest positive effect of the MLMC project in enabling unmarried and married adolescent girls to develop a savings goal (Table 4.4). Unmarried girls in the intervention arm were 1.4 times more likely than girls in the comparison arm to express a savings goal in the full sample analyses; however, we note that this effect was not strong statistically. Although no such effect was observed among married girls in the full sample analyses, married girls who were MLMC participants were 1.5 times more likely than girls in the comparison arm to express a savings goal; again, this effect was not strong statistically. Finally, no effect was observed among unmarried brothers and husbands in the full sample or restricted sample analyses. 
Figure 4.19: Percentage of unmarried and married adolescent girls and their unmarried brothers and husbands who expressed a savings goal by treatment arms, baseline and endline surveys

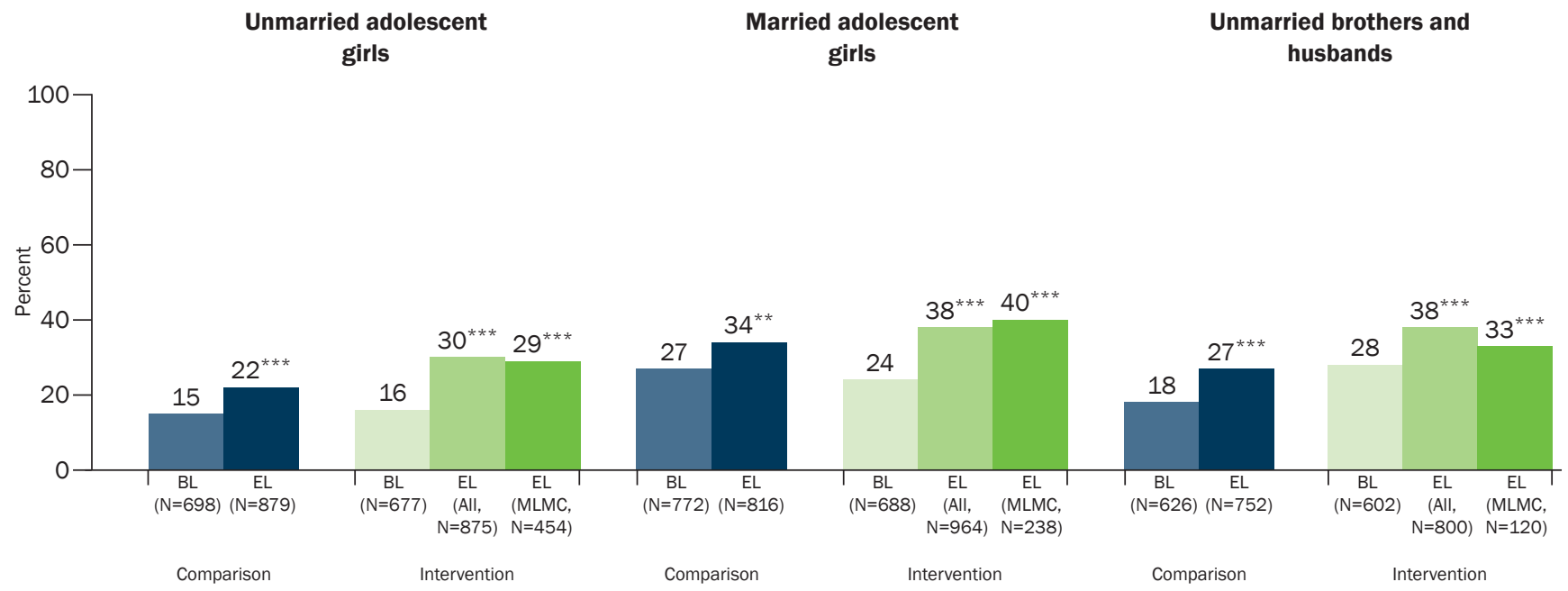

Note: All percentages shown in the figure are weighted; ${ }^{* *}$ and ${ }^{* * *}$ indicate that the difference between baseline and endline is significant at $p \leq 0.01, p \leq 0.001$, respectively; $B L=$ Baseline; $E L=E n d l i n e ; E L A l l=A l l$ respondents irrespective of their participation in $M L M C$ project; $E L$ $M L M C=$ Respondents who had participated in MLMC project.

Findings confirm the limited opportunities for acquiring vocational skills training in the study settings (Figure 4.20). Specifically, the percentage of unmarried girls who had participated in any vocational skills training programme increased by 9-21 percentage points in the intervention arm (from 16\% to 25-37\%), compared to no change in the comparison arm (7-8\% at baseline and endline). Among married girls, while no difference was observed in the full sample analyses, the MLMC participants were more likely than others to have attended a vocational skills training programme (21\% vs. 4-10\%). A similar pattern was observed among unmarried brothers and husbands: the MLMC participants were more likely than others to have attended a vocational skills training programme (20\% vs. 4-12\%).

The regression results indicate a mostly positive picture of the effect of the MLMC project in enabling study participants to attend a vocational skills training programme (Table 4.4). Specifically, although no effect of the project was observed in the full sample analyses, unmarried girls who were MLMC participants were 2.5 times more likely

Figure 4.20: Percentage of unmarried and married adolescent girls and their unmarried brothers and husbands who had participated in vocational skills training programmes by treatment arms, baseline and endline surveys

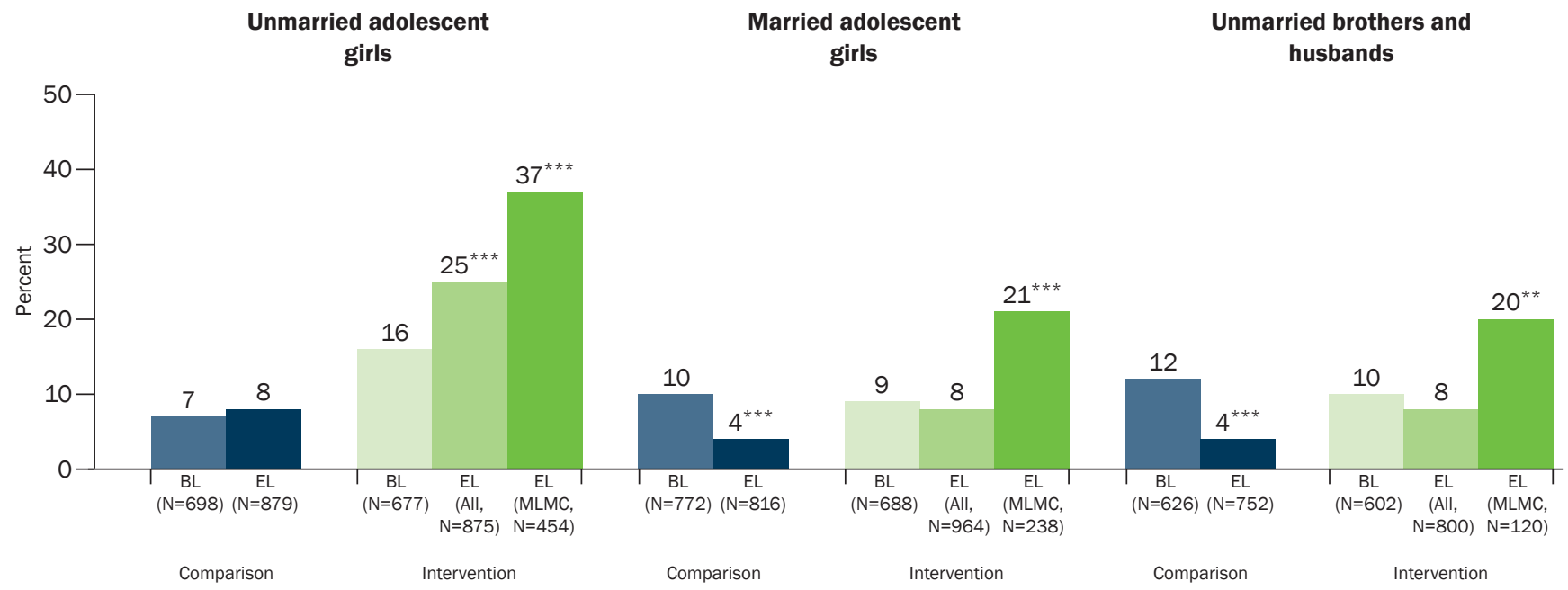

Note: All percentages shown in the figure are weighted; ${ }^{* *}$ and ${ }^{* *}$ indicate that the difference between baseline and endline is significant at $p \leq 0.01, p \leq 0.001$, respectively; $B L=$ Baseline; $E L=E n d l i n e ; E L A l l=A l l$ respondents irrespective of their participation in $M L M C$ project; $E L$ $M L M C=$ Respondents who had participated in MLMC project. 
than girls in the comparison arm to have attended a vocational skills training programme in the six months prior to the interview. Among married girls, those in the intervention arm were more likely than those in the comparison arm to have attended a course (OR 2.76 for the full sample; 8.54 for the MLMC sample). Finally, among unmarried brothers and husbands, those in the intervention arm were more likely than others to have attended a course (OR 2.76 for the full sample; 7.74 for the MLMC sample).

We note that the findings presented in this section on the effect of the MLMC project on study participants' financial literacy and related practices, including attending vocational skills training programmes, concur with study participants' perceptions of changes experienced in the six months prior to the interview (see Table 8.1).

\section{Effect on access to social spaces to network with peers among adolescent girls and their unmarried brothers and husbands}

Evaluation results show that the MLMC project contributed considerably to improving access to social spaces for unmarried girls, and moderately for married girls, and their unmarried brothers and husbands (Figure 4.21). For example, findings show that unmarried adolescent girls in the intervention arm were more likely to have reported going to social spaces such as clubs, parks or gardens at endline (25-35\%) than those in the intervention arm at baseline (10\%) and in the comparison arm at baseline and endline (5-10\%). In other words, a 15-25 percentage point difference was observed among unmarried adolescent girls in the intervention arm between baseline and endline assessments (from 10\% to 25-35\%) compared to a five percentage point decline in the comparison arm (from $10 \%$ to $5 \%$ ). Among married girls, those who reported access to social spaces increased by 6-24 percentage points in the intervention arm (from 5\% to 11-29\%), while it declined by four percentage points in the comparison arm (from 7\% to 3\%). Among unmarried brothers and husbands, the difference between the two assessments was in the range of 22-26 percentage points in the intervention arm (from 25\% to 47-61\%) and 18 percentage points in the comparison arm (from $22 \%$ to $40 \%$ ).

Figure 4.21: Percentage of unmarried and married adolescent girls and their unmarried brothers and husbands who reported access to social spaces to network with peers by treatment arms, baseline and endline surveys

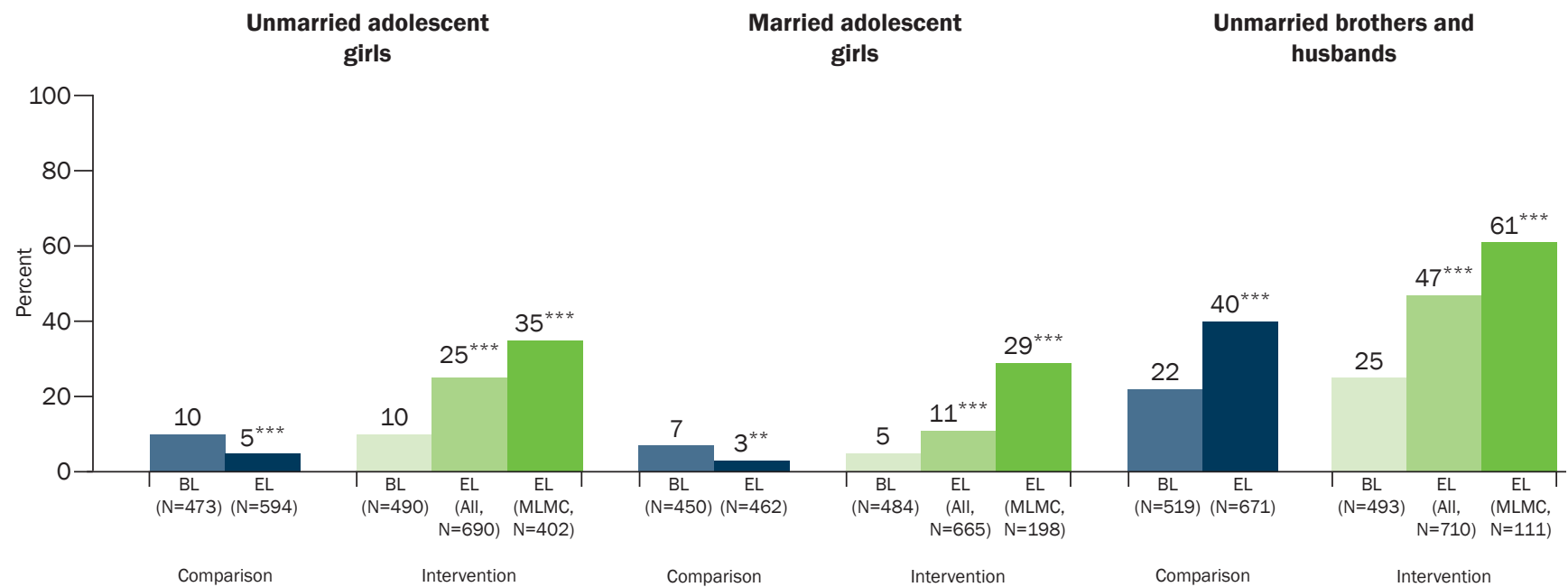

Note: All percentages shown in the figure are weighted; ${ }^{* *}$ and ${ }^{* *}$ indicate that the difference between baseline and endline is significant at $p \leq 0.01, p \leq 0.001$, respectively; $B L=$ Baseline; $E L=E n d l i n e ; E L A l l=A l l$ respondents irrespective of their participation in $M L M C$ project; $E L$ $M L M C=$ Respondents who had participated in MLMC project.

The regression result indicates that the MLMC project had a positive net effect in facilitating access to social spaces for adolescent girls and their unmarried brothers and husbands after controlling for potentially confounding factors and time (Table 4.5). Specifically, unmarried and married girls were more likely than girls in the comparison arm to report access to social spaces to network with their peers (OR 6.9 for the full sample in the case of unmarried girls; 5.0 for the full sample in the case of married girls). Among unmarried brothers and husbands, although no effect was evident in the full sample analyses, a positive net effect was observed when we restricted the analyses to the MLMC participants (OR 2.2). 
Table 4.5: Effect of exposure to the MLMC project in facilitating access to social space for unmarried and married adolescent girls and their unmarried brothers and husbands to network with their peers: Summary of regression results

\begin{tabular}{|c|c|c|c|c|c|c|}
\hline \multirow[t]{2}{*}{ Indicators } & \multicolumn{2}{|c|}{$\begin{array}{l}\text { Unmarried adolescent } \\
\text { girls }\end{array}$} & \multicolumn{2}{|c|}{$\begin{array}{c}\text { Married adolescent } \\
\text { girls }\end{array}$} & \multicolumn{2}{|c|}{$\begin{array}{l}\text { Unmarried brothers\& } \\
\text { husbands }\end{array}$} \\
\hline & $\begin{array}{c}\text { All } \\
(N=2,247)\end{array}$ & $\begin{array}{c}\text { MLMC } \\
(\mathrm{N}=1,959)\end{array}$ & $\begin{array}{c}\text { All } \\
(\mathrm{N}=2,061)\end{array}$ & $\begin{array}{c}\text { MLMC } \\
(\mathrm{N}=1,594)\end{array}$ & $\begin{array}{c}\text { All } \\
(\mathrm{N}=2,393)\end{array}$ & $\begin{array}{c}\text { MLMC } \\
(\mathrm{N}=1,794)\end{array}$ \\
\hline $\begin{array}{l}\text { Reported access to social spaces } \\
\text { to network with peers }{ }^{\#}\end{array}$ & $6.94^{* * *}$ & $12.00^{* * *}$ & $4.98^{* * *}$ & $15.59^{* * *}$ & 1.24 & $2.21^{* *}$ \\
\hline
\end{tabular}

Note: ${ }^{* *}$ and ${ }^{* * *}$ indicate that the net effect of exposure to the intervention is significant at $p \leq 0.01, p \leq 0.001$, respectively; ${ }^{*}$ Refers to odds ratio from logistic regression.

\section{Summary}

The evaluation shows a number of strong, positive effect of the MLMC project in enhancing protective assets of adolescent girls and their unmarried brothers and husbands that can reduce their vulnerability to HIV. Positive changes were observed in almost all areas that the project focused on.

First, the project contributed to enabling unmarried and married adolescent girls to network with their peers and make new friends. However, findings show no effect of the project in increasing adolescent girls' access to non familial trusted mentors to discuss their personal problems. Moreover, no positive effect of the project was observed on peer networks and interactions among unmarried brothers and husbands of adolescent girls.

Second, the project contributed to improving unmarried and married girls' agency as measured by their self-efficacy, decision making autonomy, and freedom of movement. The project, again, had little effect on improving unmarried brothers' and husbands' agency, except in improving their decision making autonomy. Third, gender role attitudes became more egalitarian among unmarried girls following the implementation of the project. However, no such effect was observed among married girls and unmarried brothers and husbands of adolescent girls.

Fourth, awareness of sexual and reproductive matters among unmarried and married girls and their unmarried brothers and husbands improved substantially with the implementation of the MLMC project. Of particular note was the improvement in awareness of HIV/AIDS.

Fifth, the project had mostly positive effect on improving financial literacy and related practices among adolescent girls and their unmarried brothers and husbands. Financial literacy improved among unmarried and married girls as well as their unmarried brothers and husbands. Additionally, the project contributed to enabling unmarried and married girls to own a savings account and operate it on their own, although no such effect was observed among unmarried brothers and husbands. The project provided unmarried girls and unmarried brothers and husbands an opportunity to visit a bank in the recent past, although no such effect was observed among married girls. Despite these positive effect, the project did not change savings habits, as measured by having some savings or expressing a savings goal.

Sixth, the project succeeded in enabling unmarried and married girls as well as their unmarried brothers and husbands to participate in vocational skills training programmes.

Seventh, the project had a positive effect in improving unmarried and married girls' as well as their unmarried brothers' and husbands' access to social spaces to interact with their peers.

Findings also highlight that the positive effect of the MLMC project was observed most often among unmarried girls and least among their unmarried brothers and husbands. This is not surprising because the reach of the intervention was highest among unmarried girls. The findings also underscore that positive effect of the project were observed more often-and of course more strongly-among MLMC participants than among all adolescent girls and their unmarried brothers and husbands in the intervention villages, particularly among married girls and unmarried brothers and husbands. 


\section{Chapter 5}

\section{Effect of the intervention on sexual risk- taking and health-seeking behaviours and practices of adolescent girls and their unmarried brothers and husbands}

In this chapter, we present evidence on the effect of MLMC on sexual risk-taking behaviours and their treatmentseeking practices for sexual and reproductive health problems among adolescent girls and their unmarried brothers and husbands.

\section{Effect on sexual experiences before and outside marriage among adolescent girls and their unmarried brothers and husbands}

The MLMC project sought to promote safe sex practices among adolescent girls and their unmarried brothers and husbands. In order to assess the extent to which it had succeeded in doing so, we asked unmarried adolescent girls and their unmarried brothers about their sexual experiences in the six months prior to the interview, and married girls and their husbands about their experiences of extra marital sex during the same period. Data on prevalence and characteristics of such experiences, including the number of sexual partners, condom use at last sex and consistent condom use at baseline and endline are presented in this section. We also present findings on the effect of the MLMC project on condom use within marriage.

\section{Prevalence of sexual experiences}

Findings related to sexual experiences among adolescent girls and their unmarried brothers and husbands in the six months prior to the interview at baseline and endline are summarised in Figure 5.1. Findings indicate that while the proportion of unmarried girls who reported sexual experiences remained the same in the period between the

Figure 5.1: Percentage of unmarried and married adolescent girls and their unmarried brothers and husbands who reported sexual experiences ${ }^{0}$ in the six months prior to the interview by treatment arms, baseline and endline surveys

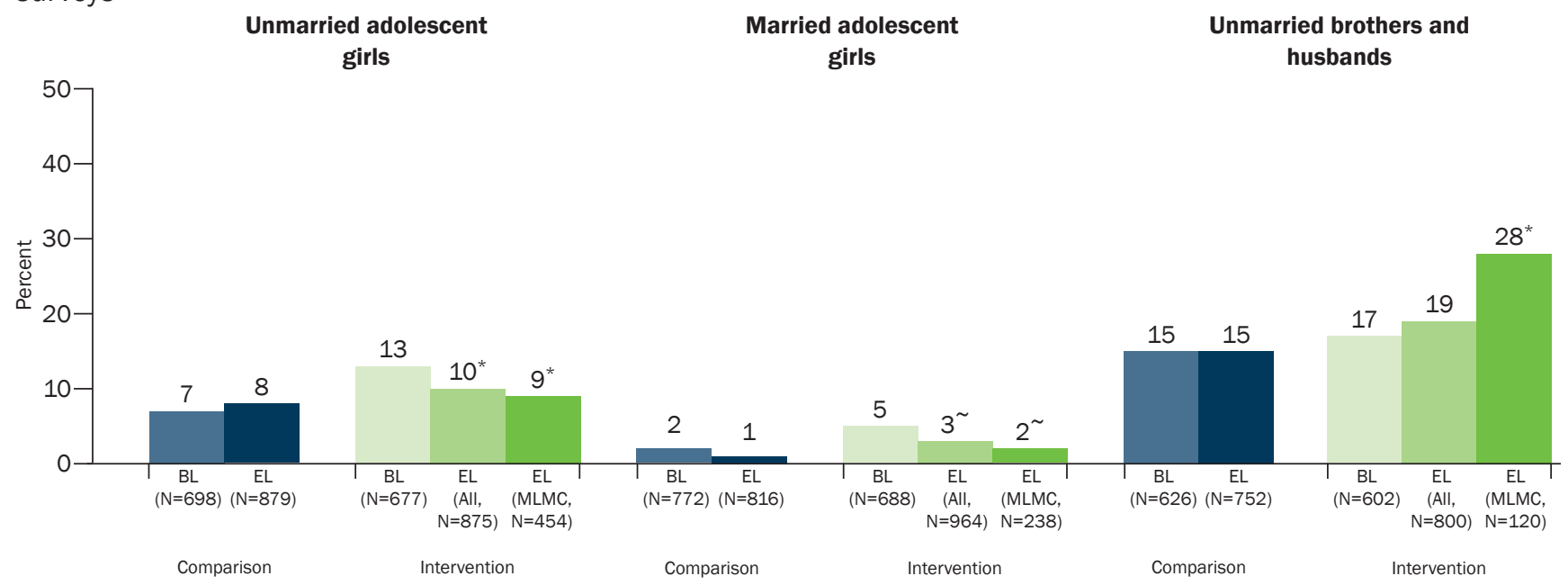

Note: All percentages shown in the figure are weighted; ${ }^{0}$ Refers to extra marital sexual relationships for the married; ${ }^{*}$ and ${ }^{*}$ indicate that the difference between baseline and endline is significant at $p \leq 0.10, p \leq 0.05$, respectively; $B L=B a s e l i n e ; E L=E n d l i n e ; E L A l l=A l l$ respondents irrespective of their participation in MLMC project; EL MLMC=Respondents who had participated in MLMC project. 
Table 5.1: Effect of exposure to the MLMC project on sexual risk-taking practices among unmarried and married adolescent girls and their unmarried brothers and husbands: Summary of regression results

\begin{tabular}{|c|c|c|c|c|c|c|}
\hline \multirow[t]{2}{*}{ Indicators } & \multicolumn{2}{|c|}{$\begin{array}{l}\text { Unmarried adolescent } \\
\text { girls }\end{array}$} & \multicolumn{2}{|c|}{$\begin{array}{l}\text { Married adolescent } \\
\text { girls }\end{array}$} & \multicolumn{2}{|c|}{$\begin{array}{c}\text { Unmarried brothers \& } \\
\text { husbands }\end{array}$} \\
\hline & All & MLIMC & All & MLMC & All & MLMC \\
\hline $\begin{array}{l}\text { Engaged in sexual relationships }{ }^{1} \\
\text { in the six months prior to the } \\
\text { interview }{ }^{\#}\end{array}$ & $0.64^{\sim}$ & $0.59^{\sim}$ & 1.19 & 0.85 & $1.55^{*}$ & $2.17^{\star *}$ \\
\hline Number of respondents & 3,129 & 2,708 & 3,240 & 2,514 & 2,780 & 2,100 \\
\hline $\begin{array}{l}\text { Reported two or more sexual } \\
\text { partners in the six months } \\
\text { preceding the interview }{ }^{2 \#}\end{array}$ & 0.89 & 0.00 & & & $0.14^{* * *}$ & $0.26^{*}$ \\
\hline $\begin{array}{l}\text { Used condom at last sex in the six } \\
\text { months preceding the interview }\end{array}$ & 1.10 & 2.10 & & & $2.36^{\sim}$ & $4.80^{* *}$ \\
\hline $\begin{array}{l}\text { Used condom consistently in the six } \\
\text { months preceding the interview }{ }^{1 \#}\end{array}$ & 1.17 & 2.11 & & & 1.98 & $3.86^{*}$ \\
\hline $\begin{array}{l}\text { Number of respondents who had } \\
\text { engaged in sexual relationships } \\
\text { in the six months prior to the } \\
\text { interview }\end{array}$ & 375 & 329 & & & 338 & 235 \\
\hline $\begin{array}{l}\text { Used condom at last sex within } \\
\text { marriage in the six months } \\
\text { preceding the interview } \#\end{array}$ & & & 1.00 & $2.04^{*}$ & 1.38 & 2.89 \\
\hline $\begin{array}{l}\text { Used condom consistently within } \\
\text { marriage in the six months } \\
\text { preceding the interview } \#\end{array}$ & & & $8.25^{\sim}$ & $26.30^{* *}$ & 0.88 & 1.66 \\
\hline Number of respondents & & & 3,173 & 2,456 & 1,968 & 1,475 \\
\hline Intends to use condom in future & $1.79^{* *}$ & $3.06^{* * *}$ & $0.77^{\sim}$ & 1.13 & $0.93^{\sim}$ & 1.29 \\
\hline Number of respondents & 3,129 & 2,708 & 3,240 & 2,514 & 2,780 & 2,100 \\
\hline
\end{tabular}

Note: $\sim$, *, and **indicate that the net effect of exposure to the intervention is significant at $p \leq 0.10, p \leq 0.05, p \leq 0.01$, respectively; ${ }^{1}$ Refers to extra marital sexual relationships for the married; ${ }^{2}$ The percentage who reported two or more sexual partners were not shown for married girls and their husbands because all those who reported extra marital sexual experience in the six months preceding the interview also reported sex with their spouse and therefore, all had two or more partners; "Refers to odds ratio from logistic regression.

baseline and endline assessments in the comparison arm (7\% and 8\%, respectively), it declined slightly in the intervention arm (from 13\% to 9-10\%). A similar pattern was evident with regard to the proportion of married girls who reported extra marital sexual experiences in the six months prior to the interview. However, a different pattern was observed among unmarried brothers and husbands; a larger proportion of the endline cohort of unmarried brothers and husbands in the intervention arm reported having engaged in sex (for the married, extra marital sexual experiences; 19-28\%) compared to their counterparts in the intervention arm at baseline (17\%) and in the comparison arm at baseline and endline (15\%).

The regression results on the net effect of exposure to the MLMC project on sexual risk-taking practices among adolescent girls and their unmarried brothers and husbands are summarised in Table 5.1. They suggest that the project had a mild, positive effect in promoting sexual abstinence among unmarried girls. Unmarried girls in the intervention arm were less likely than those in the comparison arm to report that they had engaged in sexual relationships in the six months prior to the interview (OR 0.64 for the full sample and 0.59 for the MLMC participant sample). However, no such effect was observed among married girls who reported having engaged in extra marital sexual relationships in the six months preceding the interview. Findings also show that unmarried brothers and husbands in the intervention arm were more likely than those in the comparison arm to report sexual experiences (for husbands, extra marital sexual experiences) in the six months prior to the interview (OR 1.6 for the full sample and 2.2 for the MLMC participant sample). 


\section{Multiple partnerships}

We present data on multiple partnerships in the six months preceding the interview reported by sexually experienced unmarried girls and their unmarried brothers in Figure 5.2. ${ }^{3}$ We note that the number of study participants who reported sexual experiences in the last six months was small and therefore, findings presented in this section should be interpreted with caution.

Although not statistically significant, a smaller proportion of sexually experienced unmarried girls and their unmarried brothers reported multiple partnerships at the endline than at baseline in the intervention arm (8\% vs. 0-3\% among sexually experienced unmarried girls; $55 \%$ vs. $41 \%$ among sexually experienced unmarried brothers). In the comparison arm, while no such difference was observed among sexually experienced unmarried girls, a larger proportion of sexually experienced unmarried brothers reported multiple partnerships at endline than baseline (31\% vs. 23\%).

The regression results, presented in Table 5.1, indicate that while the MLMC project had no effect on reducing multiple partnerships among sexually experienced unmarried girls, it had a positive net effect among sexually experienced unmarried brothers. Sexually experienced unmarried brothers in the intervention arm were less likely than those in the comparison arm to report multiple partnerships in the six months prior to the interview in the full sample and the restricted sample analyses (OR 0.14 and 0.26 , respectively).

Figure 5.2: Percentage of sexually experienced unmarried adolescent girls and their unmarried brothers who reported multiple sexual partnerships in the six months prior to the interview by treatment arms, baseline and endline surveys

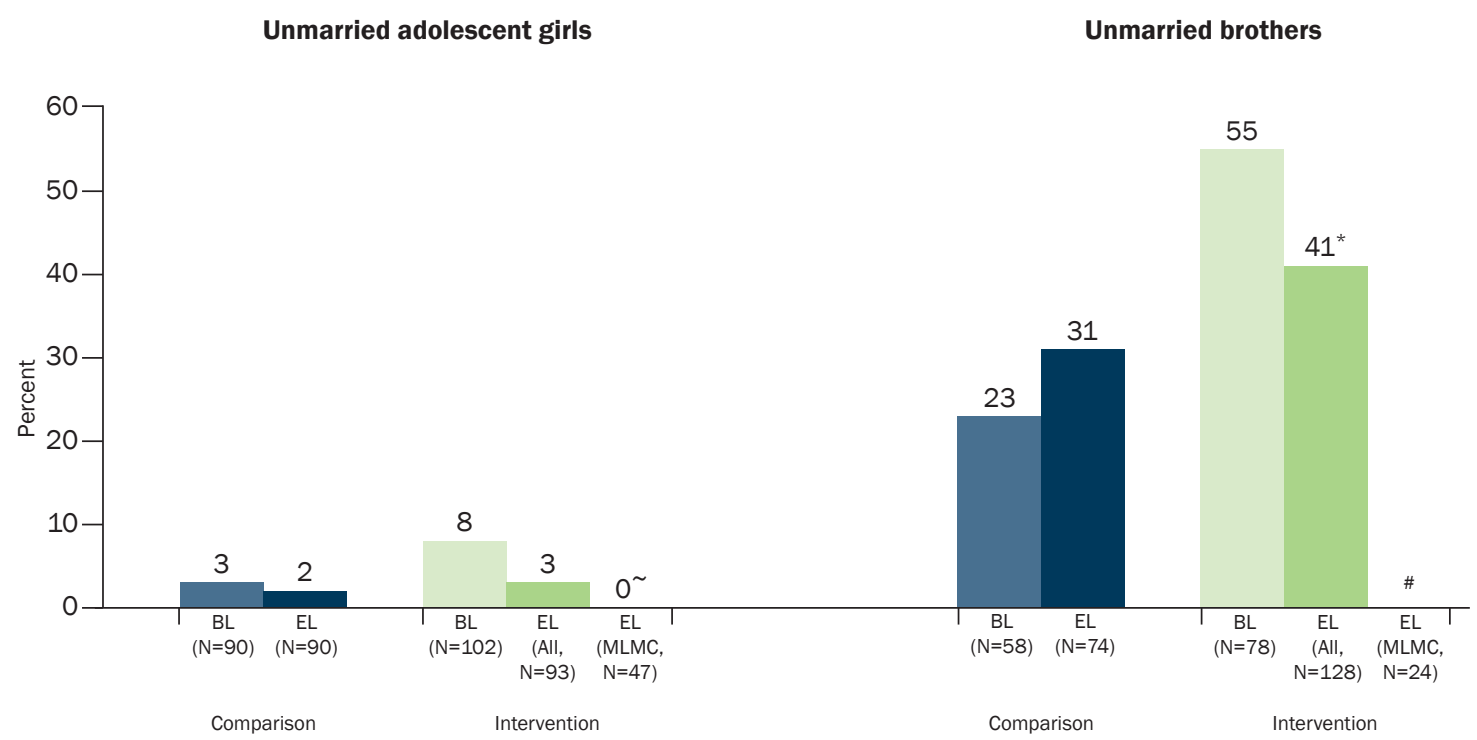

Note: All percentages shown in the figure are weighted; and *indicate that the difference between baseline and endline is significant at $p \leq 0.10, p \leq 0.05$, respectively; $B L=$ Baseline; $E L=E n d l i n e ; E L$ All $=A l l$ respondents irrespective of their participation in $M L M C$ project; $E L$ $M L M C=$ Respondents who had participated in MLMC project; "Based on fewer than 25 unweighted cases and therefore, percentage not shown.

\section{Condom use}

Findings related to condom use within and outside marriage are depicted in Figures 5.3-5.5. Findings show that the percentage of sexually experienced unmarried girls who reported that their partner had used a condom at last sex was roughly similar at baseline and endline in the intervention and comparison arms (Figure 5.3). However, although not statistically significant, MLMC participant girls in the intervention arm were more likely than others to report condom use at last sex (37\% vs. $24-31 \%)$. Among unmarried brothers and husbands, those in the intervention arm were more likely to report condom use at last sex at endline than at baseline (33\% vs. $22 \%$ ), while a reverse

\footnotetext{
${ }^{3}$ All the married girls and their husbands who reported extra marital sexual experiences in the six months prior to the interview reported sex with their spouse as well, implying multiple partnerships.
} 
Figure 5.3: Percentage of sexually experienced unmarried adolescent girls, and their unmarried brothers and husbands who reported condom use at last sex in the six months prior to the interview by treatment arms, baseline and endline surveys

Unmarried adolescent girls

Unmarried brothers and husbands

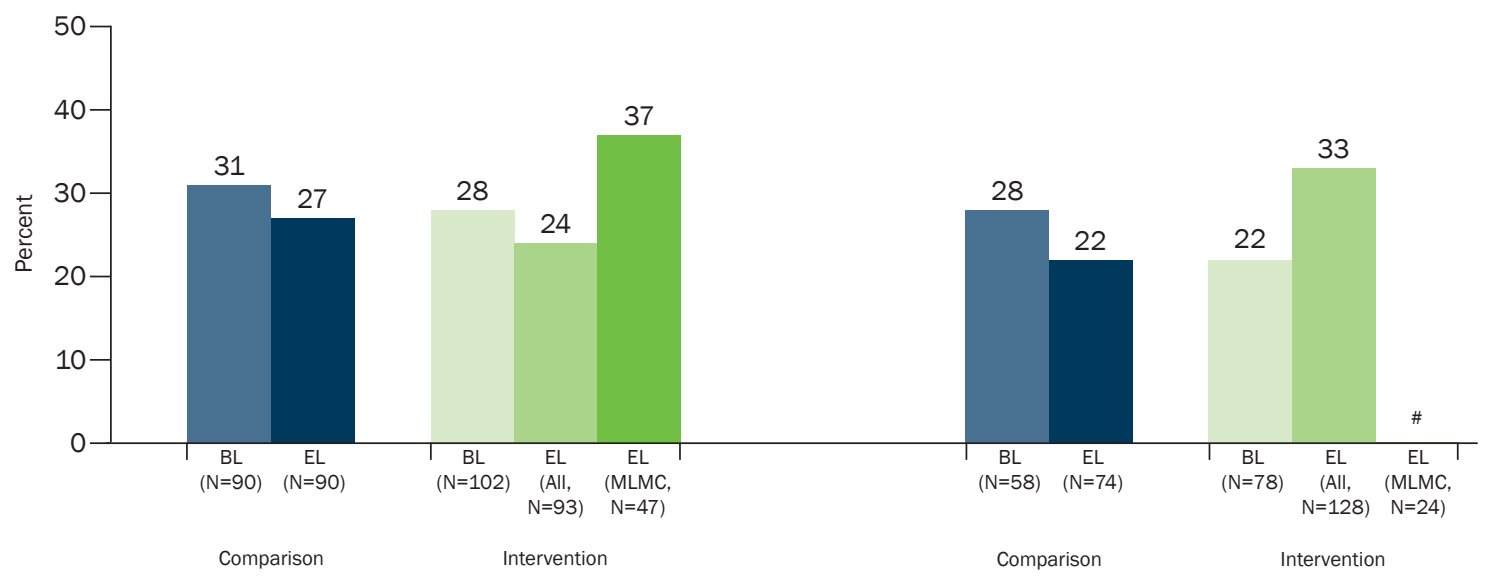

Note: All percentages shown in the figure are weighted; $B L=$ Baseline; $E L=E n d l i n e ; E L A l l=A l l$ respondents irrespective of their participation in MLMC project; EL MLMC=Respondents who had participated in MLMC project; "Based on fewer than 25 unweighted cases and therefore, percentage not shown.

pattern was observed in the comparison arm ( $22 \%$ vs. $28 \%$ ). In other words, an 11 percentage point increase was observed in the intervention arm between baseline and endline assessments, while a 6 percentage point decline was observed in the comparison arm during the same period.

The regression results show that the project had a positive effect in promoting condom use at last sex among unmarried brothers and husbands who were engaged in sexual relationships (for husbands, extra marital relationship) in the full sample and the restricted sample analyses (Table 5.1). Unmarried brothers and husbands who were engaged in sexual relationships in the intervention arm were 2.4 times more likely than those in the comparison arm to report condom use at last sex, although the effect was statistically mildly significant in the full sample analyses. In the restricted analyses, unmarried brothers and husbands who had participated in MLMC project activities were almost five times more likely to report condom use at last sex within the six months prior to the interview, compared to those in the comparison arm. However, no such effect was evident when we examined responses of unmarried girls.

Data on consistent condom use among study participants who were engaged in sexual experiences in the six months preceding the interview (for husbands, extra marital sexual experiences) are summarised in Figure 5.4. Findings show a modest decline in consistent condom use reported by sexually experienced unmarried girls in the intervention and comparison arms between the baseline and endline assessments. A different pattern was observed among unmarried brothers and husbands. As lightly larger proportion of the endline cohort of sexually experienced unmarried brothers and husbands in the intervention arm reported consistent condom use than their baseline counterparts ( $21 \%$ vs. $16 \%$ ). In the comparison arm, as with condom use at last sex, consistent condom use declined by five percentage points (from 18\% to 13\%) between the baseline and endline assessments.

The regression results indicate no effect of the MLMC project on consistent condom use among sexually experienced unmarried girls and unmarried brothers and husbands in the full sample analyses (Table 5.1). However, in the restricted analyses, unmarried brothers and husbands who had participated in the MLMC activities were almost four times more likely than those in the comparison arm to report consistent condom use.

Findings related to condom use (i.e., at last sex and consistent use) within marriage are depicted in Figure 5.5a and Figure 5.5b. They suggest that condom use continued to be limited in the intervention and comparison arms between the baseline and endline assessments-5-16 percent of married girls and their husbands reported condom use at last sex and 0-4 percent reported consistent condom use. At the same time, findings suggest that married girls who had participated in the MLMC activities were more likely than others to report condom use at last sex within 
Figure 5.4: Percentage of sexually experienced unmarried adolescent girls, and unmarried brothers and husbands who reported consistent condom use at last sex in the six months prior to the interview by treatment arms, baseline and endline surveys

Unmarried adolescent girls

Unmarried brothers and husbands

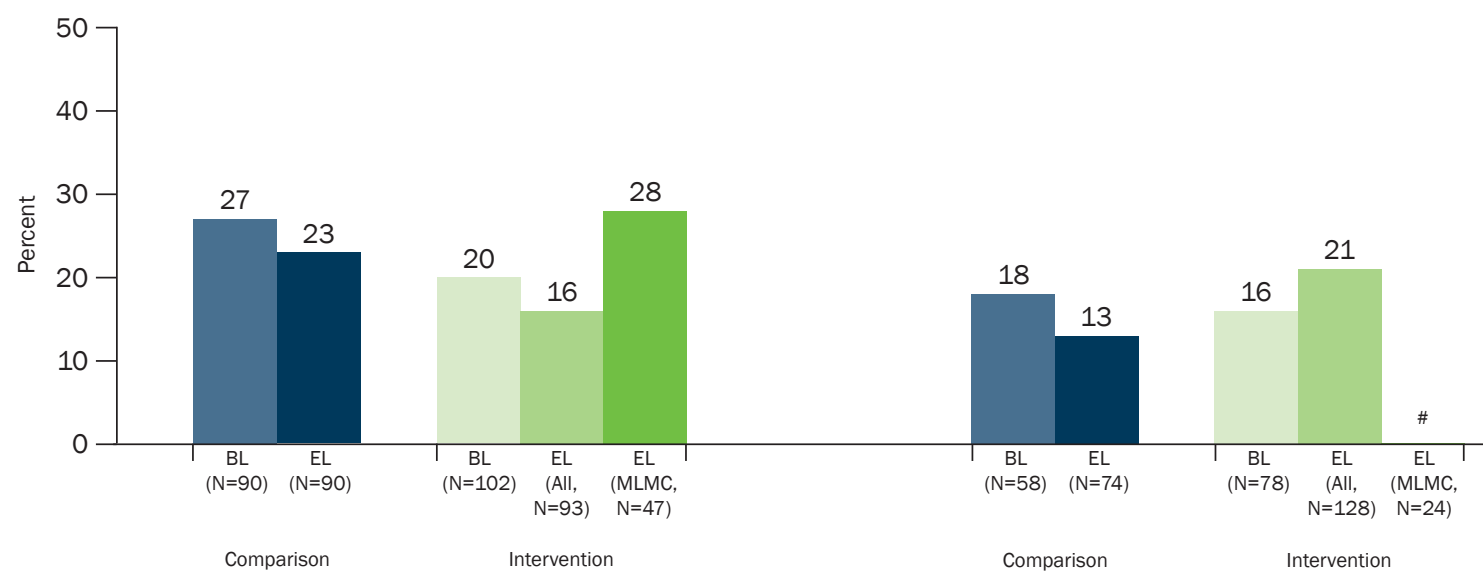

Note: All percentages shown in the figure are weighted; $B L=$ Baseline; $E L=E n d l i n e ; E L ~ A l l=A l l$ respondents irrespective of their participation in MLMC project; EL MLMC=Respondents who had participated in MLMC project; \#Based on fewer than 25 unweighted cases and therefore, percentage not shown.

Figure 5.5a: Percentage of married adolescent girls and their husbands who reported condom use at last sex within marriage in the six months prior to the interview by treatment arms, baseline and endline surveys

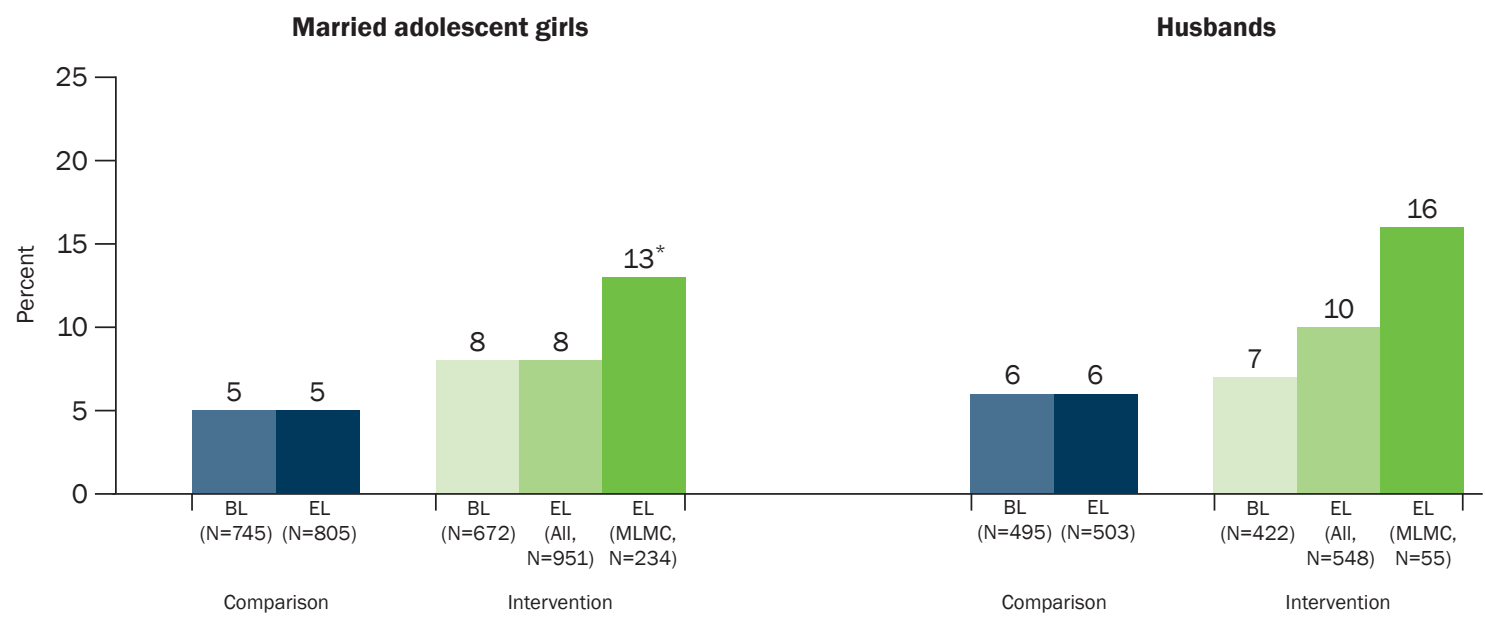

Note: All percentages shown in the figure are weighted; ${ }^{*}$ indicates that the difference between baseline and endline is significant at $p \leq 0.05$; $B L=$ Baseline; $E L=E n d l i n e ; E L A l l=A l l$ respondents irrespective of their participation in $M L M C$ project; $E L M L M C=$ Respondents who had participated in $M L M C$ project.

marriage (13\% vs. $5-8 \%)$, but no such difference was observed with respect to consistent condom use. A modest difference between baseline and endline assessments was observed in husbands' reports of condom use at last sex but not in consistent condom use within marriage in the intervention arm, while no such difference was observed in the comparison arm. However, we caution that the number of husbands who had participated in the MLMC activities was small and therefore, these findings need to be interpreted with caution.

The regression results indicate that although no effect of the project on condom use at last sex within marriage was observed in the full sample analyses, a statistically mild, positive effect was observed in the restricted analyses (Table 5.1). Married girls who were MLMC participants were twice as likely as married girls in the comparison arm to report condom use at last sex within marriage. A positive net effect on consistent condom use was found in both the 
Figure 5.5b: Percentage of married adolescent girls and their husbands who reported consistent condom use within marriage in the six months prior to the interview by treatment arms, baseline and endline surveys

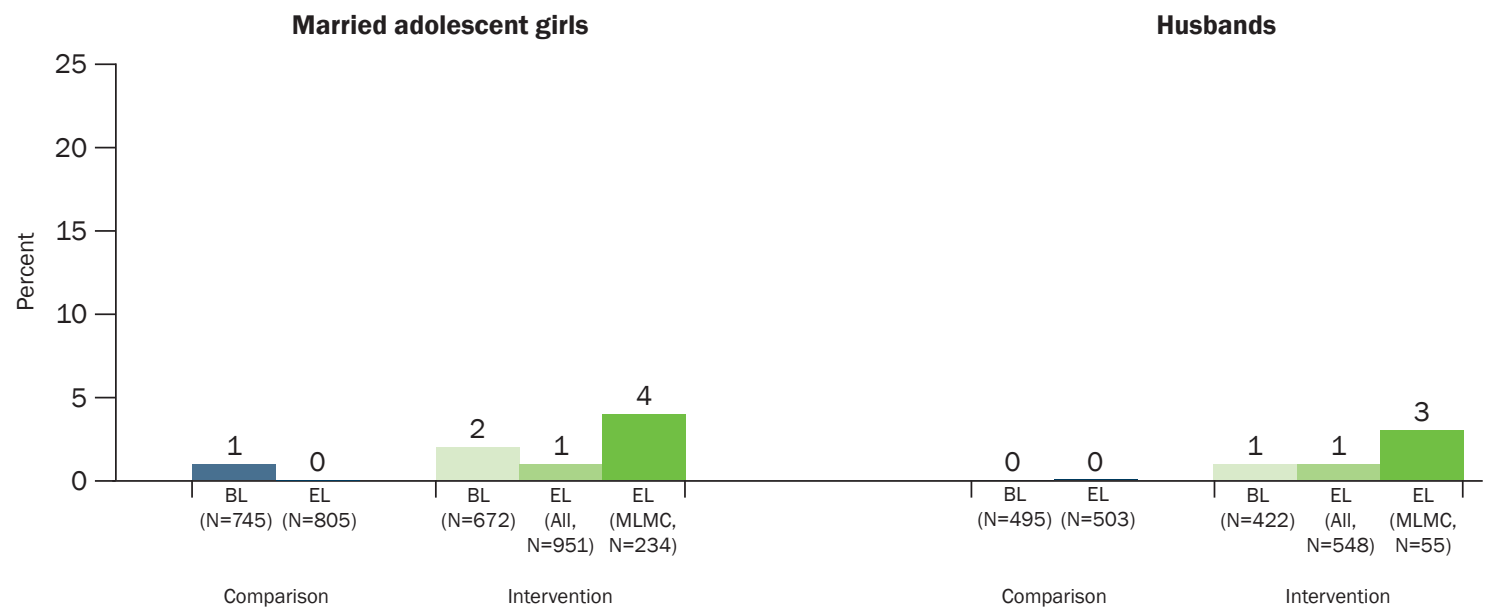

Note: All percentages shown in the figure are weighted; $B L=$ Baseline; $E L=E n d l i n e ; E L A l l=A l l$ respondents irrespective of their participation in $M L M C$ project; EL MLMC=Respondents who had participated in MLMC project.

full sample and restricted sample analyses; however, given that only a negligible minority of married girls had used condoms consistently within marriage, the findings need to be interpreted with caution. Among husbands, no effect of exposure to the project on condom use at last sex and consistent condom use within marriage was evident in the regression analyses.

The intentions to use condoms in the future changed modestly in the intervention and comparison arms across all three groups between the baseline and endline assessments (Figure 5.6). Even so, MLMC participants were somewhat more likely than others to report intentions to use condoms ( $41 \%$ vs. $9-31 \%$ among unmarried girls; $61 \%$ vs. $44-54 \%$ among married girls; and $77 \%$ vs. $61-71 \%$ among unmarried brothers and husbands).

Figure 5.6: Percentage of unmarried and married adolescent girls and their unmarried brothers and husbands who reported intentions to use condom in the future by treatment arms, baseline and endline surveys

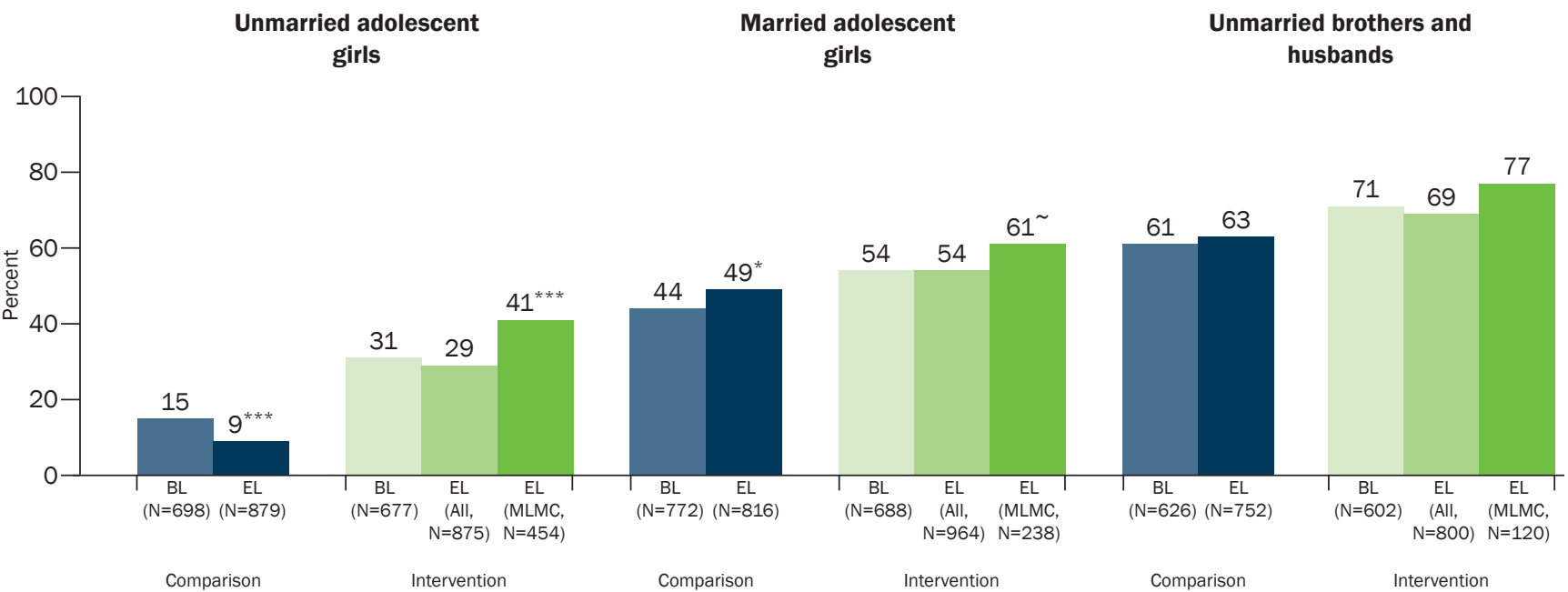

Note: All percentages shown in the figure are weighted; , * and ${ }^{* *}$ indicate that the difference between baseline and endline is significant at $p \leq 0.10, p \leq 0.05, p \leq 0.001$, respectively; $B L=$ Baseline; $E L=E n d l i n e ; E L A l l=A l l$ respondents irrespective of their participation in $M L M C$ project; $E L$ $M L M C=$ Respondents who had participated in MLMC project. 
The regression results reiterate that the MLMC project had a positive net effect among unmarried girls. Unmarried girls in the intervention arm were 1.8 (for the full sample) to 3.1 (for the restricted sample) times more likely than those in the comparison arm to report intentions to use condoms in the future (Table 5.1). However, no such effect was observed among married girls and unmarried brothers and husbands; indeed, a statistically mild, negative effect was observed in these two groups.

We note that the findings presented in this section on the effect of the MLMC project on study participants' sexual risk-taking behaviours and practices concur with study participants' perceptions of changes experienced in the six months prior to the interview (see Table 8.1).

\section{Effect on health-seeking practices among adolescent girls and their unmarried brothers and husbands}

One of the key objectives of the MLMC project was to enhance the utilization of sexual and reproductive health services by adolescent girls and their unmarried brothers and husbands. To explore the extent to which the project had succeeded in doing so, we asked study participants about whether they had undergone any HIV testing, whether they experienced symptoms of genital infections such as genital ulcers, itching in the genital area, swelling in the groin, burning sensation while passing urine, and genital discharge, and whether they sought treatment for these problems, if any. We also probed girls additionally about their menstrual hygiene practices. The changes in these practices following the implementation of the MLMC project are described in the sub-sections below.

\section{HIV testing}

Evaluation results show an increase in the utilisation of HIV testing facilities among unmarried and married girls and unmarried brothers and husbands (Figure 5.7). For example, findings show that as many as 19 percent of all unmarried girls and 40 percent of MLMC participant girls in the intervention arm reported having undergone HIV testing at endline, compared to almost none at baseline and none both at baseline and endline in the comparison arm. Fewer girls, however, knew their HIV test result; for example at endline, 10-21 percent of unmarried girls, i.e., half of the girls who had undergone an HIV test in the intervention arm, knew their test result (not shown in the table or figure).

Figure 5.7: Percentage of unmarried and married adolescent girls and their unmarried brothers and husbands who had had an HIV test by treatment arms, baseline and endline surveys

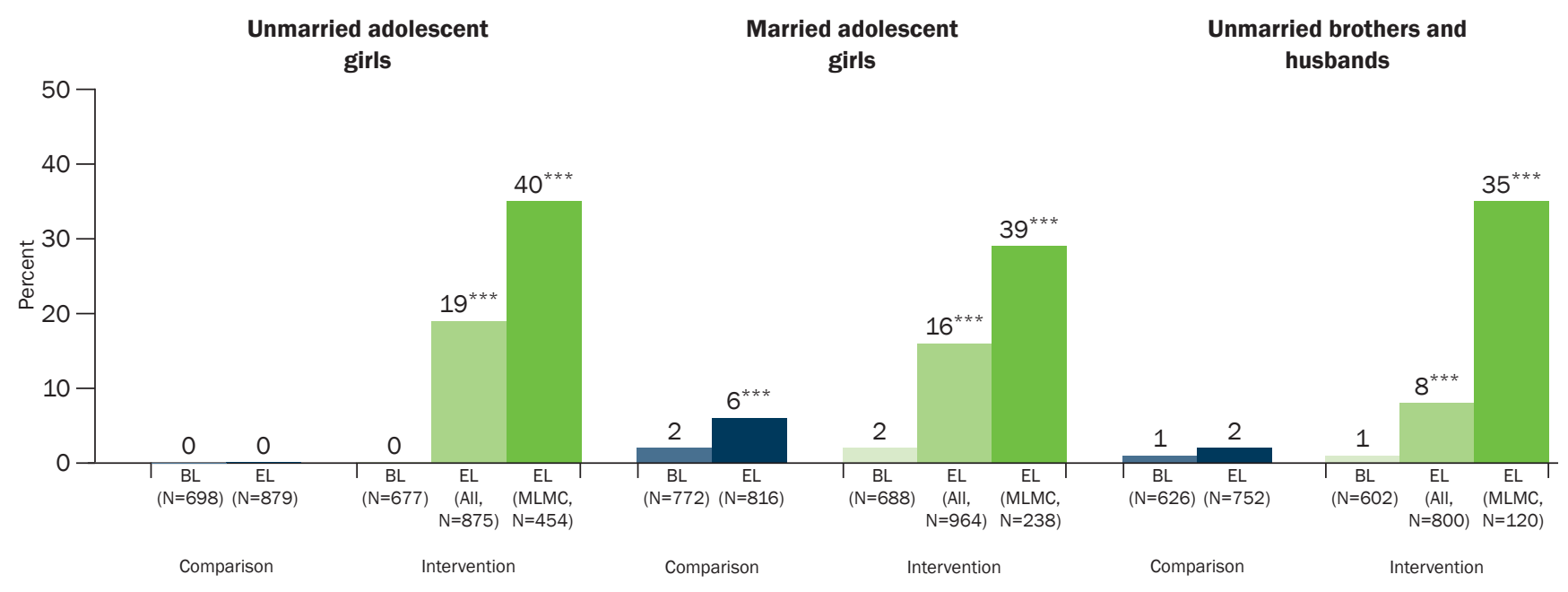

Note: All percentages shown in the figure are weighted; ${ }^{* *}{ }^{*}$ indicates that the difference between baseline and endline is significant at $p \leq 0.001$; $B L=$ Baseline; $E L=E n d l i n e ; ~ E L A l l=A l l$ respondents irrespective of their participation in $M L M C$ project; $E L M L M C=$ Respondents who had participated in MLMC project. 
Among married girls, those who had had an HIV test increased by 14 percentage points among all girls and by 37 percentage points among MLMC participant girls in the intervention arm (from $2 \%$ to $16-39 \%$ ), compared to four percentage points in the comparison arm (from $2 \%$ to $6 \%$; Figure 5.7). As with unmarried girls, fewer knew their HIV test result-11-21 percent of girls in the intervention arm at endline which translates into 54-65 percent of girls who had undergone an HIV test and six percent of girls in the comparison arm, i.e., 90 percent of all those who had undergone the test received their test result (not shown in the table or figure).

Among unmarried brothers and husbands, the difference between the two assessments was in the range of seven percentage points among all survey participants and 34 percentage points among MLMC participants in the intervention arm (from 1\% to $8-35 \%$ ) and one percentage point in the comparison arm (from $1 \%$ to $2 \%$ ). About 80 percent of those in the intervention arm and everyone in the comparison arm who reported having undergone an HIV test at endline knew their HIV test result (not shown in the table or figure).

\section{Experience of symptoms of reproductive tract infections and related treatment-seeking}

Findings, summarised in Figure 5.8, show that a sizeable number of adolescent girls and their unmarried brothers and husbands had experienced symptoms suggestive of reproductive tract infections in the three months preceding the baseline and endline interviews. In the intervention and comparison arms, fewer respondents reported such experiences at endline than at baseline across all categories of adolescents. At baseline, 18-22 percent of unmarried girls had experienced symptoms suggestive of reproductive tract infections, 9-14 percent so reported by the time of the endline. Likewise among married girls, while 32-37 percent reported an infection symptom at baseline, this dropped to 19-21 percent at endline. It also declined from 24-28 percent at baseline to 18-23 percent at endline among unmarried brothers and husbands.

Figure 5.8: Percentage of unmarried and married adolescent girls and their unmarried brothers and husbands who had experienced symptoms suggestive of reproductive tract infections in the three months prior to the interview by treatment arms, baseline and endline surveys

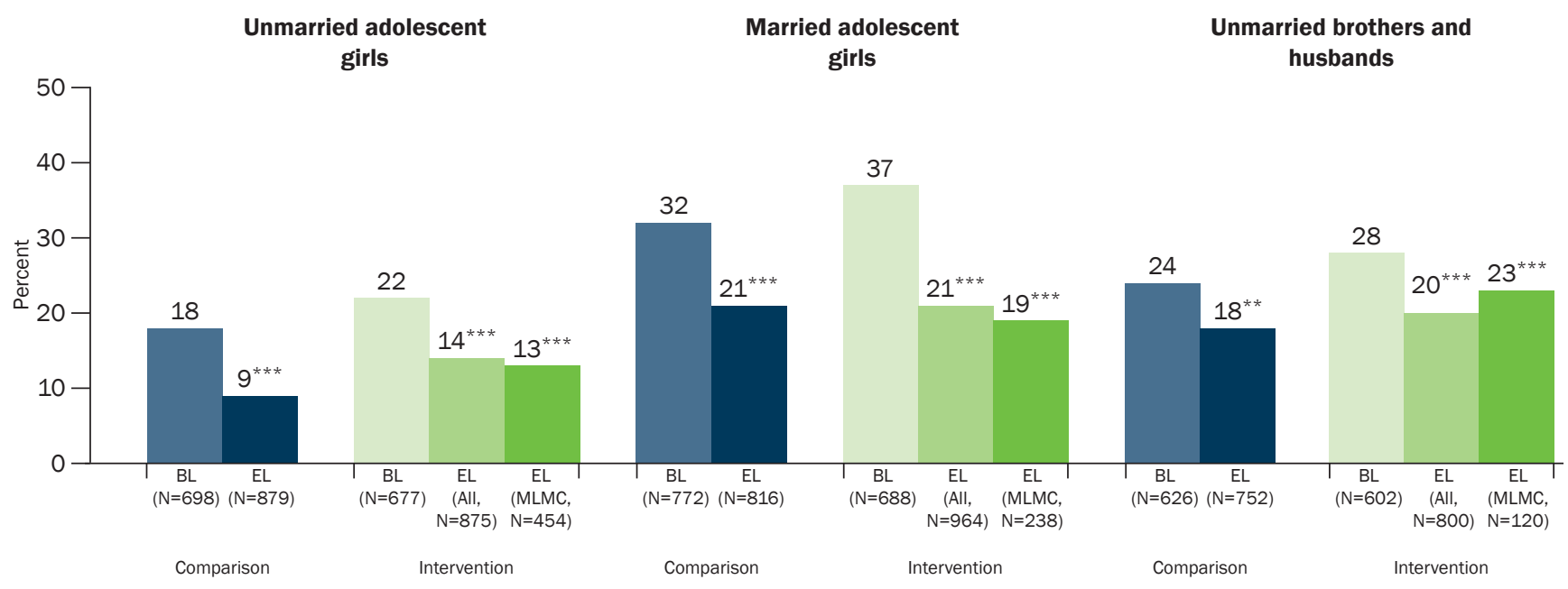

Note: All percentages shown in the figure are weighted; ${ }^{* *}$ and ${ }^{* * *}$ indicate that the difference between baseline and endline is significant at $p \leq 0.01, p \leq 0.001$, respectively; $B L=$ Baseline; $E L=$ Endline; $E L A l l=A l l$ respondents irrespective of their participation in $M L M C$ project; $E L$ $M L M C=$ Respondents who had participated in MLMC project.

Although numbers are small, findings also suggest some improvement in treatment-seeking among unmarried adolescent girls who had experienced symptoms of reproductive tract infections; however, no such difference was observed among married girls. For example, findings show that unmarried adolescent girls in the intervention arm were more likely to have sought treatment at endline (43-48\%) than those in the intervention arm at baseline (20\%) and in the comparison arm at baseline and endline (25-26\%). In other words, a 23-28 percentage point difference was observed among unmarried adolescent girls in the intervention arm between baseline and endline assessments (from $20 \%$ to $43-48 \%$ ) compared to no difference in the comparison arm (from $26 \%$ to $25 \%$ ). Among married girls, no difference between baseline and endline assessments was observed in the intervention and comparison arms 
in the full sample analyses. A different pattern was observed among unmarried brothers and husbands. While treatment-seeking for infections remained almost unchanged in the intervention arm (57\% vs. 56-60\%), it improved in the comparison arm (50\% to 66\%) between the baseline and endline assessments.

The regression results suggest a positive net effect of the MLMC project on unmarried adolescent girls' treatmentseeking practices. After controlling for potentially confounding factors and time, unmarried girls who experienced symptoms suggestive of reproductive tract infections were more than two times more likely than those in the comparison arm to have sought treatment from a healthcare provider (OR 2.6; Table 5.2). No such effect was observed among married girls. Surprisingly among unmarried brothers and husbands, a statistically weak, negative effect of the project was observed.

Table 5.2: Effect of exposure to the MLMC project on health-seeking practices: Summary of regression results

\begin{tabular}{|c|c|c|c|c|c|c|}
\hline \multirow[t]{2}{*}{ Indicators } & \multicolumn{2}{|c|}{$\begin{array}{l}\text { Unmarried adolescent } \\
\text { girls }\end{array}$} & \multicolumn{2}{|c|}{$\begin{array}{c}\text { Married adolescent } \\
\text { girls }\end{array}$} & \multicolumn{2}{|c|}{$\begin{array}{c}\text { Unmarried brothers \& } \\
\text { husbands }\end{array}$} \\
\hline & All & MLMC & All & MLMC & All & MLMC \\
\hline $\begin{array}{l}\text { Of those who had experienced symptoms of } \\
\text { reproductive tract infections, sought treatment } \\
\text { from a health care provider\# }\end{array}$ & $2.56^{*}$ & $2.60^{\sim}$ & 0.77 & 0.82 & $0.54^{\sim}$ & $0.42^{\sim}$ \\
\hline $\begin{array}{l}\text { Number of respondents who had experienced } \\
\text { symptoms of reproductive tract infections in } \\
\text { three months prior to the interview }\end{array}$ & 533 & 477 & 902 & 751 & 578 & 445 \\
\hline $\begin{array}{l}\text { Used sanitary napkins and changed the } \\
\text { napkins regularly\# }\end{array}$ & $2.06^{*}$ & $2.31^{*}$ & $1.57^{\sim}$ & 1.57 & & \\
\hline $\begin{array}{l}\text { Number of respondents who had begun } \\
\text { menstruating at the time of the interview }\end{array}$ & 3,090 & 2,675 & 3,239 & 2,513 & & \\
\hline
\end{tabular}

Note: and *indicate that the net effect of exposure to the intervention is significant at $p \leq 0.10, p \leq 0.05$, receptively; ${ }^{*}$ Refers to odds ratio from logistic regression.

Figure 5.9: Percentage of unmarried and married adolescent girls and their unmarried brothers and husbands who sought treatment for symptoms suggestive of reproductive tract infections experienced by treatment arms, baseline and endline surveys

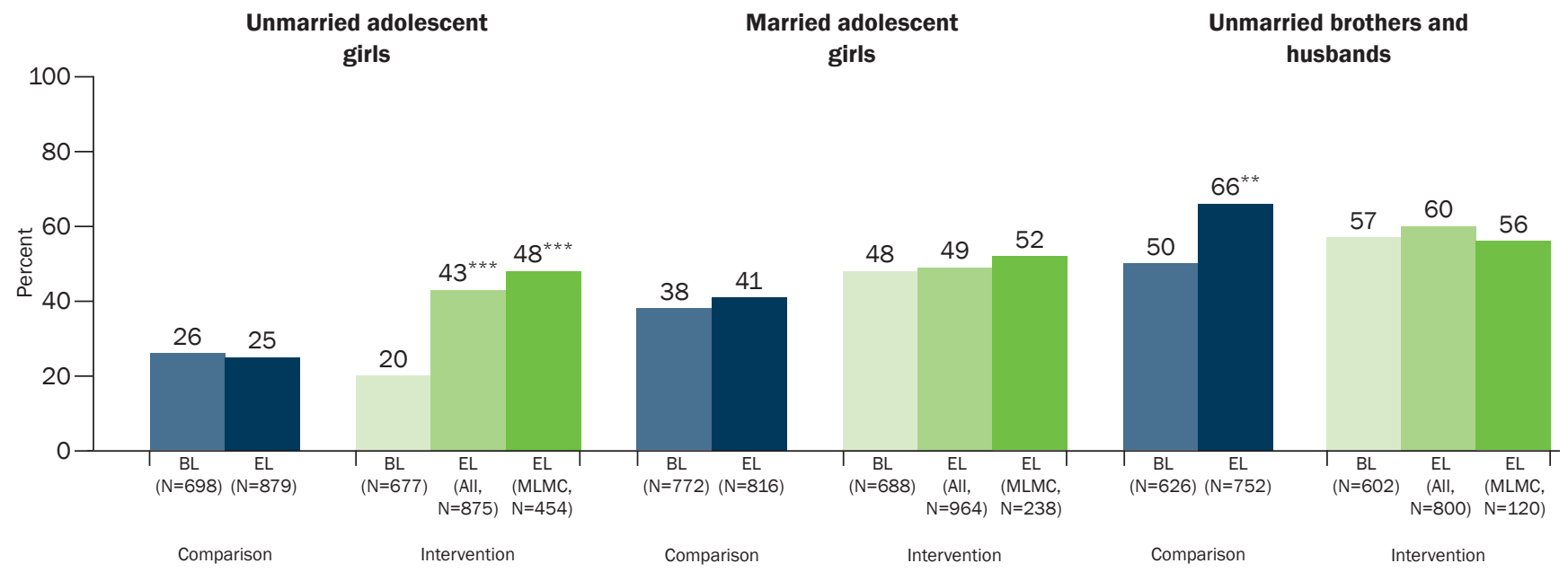

Note: All percentages shown in the figure are weighted; ${ }^{* *}$ and ${ }^{* *}$ indicate that the difference between baseline and endline is significant at $p \leq 0.01, p \leq 0.001$, respectively; $B L=$ Baseline; $E L=E n d l i n e ; E L A l l=A l l$ respondents irrespective of their participation in $M L M C$ project; $E L$ $M L M C=$ Respondents who had participated in MLMC project.

\section{Menstrual hygiene practices}

As mentioned in Chapter 2, we asked adolescent girls about their menstrual hygiene practices to capture the effect of the intervention more generally on girls' health-seeking practices. The evaluation data suggest a moderate effect of exposure to the intervention on unmarried girls' menstrual hygiene practices, but no such effect was observed 
Figure 5.10: Percentage of unmarried and married adolescent girls who reported using disposable sanitary napkins during menstruation and changing them regularly by treatment arms, baseline and endline surveys

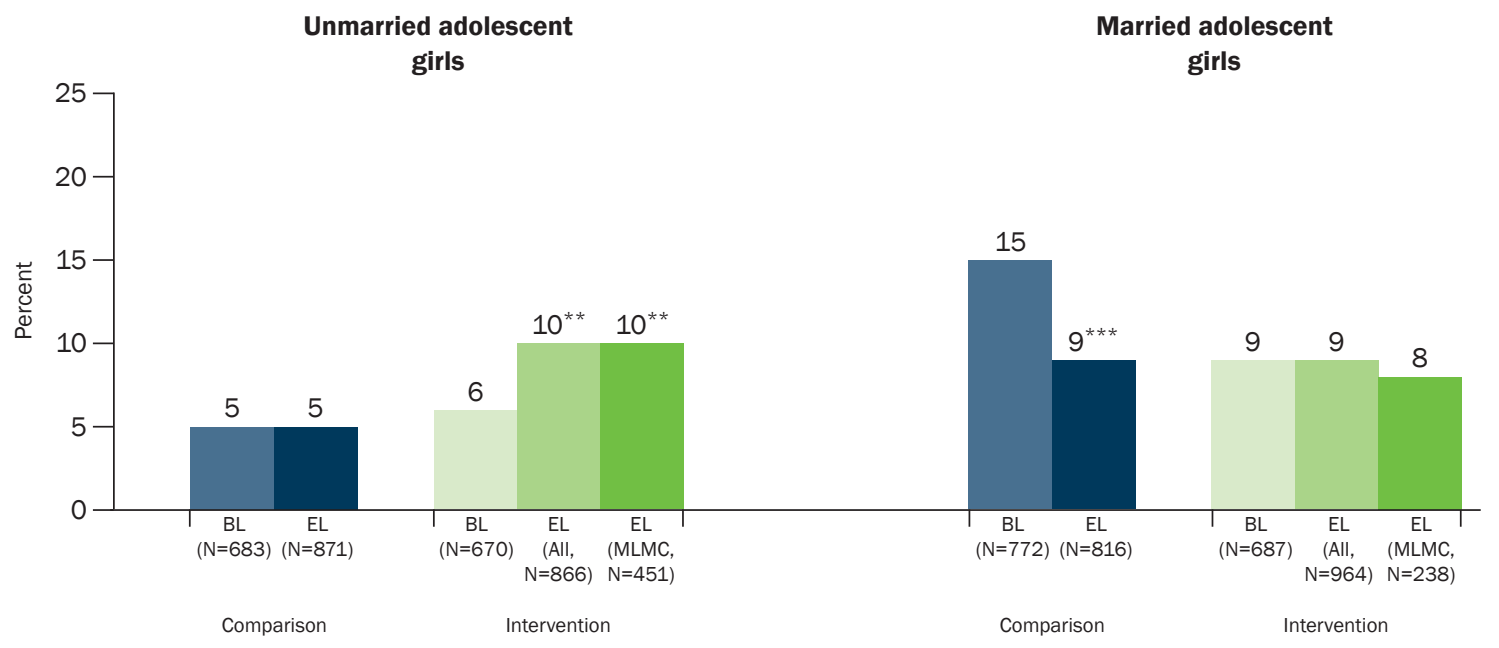

Note: All percentages shown in the figure are weighted; ${ }^{* *}$ and ${ }^{* *}$ indicate that the difference between baseline and endline is significant at $p \leq 0.01, p \leq 0.001$, respectively; $B L=$ Baseline; $E L=E n d l i n e ; E L A l l=A l l$ respondents irrespective of their participation in $M L M C$ project; $E L$ $M L M C=$ Respondents who had participated in MLMC project.

among married girls. For example, unmarried girls of the endline cohort in the intervention arm (10\%) were more likely than their counterparts in the intervention arm at baseline (6\%) and in the comparison arm at baseline and endline (5\%) to report that they used disposable sanitary napkins to absorb menstrual blood and changed the napkins regularly. The regression results show the independent positive effect of the MLMC project on menstrual hygiene practice among unmarried girls, with those in the intervention arm two times more likely than others to report using and regularly changing disposable sanitary napkins (OR 2.1 for the full sample and 2.3 for the MLMC participant sample; Table 5.2). Among married girls, a different pattern was observed: while the proportion of those who used sanitary napkins and changed the napkins regularly remained similar between baseline and endline assessments in the intervention arm (7-9\%), it declined in the comparison arm (15\% to 9\%). Although the regression results indicated a statistically weak, positive net effect of the MLMC project on married girls' menstrual hygiene practices in the full sample analyses, we note that we could not attribute this change to the MLMC project because menstrual hygiene practices remained unchanged in the intervention arm while it declined in the comparison arm.

We note that the findings presented in this section on the effect of the MLMC project on study participants' healthseeking practices concur with unmarried girls' perceptions of changes experienced in the six months prior to the interview, but not so in the case of married girls and unmarried brothers and husbands (see Table 8.1). While a significantly greater proportion of married girls and unmarried brothers and husbands in the intervention than control arms reported being confident in seeking health services, this perception was not reflected in the actual healthseeking practices they reported.

\section{Summary}

The evaluation shows, for the most part, positive effect of the MLMC project in reducing sexual risk-taking practices. First, it contributed to moderately promoting sexual abstinence among unmarried girls, but no such effect was observed with respect to engaging in extra marital relationships among married girls. At the same time, unmarried brothers and husbands in the intervention arm were more likely than others to report sexual experiences (extra marital sexual experiences for husbands). Second, the project resulted in reducing multiple partnerships among sexually experienced unmarried brothers; however, no such effect was observed among sexually experienced unmarried girls. Third, the project had a positive net effect in promoting condom use at last sex and consistent condom use within sexual relationships outside marriage among unmarried brothers and husbands who participated in the MLMC activities. We note that the number of MLMC participants who were engaged in sexual relationships outside marriage was small, and therefore these findings are indicative rather than conclusive. No such effect 
was observed among sexually experienced unmarried girls. Fourth, the project had a positive, but statistically mild effect on promoting condom use within marriage as reported by married girls. Finally, the project was successful in increasing intentions to use condoms among unmarried girls; however, no such effect was observed among married girls and unmarried brothers and husbands.

Findings show mixed results with regard to health-seeking practices. For example, the project had a positive net effect in improving health-seeking practices among unmarried girls. Specifically, unmarried girls in the intervention arm were more likely than those in the comparison arm to have sought treatment for reproductive tract infections and have used and regularly changed disposable sanitary napkins during menstruation. However, no such effect was evident among married girls. Moreover, a contrasting pattern was observed among unmarried brothers and husbands, with the project having a weak negative effect on treatment-seeking practices for reproductive tract infections. 


\section{Chapter 6}

\section{Effect of the intervention on adolescent girls' access to a supportive and safe environment}

The MLMC project has undertaken a number of activities to improve adolescent girls' access to a supportive and safe environment. In this chapter, we examine the effect of the project on adolescent girls' access to a supportive and safe environment.

\section{Effect on support received by adolescent girls from their mothers and fathers}

To assess the effect of the MLMC project on support that adolescent girls received from their mothers and fathers, we asked adolescent girls whether they had discussed selected topics-their friends, any problem in the family, sexual and reproductive matters, including HIV/AIDS - with their mother in the month prior to the interview and in the case of unmarried girls, with their father as well.

Communication between unmarried girls and their mothers on such general topics as friends and problems in the family was common in the study settings even at the baseline $(93-96 \%$ in the intervention arm and the comparison arm). Findings presented in Figure 6.1 show that the proportion of girls who discussed such general topics with their mother in the month prior to the interview remained more or less unchanged between baseline and endline assessments in the intervention arm (95-96\%), while it slightly increased in the comparison arm (93\% to 98\%). Among married girls, 81-84 percent in the intervention arm reported having discussed general topics with their mother in the month prior to the interview at baseline and endline; the corresponding percentages in the comparison arm were 87 and 93, respectively. Fewer girls discussed general topics with their father during the same reference

Figure 6.1: Percentage of unmarried and married adolescent girls who discussed general topics with their mother and father in the month prior to the interview by treatment arms, baseline and endline surveys

With mother

Unmarried adolescent girls

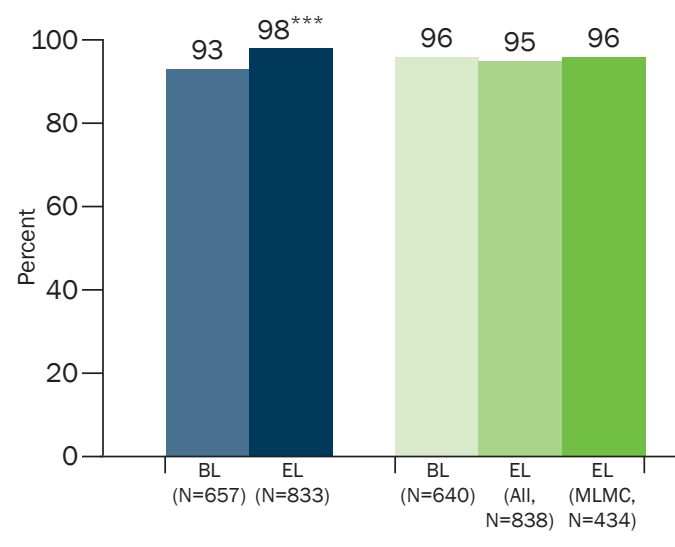

Comparison
Married adolescent girls

With father

Unmarried girls

Note: All percentages shown in the figure are weighted; ${ }^{\text {and }}{ }^{* * *}$ indicate that the difference between baseline and endline is significant at $p \leq 0.10, p \leq 0.001$, respectively; $B L=$ Baseline; $E L=$ Endline; $E L A l l=A l l$ respondents irrespective of their participation in the $M L M C$ project. $E L$ $M L M C=$ Respondents who had participated in the MLMC project. 
period both at the baseline and the endline; moreover, the proportion of such girls remained unchanged between the two assessments in the intervention and the comparison arms (59-66\%). We note that married adolescent girls were not asked whether they discussed general topics with their father for ethical reasons.

Findings presented in Figure 6.2 show that communication between unmarried adolescent girls and their mother on sexual and reproductive topics, including HIV/AIDS increased between the baseline and endline assessments in the intervention and the comparison arms; the percentage change between baseline and endline assessments were similar in both arms (8-11 points in the intervention arm and 6 points in the comparison arm). A different pattern was observed among married girls: it increased between baseline and endline assessments in the comparison arm (33\% to $45 \%$ ), while it remained similar or declined in the intervention arm (41\% to $33-40 \%$, respectively). Findings also suggest that hardly any unmarried girls discussed sexual and reproductive matters with their father in the month prior to the interview both at the baseline and the endline assessments (not shown in figure).

The regression results presented in Table 6.1 show no effect of exposure to the MLMC project in promoting communication between unmarried and married adolescent girls and their mothers on general topics or sexual and reproductive topics. In fact, a negative effect was observed for the most part because of an increase in communication between adolescent girls and their mothers in the comparison arm between the baseline and endline assessments. It is possible that mothers remained as the only confidante for girls in the comparison arm, but not so in the case of girls in the intervention arm. Likewise, the project had no effect in encouraging communication between unmarried girls and their fathers on general topics. We note that these findings contrast with girls' perceptions that they have developed a closer relationship with their parents in the six months prior to the interview (Table 8.1).

Table 6.1: Effect of exposure to the MLMC project on communication between unmarried and married adolescent girls and their mothers and fathers: Summary of regression results

\begin{tabular}{|c|c|c|c|c|}
\hline \multirow[t]{2}{*}{ Indicators } & \multicolumn{2}{|c|}{$\begin{array}{l}\text { Unmarried adolescent } \\
\text { girls }\end{array}$} & \multicolumn{2}{|c|}{$\begin{array}{l}\text { Married adolescent } \\
\text { girls }\end{array}$} \\
\hline & All & MLMC & All & MLMC \\
\hline $\begin{array}{l}\text { Discussed general topics with mother in the month prior to the } \\
\text { interview\# }\end{array}$ & $0.24^{* * *}$ & $0.28^{* *}$ & $0.51^{* *}$ & $0.39^{* * *}$ \\
\hline $\begin{array}{l}\text { Discussed sexual and reproductive topics with mother in the } \\
\text { month prior to the interview }\end{array}$ & 1.15 & 1.07 & $0.58^{* *}$ & $0.39^{\star * \star}$ \\
\hline $\begin{array}{l}\text { Number of respondents whose mother was alive at the time of } \\
\text { the interview }\end{array}$ & 2,968 & 2,564 & 2,994 & 2,324 \\
\hline $\begin{array}{l}\text { Discussed general topics with father in the month prior to } \\
\text { the interview\# }\end{array}$ & $0.77^{\sim}$ & 0.82 & & \\
\hline $\begin{array}{l}\text { Number of respondents whose father was alive at the time of } \\
\text { the interview }\end{array}$ & 2,896 & 2,500 & & \\
\hline
\end{tabular}

Note: ${ }^{\sim}{ }^{* *}$ and ${ }^{* \star *}$ indicate that the net effect of exposure to the intervention is significant at $p \leq 0.10, p \leq 0.01, p \leq 0.001$, respectively; ${ }^{\#}$ Refers to odds ratio from logistic regression.

\section{Effect on support received from brothers (for unmarried girls) and husbands (for married girls)}

Findings presented in Figure 6.3 and Table 6.2 show no effect of exposure to the MLMC project on the extent to which adolescent girls received some form of support from their brothers (for unmarried girls) or husbands (for married girls). Specifically, the percentage of unmarried girls who received some support from their brothers was similar at baseline and endline in the intervention and comparison arms (69-71\% in the intervention arm and 65$69 \%$ in the comparison arm). Likewise, the extent to which married girls received some support from their husbands in the month prior to the interview showed no change between baseline and endline assessments in the intervention and comparison arms (72-74\% in the intervention arm and $72-73 \%$ in the comparison arm). The regression results presented in Table 6.2 also show no effect of the MLMC project on the extent to which unmarried and married adolescent girls received some support from their brothers or husbands. 
Figure 6.2: Percentage of unmarried and married adolescent girls who reported having discussed sexual and reproductive topics with their mother in the month prior to the interview by treatment arms, baseline and endline surveys

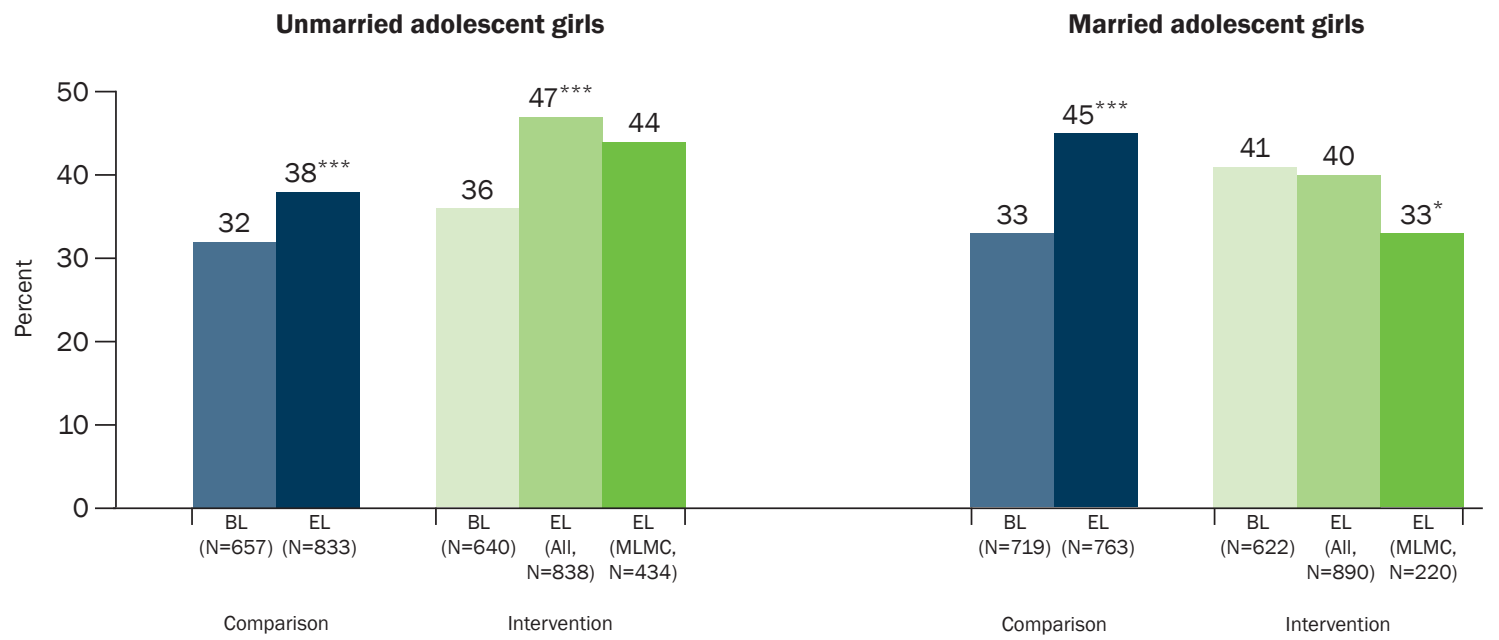

Note: All percentages shown in the figure are weighted; ${ }^{*}$ and ${ }^{* * *}$ indicate that the difference between baseline and endline is significant at $p \leq 0.05, p \leq 0.001$, respectively; $B L=$ Baseline; $E L=E n d l i n e ; E L A l l=A l l$ respondents irrespective of their participation in the $M L M C$ project; $E L$ $M L M C=$ Respondents who had participated in the MLMC project.

Figure 6.3: Percentage of unmarried and married adolescent girls who received support from their brothers (for unmarried girls) or husbands (for married girls) in the month prior to the interview by treatment arms, baseline and endline surveys

Unmarried adolescent girls

Married adolescent girls

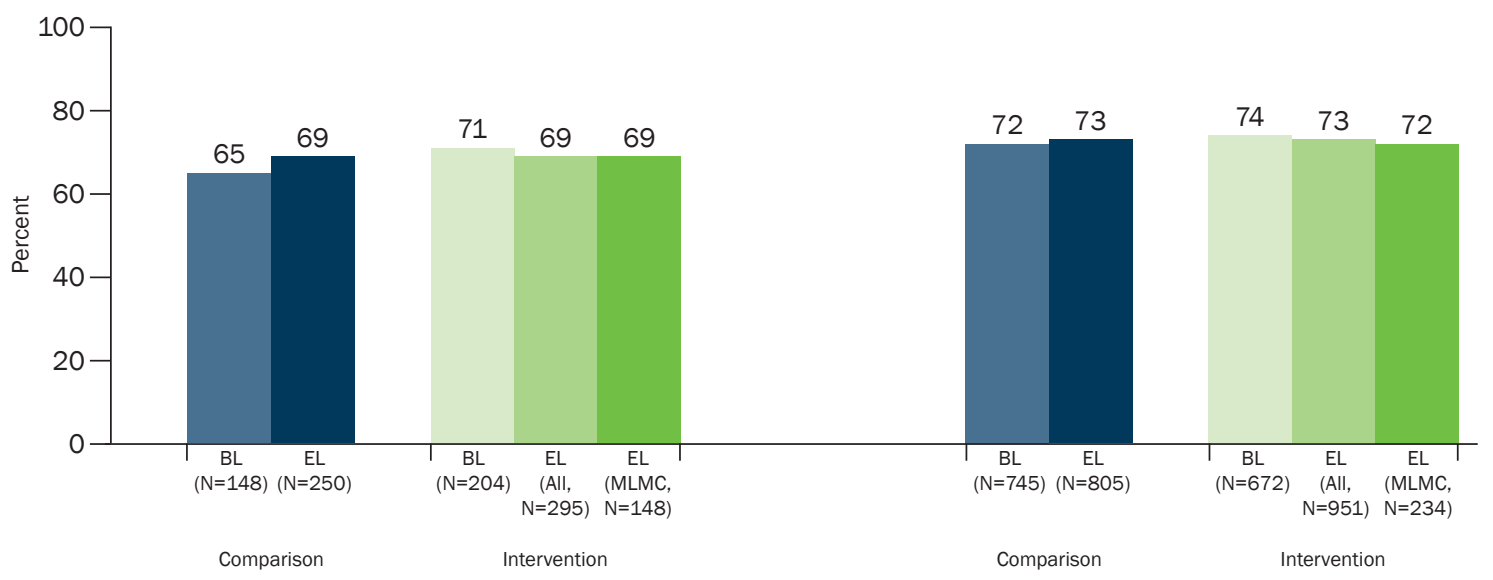

Note: All percentages shown in the figure are weighted; $B L=$ Baseline; $E L=E n d l i n e ; E L A l l=A l l$ respondents irrespective of their participation in the $M L M C$ project; EL MLMC=Respondents who had participated in the MLMC project.

The MLMC project had a mixed effect in improving spousal communication. A comparison of married girls' responses related to whether they had discussed financial matters with their husband in the month preceding the interview shows that the percentage point difference between baseline and endline was slightly larger in the intervention arm (8-12 points) than in the comparison arm (4 points; Figure 6.4). The regression results also show that those who had participated in MLMC project activities were mildly more likely to have discussed financial matters than those in the comparison arm (OR 1.6; Table 6.2). However, although a slightly larger percentage of married girls at endline than at baseline reported having discussed sexual and reproductive topics with their husband, the percentage point 
Table 6.2: Effect of exposure to the MLMC project on support received from brothers (for unmarried girls) and husbands (for married girls): Summary of regression results

\begin{tabular}{|c|c|c|c|c|}
\hline \multirow[t]{2}{*}{ Indicators } & \multicolumn{2}{|c|}{$\begin{array}{c}\text { Unmarried adolescent } \\
\text { girls }\end{array}$} & \multicolumn{2}{|c|}{$\begin{array}{l}\text { Married adolescent } \\
\text { girls }\end{array}$} \\
\hline & All & MLMC & All & MLMC \\
\hline $\begin{array}{l}\text { Received some support from brother (for unmarried girls)/ } \\
\text { husband (for married girls) in the month prior to the interview }\end{array}$ & 0.62 & 0.65 & 0.91 & 0.84 \\
\hline $\begin{array}{l}\text { Discussed financial matters with husband in the month prior to } \\
\text { the interview } \#\end{array}$ & & & 1.30 & $1.60^{\sim}$ \\
\hline $\begin{array}{l}\text { Discussed sexual and reproductive topics with husband in the } \\
\text { month prior to the interview" }\end{array}$ & & & 0.87 & 1.21 \\
\hline Experienced marital violence in the month prior to the interview\# & & & $0.41^{* * *}$ & $0.40^{* * *}$ \\
\hline Number of respondents & 897 & 750 & 3,173 & 2,456 \\
\hline
\end{tabular}

Note: and ${ }^{* *}$ indicate that the net effect of exposure to the intervention is significant at $p \leq 0.10, p \leq 0.001$, respectively; ${ }^{\# R e f e r s ~ t o ~}$ odds ratio from logistic regression.

Figure 6.4: Percentage of married adolescent girls who had discussed financial and sexual and reproductive matters with their husband in the month prior to the interview, baseline and endline surveys

Financial matters

Sexual and reproductive matters

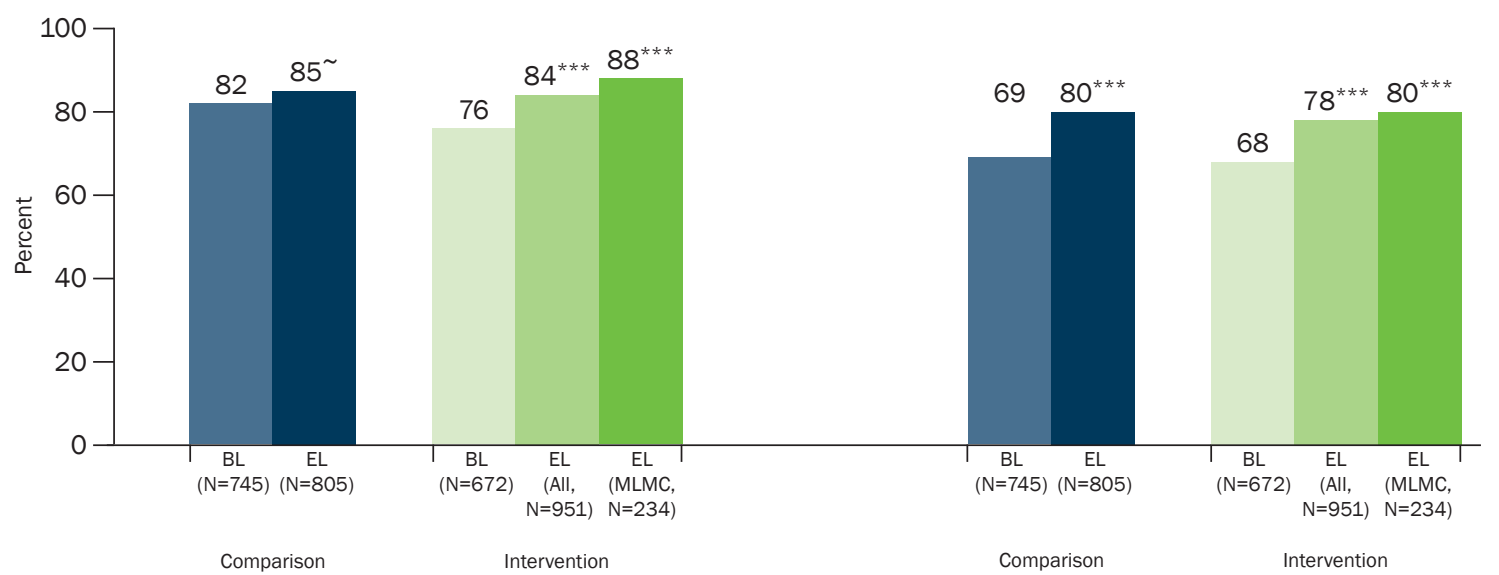

Note: All percentages shown in the figure are weighted; ${ }^{\text {and }}{ }^{* * *}$ indicate that the difference between baseline and endline is significant at $p \leq 0.10, p \leq 0.001$, respectively; $B L=$ Baseline; $E L=E n d l i n e ; E L A l l=A l l$ respondents irrespective of their participation in the $M L M C$ project; $E L$ $M L M C=$ Respondents who had participated in the MLMC project.

difference between baseline and endline was more or less similar in the intervention arm (10-12 points) and the comparison arm (11 points). The regression results reiterate that married girls in the intervention arm were no more likely than those in the comparison arm to have discussed sexual and reproductive topics with their husband in the month prior to the interview.

Finally, findings show that the MLMC project succeeded in reducing married girls' experience of marital violence. Findings presented in Figure 6.5 show that while marital violence increased between the baseline and endline assessments in the comparison arm (from 10\% to 17\%), it declined slightly in the intervention arm (20\% to $17-18 \%$ ). The regression results show that the project had a positive net effect in reducing married girls' experience of marital violence; married girls in the intervention arm were half as likely as those in the comparison arm to have experienced marital violence (OR 0.41 for the full sample, 0.40 for the MLMC participant sample; Table 6.2). 
Figure 6.5: Percentage of married adolescent girls who experienced marital violence in the month prior to the interview by treatment arms, baseline and endline surveys

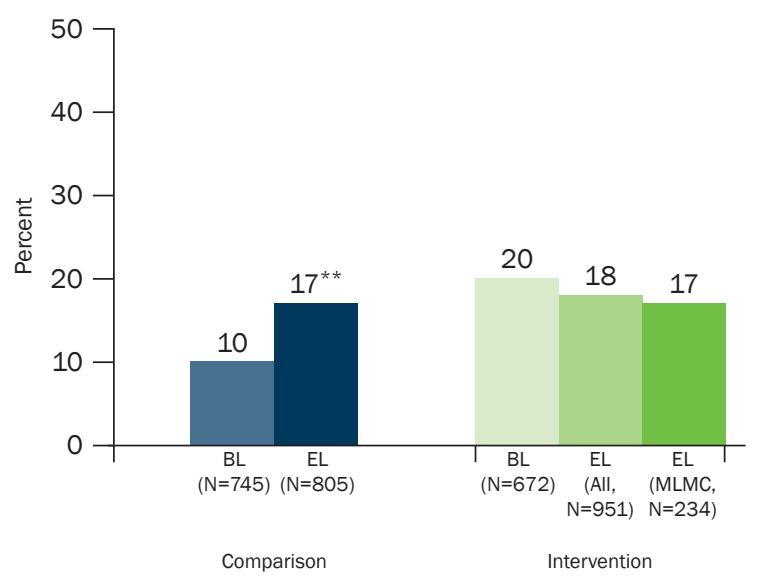

Note: All percentages shown in the figure are weighted; ${ }^{* *}$ indicates that the difference between baseline and endline is significant at $p \leq 0.01 ; B L=$ Baseline; $E L=E n d l i n e ; E L A l l=A l l$ respondents irrespective of their participation in MLMC project; EL MLMC=Respondents who had participated in the MLMC project.

\section{Effect on adolescent girls' safety within their village}

The evaluation also assessed adolescent girls' perception of safety in their village and their experience of sexual harassment. Findings presented in Figure 6.6 show a positive effect of exposure to the MLMC project on girls' sense of safety within their village. Specifically, a larger proportion of unmarried girls in the intervention arm at endline reported that they felt safe walking alone in their village or when they were at a bus stop alone, and felt confident that adults in the community would help if they experienced sexual harassment (50-56\%) compared to their counterparts in the intervention arm at baseline and in the comparison arm at baseline and endline (40-41\%). A similar change was evident among married girls as well (51-60\% vs. $45-46 \%$ ).

The regression results presented in Table 6.3 confirm a positive effect of the MLMC project on adolescent girls' perceptions of safety in their community. Unmarried girls in the intervention arm were 1.4 (for the full sample) to 1.9 (for the MLMC participant sample) times more likely than those in the comparison arm to report that they felt safe walking alone in their village or when they were at a bus stop,

and felt confident that adults in the community would help if they experienced sexual harassment. Married girls, similarly, were 1.3 (for the full sample) to 1.9 (for the MLMC participant sample) times more likely than those in the comparison arm to feel this way.

Figure 6.6: Percentage of unmarried and married adolescent girls who felt safe in their village and confident about community support if experienced sexual harassment by treatment arms, baseline and endline surveys

Unmarried adolescent girls

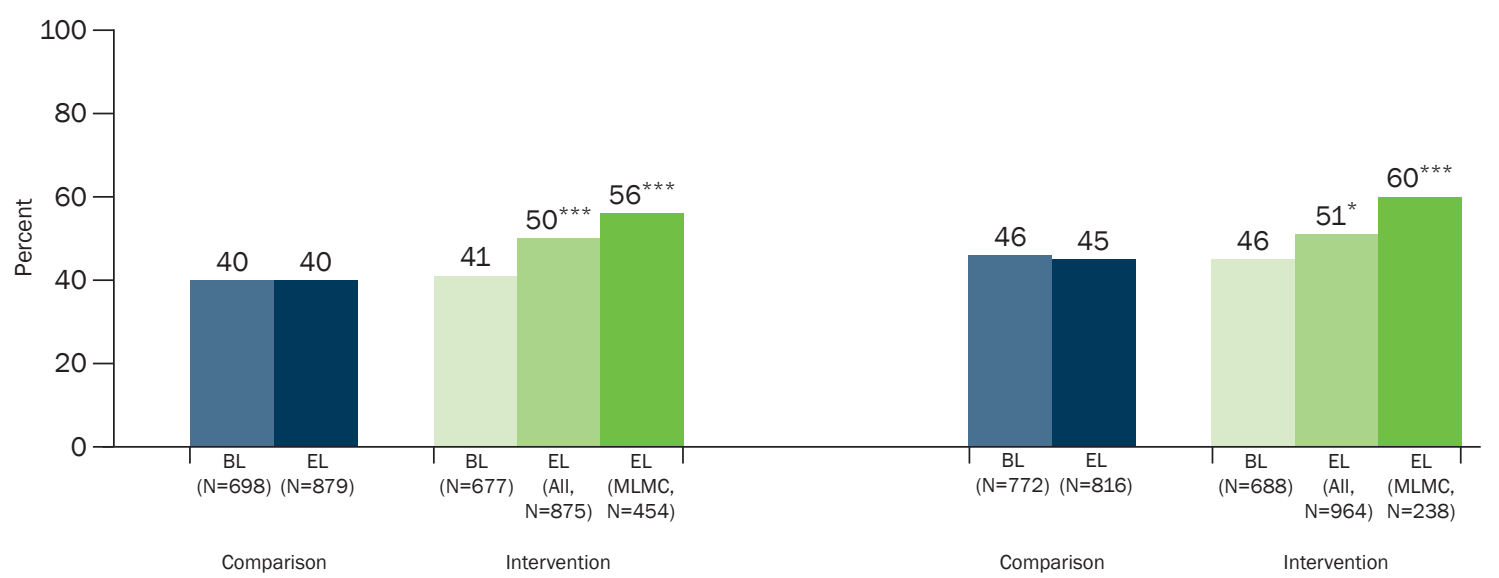

Note: All percentages shown in the figure are weighted; * and ${ }^{* *}$ indicate that the difference between baseline and endline is significant at $p \leq 0.05, p \leq 0.001$, respectively; $B L=$ Baseline; $E L=E n d l i n e ; E L A l l=A l l$ respondents irrespective of their participation in the $M L M C$ project; EL $M L M C=$ Respondents who had participated in the MLMC project. 
Table 6.3: Effect of exposure to the MLMC project on unmarried and married adolescent girls' perceptions of safety and experience of sexual harassment: Summary of regression results

\begin{tabular}{|c|c|c|c|c|}
\hline \multirow[t]{2}{*}{ Indicators } & \multicolumn{2}{|c|}{$\begin{array}{l}\text { Unmarried adolescent } \\
\text { girls }\end{array}$} & \multicolumn{2}{|c|}{$\begin{array}{l}\text { Married adolescent } \\
\text { girls }\end{array}$} \\
\hline & All & MLMC & All & MLMC \\
\hline $\begin{array}{l}\text { Felt safe inside their village and confident about support } \\
\text { from community in case of sexual harassment experience }\end{array}$ & $1.43^{*}$ & $1.89^{* * *}$ & $1.31^{\sim}$ & $1.86^{* * *}$ \\
\hline Knew the location of the nearest police station\# & $2.49^{* * *}$ & $3.33^{* * *}$ & 0.82 & 1.19 \\
\hline $\begin{array}{l}\text { Experienced non contact forms of sexual harassment in the } \\
\text { six months prior to the interview\# }\end{array}$ & $1.39^{*}$ & $1.62^{* *}$ & 0.95 & 1.26 \\
\hline \multirow[t]{2}{*}{$\begin{array}{l}\text { Experienced contact forms of sexual harassment } \\
\text { (non consensual sexual touch, attempted rape, or forced sex) } \\
\text { in the six months prior to the interview } \#\end{array}$} & $0.59^{\sim}$ & 0.70 & 0.81 & 0.59 \\
\hline & & & & 2,5 \\
\hline Number of respondents & 3,129 & 2,708 & 3,240 & 14 \\
\hline
\end{tabular}

Note: $\sim,{ }^{*}{ }^{* *}$ and ${ }^{* * *}$ indicate that the net effect of exposure to the intervention is significant at $p \leq 0.10, p \leq 0.05, p \leq 0.01, p \leq 0.001$, respectively; ${ }^{\#}$ Refers to odds ratio from logistic regression.

The project had a positive effect on unmarried girls' awareness of the location of the nearest police station. For example, although a similar proportion of girls in the intervention and comparison arms were aware of the location of the nearest police station at endline, the percentage change between the baseline and endline assessments was larger in the intervention arm than in the comparison arm (10-13 percentage points vs almost no change; Figure 6.7). The regression results indicate that unmarried girls in the intervention arm were 2.5 (for the full sample) to 3.3 (for the MLMC participant sample) times more likely than those in the comparison arm to report awareness of the nearest police station (Table 6.3). However, no such change was observed among married girls.

Figure 6.7: Percentage of unmarried and married adolescent girls who were aware of the location of the nearest police station by treatment arms, baseline and endline surveys

Unmarried adolescent girls

Married adolescent girls

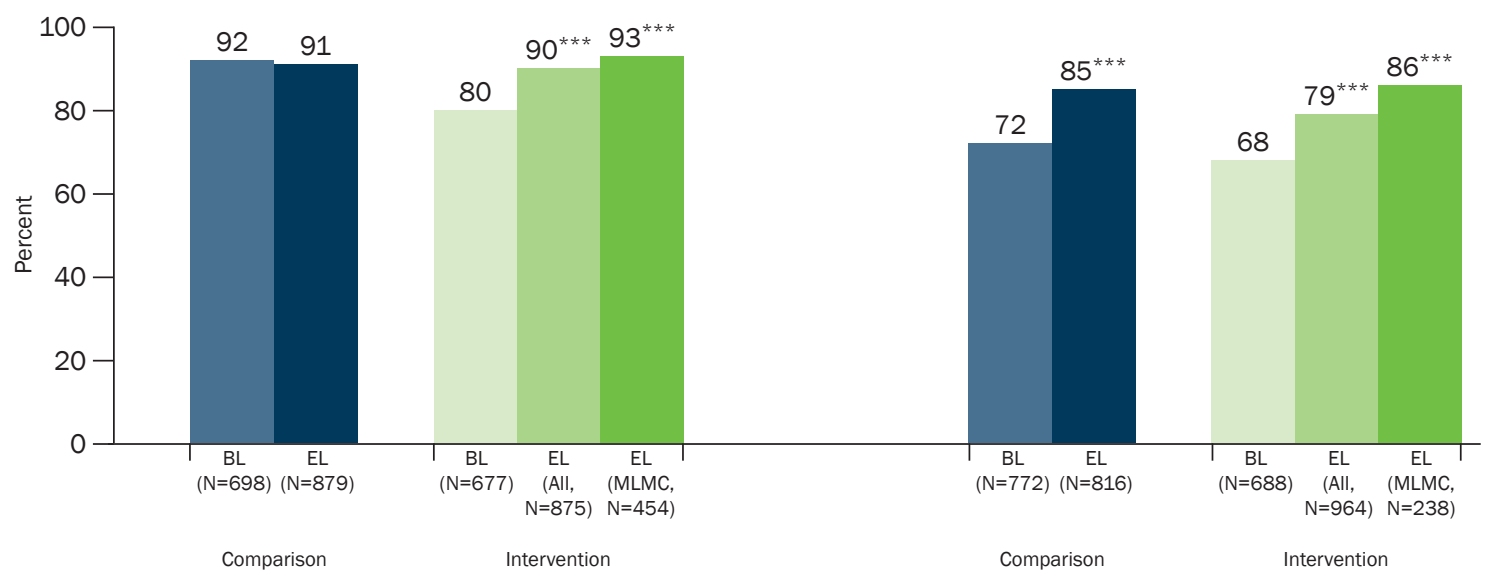

Note: All percentages shown in the figure are weighted; ${ }^{* *}$ indicates that the difference between baseline and endline is significant at $p \leq 0.001$; $B L=$ Baseline; $E L=E n d l i n e ; E L A l l=A l l$ respondents irrespective of their participation in the $M L M C$ project; $E L M L M C=$ Respondents who had participated in the MLMC project. 
Figure 6.8: Percentage of unmarried and married adolescent girls who had experienced non contact forms of sexual harassment in the six months prior to the interview by treatment arms, baseline and endline surveys

Unmarried adolescent girls

Married adolescent girls

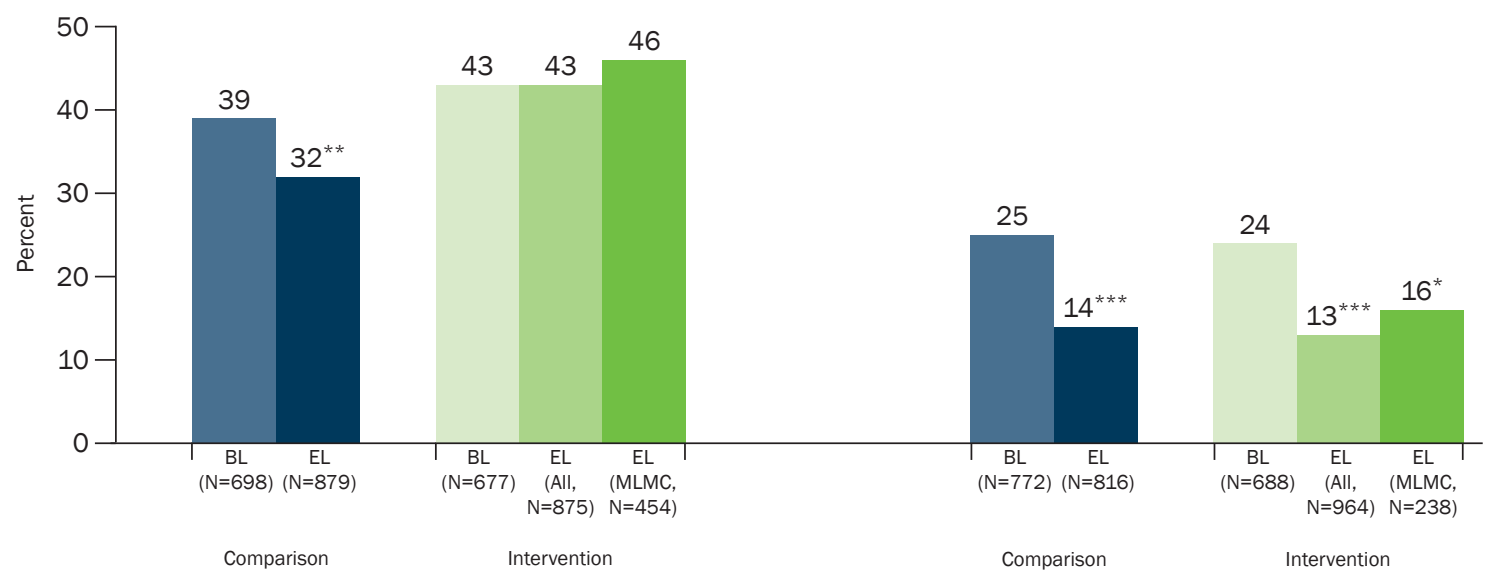

Note: All percentages shown in the figure are weighted; ${ }^{* *}$ and ${ }^{* * *}$ indicate that the difference between baseline and endline is significant at $p \leq 0.05, p \leq 0.01, p \leq 0.001$, respectively; $B L=$ Baseline; $E L=E n d l i n e ; E L A l l=A l l$ respondents irrespective of their participation in the $M L M C$ project; $E L M L M C=$ Respondents who had participated in the MLMC project.

Although higher levels of awareness of the nearest police station were observed among married girls at endline than baseline, the percentage point differences were roughly similar in the intervention and comparison arms (11-18 and 13 percentage points, respectively). The regression results also indicate no effect of exposure to the project on married girls' awareness of the nearest police station.

Adolescent girls' experience of non contact forms of sexual harassment in the six months prior to the interview at baseline and endline are depicted in Figure 6.8. Findings show that while the extent to which unmarried girls had experienced non contact forms of sexual harassment remained similar at baseline and endline in the intervention arm (43-46\%), it slightly declined in the comparison arm (39\% to 32\%). The regression results indicate that unmarried girls in the intervention arm were more likely than those in the comparison arm to have experienced non contact forms of sexual harassment in the six months prior to the interview (OR 1.4 for the full sample and 1.6 for the MLMC participant sample; Table 6.3). It is not clear whether the increased risk observed in the intervention arm was because of increased awareness and recognition of sexual harassment by girls who were exposed to the intervention. Among married girls, it declined to a similar extent in both the intervention and the comparison arms between baseline and endline assessments (from $24 \%$ to $13-16 \%$ in the intervention arm; from $25 \%$ to $14 \%$ in the comparison arm). The regression results show no effect of the MLMC project on married girls' experience of non contact forms of sexual harassment.

A different pattern was observed with respect to adolescent girls' experience of contact forms of sexual harassment. Findings presented in Figure 6.9 show moderate changes in adolescent girls' experience of contact forms of sexual harassment. Unmarried girls in the intervention arm at endline were less likely than their baseline counterparts to report experience of contact forms of sexual harassment (14\% to $9-10 \%$ ), while no change was observed in the comparison arm. The regression results also suggest that unmarried girls in the intervention arm were less likely than others to have experienced contact forms of sexual harassment, although the effect was statistically weak (OR 0.59 for the full sample; Table 6.3). No such change was evident among married girls. Married girls in the intervention and comparison arms at endline were less likely than their baseline counterparts to report experience of contact forms of sexual harassment (6\% to $2-3 \%$ in the intervention arm and $4 \%$ to $2 \%$ in the comparison arm). 
Figure 6.9: Percentage of unmarried and married adolescent girls who had experienced contact forms of sexual harassment in the six months prior to the interview by treatment arms, baseline and endline surveys

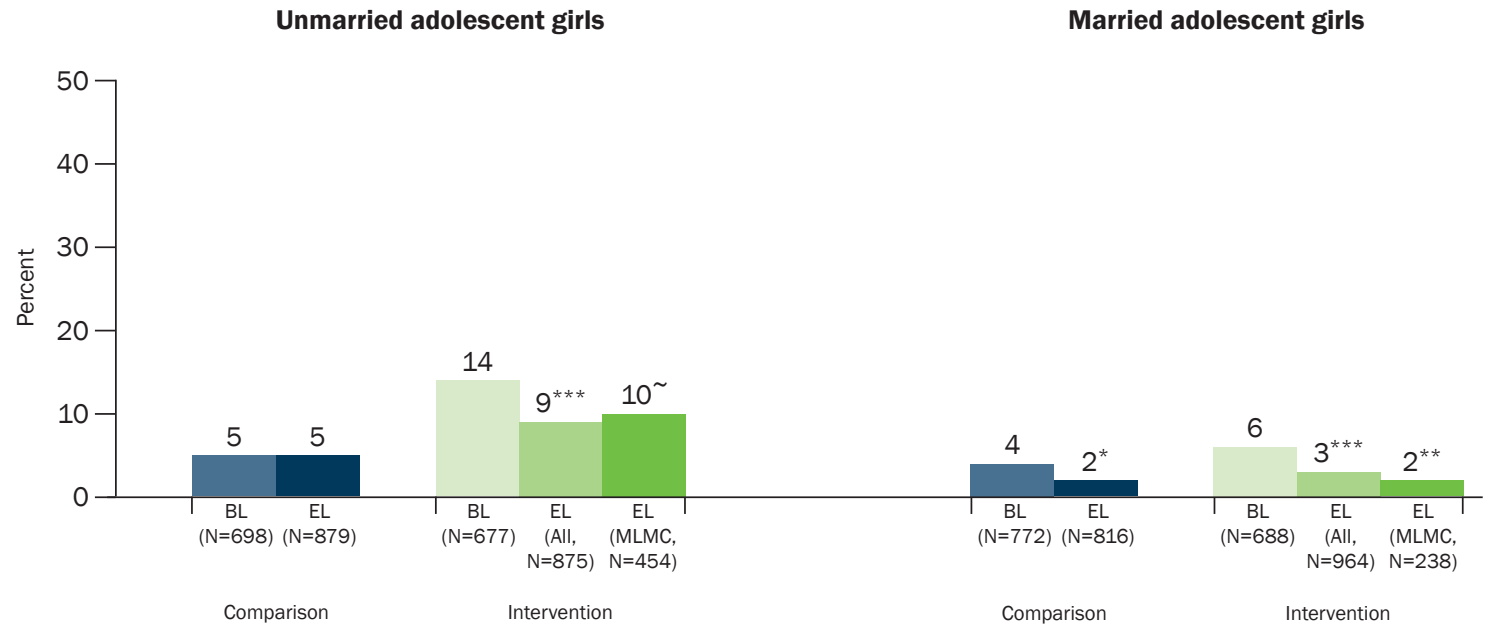

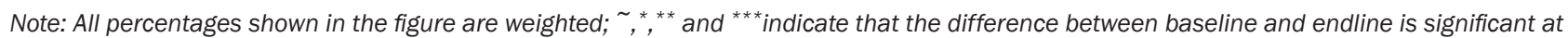
$p \leq 0.10, p \leq 0.05, p \leq 0.01, p \leq 0.001$, respectively; $B L=$ Baseline; $E L=E n d l i n e ; E L A l l=A l l$ respondents irrespective of their participation in the $M L M C$ project; $E L M L M C=$ Respondents who had participated in the MLMC project.

\section{Summary}

The evaluation indicates mixed results with regard to improving support and safety for adolescent girls. The positive changes following the implementation of the MLMC project included a decline in marital violence, improvement in unmarried and married girls' perceptions of safety in their village, and an increase in unmarried girls' awareness of the nearest police station. However, the project had no effect on such indicators as communication between adolescent girls and their parents or parents-in-law, support provided to unmarried girls by their brothers or to married girls by their husbands, and experience of noncontact forms of sexual harassment. 


\section{Chapter 7}

\section{Effect of the intervention on awareness and practices of mothers and fathers of adolescent girls}

This chapter describes the effect of the intervention on awareness and practices of mothers and fathers of unmarried and married adolescent girls. Specifically, we present findings regarding the changes in their awareness of sexual and reproductive matters, their gender role attitudes, and their socialisation practices, drawing on baseline and endline survey data collected from mothers and fathers.

\section{Effect on awareness of sexual and reproductive matters among mothers and fathers}

Findings presented in Figures 7.1-7.6 and Table 7.1 highlight that the MLMC project contributed to raising awareness of sexual and reproductive matters, including HIV/AIDS, among mothers of adolescent girls. However, no such effect was observed among fathers of adolescent girls. For example, Figure 7.1 shows that the endline cohort of mothers in the intervention arm were better informed about sexual and reproductive matters than their baseline counterparts in the intervention arm and their baseline and endline counterparts in the comparison arm (9.2 vs. 7.5-7.6 on a scale that ranged from 0-19). Among fathers, the endline cohort was better informed than the baseline cohort in both the intervention and the comparison arms, with the extent of change between the baseline and endline more or less similar in both arms, indicating no effect of exposure to the intervention among them.

The regression results show a positive net effect of the MLMC project in improving awareness of sexual and reproductive matters among mothers of adolescent girls (regression coefficient of 0.18; Table 7.1). However, no such effect was observed among fathers of adolescent girls.

Figure 7.1: Mean score on the index of awareness of sexual and reproductive matters obtained by mothers and fathers of unmarried and married adolescent girls by treatment arms, baseline and endline surveys

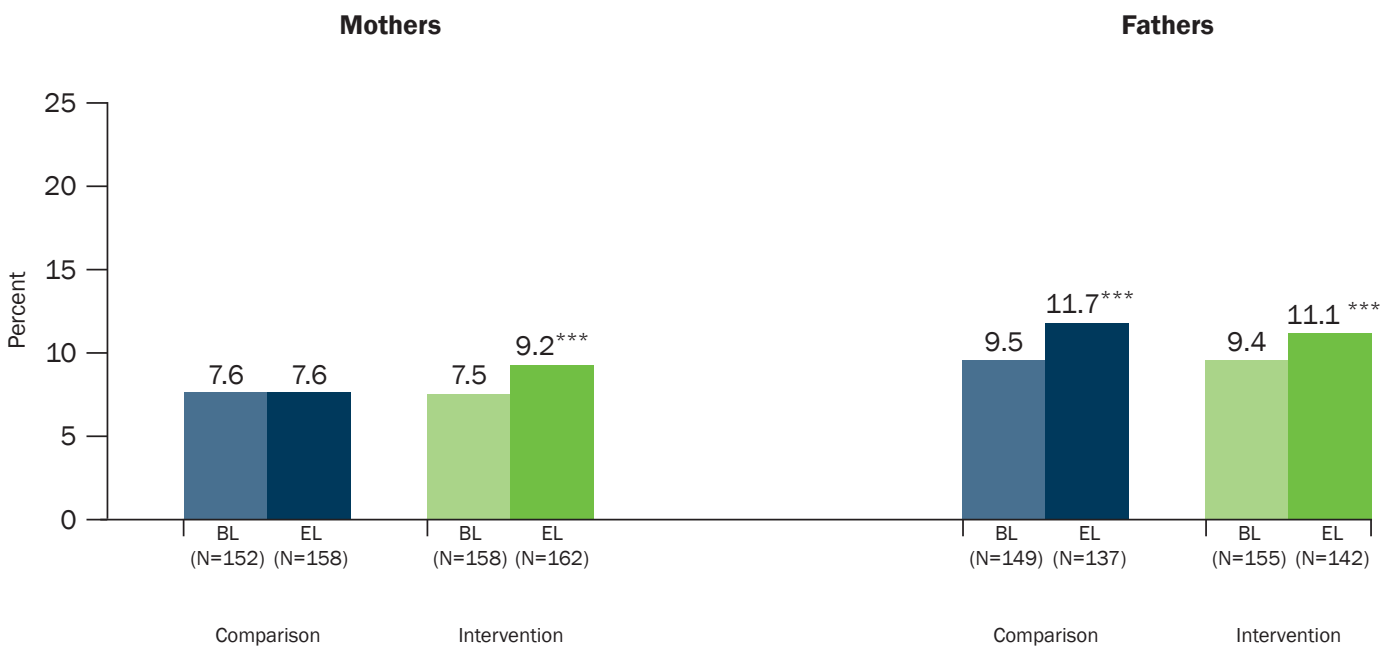

Note: All percentages shown in the figure are weighted; ${ }^{* *}{ }^{*}$ indicates that the difference between baseline and endline is significant at $p \leq 0.001$; $B L=$ Baseline; $E L=$ Endline. 
Table 7.1: Effect of exposure to the MLMC project on awareness of sexual and reproductive matters among mothers and fathers of unmarried and married adolescent girls: Summary of regression results

\begin{tabular}{|c|c|c|}
\hline Indicators & Mothers & Fathers \\
\hline Index of awareness of sexual and reproductive matters (mean score, range 0 to 19 ) & $0.18^{* *}$ & -0.05 \\
\hline Heard about HIV/AIDS $\#$ & $3.83^{* *}$ & 0.73 \\
\hline Knew about two ways of preventing HIV transmission" & $5.28^{*}$ & 0.84 \\
\hline Rejected two misconceptions about HIV/AIDS\# & $5.51^{\sim}$ & $0.46^{\sim}$ \\
\hline Displayed comprehensive awareness about HIV/AIDS\# & - & $0.43^{\sim}$ \\
\hline Knew a facility to go for an HIV test ${ }^{\#}$ & 1.85 & 0.64 \\
\hline Number of respondents & 630 & 583 \\
\hline
\end{tabular}

Note: ${ }^{*}$ " and ${ }^{*}$ indicate that the net effect of exposure to the intervention is significant at $p \leq 0.10, p \leq 0.05, p \leq 0.01$, respectively; \#Refers to odds ratio from logistic regression; @Refers to regression coefficient from linear regression; - Not calculated because none of the mothers displayed comprehensive awareness of HIV/AIDS at endline.

Findings presented in Figure 7.2 indicate that the endline cohort of mothers in the intervention arm were more likely than others to have heard about HIV/AIDS (33\% vs. 11-13\%). Among fathers, a larger proportion had heard about HIV/AIDS at endline than baseline in both the intervention and comparison arms. The percentage point difference between baseline and endline assessments was more or less similar in the intervention and comparison arms (11 percentage points in the intervention arm and 17 percentage points in the comparison arm). The regression results show a positive net effect of exposure to the MLMC project among mothers; those in the intervention arm were 3.8 times more likely to have heard about HIV/AIDS than those in the comparison arm (Table 7.1). However, no such effect was observed among fathers.

Figure 7.2: Percentage of mothers and fathers of unmarried and married adolescent girls who were aware of HIV/ AIDS by treatment arms, baseline and endline surveys

Mothers

Fathers

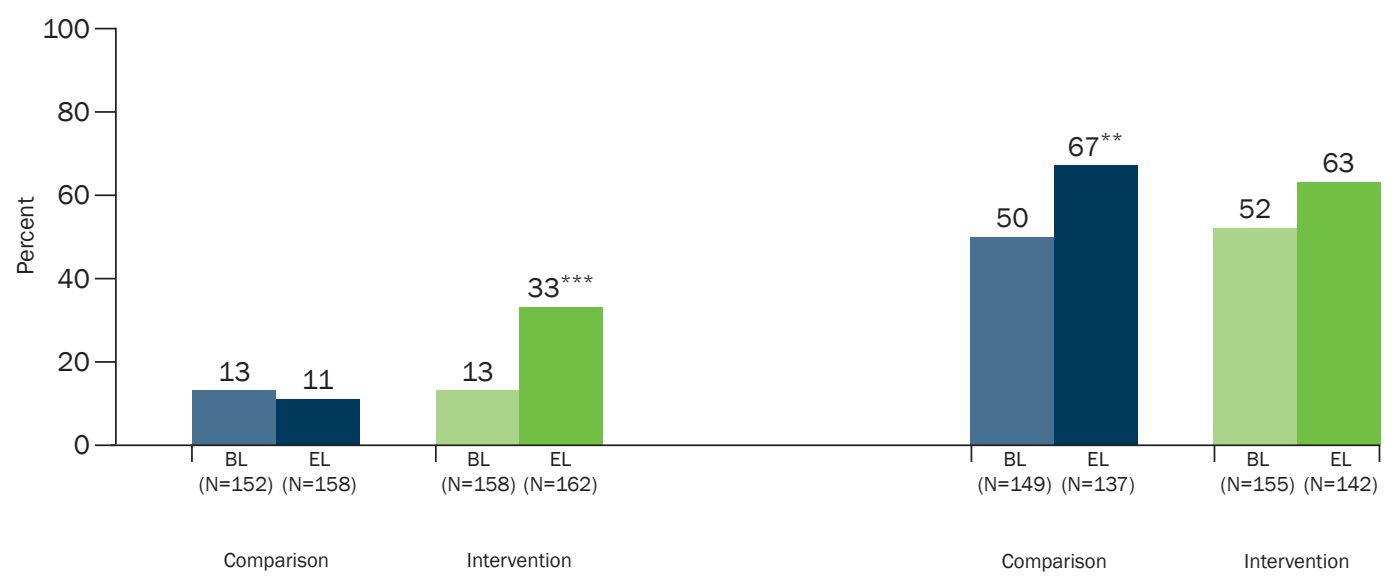

Note: All percentages shown in the figure are weighted; ${ }^{* *}$ and ${ }^{* *}$ indicate that the difference between baseline and endline is significant at $p \leq 0.01, p \leq 0.001$, respectively; $B L=$ Baseline; $E L=$ Endline.

The level of awareness of two ways of preventing HIV transmission, namely, consistent condom use and singlepartner relationship, remained similar among mothers of adolescent girls in the intervention arm between the two assessments (10-13\%), while it declined in the comparison arm (8\% to $2 \%$ ) (Figure 7.3 ). A different pattern was observed among fathers. The percentage of fathers who knew about two ways of preventing HIV transmission increased by 12 percentage points in the intervention arm and 18 percentage points in the comparison arm between the baseline and endline assessments. 
Figure 7.3: Percentage of mothers and fathers of unmarried and married adolescent girls who knew about two ways of preventing HIV transmission by treatment arms, baseline and endline surveys

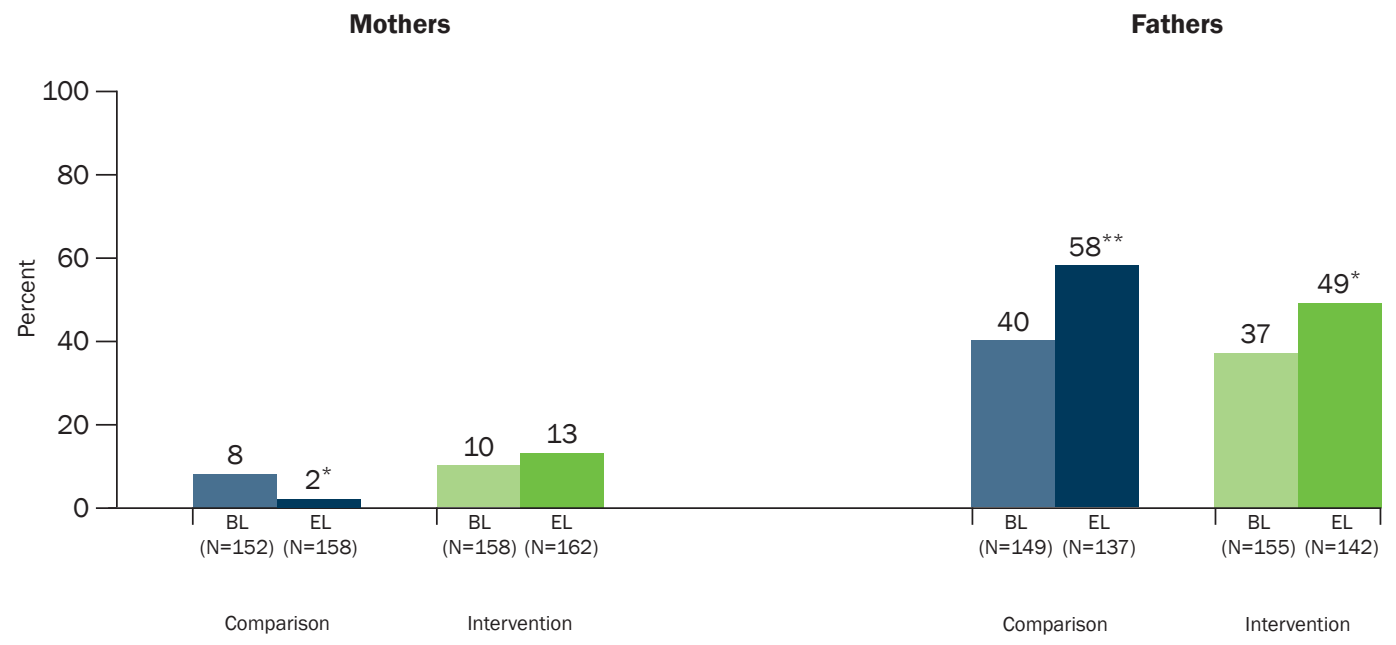

Note: All percentages shown in the figure are weighted; ${ }^{*}$ and ${ }^{* *}$ indicate that the difference between baseline and endline is significant at $p \leq 0.05$, $p \leq 0.01$, respectively; $B L=$ Baseline; $E L=$ Endline.

Although the regression results show a positive effect of exposure to the MLMC project on mothers awareness of two ways of preventing HIV transmission, we note that the significant change observed could not be attributed to exposure to the intervention (because awareness levels remained unchanged in the intervention arm, while it declined in the comparison arm). Among fathers too, no positive effect was observed.

Figure 7.4 show the percentage of study participants who dispelled misconceptions about HIV transmission. The endline cohort of mothers in the intervention arm were somewhat more likely to reject misconceptions about HIV transmission than their baseline counterparts in the intervention arm and their baseline and endline counterparts in the comparison arm (9\% vs. 2-4\%). Among fathers, a larger proportion in the comparison arm rejected at least two misconceptions about HIV transmission at endline (27\%) compared to their endline counterparts in the intervention arm (22\%) and their baseline counterparts in both the intervention and the comparison arms (16-20\%).

Figure 7.4: Percentage of mothers and fathers of unmarried and married adolescent girls who rejected at least two misconceptions about HIV transmission by treatment arms, baseline and endline surveys

Mothers

Fathers

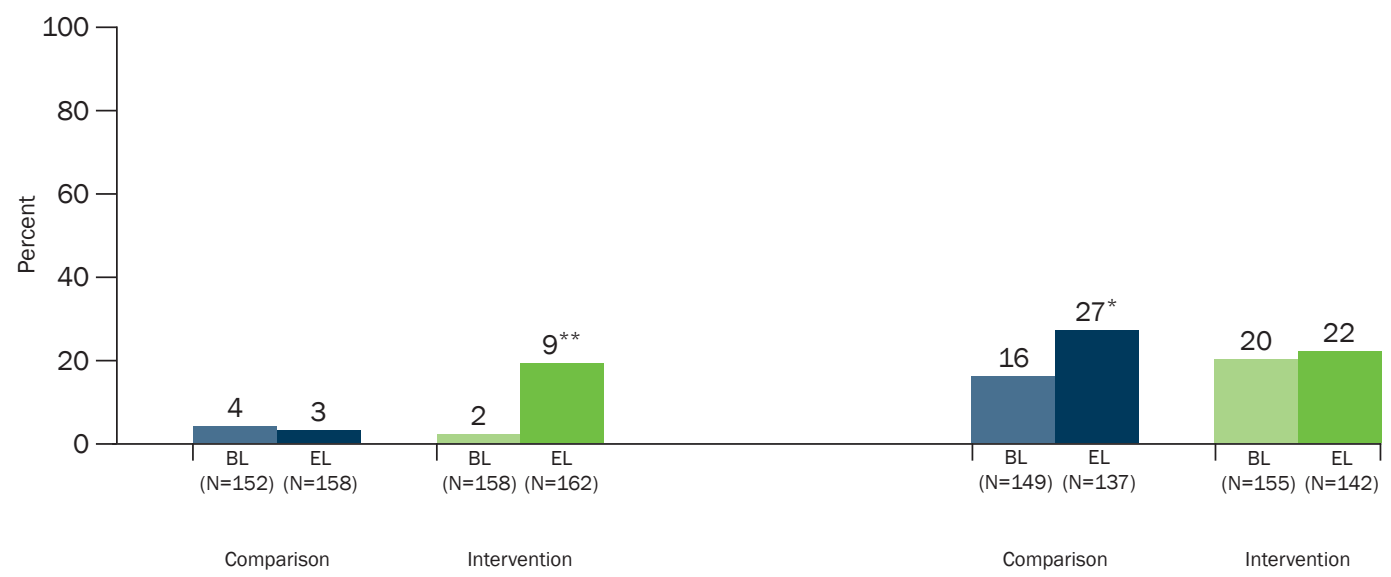

Note: All percentages shown in the figure are weighted; ${ }^{*}$ and ${ }^{* *}$ indicate that the difference between baseline and endline is significant at $p \leq 0.05$, $p \leq 0.01$, respectively; $B L=$ Baseline; $E L=$ Endline. 
The regression results confirm a statistically weak, positive net effect of exposure to the MLMC project in enabling mothers and mothers-in-law to reject misconceptions about HIV transmission (OR 5.5) (Table 7.1). However, it failed to have any effect in enabling fathers to do so.

Findings presented in Figure 7.5 show that comprehensive awareness of HIV/AIDS remained limited among mothers and fathers of adolescent girls. For example, four percent or less of mothers displayed comprehensive awareness of HIV/AIDS at baseline and endline in the intervention and comparison arms. A different pattern was observed among fathers. A larger proportion of the endline cohort of fathers in the comparison arm displayed comprehensive awareness of HIV/AIDS than their baseline counterparts in the comparison arm and their baseline and endline counterparts in the intervention arm (26\% vs. $12-15 \%)$. As such, the regression results indicate that the intervention had no effect in raising comprehensive awareness of HIV/AIDS among mothers and fathers (Table 7.1).

Figure 7.5: Percentage of mothers and fathers of unmarried and married adolescent girls who displayed comprehensive awareness of HIV/AIDS by treatment arms, baseline and endline surveys

Mothers

Fathers

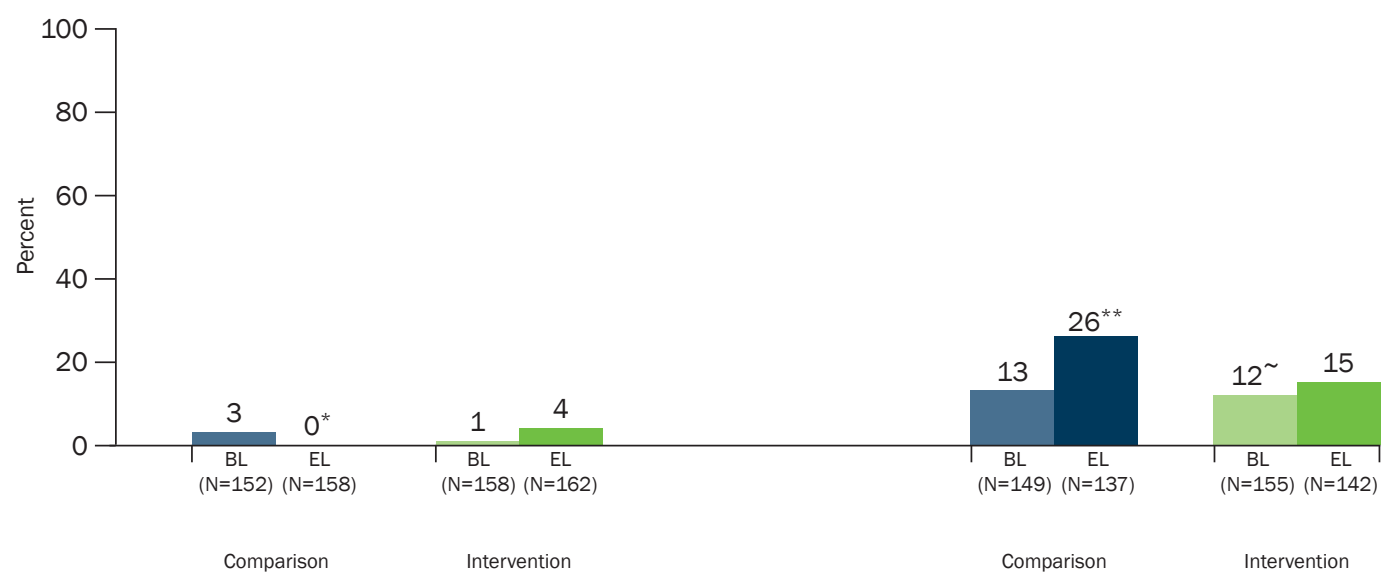

Note: All percentages shown in the figure are weighted; ${ }^{*}$ and ${ }^{* *}$ indicate that the difference between baseline and endline is significant at $p \leq 0.10, p \leq 0.05, p \leq 0.01$, respectively; $B L=$ Baseline; $E L=$ Endline.

Finally, findings related to awareness among mothers and fathers of a facility to go to for an HIV test are presented in Figure 7.6. A larger proportion of endline cohort of mothers in the intervention arm reported that they knew a facility to go to for an HIV test than their baseline counterparts in the intervention arm and their baseline and endline counterparts in the comparison arm (20\% vs. 8-9\%). In other words, 12 percentage-point improvements in awareness of a facility to go to for an HIV test was observed in the intervention arm between the two assessments, compared to almost no change in the comparison arm. Among fathers, although awareness of a facility where one can obtain an HIV test increased both in the intervention and comparison arms, the percentage difference was smaller in the intervention arm (10 points) than in the comparison arm (20 points). As such, the regression results show that the intervention had no effect in raising awareness of a facility where one can obtain an HIV test among mothers and fathers (Table 7.1).

\section{Parental gender role attitudes and socialisation practices}

The mean scores obtained by mothers and fathers on the index of gender egalitarian attitudes, depicted in Figure 7.7, show significant changes in their gender role attitudes between the baseline and endline assessments. Gender role attitudes of mothers and fathers became more gender egalitarian in the intervention arm following the implementation of the MLMC project. Mothers in the intervention arm scored 5.3 on the index of gender egalitarian attitudes at endline compared to 4.9 scored by their baseline counterparts in the intervention arm and 4.8-5.0 scored by their baseline and endline counterparts in the comparison arm. Fathers scored 6.5 at endline compared to 5.2 at baseline in the intervention arm; the corresponding scores in the comparison arm were 6.3 and 5.7. The regression results show a positive net effect of the project on the gender role attitudes of mothers (regression coefficient of 0.14 ) and fathers (regression coefficient of 0.14) of adolescent girls (Table 7.2). 
Figure 7.6: Percentage of mothers and fathers of unmarried and married adolescent girls who knew a facility to go to for an HIV test by treatment arms, baseline and endline surveys

Mothers

Fathers

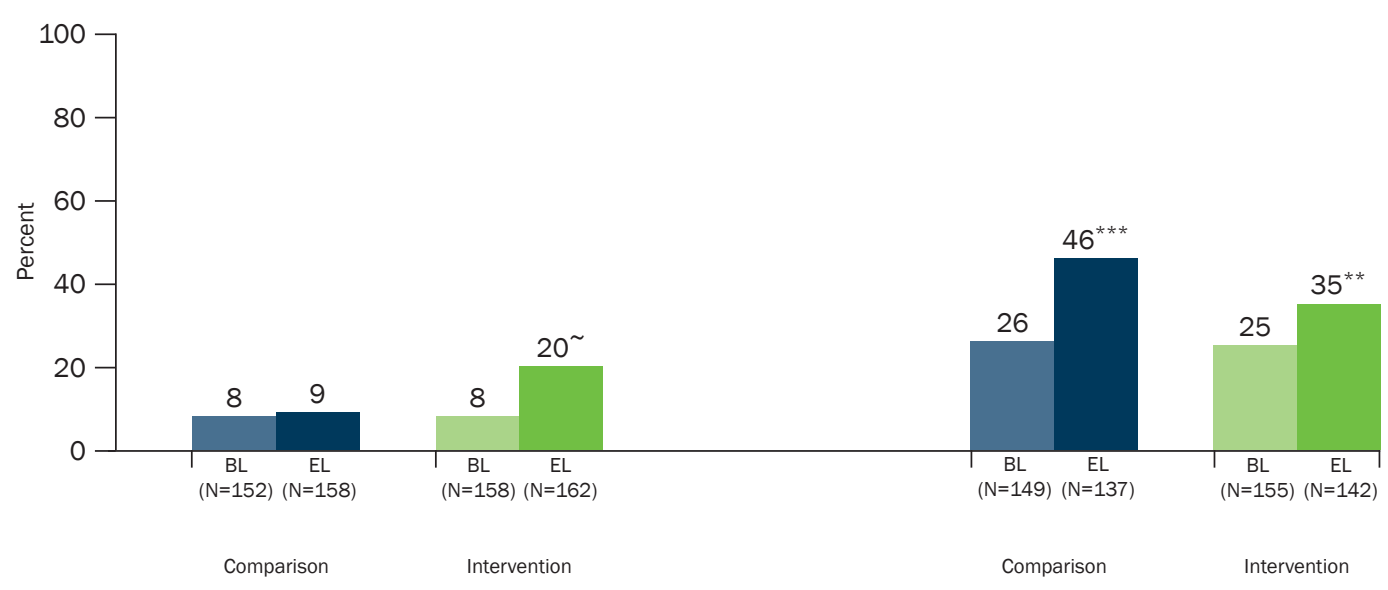

Note: All percentages shown in the figure are weighted; $\sim{ }^{* *}$ and ${ }^{* * *}$ indicate that the difference between baseline and endline is significant at $p \leq 0.10, p \leq 0.01, p \leq 0.001$, respectively; $B L=$ Baseline; $E L=E n d l i n e$.

Figure 7.7: Mean score on the index of gender egalitarian attitudes obtained by mothers and fathers of unmarried and married adolescent girls by treatment arms, baseline and endline surveys

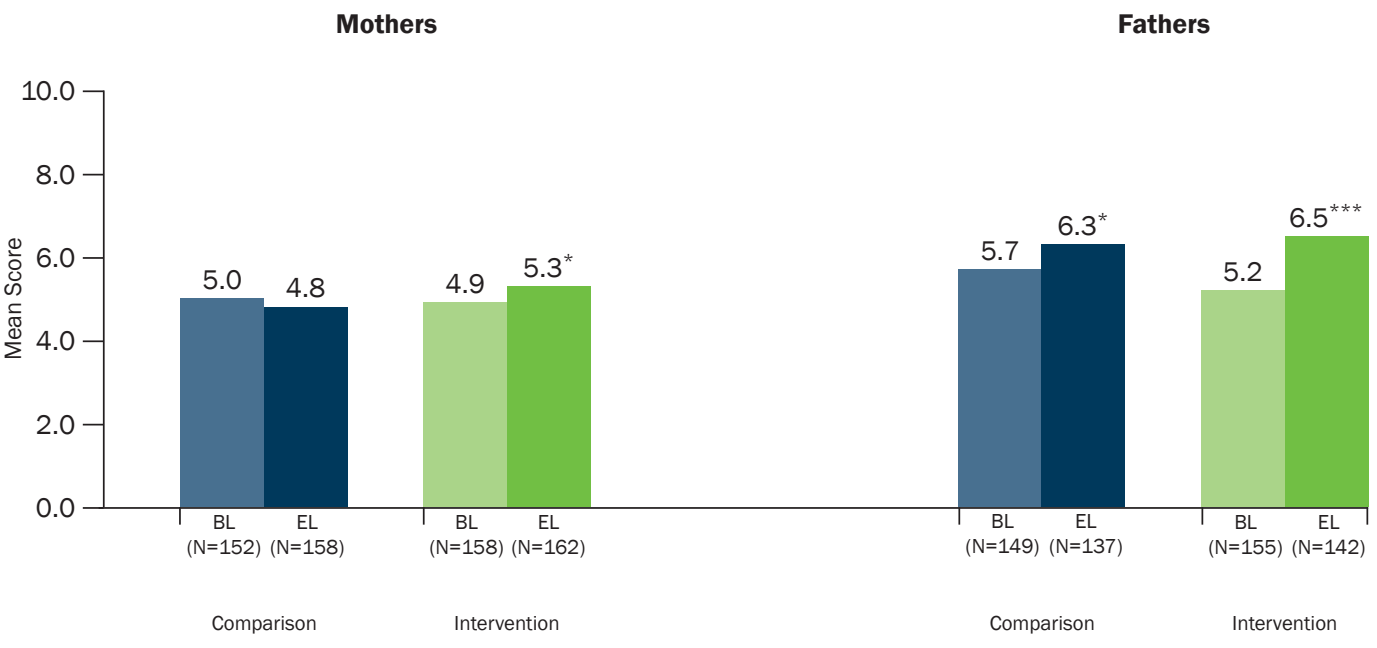

Note: All means shown in the figure are weighted; ${ }^{*}$ and ${ }^{* * *}$ indicate that the difference between baseline and endline is significant at $p \leq 0.05$, $p \leq 0.001$, respectively; $B L=$ Baseline; $E L=$ Endline.

Findings related to the extent to which mothers and fathers treated their daughters/daughters-in-law and sons equally at baseline and endline are depicted in Figure 7.8. They suggest that although an equal proportion of mothers reported that they treated their daughters and sons equally in the intervention and comparison arms at endline, the percentage change between baseline and endline assessment was larger in the intervention arm (from 19\% to 31\%) than the comparison arm (from 29\% to 31\%). A reverse pattern was observed among fathers: the percentage change between baseline and endline was smaller in the intervention arm (27-28\%) than the comparison arm (from $20 \%$ to $30 \%$ ). The regression results, however, indicate no effect of exposure to the MLMC project in enabling mothers and fathers to adopt gender egalitarian practices (Table 7.2). 
Figure 7.8: Percentage of mothers and fathers of unmarried and married adolescent girls who reported that they treated their daughters/daughters-in-law and sons equally by treatment arms, baseline and endline surveys

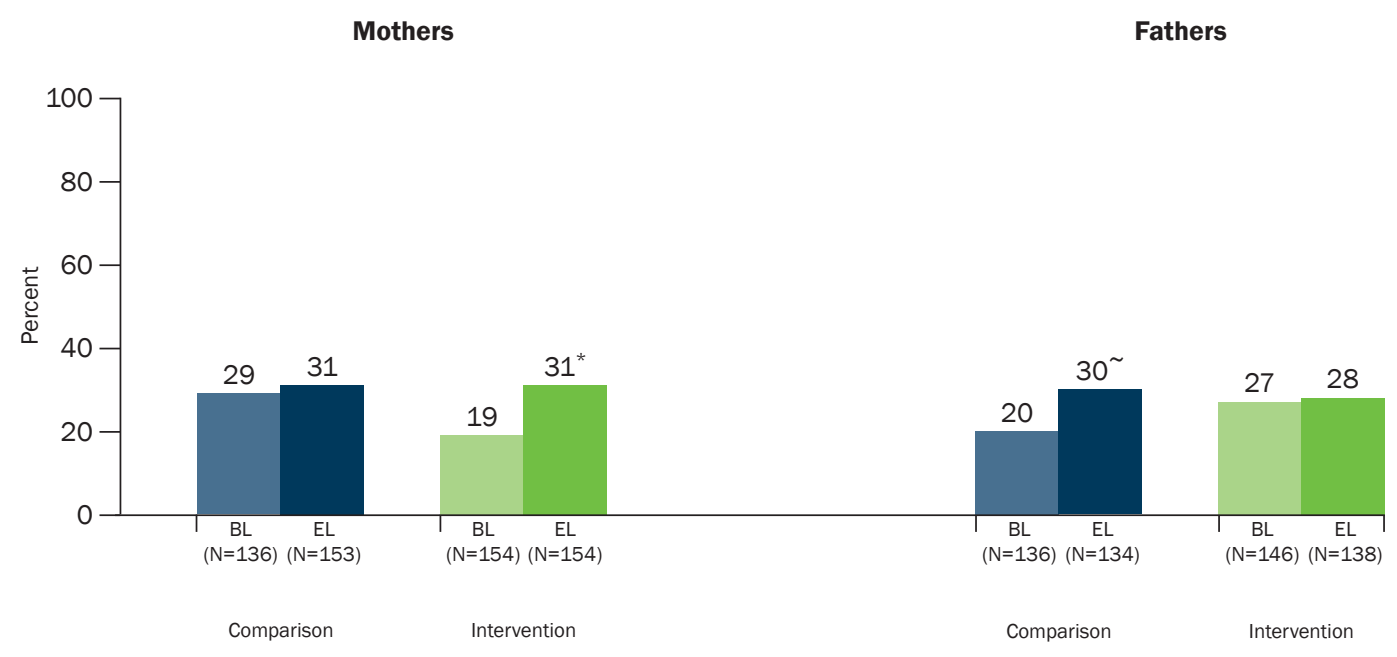

Note: All percentages shown in the figure are weighted; and *indicate that the difference between baseline and endline is significant at $p \leq 0.10$, $p \leq 0.05$, respectively; $B L=$ Baseline; $E L=$ Endline.

Table 7.2: Effect of exposure to the MLMC project on gender role attitudes and socialisation practices among mothers and fathers of unmarried and married adolescent girls: Summary of regression results

\begin{tabular}{|c|c|c|}
\hline Indicators & Mothers & Fathers \\
\hline Index of gender egalitarian attitudes (mean score, range 0-12] & $0.14^{*}$ & $0.138^{*}$ \\
\hline Treated daughters and sons equally & 1.58 & 0.60 \\
\hline $\begin{array}{l}\text { Held similar aspirations for daughters/daughters-in-law and sons in terms of } \\
\text { education, work, and marriage (for unmarried)/education and work (for married) }\end{array}$ & 0.80 & 0.93 \\
\hline Number of respondents & 630 & 583 \\
\hline $\begin{array}{l}\text { Discussed general topics with daughters/daughters-in-law in the month preceding } \\
\text { the interview"\# }\end{array}$ & $0.51^{\sim}$ & 1.28 \\
\hline $\begin{array}{l}\text { Discussed sexual and reproductive health topics with daughters/daughters-in-law } \\
\text { in the month preceding the interview\# }\end{array}$ & $0.39^{*}$ & NA \\
\hline Number of respondents & 630 & $294^{1}$ \\
\hline
\end{tabular}

Note: and *Indicate that the net effect of exposure to the intervention is significant at $p \leq 0.10, p \leq 0.05$, respectively; ${ }^{\#}$ Refers to odds ratio from logistic regression; ${ }^{@}$ Refers to regression coefficient from linear regression; ${ }^{1}$ Excludes father-in-law.

Findings related to mothers who communicated general and sexual and reproductive topics with their adolescent daughters/daughters-in-law and fathers who discussed general topics with their daughters are depicted in Figure 7.9. They suggest that although similar proportions of mothers reported that they discussed general topics and sexual and reproductive topics with their daughters/daughters-in-law in the intervention and comparison arms at endline, the percentage point difference between the baseline and endline assessment was, surprisingly, smaller in the intervention arm (14 percentage points, from $71 \%$ to $85 \%$ with respect to general topics; a negative difference of 4 percentage points, from $32 \%$ to $28 \%$ with respect to sexual and reproductive topics) than the comparison arm (28 percentage points, from $57 \%$ to $85 \%$, and 11 percentage points, from $20 \%$ to $31 \%$, respectively). Correspondingly, the regression results indicate a statistically weak, negative net effect of exposure to the MLMC project on communication between mothers and their daughters/daughters-in-law about general topics and a statistically significant, negative effect on discussion on sexual and reproductive matters. 
Figure 7.9: Percentage of mothers and fathers of unmarried and married adolescent girls who communicated with their daughters/daughters-in-law, baseline and endline surveys

Mothers

Discussed general topics with daughters/daughters-in-law
Discussed sexual and reproductive topics with daughters/daughters-in-law
Fathers

Discussed general topics with daughters

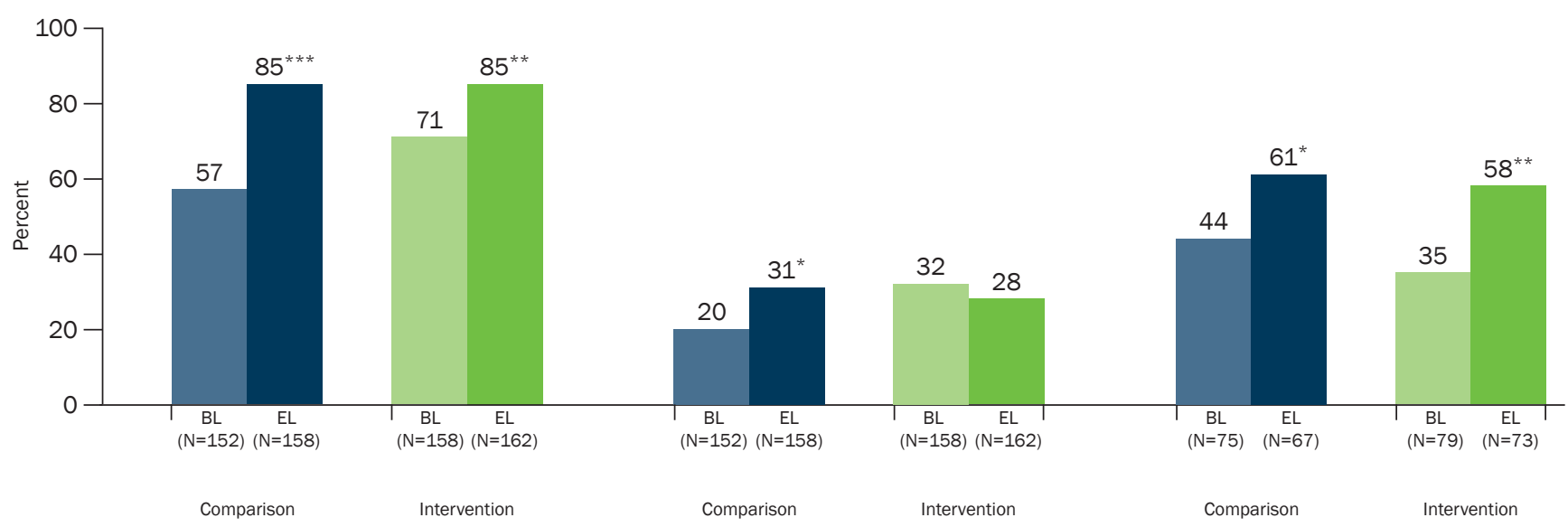

Note: All percentages shown in the figure are weighted; ${ }^{* *}$ and ${ }^{* * *}$ indicate that the difference between baseline and endline is significant at $p \leq 0.05, p \leq 0.01, p \leq 0.001$, respectively; $B L=$ Baseline; $E L=$ Endline.

A different pattern was observed among fathers: a 23 percentage point difference was observed in the intervention arm (from 35\% to 58\%) compared to a 17 percentage point difference in the comparison arm (from $44 \%$ to $61 \%$ ) with respect to discussing general topics with their daughers; we note that none of the fathers reported that they discussed sexual and reproductive matters with their daughters in the month prior to the interview at baseline and endline. The regression results, however, indicate no effect of exposure to the MLMC project on communication between fathers and their daughters on general topics (Table 7.2).

\section{Summary}

Findings presented in this chapter show that the MLMC project had mixed effect on the mothers and fathers of adolescent girls. On a positive note, the project contributed to improving awareness and practices of mothers and fathers of sexual and reproductive matters, including awareness of HIV/AIDS and ways of preventing HIV transmission, among mothers of adolescent girls, and enabling them to uphold gender egalitarian attitudes. At the same time, the project had no effect in enabling mothers to adopt gender egalitarian socialisation practices. Findings also show that the project had, for the most part, no effect on fathers' knowledge and practices, except that they were more likely than their counterparts in the comparison arm to uphold gender egalitarian attitudes. 


\section{Chapter 8}

\section{Changes in attitudes and practices among adolescent girls and their family members: self-assessments}

This chapter presents data on adolescent girls' and their family members' perceptions of changes that they had experienced in the six months preceding the interview which roughly corresponded with the intervention period in the intervention and comparison arms.

\section{Changes experienced by adolescent girls and their unmarried brothers and husbands}

At the endline, we asked adolescent girls and their unmarried brothers and husbands in the intervention and comparison arms about changes they had experienced in the six months prior to the interview. Findings are summarised in Table 8.1. Findings suggest that for all indicators, a larger proportion of adolescent girls and their unmarried brothers and husbands in the intervention arm perceived positive changes in their life in the six months prior to the interview, compared to their counterparts in the comparison arm.

Specifically, adolescent girls and their unmarried brothers and husbands in the intervention arm were more likely than their counterparts in the comparison arm to report positive changes in their agency and gender role attitudes in the six months prior to the interview. For example, unmarried girls in the intervention arm were almost three times more likely than those in the comparison arm to report that they were able to speak without hesitation at the time of the interview compared to previously (41\% vs. $16 \%$ ). Similar differences were observed among married girls ( $32 \%$ vs. $16 \%$ ), unmarried brothers ( $26 \%$ vs. $10 \%$ ) and husbands (15\% vs. $4 \%$ ). Likewise, adolescent girls and their unmarried brothers and husbands in the intervention arm were more likely than those in the comparison arm to report that they knew more about their rights now than earlier (37\% vs. $5 \%$ of unmarried girls; $30 \%$ vs. $10 \%$ of married girls; $20 \%$ vs. $4 \%$ of unmarried brothers; and $19 \%$ vs. $5 \%$ of husbands). They were also more likely than their counterparts in the comparison arm to report that they had been able to express their opinion if they disagreed with someone now than previously ( $42 \%$ vs. $20 \%$ of unmarried girls; $34 \%$ vs. $17 \%$ of married girls; $24 \%$ vs. $13 \%$ of unmarried brothers; and $27 \%$ vs. $7 \%$ of husbands). Unmarried and married girls in the intervention arm, compared to those in the comparison arm, were, additionally, more likely to report that they were less afraid of going somewhere by themselves now than previously ( $31 \%$ vs. $8 \%$ of unmarried girls; $21 \%$ vs. $7 \%$ of married girls). Findings also show that adolescent girls and their unmarried brothers and husbands in the intervention arm were more likely than those in the comparison arm to report that they were less likely to justify violence against women and girls now than earlier (28\% vs. $3 \%$ of unmarried girls; $20 \%$ vs. $5 \%$ of married girls; $25 \%$ vs. $1 \%$ of unmarried brothers; and $23 \%$ vs. $2 \%$ of husbands).

Adolescent girls and their unmarried brothers and husbands in the intervention arm were more likely to report that they were better informed about selected matters now than earlier, compared to their counterparts in the comparison arm. For example, unmarried and married girls in the intervention arm were more likely than those in the comparison arm to report that they were informed about many new issues now than previously (48\% vs. $19 \%$ of unmarried girls; $44 \%$ vs. $31 \%$ of married girls). Similarly, a larger proportion of adolescent girls and their unmarried brothers and husbands in the intervention arm than the comparison arm reported that they were more informed about HIV/AIDS now than earlier ( $42 \%$ vs. $7 \%$ of unmarried girls; $28 \%$ vs. $8 \%$ of married girls; $34 \%$ vs. $10 \%$ of unmarried brothers; and $26 \%$ vs. $6 \%$ of husbands). They were also likely to report that they were better informed about safe sex practices now than previously (32\% vs. $9 \%$ of unmarried girls; $41 \%$ vs. $21 \%$ of married girls; $36 \%$ vs. $7 \%$ of unmarried brothers; and $31 \%$ vs. $3 \%$ of husbands).

Findings also show that adolescent girls and their unmarried brothers and husbands in the intervention arm were more likely than their counterparts in the comparison arm to report positive changes in terms of economic empowerment. For example, a larger proportion of unmarried girls in the intervention arm, compared to those in the 
Table 8.1: Unmarried and married adolescent girls' and their unmarried brothers' and husbands' perceptions of changes experienced in the six months preceding the interview by treatment arms, endline survey

\begin{tabular}{|c|c|c|c|c|c|c|c|c|}
\hline \multirow[t]{2}{*}{ Indicators (\%) } & \multicolumn{2}{|c|}{$\begin{array}{l}\text { Unmarried } \\
\text { adolescent girls }\end{array}$} & \multicolumn{2}{|c|}{$\begin{array}{l}\text { Married } \\
\text { adolescent girls }\end{array}$} & \multicolumn{2}{|c|}{ Unmarried brothers } & \multicolumn{2}{|c|}{ Husbands } \\
\hline & C & $\mathbf{I}$ & C & $\mathbf{I}$ & C & $\mathbf{I}$ & C & I \\
\hline $\begin{array}{l}\text { Can speak without hesitation } \\
\text { or fear }\end{array}$ & 15.5 & $40.6^{* * *}$ & 15.5 & $31.9^{* * *}$ & 10.3 & $25.8^{* * *}$ & 3.9 & $14.7^{* * *}$ \\
\hline Knows own rights better & 5.2 & $37.0^{* * *}$ & 9.7 & $29.7^{* * *}$ & 4.3 & $20.0^{* * *}$ & 5.4 & $18.5^{* * *}$ \\
\hline $\begin{array}{l}\text { Can speak out when s/he } \\
\text { disagrees with someone }\end{array}$ & 19.5 & $41.9^{* * *}$ & 16.6 & $33.5^{* * *}$ & 12.8 & $24.4^{* * *}$ & 7.2 & $26.9^{* * *}$ \\
\hline $\begin{array}{l}\text { Is not afraid of going } \\
\text { anywhere by self }\end{array}$ & 8.0 & $31.3^{* * *}$ & 6.5 & $21.2^{* \star *}$ & - & - & - & - \\
\hline $\begin{array}{l}\text { Is less likely to justify violence } \\
\text { against girls }\end{array}$ & 2.9 & $28.3^{* * *}$ & 4.5 & $19.8^{* * *}$ & 1.3 & $25.0^{* * *}$ & 1.6 & $22.7^{* * *}$ \\
\hline $\begin{array}{l}\text { Is better informed about new } \\
\text { issues }\end{array}$ & 19.2 & $48.0^{* * *}$ & 30.9 & $43.6^{* * *}$ & 25.5 & 29.0 & 25.1 & 24.1 \\
\hline Knows more about HIV & 7.3 & $42.2^{* * *}$ & 8.3 & $28.4^{* \star *}$ & 9.9 & $34.0^{* * *}$ & 5.6 & $25.8^{* * *}$ \\
\hline $\begin{array}{l}\text { Is better informed about safe } \\
\text { sex practices }\end{array}$ & 8.7 & $32.1^{* * *}$ & 21.0 & $40.9^{* \star *}$ & 6.8 & $35.7^{* * *}$ & 3.4 & $31.3^{* * *}$ \\
\hline Acquired a vocational skill & 5.2 & $14.5^{* \star *}$ & 2.2 & $4.9^{* \star}$ & 2.0 & $5.9^{* *}$ & 0.9 & 3.0 \\
\hline Started looking for a job & 2.7 & $6.9^{* * *}$ & 7.2 & 7.2 & 9.6 & $15.0^{*}$ & 12.5 & 16.2 \\
\hline Developed savings habits & 27.1 & $45.3^{* \star *}$ & 26.6 & $45.2^{* * *}$ & 13.5 & $28.7^{\star \star *}$ & 19.9 & $42.4^{* * *}$ \\
\hline Made new friends & 2.0 & $13.1^{* * *}$ & 1.1 & $3.5^{* * *}$ & 12.7 & $20.3^{* *}$ & 5.1 & 7.1 \\
\hline $\begin{array}{l}\text { Developed closer relationship } \\
\text { with parents }\end{array}$ & 8.5 & $26.9^{* * *}$ & 6.7 & $18.3^{* * *}$ & 4.5 & $31.5^{* * *}$ & 6.8 & $21.0^{* * *}$ \\
\hline $\begin{array}{l}\text { Developed closer relationship } \\
\text { with siblings/spouse }\end{array}$ & 4.2 & $19.9^{* * *}$ & 32.5 & $47.4^{* * *}$ & 5.4 & $30.5^{* * *}$ & 20.6 & $42.7^{* * *}$ \\
\hline $\begin{array}{l}\text { Became confident in seeking } \\
\text { health services }\end{array}$ & 6.8 & $23.6^{* * *}$ & 9.4 & $24.2^{* * *}$ & 11.4 & $34.9^{* * *}$ & 16.7 & $34.0^{* * *}$ \\
\hline Number of respondents & 879 & 875 & 816 & 964 & 246 & 250 & 506 & 550 \\
\hline
\end{tabular}

Note: All percentages are weighted; $C$ and I indicate comparison arm and intervention arm, respectively; ${ }^{*},{ }^{* *}$ and ${ }^{* * *}$ indicate that the difference between the intervention and comparison arms is significantly different at $p \leq 0.05, p \leq 0.01, p \leq 0.001$, respectively; - not asked.

comparison arm, reported that they acquired a vocational skill in the six months prior to the interview (15\% vs. $5 \%$ ). Likewise, adolescent girls and their unmarried brothers and husbands in the intervention arm were more likely than those in the comparison arm to report that they developed savings habits in the six months prior to the interview ( $45 \%$ vs. $27 \%$ of unmarried and married girls, respectively; $29 \%$ vs. $14 \%$ of unmarried brothers; and $42 \%$ vs. $20 \%$ of husbands).

Furthermore, unmarried girls and unmarried brothers in the intervention arm were more likely than their counterparts in the comparison arm to report that they made new friends in the six months prior to the interview ( $13 \%$ vs. $2 \%$ of unmarried girls; $20 \%$ vs. $13 \%$ of unmarried brothers). Moreover, all categories of study participants in the intervention arm were more likely than their counterparts in the comparison arm to report that they had developed closer relationships with their mothers and fathers over the past 6 months ( $27 \%$ vs. $9 \%$ of unmarried girls; $18 \%$ vs. $7 \%$ of married girls; $32 \%$ vs. $5 \%$ of unmarried brothers; and $21 \%$ vs. $7 \%$ of husbands). They were also more likely to report that they had developed closer relationships with their siblings (unmarried)/spouse (married) now than previously ( $20 \%$ vs. $4 \%$ of unmarried girls; $47 \%$ vs. $33 \%$ of married girls; $31 \%$ vs. $5 \%$ of unmarried brothers; and $43 \%$ vs. $21 \%$ of husbands).

Finally, adolescent girls and their unmarried brothers and husbands in the intervention arm were more likely than those in the comparison arm to report that they became more confident about seeking health services (24\% vs. $7 \%$ of unmarried girls; $24 \%$ vs. $9 \%$ of married girls; $35 \%$ vs. $11 \%$ of unmarried brothers and $34 \%$ vs. $17 \%$ of husbands). 


\section{Changes experienced by mothers and fathers of adolescent girls}

Mothers and fathers of adolescent girls who participated in the endline survey in the intervention and comparison arms were asked about changes that they had experienced in the six months prior to the interview. Findings are summarised in Table 8.2.

Findings indicate that mothers in the intervention arm were more likely than their counterparts in the comparison arm to report positive changes in the six months prior to the interview. For example, a larger proportion of mothers in the intervention arm reported that they became comfortable discussing sexual and reproductive matters with their daughter/daughter-in-law, compared to those in the comparison arm (35\% vs. $16 \%)$. They were also more likely to report that they had developed a closer relationship with their daughter/daughter-in-law (31\% vs. 20\%). Finally, mothers in the intervention arm were more likely than those in the comparison arm to report that they became comfortable discussing sexual and reproductive matters with their sons (14\% vs. $2 \%)$. No such differences were observed in the perceptions of fathers.

Table 8.2: Perceptions of mothers and fathers about changes that they had experienced in the six months preceding the interview by treatment arms, endline survey

\begin{tabular}{lrrrr}
\hline Indicators (\%) & \multicolumn{2}{c}{ Mothers } & \multicolumn{2}{c}{ Fathers } \\
\cline { 2 - 5 } & C & I & C & I \\
\hline Became comfortable discussing sexual and reproductive & & & & \\
matters with daughter/daughter-in-law ${ }^{1}$ & 15.8 & $35.2^{* * *}$ & 0.0 & 1.4 \\
Developed closer relationship with daughter/daughter-in-law ${ }^{1}$ & 20.3 & $30.9^{*}$ & 2.2 & 4.9 \\
Became comfortable discussing sexual and reproductive & & & & \\
matters with sons & 1.9 & $14.2^{* * *}$ & 2.9 & 0.7 \\
Developed closer relationship with sons & 14.6 & 14.8 & 2.9 & 3.5 \\
Number of respondents & $\mathbf{1 5 8}$ & $\mathbf{1 6 2}$ & $\mathbf{1 3 7}$ & $\mathbf{1 4 2}$ \\
\hline
\end{tabular}

Note: ${ }^{1}$ Excludes fathers-in-law; $C$ and I indicate comparison arm and intervention arm, respectively; ${ }^{*}$ and ${ }^{* * *}$ indicate that the difference between the intervention and comparison arms is significantly different at $p \leq 0.05, p \leq 0.001$, respectively.

\section{Summary}

Findings suggest that a larger proportion of adolescent girls and their unmarried brothers and husbands in the intervention arm perceived positive changes in their life in the six months prior to the interview, compared to their counterparts in the comparison arm. Specifically, study participants in the intervention arm were more likely than their counterparts in the comparison arm to report positive changes in their agency and gender role attitudes in the six months prior to the interview. They were also more likely to report that they were better informed about selected matters now than earlier, compared to their counterparts in the comparison arm.

Findings also show that adolescent girls and their unmarried brothers and husbands in the intervention arm were more likely than their counterparts in the comparison arm to report positive changes in terms of economic empowerment. Furthermore, unmarried girls and unmarried brothers in the intervention arm were more likely than their counterparts in the comparison arm to report that they made new friends in the six months prior to the interview. All categories of study participants in the intervention arm were more likely than their counterparts in the comparison arm to report that they had developed closer relationships with their mothers and fathers, and with their siblings (unmarried)/spouse (married).

Findings indicate that mothers in the intervention arm were more likely than their counterparts in the comparison arm to report positive changes in terms of their interactions with their adolescent children in the six months prior to the interview. However, no such differences were observed in the perceptions of fathers in the intervention and comparison arms. 


\section{Chapter 9 \\ Summary and recommendations}

This chapter summarises the major findings of the evaluation with regard to the relevance, acceptability, feasibility, and effectiveness of the MLMC project. It also provides key recommendations for future programmes.

\section{Relevance of the MLMC project}

The Meri Life Meri Choice project was implemented to reduce rural adolescent girls' vulnerability to HIV. The baseline assessment prior to launching the intervention underscored that adolescent girls, their unmarried brothers, and husbands in the study settings were vulnerable to HIV in many, but different, ways. Adolescent girls and their brothers and husbands were not typically endowed with assets that can prevent conditions that are precursors of HIV. For example, social isolation characterised the lives of many adolescent girls in the study settings. Moreover, they lacked social spaces to network with their peers. Few adolescent girls exercised agency in their lives. Adolescent girls and their brothers and husbands all adhered to unequal gender norms. They remained largely uninformed about sexual and reproductive matters, including HIV/AIDS. Moreover, what they knew about these matters was far from comprehensive. They lacked financial literacy and opportunities to acquire livelihood skills. Sizeable proportions had engaged in unprotected sex. Treatment-seeking for sexual health problems was limited among girls as well as their brothers and husbands. Moreover, a supportive and safe environment was by and large lacking for many adolescent girls. Findings also show that mothers and fathers were not equipped with knowledge and skills to play a protective role in the lives of their adolescent children. In short, the baseline assessment highlights the vulnerability of adolescents to HIV, the limited role of parents in addressing these vulnerabilities, and the relevance of a project like the MLMC in the study settings as well as in other settings in which adolescent girls and their brothers and husbands face similar disadvantages.

Moreover, the lessons learned from implementing the MLMC project, beginning with a proof-of-concept phase and upscaling it to a larger number of villages, are of huge policy and programme relevance in the Indian context, particularly in the wake of launching the Rashtriya Kishor Swasthya Karyakram that seeks to enable adolescents to realise their full potential by making informed and responsible decisions concerning their health and well-being and by accessing the services and support they need to implement their decisions.

\section{Acceptability and feasibility of the MLMC project}

Findings indicate that the majority of study participants in the intervention arm were aware of MLMC project. Between two-thirds and four-fifths of adolescent girls and their unmarried brothers and husbands had heard about the project.

Participation in MLMC project activities ranged from nine percent among husbands to 48 percent among unmarried girls. The most prominent reason motivating adolescent girls and their unmarried brothers and husbands for participating in the project activities was the opportunity to get information on different issues. Other frequently cited reasons included the desire to acquire a vocational skill and the opportunity that the project offered to be with their friends, to make new friends and to interact in a group. Findings also show that the vast majority did not attend activities for the full length of the project. In fact, just 25 percent of unmarried girls, 15 percent of married girls and 7-10 percent of their unmarried brothers and husbands who had participated in MLMC project activities reported that they had attended the activities for the full 5-6 months. The major reasons cited for not attending the project activities regularly included inconvenient schedule of MLMC project activities and household workload.

The major activity carried out as part of the MLMC project was imparting a life skills education curriculum that comprised 21 sessions for unmarried girls, 14 sessions for married girls, and 21 sessions for unmarried brothers and husbands of eligible girls. Half or more of unmarried girls and one-third or more of married girls recalled each of the topics included in the curriculum. Three-quarters or more of unmarried and married girls who had attended the sessions reported that they had learned something new about the topic discussed in the sessions that they had 
attended. Likewise, 60 percent or more of unmarried girls and 50 percent or more of married girls reported that this was the first time anyone had discussed the topics included in the life skills education curriculum. About one-third or more of unmarried brothers and one-quarter or more of husbands recalled each of the topics included in the curriculum. Some 80 percent or more of unmarried brothers and husbands who had attended the sessions reported that they had learned something new about the topic discussed in the sessions that they attended, and 50 percent or more of unmarried brothers and 70 percent or more of husbands reported that this was the first time anyone had discussed the topics included in the life skills education curriculum.

Findings also show that a substantial proportion of MLMC participants were supported in undergoing HIV testing and seeking treatment for symptoms of reproductive tract infections, as well as in attending vocational skills training programmes and opening a bank account. For example, 49 percent of unmarried girls and 39 percent of married girls who had participated in MLMC project activities had an opportunity to undergo an HIV test. So did 44 percent of unmarried brothers and 24 percent of husbands. Some 17-21 percent of unmarried and married girls and 9-21 percent of unmarried brothers and husbands who had participated in MLMC project activities reported that they were given a referral slip to seek services for symptoms of reproductive tract infections or for HIV testing. About three-fifths of unmarried girls and over two-fifths of married girls received information about vocational skills training programmes from the project staff, and 25 percent of unmarried girls and 14 percent of married girls received support from project staff in attending a vocational skills training programme. Compared to adolescent girls, far fewer unmarried brothers and husbands received information about vocational skills training programmes or support in attending such a programme. The project staff also assisted 21 percent of unmarried girls and 14 percent of married girls in opening a bank account. The corresponding percentages among unmarried brothers and husbands were four and 13 , respectively.

Findings suggest that a larger proportion of adolescent girls and their unmarried brothers and husbands in the intervention arm perceived positive changes in their life in the six months prior to the interview, compared to their counterparts in the comparison arm. Specifically, adolescent girls and their unmarried brothers and husbands in the intervention arm were more likely than their counterparts in the comparison arm to report positive changes in their agency and gender role attitudes in the six months prior to the interview. They were also more likely to report that they were better informed about selected matters now than earlier, compared to their counterparts in the comparison arm.

Findings also show that adolescent girls and their unmarried brothers and husbands in the intervention arm were more likely than their counterparts in the comparison arm to report positive changes in terms of economic empowerment. Furthermore, unmarried girls and unmarried brothers in the intervention arm were more likely than their counterparts in the comparison arm to report that they made new friends in the six months prior to the interview. All categories of study participants in the intervention arm were more likely than their counterparts in the comparison arm to report that they had developed closer relationships with their mothers and fathers, and with their siblings (unmarried)/spouse (married).

Finally, findings show that 80 percent or more of mothers and fathers had heard about the MLMC project. However, fewer had participated in any project activities-29 percent of mothers and 23 percent of fathers. Even so, findings indicate that mothers in the intervention arm were more likely than their counterparts in the comparison arm to report positive changes in terms of their interactions with their adolescent children in the six months prior to the interview. However, no such differences were observed in the perceptions of fathers in the intervention and comparison arms.

\section{Effectiveness of the MLMC project}

The MLMC project sought to reduce adolescent girls' vulnerability to HIV by enhancing their protective assets, including knowledge and skills that can reduce vulnerability to HIV, enabling them to adopt safe practices to reduce their vulnerability to HIV, enhancing their access to a supportive and safe environment at the family and community level, and encouraging mothers and fathers to play a supportive role in reducing adolescent girls' HIV vulnerability. As summarised below, the MLMC project was effective in meeting these objectives to a large extent, particularly in the case of unmarried girls. 


\section{Effectiveness in enhancing protective assets of adolescent girls and their unmarried brothers and husbands}

The evaluation shows that the MLMC project was effective, for the most part, in enhancing protective assets of adolescent girls that can reduce their vulnerability to HIV. First, the project contributed to enabling unmarried and married adolescent girls to network with their peers and make new friends. Second, the project contributed to improving unmarried and married girls' agency as measured by their self-efficacy, decision making autonomy, and freedom of movement. Third, gender role attitudes became more egalitarian among unmarried girls following the implementation of the project, although no such effect was observed among married girl. Fourth, awareness of sexual and reproductive matters among unmarried and married girls improved substantially with the implementation of the MLMC project. Of particular note was the improvement in awareness of HIV/AIDS. Fifth, financial literacy improved among unmarried and married girls. Additionally, the project contributed to enabling unmarried and married girls to own a savings account and operate it on their own. The project provided unmarried girls an opportunity to visit a bank in the recent past, although no such effect was observed among married girls. Sixth, the project succeeded in enabling unmarried and married girls to participate in vocational skills training programmes.

At the same time, the project was not effective in increasing adolescent girls' access to non familial trusted mentors to discuss their personal problems or in promoting savings habits among adolescent girls. Findings also highlight that the MLMC project was more effective in enhancing protective assets of unmarried girls than married girls. This is not surprising because the reach of the intervention was highest among unmarried girls. Findings also show that the effectiveness of a group-based model like MLMC differed between adolescent girls and their brothers and husbands. In fact, the project was less effective in enhancing the protective assets of unmarried brothers and husbands of adolescent girls than of adolescent girls. They also underscore that the project was more effective among MLMC participants than all adolescent girls and their unmarried brothers and husbands.

\section{Effectiveness in reducing sexual risk-taking and promoting health-seeking behaviours and practices among adolescent girls and their unmarried brothers and husbands}

The evaluation shows that the MLMC project had a different effect in reducing sexual risk-taking practices among adolescent girls and their unmarried brothers and husbands. First, it contributed to moderately promoting sexual abstinence among unmarried girls, but no such effect was observed with respect to engaging in extra marital relationships among married girls. Contrary to what was hypothesised, unmarried brothers and husbands in the intervention arm were more likely than others to report sexual experiences (extra marital sexual experiences for husbands). Second, the project resulted in reducing multiple partnerships among sexually experienced unmarried brothers; however, no such effect was observed among sexually experienced unmarried girls. Third, the project had a positive net effect in promoting condom use at last sex and consistent condom use within sexual relationships outside marriage among unmarried brothers and husbands who had participated in the MLMC activities; we note that the number of MLMC participants who were engaged in sexual relationships outside marriage was small, and therefore, these findings are indicative rather than conclusive. No such effect was observed among sexually experienced unmarried girls. Fourth, the project had a positive effect in promoting condom use within marriage as reported by married girls. We note that husbands' reports showed a similar positive effect with respect to condom use at last sex in the restricted analysis of MLMC participants, concurring with the girls' reports. Finally, the project was successful in increasing intentions to use condoms among unmarried girls; however, no such effect was observed among married girls and unmarried brothers and husbands.

Findings show mixed results with regard to effectiveness of the project in promoting health-seeking practices. For example, the project had a positive net effect in improving health-seeking practices among unmarried girls. Specifically, unmarried girls in the intervention arm were more likely than those in the comparison arm to have sought treatment for reproductive tract infections and to have used and regularly changed disposable sanitary napkins during menstruation. However, no such effect was evident among married girls. Moreover, a contrasting pattern was observed among unmarried brothers and husbands, with the project having a weak negative effect on treatment-seeking practices for reproductive tract infections. 


\section{Effectiveness in enhancing adolescent girls' access to a supportive and safe environment}

The evaluation indicates mixed results with regard to improving adolescent girls' access to a supportive environment. The positive changes following the implementation of the MLMC project included a decline in marital violence, improvement in unmarried and married girls' perceptions of safety in their community, and an increase in unmarried girls' awareness of the nearest police station. However, the project had no effect on such indicators as communication between adolescent girls and their parents, support provided to unmarried girls by their brothers or to married girls by their husbands, and experience of non contact forms of sexual harassment.

\section{Effectiveness in improving awareness and practices of mothers and fathers of adolescent girls}

Findings show that the MLMC project had mixed effect on the mothers and fathers of adolescent girls. On a positive note, the project contributed to improving awareness and practices of mothers and fathers of sexual and reproductive matters, including awareness of HIV/AIDS and ways of preventing HIV transmission, among mothers of adolescent girls, and enabling them to uphold gender egalitarian attitudes. At the same time, the project had no effect in enabling mothers to adopt gender egalitarian socialisation practices. Findings also show that the project had, for the most part, no effect on fathers' knowledge and practices, except that they were more likely than their counterparts in the comparison arm to uphold gender egalitarian attitudes.

\section{Sustainability of the MLMC project}

The evaluation of the MLMC project demonstrates that a safe space model and a peer educator model can be effective and acceptable. There exists a great potential for up-scaling and sustaining projects like MLMC by drawing links with available programmes, such as the Sabla programme for adolescent girls, the NYKS Youth Clubs largely attended by boys, and the Rashtriya Kishor Swasthya Karyakram that rely on such strategies as a peer education approach and group formation.

\section{Recommendations}

We highlight below a few recommendations emerging from the evaluation that have relevance for adolescent programming in the country, including for scaling up interventions for adolescents.

The evaluation highlights the fact that the MLMC project had a differential impact on different categories of study participants: the project had maximum impact on the lives of unmarried adolescent girls, the group that was reached most by the intervention activities, and least impact in the lives of unmarried brothers and husbands, the group that was reached the least. These findings underscore the importance of reaching out to a critical mass of target groups to generate the desired impact at the community level as well as revisiting strategies used to mobilise the hard-toreach, particularly the married. Enrolling the married, particularly girls, additionally calls for expanded efforts to make husbands and in-laws the allies of the project.

Although the project was successful in reducing sexual risk-taking practices, it had limited success in promoting health-seeking practices, for example, for seeking treatment for symptoms of genital infections among married girls and unmarried brothers and husbands of adolescent girls. These findings emphasise that healthcare providers need to be oriented, to a greater extent than projects like MLMC have done, to the special needs of different categories of adolescents and young people and make special efforts to provide sexual and reproductive health services directly to them through community outreach and clinic-based services.

Ensuring regular attendance of girls and their brothers and husbands was a major challenge faced by the MLMC project. Flexibility in timing, locations, and forums suitable for different categories of adolescents needs to be explored. Moreover, programme designs must take into consideration adolescents' own preferences with regard to components other than life skills education to be included in the programme.

Strategies for reaching boys and husbands in models like MLMC need to be reconsidered. Delivering life skills education through forums more acceptable to boys than Gender Resource Centres may be considered. Moreover, reaching boys in order to improve girls' situation needs to be replaced by more boy-focussed objectives as well. 
Findings suggest that mothers and father may not have been fully engaged in the MLMC programme and the intervention had limited success in equipping parents and parents-in-law with knowledge and skills to play a supportive role in reducing adolescent girls' vulnerability. In order to engage mothers and fathers more comprehensively, projects like the MLMC may need to consider a more structured programme for parents that responds to the priorities expressed by mothers and father, and at the same time break down traditional gendered socialisation practices, build greater communication between parents and children, and encourage parental participation in addressing the sexual and reproductive health concerns of their children.

Finally, the MLMC experience highlights several lessons of up-scaling programmes for adolescents. First, having a proof-of-concept phase that allows programme implementers to understand what worked, what was acceptable, and what was relevant, and to tailor the project design based on lessons learned during the proof-of-concept phase is important. Second, even when scaling up, phasing is important for managing the implementation with quality. Third, strong capacity-building efforts to identify and train peer mentors and a strong supportive supervision mechanism are required. Fourth, it is important to have government buy-in from the very beginning of the project. 
Annex 1: Detailed description of the selection of intervention and comparison arms and sample size calculation

We based the selection of intervention villages on the assumptions that: (1) MAMTA and partner organisations will set up 1,200 Gender Resource Centres in the two states taken together, as specified in the intervention protocol, and that an equal number of GRCs will be established in Madhya Pradesh and Uttar Pradesh; (2) the project will attempt to reach out to roughly 26,000 vulnerable girls from the 12 blocks; (3) ensuring some degree of geographical contiguity is important from the perspective of convenience of project implementation; and (4) it is important, at the same time, to capture variations in socio-demographic characteristics within selected blocks so that the intervention villages selected within each block represent the block as a whole. Given that population size and, correspondingly, the number of households containing vulnerable girls-i.e., unmarried and married girls belonging to socially disadvantaged castes, tribes and religions-varied widely by blocks, we decided to distribute the GRCs proportionately by the number of vulnerable households within the selected blocks ${ }^{4}$ so as to ensure uniformity in the programme coverage across the selected blocks and the representativeness of the outcome indicators at the state level. In order to ensure geographic contiguity of intervention villages in each block, we first arranged the villages in the block in order of their administrative numbers given in the Census data sets. ${ }^{5}$ The villages within the block were then stratified into clusters of approximately equal population size based on the projected population of the block, a standard procedure followed in sample selections. In total, 12 clusters were created in each block in order to maximise intra-block variation. The number of clusters to be selected in each block was obtained by dividing the total number of GRCs to be established in the block by the average number of villages in the cluster, but not exceeding a total of six clusters so that we covered half of the block at the maximum. In this way, we decided to select 4-6 clusters per block. Additionally, to capture the intra-block variations in socio-demographic characteristics, we computed cluster-level measures of three indicators-female literacy rate, proportion of population belonging to scheduled castes and tribes, and proportion of males engaged in non-agricultural work-using village-level information available from the primary census abstract. We then calculated a composite index based on these values; the value of the composite index ranged from 0 to 3 . We stratified the clusters according to the composite index value and allocated the number of clusters to be selected from each stratum proportionately, based on the distribution of the composite index value. Within each stratum, cluster(s) were selected using systematic random sampling, and all the villages in the clusters thus selected were included in the intervention arm. We note that the averages of three indicators for the selected clusters matched well with the block averages.

We based our calculation of the number of girls, their brothers/husbands, and their parents to be interviewed in each arm on the following assumptions. First, given that the evaluation sought to estimate the impact of the MLMC project and given that a quasi-experimental design was adopted, we decided to use the difference-in-differences (DiD) analytical technique to estimate average impact of the MLMC project on any outcome variable of interest. Since identical data were collected at both baseline and endline for the outcome measure $\mathrm{Y}$, from both the intervention and comparison arms, we estimated the average impact of the MLMC project using the following formula:

$$
E\left[\left(Y_{\text {Treat }, 1}-Y_{\text {Treat }, 0}\right)-\left(Y_{\text {comp }, 1}-Y_{\text {comp }, 0}\right) \mid\right] \equiv E[Z]
$$

where: $Y_{\text {Treat }, 0}=$ outcome at the baseline in the intervention arm; $Y_{\text {Treat, } 1}=$ outcome at the endline in the intervention arm; $Y_{\text {comp }, 0}=$ outcome at the baseline in the comparison arm; $Y_{\text {comp, } 1}=$ outcome at the endline in the comparison arm; and $Z$ = difference-in-difference estimator (impact of the intervention).

Second, since a random sample of households containing vulnerable girls (by systematic random sampling) within a cluster (village) were selected by probability proportional to size within the selected blocks, clustering at the villagelevel was expected. Taking into account the clustering effect, the fact that samples at baseline and endline were

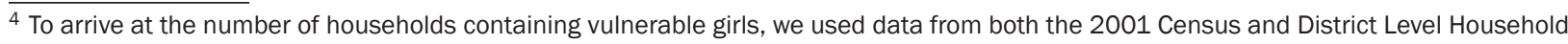
Survey-3 conducted in 2007-08. We first projected the population of the selected blocks to mid-2011, using 2001 Census data and the estimated decadal growth rate. Second, because Census data do not permit estimation of households containing a vulnerable girl, we used DLHS-3 data to obtain the percentage of households containing a vulnerable girl in 2007-08. Third, we applied this percentage to the projected block population in 2011. Between $27 \%$ and $36 \%$ of households in the selected districts were thus calculated to contain at least one vulnerable adolescent girl.

${ }^{5}$ We note that villages are typically numbered consecutively according to their geographical location in the Census data sets.
} 
chosen independently, and the need for detecting a small effect size, $\Delta Z$, the formula for calculating sample size was written as:

$$
\left[\left(\xi_{1-\frac{\alpha}{2}}+\xi_{1-\beta}\right)^{2} \frac{4 \hat{\sigma}^{2}}{\Delta Z^{2}}\right]=\frac{n M}{1+\rho(M-1)}
$$

where: $n=$ number of sampled clusters; $M=$ number of sampled households in each cluster; $\rho=$ intra-cluster $\pi \rho$ correlation; $\hat{\sigma}=$ estimated standard deviation of $\mathrm{Y} ; \zeta \sim \mathrm{N}(0,1) ; \alpha=$ type I error; $\beta=$ type II error (1- $\beta=$ power).

In determining sample size, several issues were considered. First, outcome measures for which impact needed to be assessed came from several groups: individual samples of adolescent girls (married and unmarried), brothers or husbands of adolescent girls, as well as parents of adolescent girls. Therefore, in determining sample size, we focused on obtaining an adequate sample for a total of five categories of target groups, that is, unmarried girls aged 15-19 years, married girls aged 15-21 years, unmarried adolescent brothers aged 15-19 years, married young men aged 15-24 years and parents of girls aged 15-21 years.

We elaborate here on the steps followed in determining the sample size, taking the example of married girls aged 15-21 years. Let $\mathrm{N}=\mathrm{nM}$ be the total sample of married adolescent girls aged 15-21 years in the intervention arm in any state. The term, $1+\rho(\mathrm{M}-1)$, is known as the "design effect", that is, the effect of the clustered nature of respondent sampling on the variance of the outcome measure (Y). Since a value is not available for $\rho$, intra-cluster correlation, we assumed in our calculations below, a value for the design effect, denoted by $\mathrm{d}$, that is similar to that usually observed in large sample surveys.

Assuming that $p$ is the proportion of married adolescent girls aged 15-21 years reporting positive outcomes of $\mathrm{Y}$, we rewrote the above formula as:

$$
N=\frac{\left\{\xi_{1-\alpha / 2}+\xi_{1-\beta}\right\}^{2} \times 4 \times d \times p(1-p)}{(\Delta z)^{2}}
$$

MAMTA aimed to achieve a 50-75\% increase in the baseline value of $Y$ (e.g., knowledge of sexual and reproductive matters, including HIV) by the end of the project; hence, effect size $(\Delta z)$ was assumed to be $50-75 \%$ of the baseline value of $p$. We also assumed a design effect (d) of 1.25, an effect typically observed for many outcomes for rural women documented in the National Family Health Survey (NFHS). Further, we assumed the values of $\alpha$ and $\beta$ to be 0.05 and 0.20 , respectively.

We also note that Phase 1 of the MLMC project showed that the participation of the targeted groups was not universal, and therefore, we also factored data from Phase 1 on the level of participation of specific groups in the intervention activities to calculate the sample size for the impact evaluation of the Phase 2.

In arriving at a value for $\mathrm{p}$, we reviewed several outcome measures described in the intervention protocol and gathered information related to those from existing data, such as the National Family Health Survey 2005-06 (IIPS and Macro International, 2007) and the Behavioural Surveillance Survey 2006 (National Institute of Medical Statistics and NACO, 2008). We based our calculation of sample size on data from the BSS pertaining to adolescents' knowledge of HIV prevention. We used this indicator because it constituted a more widely achievable benchmark of success than indicators of safe behaviours such as consistent condom use or limiting multiple partnerships as these events were experienced by a minority of adolescents and basing our sample size calculation on such rare events would increase the sample size unrealistically.

For girls aged 15-19 years in rural areas, BSS data indicate that 24\% in Madhya Pradesh and $43 \%$ in Uttar Pradesh knew about two ways of preventing HIV infection, resulting in an average of $34 \%$ for the two states taken together. Using the above assumptions, we obtained a sample size (N) of 277 married girls aged 15-19 years in the intervention arm and an equal number in the control arm for the two states taken together. Further, assuming a $90 \%$ response rate for the married girls' survey and $77 \%$ participation rate in the intervention activities, the required sample size was revised to 388 in each arm. In this way, using the same indicator, we estimate a sample size of 
481 for unmarried girls in each arm. Given that knowledge about HIV prevention is much higher among boys than girls, we use a different indicator, namely comprehensive awareness about HIV/AIDS, and applying this in a similar way, arrive at a sample size of 550 unmarried boys aged 15-19, and 550 married young men aged 15-24 in the intervention arm and an equal number in the control arm for the two states taken together.

In summary, the target sample size was 961 unmarried adolescent girls aged 15-19 years, 774 married girls and 2,200 unmarried brothers aged 15-19 years and husbands aged 15-24 years of eligible unmarried and married girls, respectively, in the intervention and comparison arms together for the two states taken together.

For calculating the sample size for interviews of parents, we drew on data from NFHS-3 pertaining to the percentage of fathers who favoured imparting sexuality education to girls in school, and arrived at a sample size of 295 parents (mothers and fathers) in the intervention arm and an equal number in the comparison arm.

Annex Table 1: Sample size required in the intervention and comparison arms for two states taken together

\begin{tabular}{|c|c|c|c|c|c|c|}
\hline \multirow{2}{*}{$\begin{array}{l}\text { Type of } \\
\text { respondents }\end{array}$} & \multirow[t]{2}{*}{ Indicator (p) } & \multirow[t]{2}{*}{ Source } & \multirow[t]{2}{*}{ Value of $p$} & \multirow{2}{*}{$\begin{array}{l}\text { Expected } \\
\text { increase }\end{array}$} & \multicolumn{2}{|c|}{ Estimated sample size } \\
\hline & & & & & Intervention & Comparison \\
\hline $\begin{array}{l}\text { Unmarried } \\
\text { adolescent girls } \\
\text { aged } 15-19\end{array}$ & $\begin{array}{l}\% \text { of girls who knew two } \\
\text { ways of preventing HIV/ } \\
\text { AIDS infection }\end{array}$ & $\begin{array}{l}\text { BSS, Youth } \\
2006\end{array}$ & 0.34 & $75 \%$ & 481 & 481 \\
\hline $\begin{array}{l}\text { Married adolescent } \\
\text { girls aged 15-19 }\end{array}$ & $\begin{array}{l}\% \text { of girls who knew two } \\
\text { ways of preventing HIV/ } \\
\text { AIDS infection }\end{array}$ & $\begin{array}{l}\text { BSS, Youth } \\
2006\end{array}$ & 0.34 & $75 \%$ & 387 & 387 \\
\hline $\begin{array}{l}\text { Unmarried boys } \\
\text { aged } 15-19\end{array}$ & $\begin{array}{l}\% \text { of boys who displayed } \\
\text { comprehensive } \\
\text { knowledge of HIV/AIDS }\end{array}$ & $\begin{array}{l}\text { BSS, Youth } \\
2006\end{array}$ & 0.388 & $75 \%$ & 550 & 550 \\
\hline $\begin{array}{l}\text { Married boys } \\
\text { aged } 15-24\end{array}$ & $\begin{array}{l}\% \text { of boys who displayed } \\
\text { comprehensive } \\
\text { knowledge of HIV/AIDS }\end{array}$ & $\begin{array}{l}\text { BSS, Youth } \\
2006\end{array}$ & 0.388 & $75 \%$ & 550 & 550 \\
\hline $\begin{array}{l}\text { Parents of eligible } \\
\text { unmarried and } \\
\text { married adolescent } \\
\text { girls }\end{array}$ & $\begin{array}{l}\% \text { of fathers who were } \\
\text { supportive of teaching } \\
\text { girls in school about sex } \\
\text { and sexual behaviour }\end{array}$ & NFHS-3 & 0.628 & $50 \%$ & 295 & 295 \\
\hline
\end{tabular}

Note: BSS-Behavioural Surveillance Survey; NFHS-National Family Health Survey. 
Annex 2: Calculation of household wealth index

Household economic status was measured using a standard of living index composed of household asset data on ownership of selected durable goods, including means of transportation, as well as data on access to a number of amenities. The standard of living index was constructed by allocating the following scores to a household's reported assets or amenities:

Type of house: 2 for pucca; 1 for semi-pucca; 0 for kachcha.

Agricultural land owned: 4 for more than 10 acres; 3 for more than 5 to 10 acres; 2 for more than 2.5 to 5 acres; 1 for less than 2.6 acres; 1 for do not know how much land; 0 for no.

Irrigated land: 1 for irrigated land, and 0 for no irrigated land.

Access to toilet facility: 4 for own toilet; 2 for shared or own pit toilet; 1 for shared pit toilet; 0 for no facility.

Fuel for cooking: 2 for electricity, liquid petroleum gas, or biogas; 1 for coal/charcoal/kerosene/wood/crop residue/ dung cakes; 0 for other fuels.

Source of drinking water: 4 for own piped water; 3 for own open well; 2 for public or shared piped water, hand pump, or covered well; 1 for public/shared open well; 0 for other water sources.

Access to electricity: 3 for electricity; 0 for no electricity.

Ownership of different durable goods: 4 for a car/truck; 3 each for motor cycle/scooter, refrigerator, computer/ laptop, land line/mobile, colour television; 2 each for bicycle, electric fan, sewing machine, water pump, animal drawn cart; 1 for a watch/clock The index score, so constructed, ranged from 0 to 54 . 


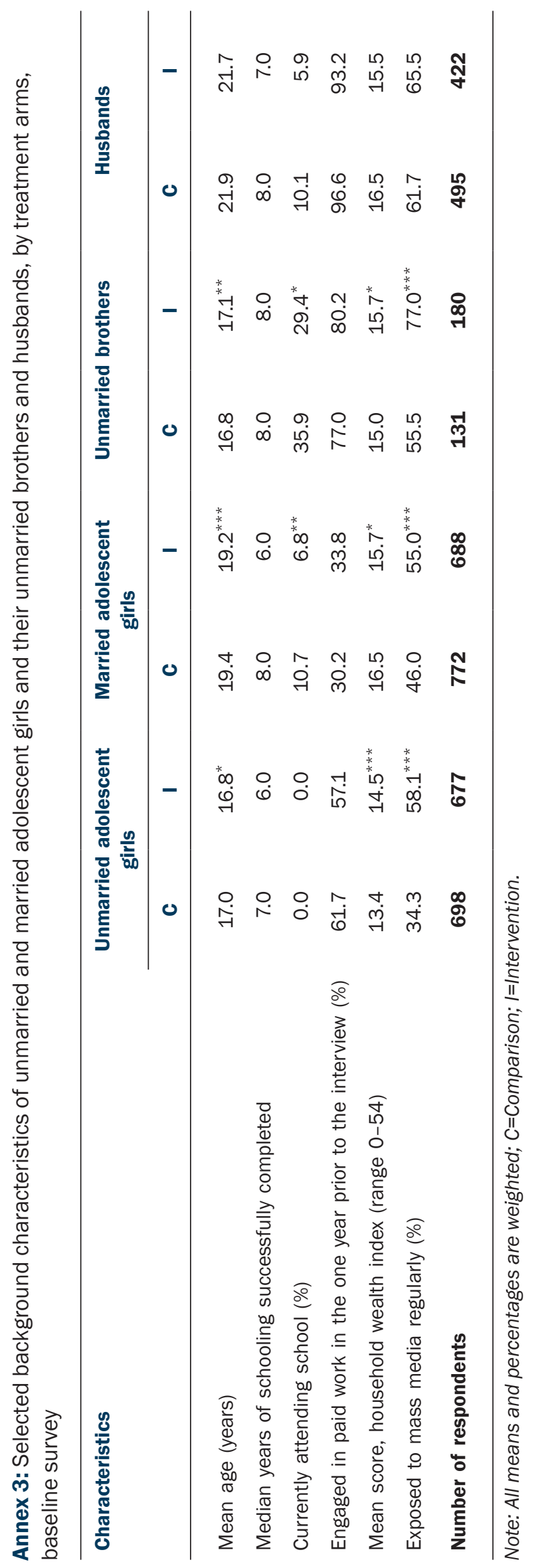




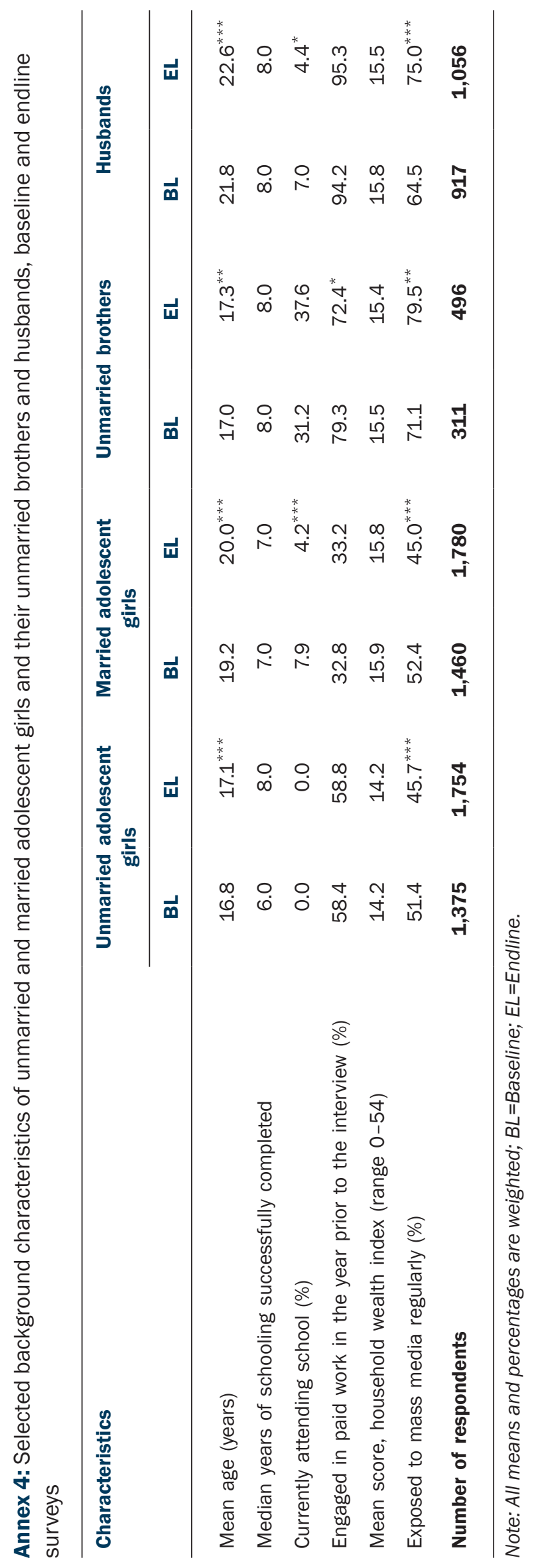


Annex 5: Items included in the summary measures related to agency and gender role attitudes and their baseline values

\begin{tabular}{|c|c|c|c|c|}
\hline Items included in summary measures & $\begin{array}{c}\text { Unmarried } \\
\text { adolescent } \\
\text { girls }\end{array}$ & $\begin{array}{c}\text { Married } \\
\text { adolescent } \\
\text { girls }\end{array}$ & $\begin{array}{c}\text { Unmarried } \\
\text { brothers }\end{array}$ & Husbands \\
\hline
\end{tabular}

\section{Self-efficacy}

Respondent able to express her/his opinion about something that concerns to her/his mother

$\begin{array}{rrrr}58.1 & 54.5 & 49.6 & 43.6 \\ 8.8 & 9.4 & 39.8 & 37.6 \\ 41.9 & 43.6 & 68.1 & 77.3 \\ \mathbf{3 1 . 1} & \mathbf{2 9 . 9} & \mathbf{4 9 . 7} & \mathbf{4 6 . 0} \\ & & & \\ 58.9 & 43.4 & 87.8 & 96.9 \\ 65.0 & 60.0 & 71.0 & 78.7 \\ 1.0 & 2.8 & 3.5 & 5.6\end{array}$

Respondent able to express her/his opinion about something that concerns to her/his father

Respondent able to confront a person who did something wrong to her/him

\section{Displayed self-efficacy (\%)}

Decision making autonomy: made/will make independent decisions on the following:

Going to a friend's house

Spending her/his own money

Whom to marry

Made/will make independent decision in personal matters (\%)

47.6

36.3

67.0

79.1

Mobility: free to visit the following locations unescorted

A shop or market inside the village

A health facility inside village

31.9

A programme inside the village

22.9

A friend/relative inside the village

72.0

$$
44.7
$$

99.7

100.0

A shop or market outside the village

10.7

A health facility outside village

A programme outside the village

A friend/relative outside the village

Index of mobility (mean score, range $0-8 ; \alpha$ : 0.7-0.8)

\section{Gender role attitudes}

Educating boys is more important than educating girls (disagree)

It is better for girls to get married early than to complete at least class 12 (disagree)

50.4

99.3

99.5

12.6

91.6

99.5

It is wrong for a girl to have male friends (disagree)

Girls like to be teased by boys (disagree)

41.0

It is necessary to give a dowry (disagree)

A woman should obtain her husband's permission for most things (disagree)

Husband alone/mainly should decide how household money is to be spent(disagree)

Doing household chores (cooking, cleaning, washing) is only women's responsibility (disagree)

A woman should tolerate violence to keep her family together (disagree)

$$
69.8
$$

$$
12.5
$$$$
6.5
$$

69.8

$$
73.3
$$

51.0

$\begin{array}{rrr}6.1 & 5.1 & 5.4 \\ \mathbf{1 , 4 6 0} & \mathbf{3 1 1} & \mathbf{9 1 7}\end{array}$




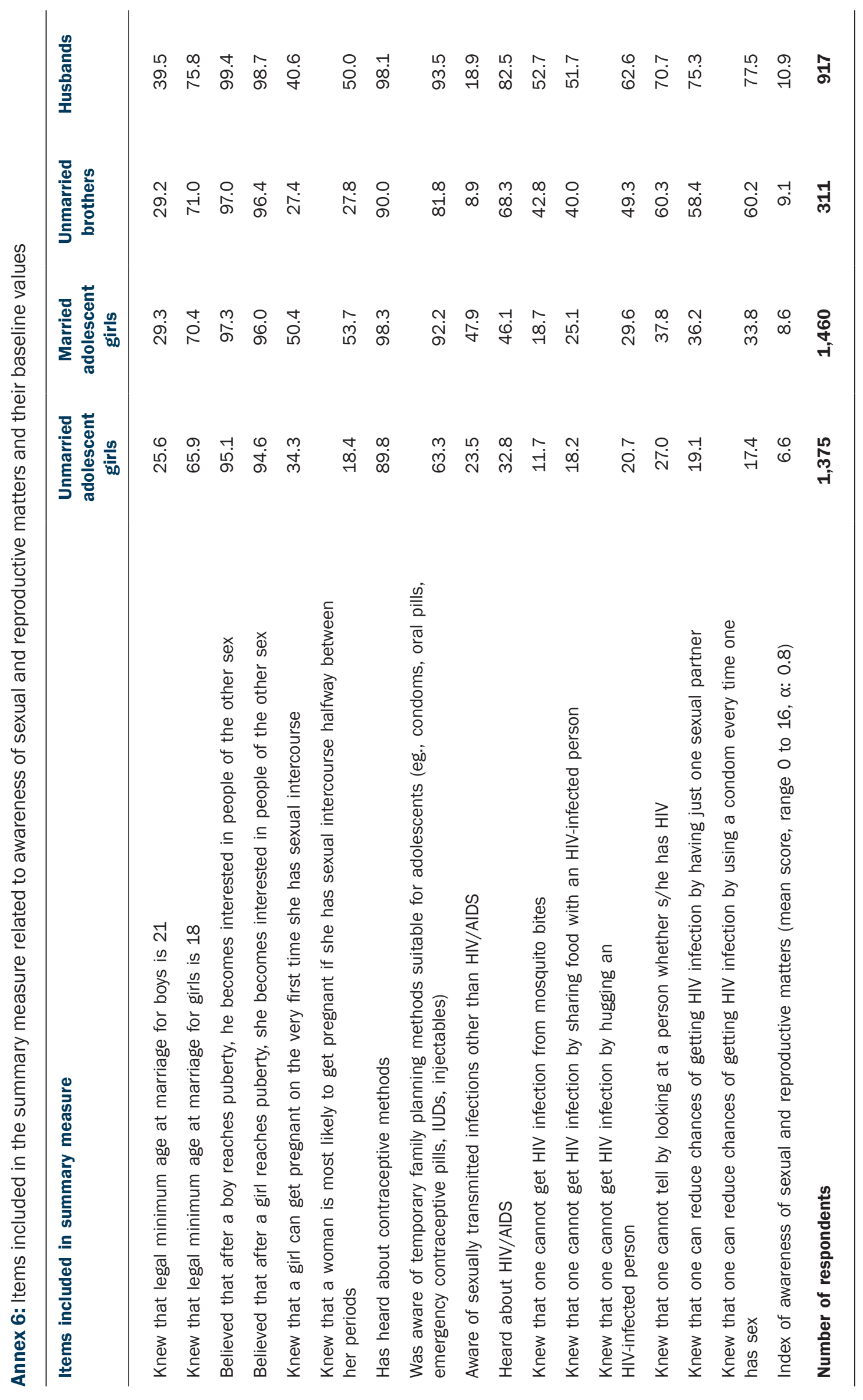




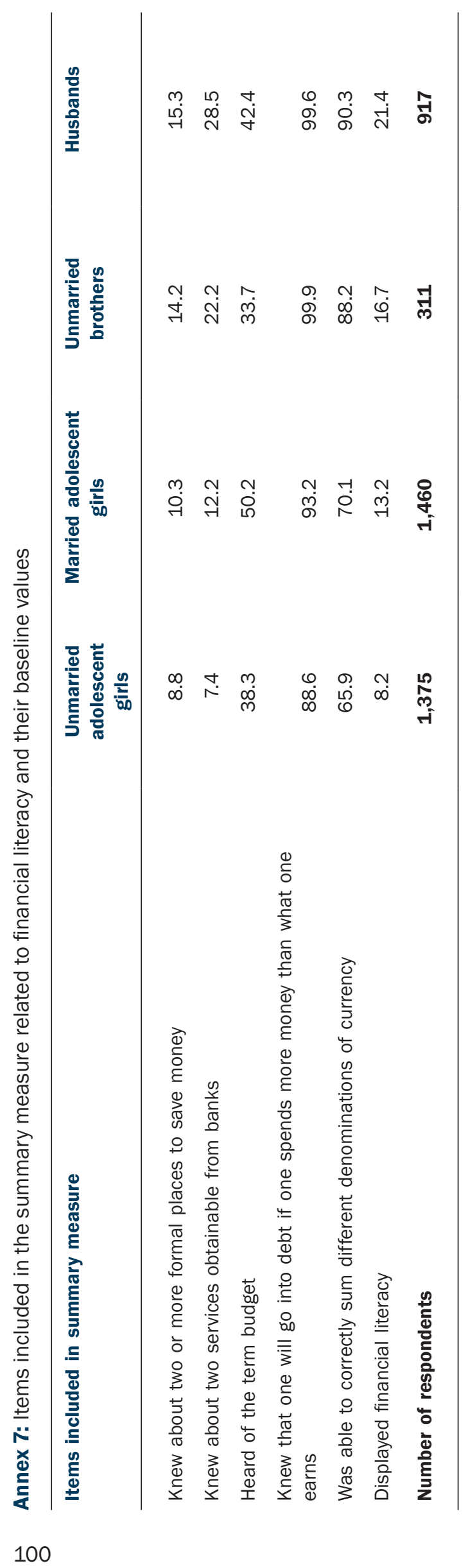




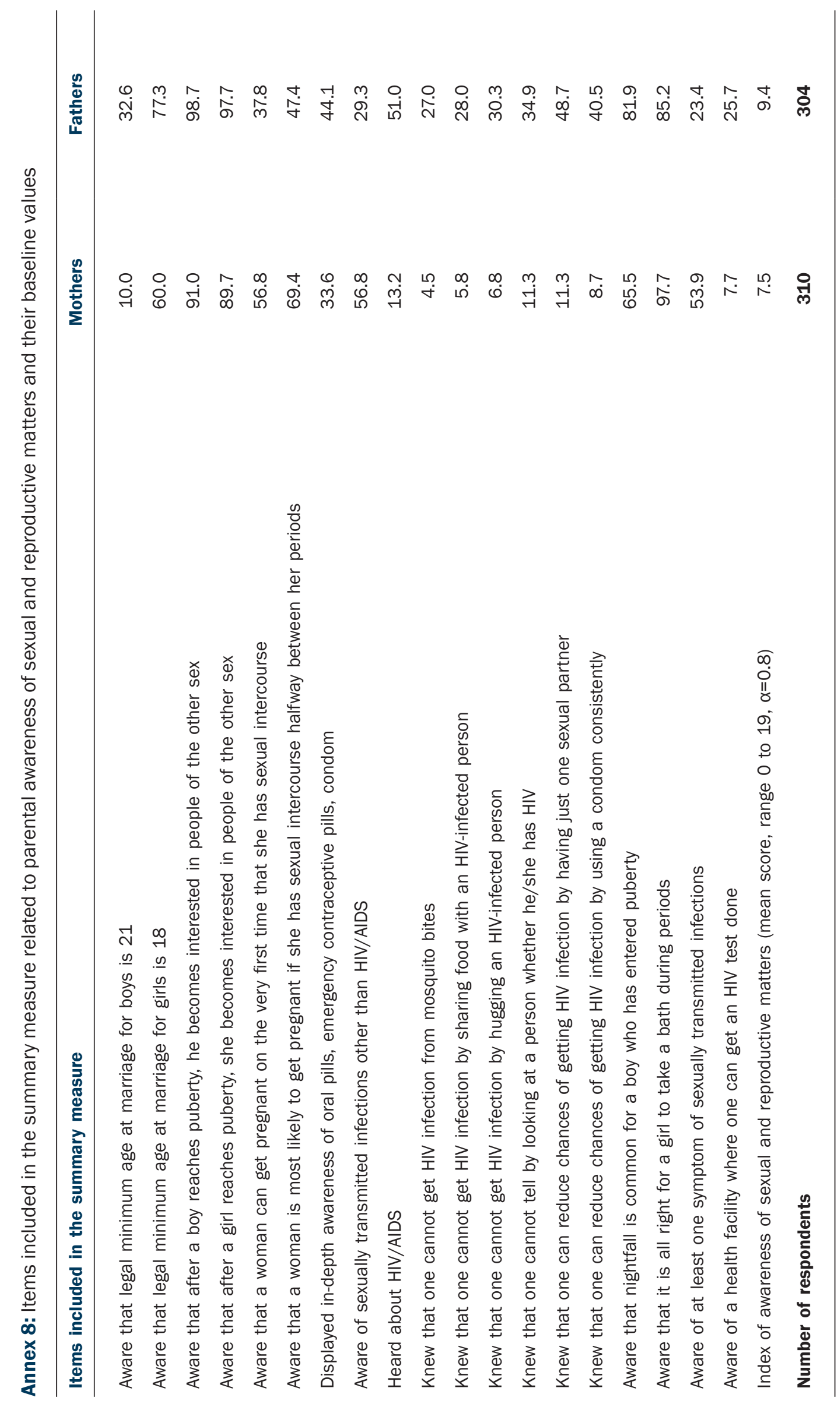




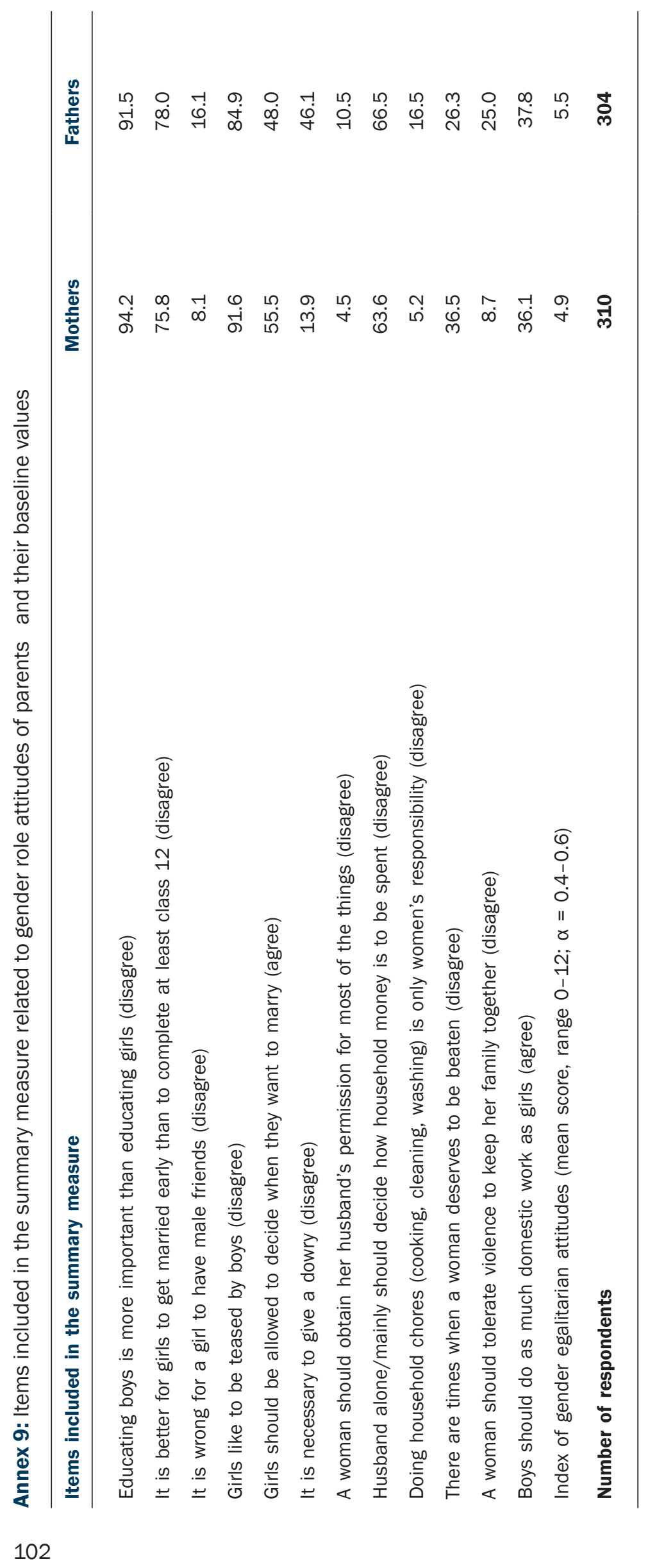




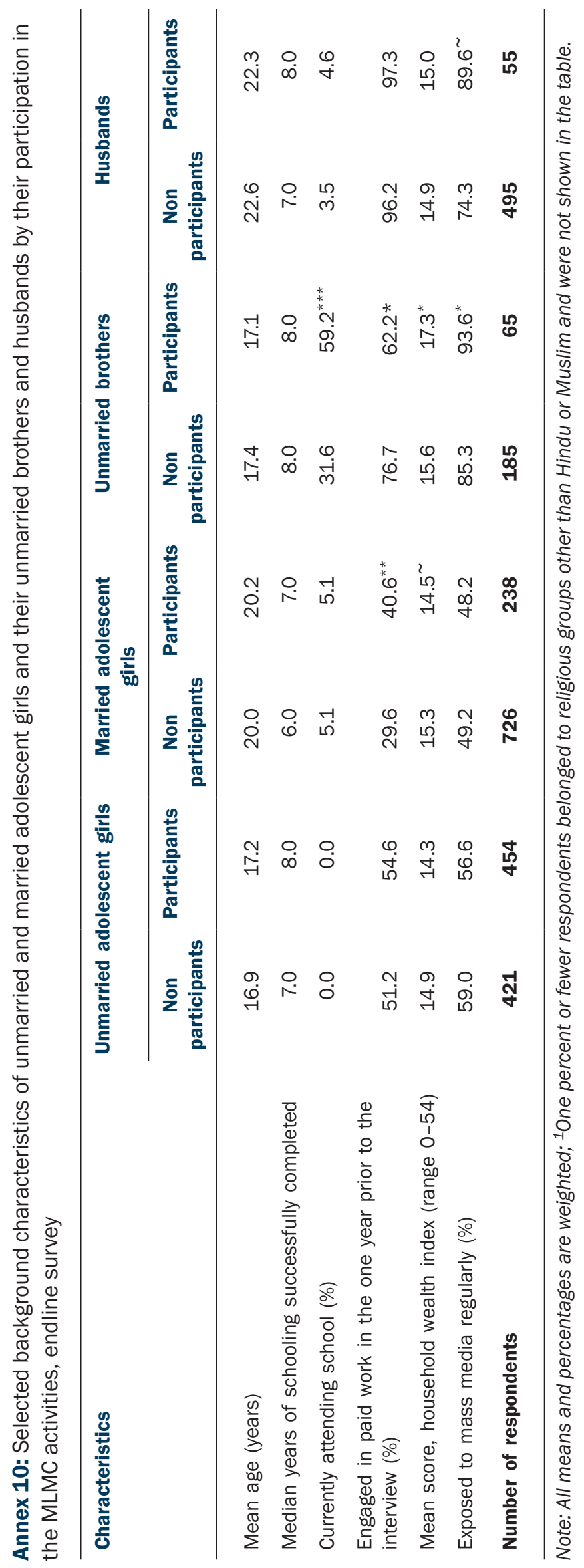




\section{References:}

Acharya, R., S. Kalyanwala, S.J. Jejeebhoy, et al. 2009. Broadening girls' horizons: Effects of a Life Skills Education Programme in Rural Uttar Pradesh. New Delhi: Population Council.

Ashenfelter, O. 1978. "Estimating the effect of training programs on earnings," Review of Economics and Statistics 60(1): 47-57.

Ashenfelter, O. and D. Card. 1985. "Using the longitudinal structure of earnings to estimate the effect of training programs," Reviews of Economics and Statistics 67(4): 648-660.

Bruce, J., M. Temin and K. Hallman. 2012. "Evidence-Based Approaches to Protecting Adolescent Girls at Risk of HIV." AIDSTAR-One Spotlight on Gender. Washington, DC: USAID.

International Institute for Population Sciences (IIPS) and Population Council. 2010. Youth in India: Situation and Needs 2006-2007. Mumbai: IIPS.

International Institute for Population Sciences (IIPS) and Macro International. 2007. National Family Health Survey (NFHS-3), 2005-06: India, Volume I. Mumbai: IIPS.

International Institute for Population Sciences (IIPS). 2010. Global Adult Tobacco Survey, GATS India 2009-2010. Mumbai: IIPS.

Jejeebhoy, S. J and K.G. Santhya. 2015. "Parent-child communication and sexual and reproductive health matters," in A.K. Shiva Kumar et al. (eds.), India’s Children: Essays on Social Policy. New Delhi: Oxford University Press

Jejeebhoy, S. J and K. G. Santhya. 2011. Parent-Child Communication on Sexual and Reproductive Health Matters: Perspectives of Mothers and Fathers of Youth in India. New Delhi: Population Council.

Jejeebhoy, S. J., K. G. Santhya, S. K. Singh, et al. 2014. Provision of Adolescent Reproductive and Sexual Health Services In India: Provider Perspectives. New Delhi: Population Council.

Ministry of Health and Family Welfare (MOHFW). 2014. National Rural Health Mission, Rashtriya Kishor Swasthya Karyakram (RKSK). New Delhi: Ministry of Health and Family Welfare, Government of India.

Ministry of Human Resource Development, 2014. Statistics of School Education 2011-12. New Delhi: Government of India.

Ministry of Women and Child Development, 2015. “Rapid Survey on Children 2013-2014." India Fact Sheet. New Delhi: Ministry of Women and Child Development.

National Institute of Medical Statistics and National AIDS Control Organisation (NACO). 2008. National Behavioural Surveillance Survey (BSS), 2006; Youth (15-24 Years). New Delhi: NACO, Ministry of Health and Family Welfare, Government of India.

Office of the Registrar General and Census Commissioner, India. 2013. Census of India 2011: Primary Census Abstract, Data Highlights, India, Series 1. New Delhi:

Office of the Registrar General and Census Commissioner, India. Accessed on 6 October, 2014 at http://www.censusindia.gov. in/2011census/PCA/PCA Highlights/pca highlights india.html.

Office of the Registrar General and Census Commissioner, India, 2014. A Profile of Adolescents and Youth in India. New Delhi: Office of the Registrar General and Census Commissioner.

Office of the Registrar General and Census Commissioner, India. 2015a. "C2 Marital status by age and sex, India." Accessed on 6 October, 2015 at http://www.censusindia.gov.in/2011census/C-series/c-2.html.

Office of the Registrar General and Census Commissioner, India. 2015b. "F-1 Number of women and ever married women by present age, parity and total children ever born by sex, India." Accessed on 6 October, 2015 at http://www.censusindia.gov. in/2011census/F-series/F-1.html.

Office of the Registrar General, n.d. Table 1: Maternal Mortality Ratio (MMR), Maternal Mortality Rate and Life Time Risk; India, EAG \& Assam, South and Other states, 2011-13. New Delhi:

Office of the Registrar General. Accessed on 6 October, 2015 at http://www.censusindia.gov.in/vital statistics/mmr bulletin_2011-13.pdf. 
Parasuraman, Sulabha, Sunita Kishor, Shri Kant Singh, and Y. Vaidehi. 2009. A Profile of Youth in India. National Family Health Survey (NFHS-3), India, 2005-06. Mumbai: International Institute for Population Sciences; Calverton, MD: ICF Macro.

Planning Commission. 2013. “Press Note on Poverty Estimates, 2011-12.” New Delhi: Planning Commission.

Planning Commission. 2014. Data-book Compiled for Use of Planning Commission. New Delhi: Planning Commission.

Santhya, K.G., N. Haberland, A. Das, et al. 2008. Empowering Married Young Women and Improving their Sexual and Reproductive Health: Effects of the First-time Parents Project. New Delhi: Population Council.

Santhya, K. G., R. Prakash, S. J. Jejeebhoy, and S. K. Singh. 2014. Accessing Adolescent Friendly Health Clinics in India: The Perspectives of Adolescents and Youth. New Delhi: Population Council.

Santhya, K.G., S.J. Jejeebhoy, and S. Ghosh. 2007. Addressing the Sexual and Reproductive Health Needs of Young People: Perspectives and Experiences of Stakeholders from the Health and Non-Health Sectors. New Delhi: Population Council.

Sebstad, J. and J. Bruce. 2004. "Building Assets for Safe and Productive Lives: A Report on a Workshop on Adolescent Girls' Livelihoods." Presented at Adolescent Girls Livelihoods Meeting. New York: Population Council.

SEWA, SEWA Academy, S. Kalyanwala, et al. 2006. Influencing Girls' Lives: Acceptability and Effectiveness of a Livelihoods Skill Building Intervention in Gujarat. New Delhi: Population Council.

World Health Organization (WHO). 2007. Helping Parents in Developing Countries Improve Adolescents' Health. Geneva: WHO. 


\section{Authors}

Sunil Mehra, Executive Director, MAMTA-Health Institute for Mother and Child, New Delhi

Rajesh Ranjan Singh, Chief Operating Officer, MAMTA-Health Institute for Mother and Child, New Delhi

Vandana Nair, Assistant Director, MAMTA-Health Institute for Mother and Child, New Delhi

K G Santhya, Senior Associate, Population Council, New Delhi

A J Francis Zavier, Senior Programme Officer, Population Council, New Delhi 


\title{
List of Investigators
}

\author{
Household Listers \\ Devendra Kumar \\ Kundan Kumar \\ Deepak Kumar Pandey \\ Hrishikesh Pandey \\ Brhamanand Saraswati \\ Avadhesh Singh \\ Anil Kumar Sinha \\ Jai Shankar Tiwari
}

\section{Field Investigators}

Shilpa Bagde

Manish Bajpai

Ashwini Rana

Vipul Bajpai

Rakhi Burman

Shiva Chaturvedi

Saraswati Chaudhari

Hemraj Daima

Mena Devi

Ajay Kumar Dubey

Tasnim Faruque

Madhulata Gupta

Ravi Kumar Jain

Ashish Jha

Jagjot Kaur

Najma Khan

Nasim Kousar

Kamlesh Kumar

Yashoda Kumari

Divakar Maji

Vijay Nigam

Satish Kumar Pal

Alok Kumar Pandey

Neha Pandey

Vinesh Kumar Pillai

Jalendri Rana

Snehlata Rana

Premlata Rathore

Anjana Sahu

Nanda Sahu

Sharqa Shams

Ram Shankar

Anju Sharma

Sarita Sharma

Parmod Shukla

Rajnikant Shukla

Kalpana Singh

Nagendra Singh

Rachna Singh

Raja Singh

Munni Tigga

Rakesh Tiwari

Sidheswar Tiwari

Yograj Tiwari

Priyanka Vaishnav

Meera Verma

Priti Verma

Omvir 
Printed at :

Systems Vision

Email:systemsvision96@gmail.com

Mobile:98102 12565 


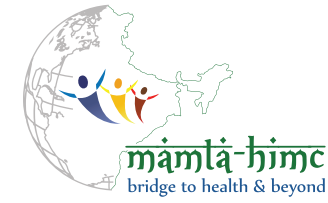

